\title{
Structural transformation and economic development : can development traps be avoided?
}

Citation for published version (APA):

Lavopa, A. M. (2015). Structural transformation and economic development : can development traps be avoided? [Doctoral Thesis, Maastricht University]. Maastricht University. https://doi.org/10.26481/dis.20150312al

Document status and date:

Published: 01/01/2015

DOI:

10.26481/dis.20150312al

Document Version:

Publisher's PDF, also known as Version of record

\section{Please check the document version of this publication:}

- A submitted manuscript is the version of the article upon submission and before peer-review. There can be important differences between the submitted version and the official published version of record.

People interested in the research are advised to contact the author for the final version of the publication, or visit the DOI to the publisher's website.

- The final author version and the galley proof are versions of the publication after peer review.

- The final published version features the final layout of the paper including the volume, issue and page numbers.

Link to publication

\footnotetext{
General rights rights.

- You may freely distribute the URL identifying the publication in the public portal. please follow below link for the End User Agreement:

www.umlib.nl/taverne-license

Take down policy

If you believe that this document breaches copyright please contact us at:

repository@maastrichtuniversity.nl

providing details and we will investigate your claim.
}

Copyright and moral rights for the publications made accessible in the public portal are retained by the authors and/or other copyright owners and it is a condition of accessing publications that users recognise and abide by the legal requirements associated with these

- Users may download and print one copy of any publication from the public portal for the purpose of private study or research.

- You may not further distribute the material or use it for any profit-making activity or commercial gain

If the publication is distributed under the terms of Article $25 \mathrm{fa}$ of the Dutch Copyright Act, indicated by the "Taverne" license above, 


\section{STRUCTURAL \\ TRANSFORMATION \\ AND ECONOMIC DEVELOPMENT \\ Can Development Traps be Avoided?}

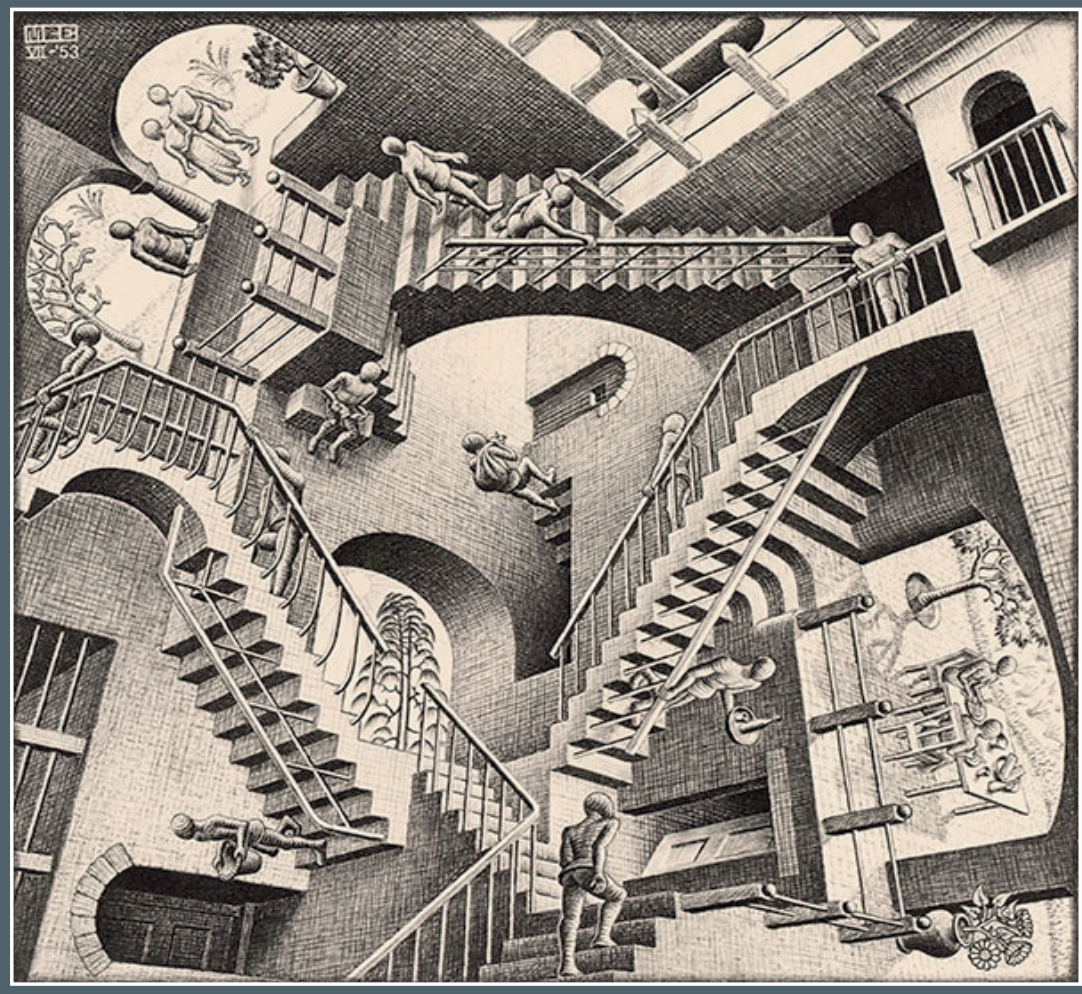

Alejandro Martín Lavopa 
(C) copyright Alejandro Martín Lavopa, Maastricht 2015

Cover Picture: M.C. Escher, "Relativity".

All M.C. Escher works (C) 2015 The M.C. Escher Company - the Netherlands. All rights reserved. Used by permission. www.mcescher.com

Printing: Datawyse | Universitaire Pers Maastricht

ISBN 9789461594167 


\section{Structural Transformation and Economic Development.}

\section{Can Development Traps be Avoided?}

\section{DISSERTATION}

to obtain the degree of Doctor at Maastricht University, on the authority of the Rector Magnificus, Prof. Dr. L.L.G. Soete in accordance with the decision of the Board of Deans, to be defended in public on Thursday 12 March 2015, at 12.00 hours

by

\section{Alejandro Martín Lavopa}

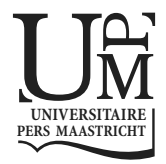




\section{Supervisors:}

Prof. Dr. Adam Szirmai

Prof. Dr. Bart Verspagen

Assessment Committee:

Prof. Dr. Robin Cowan (Chair)

Dr. Marco Capasso

Prof. Dr. Giovanni Dosi (Sant'Anna School of Advanced Studies, Pisa)

Prof. Dr. Marcel Timmer (Groningen University) 


\section{CONTENTS}

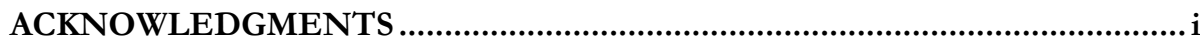

SUMMARY

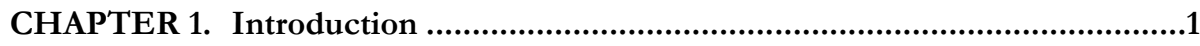

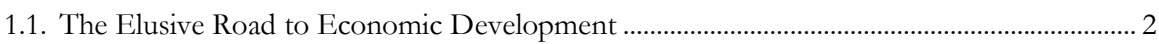

1.2. Structural Change and Technological Upgrading.................................................................... 3

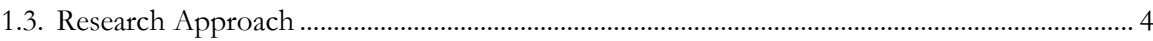

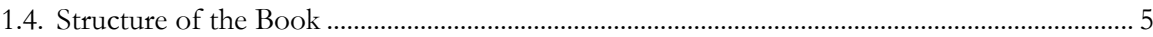

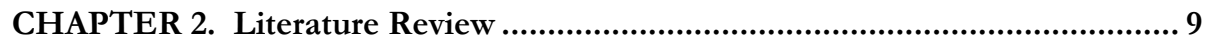

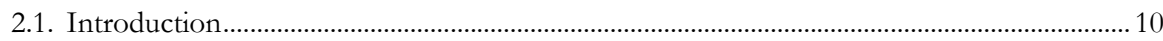

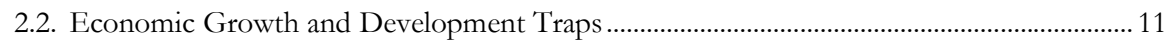

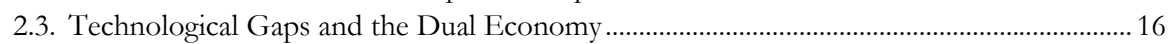

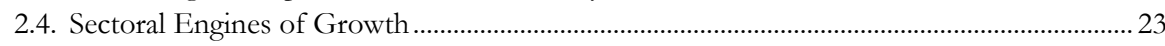

2.5. Specialization Patterns and Economic Development ............................................................... 31

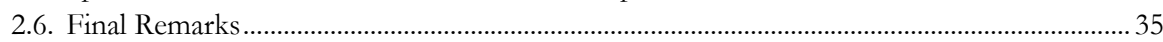

CHAPTER 3. Technological Catch Up in a Balance-of-Payments

Constrained Dual Economy ........................................................................ 37

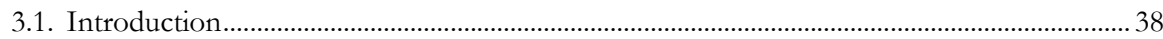

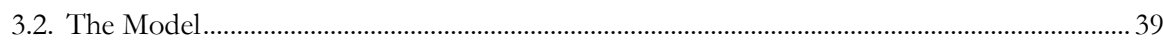

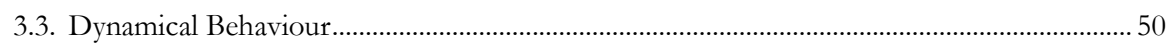

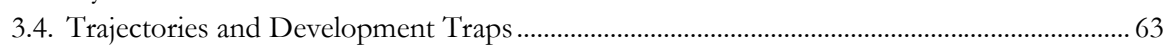

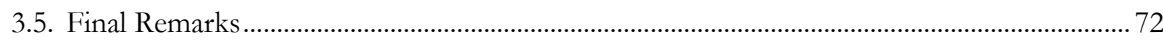

CHAPTER 4. Structural Modernisation and Development Traps ................... 75

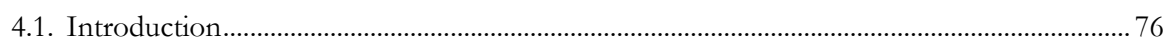

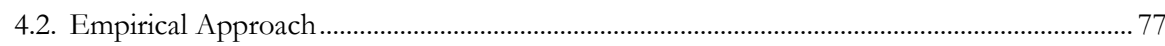

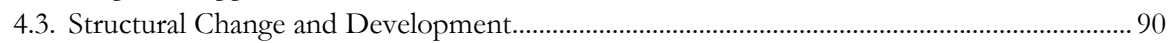

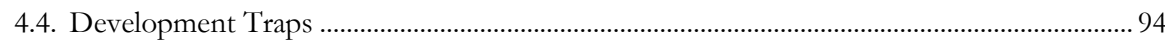

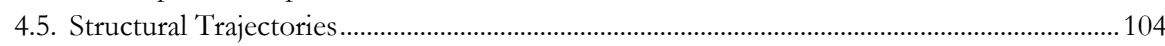

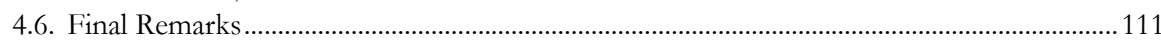

CHAPTER 5. Structural Modernisation, Trade Specialization and

Economic Growth. The Role of Manufacturing.......................................... 113

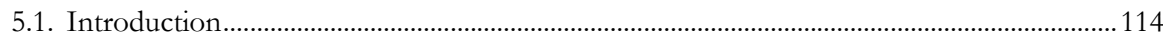

5.2. Structural Modernisation and Economic Growth .................................................................. 115

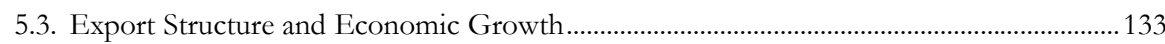

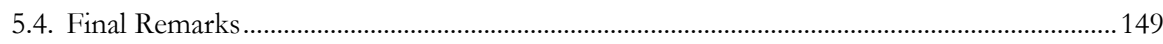


CHAPTER 6. Sectoral Heterogeneities and Structural Change in the

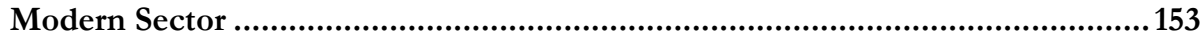

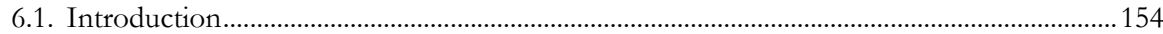

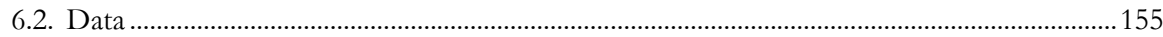

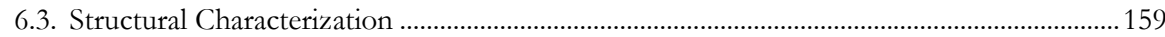

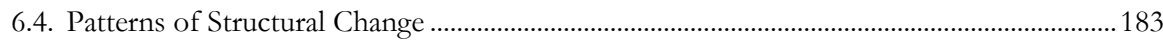

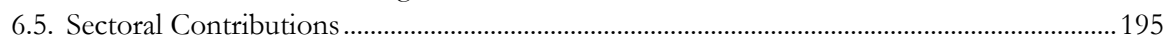

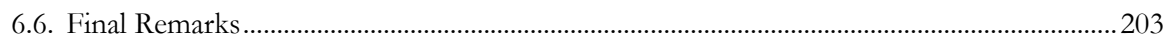

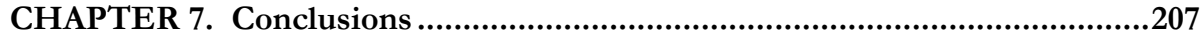

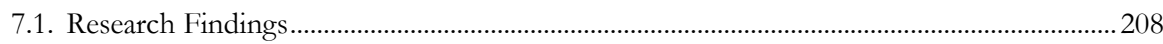

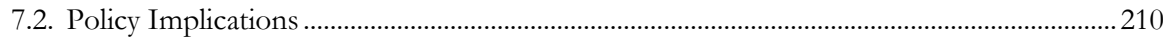

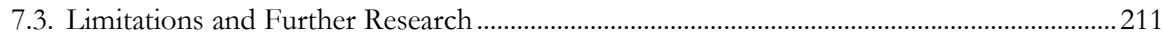

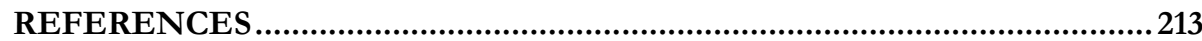

APPENDIX A. Appendix to Chapter 3 .......................................................225

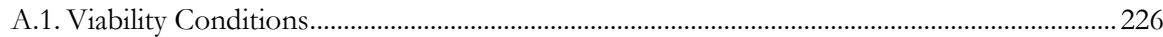

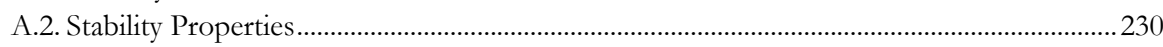

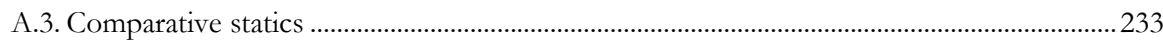

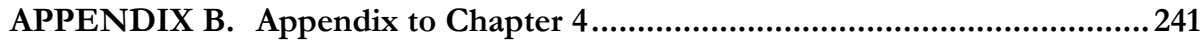

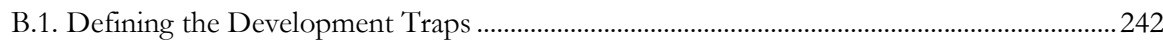

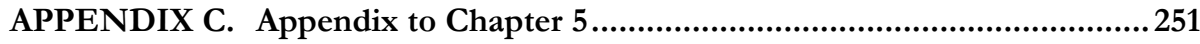

C.1. Regression Results (Figure 5.2 and Figure 5.3)....................................................................252

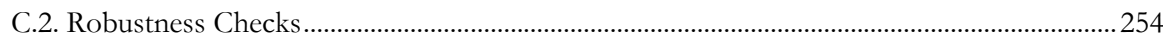

APPENDIX D. Appendix to Chapter 6......................................................261

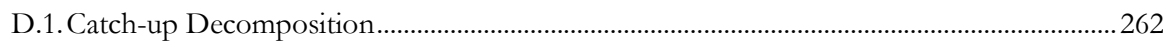

APPENDIX E. Constructing the Dataset ...................................................265

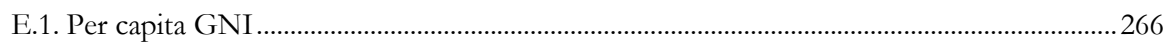

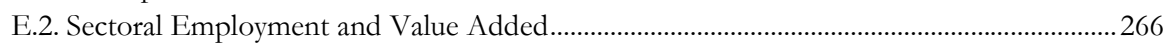

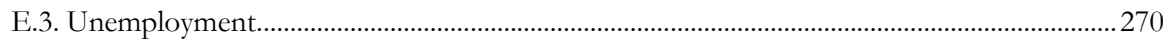

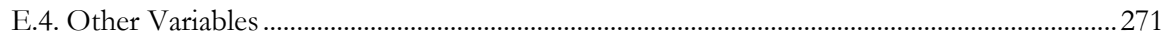

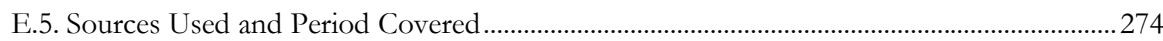

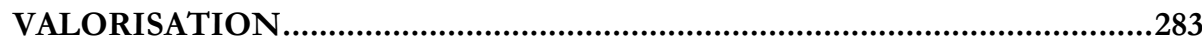

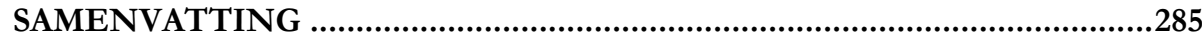

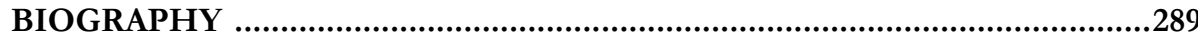




\section{LIST OF TABLES}

Table 3.1. Definition and interpretation of each term in the dynamic system ......................................... 52

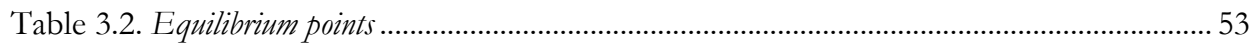

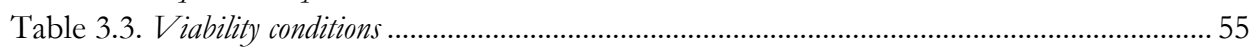

Table 3.4. Viability conditions under different restrictions on the signs of $A, D$ and the slope

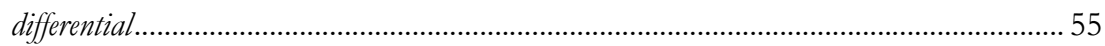

Table 3.5. Stability properties of the equilibria under different cases...................................................... 58

Table 3.6. Comparative statics in the vicinity of Equilibrium 4 (sign of the partial derivatives with respect to the deep parameters of the model)....................................................................... 70

Table 4.1. Sectoral disaggregation and definition of Modern Market Activities (MMA)....................... 78

Table 4.2. Transition matrix for countries that have successfully improved their income category between 1950-2013 and are unlikely to be in the middle-income trap. 52 countries. ............ 96

Table 4.3. Countries in a development trap. 2013, 30 countries. ......................................................... 97

Table 4.4. Countries in a development trap by regions of the structural modernization landscape.

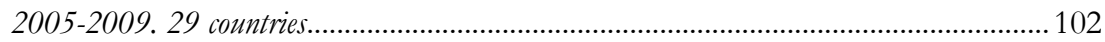

Table 4.5. Typology of countries based on the regions of the structural modernization landscape ............. 104

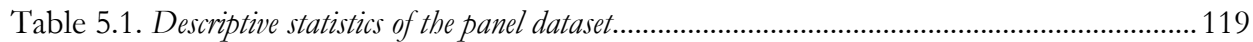

Table 5.2. Hausman's (1978) specification test for the explanatory variables........................................ 122

Table 5.3. Determinants of growth. The role of modern market activities. Hausman-Taylor estimates

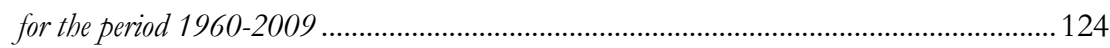

Table 5.4. Determinants of growth: the effect of $M M A$ composition including interactions with explanatory variables. 1960-2009, Hausman-Taylor estimates........................................ 129

Table 5.5. Classification of Manufacturing exports by technology intensity ............................................ 135

Table 5.6. Classification of Manufacturing exports by average level of income elasticity ..........................136

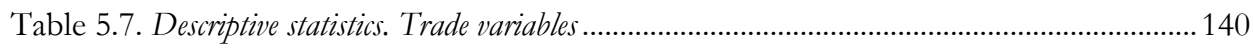

Table 5.8. Hausman's (1978) specification test for the explanatory trade variables ................................142

Table 5.9. Determinants of growth. The role of exports ........................................................................ 143

Table 5.10. Determinants of growth: the role of different manufacturing value added exports groups ..... 146

Table 6.1. Sectoral disaggregation within Modern Market Activities...................................................157

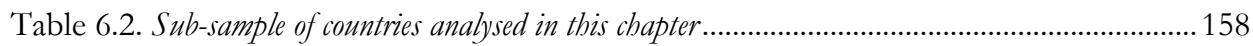

Table 6.3. Relative labour productivity (world frontier $=100$ ) in $M M A$ and sectoral dispersion, by country. 5-year averages around 2007........................................................................ 169

Table 6.4. Sectoral productivity in the world leader (United States). Absolute and relative levels. 5year averages around 1972 and 2007.

Table 6.5. Decomposition results. First period (1972-1982). Percentage points of the aggregate growth rate in $M M A$ relative productivity

Table 6.6. Decomposition results. Second period (1982-2007) Percentage points of the aggregate growth rate in $M M A$ relative productivity.

Table 6.7. Decomposition results: concentration degree of the catching up process. 1972-1982 and 1982-2007. 
Table 6.8. Annual growth rates of the structural modernisation index, the relative productivity of $M M A$ and the share of MMA workers in total labour force, by country and sub-period (in percentages).

Table A. 1. Cases in which VC1 and VC2 are satisfied 226

Table A. 2. Cases in which VC3 and VC4 are satisfied 226

Table A. 3. VC1 and VC2 in Case 1 227

Table A. 4. VC1 and VC2 in Case 1 (in terms of slopes and intercepts)..... 227

Table A. 5. VC3 and VC4 in Case 1 (in terms of slopes and intercepts) 228

Table A. 6. VC1 and VC2 in Case 2 (in terms of slopes and intercepts)

Table A. 7. VC3 and VC4 in Case 2 (in terms of slopes and intercepts)

Table A. 8. Trace and determinant of the Jacobian for each equilibria.

Table A. 9. Trace and determinant signs and stability properties of the equilibria in each sub-case .......232 Table A. 10. Partial derivatives in terms of $A, B, C, D, E$ and $F$ with respect to the deep parameters of the model.

Table B. 1. Economies that turned to lower-middle incomes (LMI) after 1950 and graduated to upper-middle incomes (UMI) before 2014. 11 countries.

Table B. 2. Economies that turned to upper-middle incomes (UMI) after 1950 and graduated to high incomes (HI) before 2014. 20 countries.

Table B. 3. Characterization of middle-income economies (MIEs). 40 countries.

Table B. 4. Projected number of years needed by the low-income economies (LIEs) of our sample to turn into lower-middle-income economies (LMIE), given the growth rate of the last 20 years. 23 countries......

Table C. 1. Determinants of growth: manufacturing value added exports by technology intensity groups interacted with relative productivity in manufacturing.

Table C. 2. Determinants of growth: manufacturing value added exports by technology intensity groups interacted with relative productivity in manufacturing.

Table C. 3. Hausman's (1978) specification test for the models estimated in the chapter.

Table C. 4. Robustness check: the effect of alternative measures for the key variables of Model 2.

Table C. 5. Robustness check: the effect of an alternative specification for the composition of the modern sector

Table C. 6. Robustness check: the effect of sectoral composition by income level...

Table E. 1. Additional sources for sectoral employment.

Table E. 2. Sources used and period covered by country: Per capita GNI.

Table E. 3. Sources used and period covered by country: Sectoral Employment and V alue Added........ 278

Table E. 4. Sources used and period covered by country (Latin American countries): Unemployment rate

Table E. 5. Sources used and period covered by country (non-OECD, Asian and African countries): Unemployment rate

Table E. 6. Manufacturing value added exports. Sources and coverage by country..... 


\section{LIST OF FIGURES}

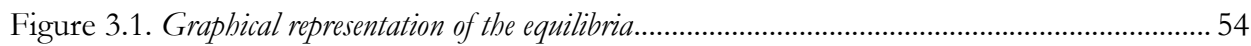

Figure 3.2. Graphical representation of the different cases..................................................................... 57

Figure 3.3. Illustrative trajectories under different stability properties in Eq. 4 ..................................... 59

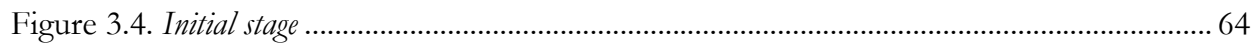

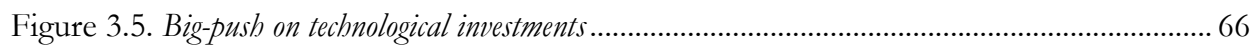

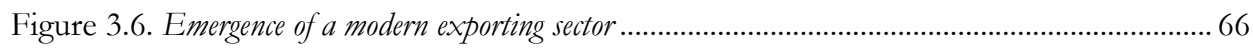

Figure 3.7. Path towards successful development ................................................................................. 68

Figure 3.8. Acceleration of global technological change and real appreciation of the domestic currency ...... 72

Figure 4.1. Structural Modernization Landscape: Level curves and structural trajectories ...................... 82

Figure 4.2. Share of labour force in Modern Market Activities (MMA) and Industry by levels of per capita Gross National Income (GNI), at constant PPP dollars of 2005. Five year averages between 1950 and 2009 for 97 countries.

Figure 4.3. Relative labour productivity in Modern Market Activities (MMA) by levels of per capita Gross National Income (GNI), at constant PPP dollars of 2005. Five year averages between 1950 and 2009 for 97 countries.

Figure 4.4. Structural modernization index by levels of per capita Gross National Income (GNI), at constant PPP dollars of 2005. Five year averages between 1950 and 2009 for 97 countries.

Figure 4.5. Structural modernization index by levels of per capita GNI at constant PPP dollars of 2005. Average values between 2005 and 2009 for countries in low or middle-income traps.

Figure 4.6. Structural modernization landscape. Average values between 2005 and 2009 for high income countries and countries in a development trap.

Figure 4.7. Structural trajectories (five year averages). Rep. of Korea and Taiwan ................................ 105

Figure 4.8. Structural trajectories (five year averages). Hong Kong and Singapore ............................... 106

Figure 4.9. Structural trajectories (five year averages). China and Thailand ....................................... 107

Figure 4.10. Structural trajectories (five year averages). Brazil and South Africa................................ 109

Figure 4.11. Structural trajectories (five year averages). Bolivia and Philippines ................................... 110

Figure 4.12. Structural trajectories (five year averages). Ethiopia and Tanzania ................................. 111

Figure 5.1. Marginal effect of different explanatory variables on growth, when interacted with share of Manufacturing in $M M A$.

Figure 5.2. Marginal effect of manufacturing value added exports in different technology intensity groups, by level of relative productivity in manufacturing.

Figure 5.3. Marginal effect of manufacturing value added exports in different income elasticity groups, by level of relative productivity in manufacturing.

Figure 6.1. Distribution of labour by sectoral technological gaps. .......................................................160

Figure 6.2. Distribution labour by sectoral technological gaps. .......................................................... 161

Figure 6.3. Stylized trajectories in the distribution of labour by sectoral technological gaps ..................... 163

Figure 6.4. Productivity at the frontier (millions of 2005 international dollars). By sector, 1970-2009

(5yr averages)...... 
Figure 6.5. Relationship between sectoral heterogeneity and technological catching up. 30 countries, 5year average around 20007.

Figure 6.6. Distribution of labour by sectoral relative productivity. India and the United States, 5year averages around 2007.

Figure 6.7. Distribution of labour by sectoral relative productivity in successful mature bigh-income economies. 5-year averages around 1972, 1982 and 2007.

Figure 6.8. Distribution of labour by sectoral relative productivity in successful newly bigh-income economies. 5-year averages around 1972, 1982 and 2007.

Figure 6.9. Distribution of labour by sectoral relative productivity in countries trapped at middle incomes. 5-year averages around 1972, 1982 and 2007.

Figure 6.10. Distribution of labour by sectoral relative productivity at the frontier. Brazil, India and the United States, 5-year averages around 2007.

Figure 6.11. Distribution of labour by sectoral relative productivity at the frontier in 2007. Korea, 5 year averages around 1972, 1982 and 2007

Figure 6.12. Harberger diagram

Figure B. 1. Distribution of countries according to the number of years they needed to graduate from lower-middle income (LMI) to upper-middle income (UMI) category.

Figure B. 2. Distribution of countries according to the number of years they needed to graduate from upper-middle income (UMI) to high income (HI) category.

Figure B. 3. Distribution of low income countries (LICs) according to the projected number of years they will need to graduate to the lower-middle income (LMI) category. 


\section{ACKNOWLEDGMENTS}

Any piece of new knowledge is the result of collaborative thinking, and this thesis is certainly not an exception. For this reason, I would like to use the first pages of this book to acknowledge all the people who contributed in the development of this thesis.

First and foremost, I would like to thank my promoter and supervisor, Eddy Szirmai, for his constant guidance and encouragement throughout the Phd process. Besides being an excellent supervisor, always ready to give me his advice on the many issues and problems that aroused during this research, he has definitely shaped my approach to doing research in a way that will go far beyond this thesis. After these years working with him I have learnt to be as rigorous as possible and back all my statements with solid empirical evidence. I am also grateful for his full trust on me and the many opportunities he gave me to collaborate in different research projects. My involvement in these projects not only broadened my perspective on key economic development issues but also opened many doors for my future professional career.

I would also like to thank my co-supervisor, Bart Verspagen, who has guided me into a completely unexplored area: the art of economic modeling. The theoretical foundations of this thesis would have certainly been less solid without his sharp advice. Our meetings to discuss the theoretical model have been invaluable learning experiences that I have very much appreciated.

The thesis has also greatly benefited from the excellent comments and suggestions of the member of the assessment committee: Robin Cowan, Marco Capasso, Giovani Dosi and Marcel Timmer. Their comments gave new ideas and helped me to improve some weak points of the thesis. I could not, however, make justice to all their thoughtful points. Many of these suggestions, in fact, will remain fertile ground of though for my future research.

My research has also been shaped and improved by fruitful debates and talks with my fellow $\mathrm{PhD}$ students and researchers from UNU-MERIT and Maastricht University. To begin with, I had benefited from an outstanding cohort of colleagues with whom I have shared not only inspiring discussions (inside and outside the institute) but also extremely beautiful moments. So I want to deeply thank Daniel O., François, Giorgio, Jocelyn, Samyukta, Sayan and Tatevik for being the best batch ever and Francesca and Jennifer T. for being the best adopted mates! Besides them I also had the pleasure to meet and share great experiences with many other students and researchers. The list is large, so here I will only mention some of them. Thanks to you all for sharing these years with me: Agustín, Alejandro, Alison, Andrea, Andrés, Andy, Charlotte, Claudio, Craig, Daniel V., Eduardo, Elisa, Ezequiel, 
Francisco, Iman, Irina, Jennifer W., Jojo, Juan Carlos, Julieta, Lilia, Luciana, Mary, Michiko, Omar, Paula, Paulina, Rodolfo, Shuan, Simone, Stefania F., Stefania I. and Tobias.

Even though most of this thesis has been developed and written in Maastricht, it has also benefited from close collaborations with other researchers from different corners of the world. Among them, I would like to specially thank Mario Cimoli, Gabriel Porcile and the other members of the Division of Production, Productivity and Management of ECLAC. The thesis has greatly benefited from my research visit there in 2012 which brought me much closer to the theoretical insights and empirical analysis of the Latin American Structuralism. I am also grateful to Ludovico Alcorta, Nobuya Haraguchi, Michele Clara, Nicola Cantore and the other members of the Development Policy, Statistics and Research Branch of UNIDO. My collaboration in different projects of this research team and my direct involvement in the Industrial Development Report 2014 put me in closer contact with the current debate on the role of manufacturing and industrialization in economic growth and the main challenges faced by low and middle income economies in their path towards development. Finally, I would like to thank Marcel Timmer, Gaaitzen de Vries, Bart Los and the other members of the research team of the Groningen Growth and Development Center (GGDC) for giving me extremely helpful comments and suggestion at different stages of my Phd research and for providing me invaluable help in the construction of my dataset. The empirical chapters of this thesis would certainly not be as comprehensive as they are now without your thoughtful advice and the many dataset you have been producing in the last years.

This research has also benefited from comments and suggestions at different conferences and workshops around the world: Tampere, Buenos Aires, Brisbane, Sao Paulo and Addis Ababa. From these experiences I would like to specially thank the enlightening comments and suggestions of Jorge Katz, Franco Malerba, Jorge Niosi, Chan Yuan Wong and Mercedes Campi.

Coming from abroad, it has not always been easy to adapt to a completely new environment, 11.000 kilometers away from home. This adaptation would have definitely not been as smooth if Eveline had not been around supporting me in every stage of my research. My most sincere thank for all the efforts she daily makes to transform the institute in our second home. Your efforts definitely make a difference. I would also like to express my gratitude to the other staff members that make UNU-MERIT such a lovely place to conduct research: Ad, Eric, Herman, Howard, Marc, Mitie, Mourik and Wilma.

Being a long journey, this thesis had also a starting point, and it would have never been possible without the strong support of some people back in Argentina. I would like to thank specially to Alberto Müller, Javier Lindenboim and Daniel 
Heymann for their kind support back in the days in which doing a Phd abroad was just an ambitious and loosely defined project. I would also like to acknowledge the fundamental role played by the University of Buenos Aires in my academic formation. A completely free and public University with such level of excellence is a precious privilege that I, as Argentinean, had the opportunity to enjoy. I hope that this piece of research is a good reflection of it.

Finally, I would like to dedicate this thesis to my closest ones and my family back in Argentina. A mis mejores amigos, Chris, Fede y Juan, siempre listos para hablar a la distancia y hacer desaparecer cualquier tipo de nostalgia a lo largo de estos años; a mi familia, Fede, Linda y Renu, siempre recordándome la calidez del hogar; y a Francesca, my compañera más cercana y mi punto de referencia más claro en este largo viaje. A todos ustedes mi más profundo agradecimiento por estar siempre ahí, al lado mío, apoyándome en cada paso que di para terminar esta tesis. 



\section{SUMMARY}

The main goal of this thesis is to investigate economic development as a process of structural transformation. In particular, the thesis postulates that there are two key transformations that need to be achieved in order to catch up with the advanced world: on one hand, the absorption of an increasing share of the labour force in the modern part of the economy (structural change); on the other hand, the technological upgrading of these modern sectors (technological catch up). Failure to achieve either of these transformations will eventually lead to low- or middleincome traps, in which only a fraction of the society can reap the benefits of the international flows of technological knowledge.

This general hypothesis is grounded in a series of theoretical contributions that, from different perspectives, have acknowledged the fundamental role of structural change and technological catch up in the process of economic development. The first part of the thesis is devoted to building a formal mathematical model of catch up that, combining these theoretical perspectives, is able to deliver interesting insights on different structural trajectories that an economy may follow in its path towards development. An original contribution of this model is that the follower economy is depicted as having a dual structure and a balance-of-payments restriction on economic growth, in line with the characterizations typically done to describe this sort of economies. The model is able to generate multiple equilibria in a simple and easily traceable fashion. The obtained equilibria, in turn, are interpreted as the contrasting outcomes which can be observed in records of historical experiences. According to the model, depending on initial conditions and underlying parameter, an economy can successful catch up with the most advanced economies, by increasing the size of its modern sector and closing the modern sector's gap with the technological frontier. But it can also fail to do so and end up at intermediate stages, either at low or middle-income ranges, in a so-called development trap. The final outcome is determined by the dynamic interaction of structural change and technological upgrading in the process of economic growth.

The salient outcomes of the model are compared with patterns in the empirical data in the second part of the thesis. In order to do this a large dataset is constructed on employment, value added and other variables, broken down by sector and in units comparable across time and space. These variables are used to build an index of structural modernization to study economic development. This index connects the main theoretical insights of the model with real world empirical trends. In short, it calculates the productivity gap with respect to the world frontier in an aggregate of activities that is regarded as the modern part of the economy and weights it by the share of these activities in total labour force. Hence, it combines a techno- 
logical dimension (the relative productivity) and a structural dimension (the size of the modern sector) thus providing a concise measure of the degree of modernity of an economy. The estimates of this index are used to explore the relationship between structural modernization and the aforementioned development traps. In analysing this relationship, the interactive nature of structural change and technological catch up is stressed. Important insights are obtained regarding the nature of low and middle-income development traps. The examination of this index across a large dataset of countries confirms that countries caught in development traps are, at the same time, countries that have been unable to achieve the proper level of modernisation. That is, countries that have either failed to expand their modern sector and absorb productively their labour force, or have failed to tap into international flows of technological knowledge and reduce their gap with the world frontier.

This line of research is explored further and the key variables constructed before are analysed within the general framework of growth regressions to explore their impact on economic growth. Econometric panel data techniques are used to estimate a variety of models and explore the role of these variables in driving economic growth. Following the theoretical underpinnings detailed in the first part of the thesis, this econometric analysis also explores the role of different sectoral composition of the modern part of the economy in driving the growth process. In particular, it explores several interactions between the explanatory variables and the shares of three broad sectors that jointly constitute the modern part of the economy: Manufacturing, Non-manufacturing industry and Modern market services. Furthermore, it analyses the role of exports and particular patterns of trade specialization in this process, giving special attention to the role played by manufacturing exports. This exercise reveals interesting patterns that contribute in the understanding of why some countries are caught in development traps. On one hand, the results of the econometric regressions indicate that the sectoral composition of the modern sector significantly matters for the final outcome in terms of economic growth. According to these findings, having a vibrant and dynamic manufacturing sector would counterbalance the tendency of growth rates to slow down as countries achieve higher levels of structural modernisation. Moreover, the positive effects of other variables included in the regressions seem to be mediated by the relative size of manufacturing within the modern part of the economy. The positive effects typically found for education and openness in driving economic growth are stimulated by a larger manufacturing sector and hampered by a smaller one. The regression results also highlight the key role of exports in this process, which would also counterbalance the tendency for growth rates to decline as countries achieve higher levels of modernisation. Higher exports would tend to alleviate the balanceof-payments restriction and, at the same time, stimulate technological learning and capacity building stemming from the exposure to foreign markets. However, not all 
exports seem to deliver the same growth benefits. According to our results, it is the export of manufacturing value added that contributes most to economic growth.

Being aware of the important heterogeneities that characterise the modern sector in developing countries, the final part of the thesis is devoted to explore in further detail the sectoral composition of the modern sector and its evolution over time. In order to do this, the analysis is concentrated on a more restricted number of countries and a shorter period of time for which the required data is available. Looking at 30 countries over the period 1970-2010, it identifies some stylized patterns of structural change within the modern part of the economy and relates them to the contrasting outcomes in terms of successful development and middleincome traps identified in the previous chapters of the thesis. An important finding is that the technological upgrading of the modern sector also depends on the structural transformations that take place within this aggregate. Shifts of economic activity towards sectors with higher levels of productivity and higher technological potential have been a key element in the catching up dynamics of successful economies. In contrast, the patterns of catch up in those countries caught in the middleincome trap (especially in Latin America) have been concentrated in a few industries and tended towards a polarize structure where the differences between sectors have increased over the last forty years. These results suggest that an important challenge ahead for these economies is how to achieve a broad diffusion of technological learning across a larger number of sectors, even within the modern part of the economy. 



\section{CHAPTER 1 . Introduction}




\subsection{The Elusive Road to Economic Development}

By the end of the Second World War, Latin America was expected to be the next region of the planet to join the privileged group of rich nations. More than half century later, however, the countries of the region still remain at middle income ranges, facing considerable challenges to reduce their social, economic and technological gaps with the advanced economies.

In a similar vein, after gaining independence, many sub-Saharan African countries were expected to achieve an important acceleration in their rates of growth, taking advantage of their backward position and the wave of foreign capital seeking for higher returns than those in their domestic markets. Fifty years later, the outcomes observed in the vast majority of these economies can better be described as a growth tragedy, in stark contrast with the original optimism of the independence days.

Though not strictly comparable, the trajectories followed by both regions illustrate clearly how difficult it is to move up the income ladder. Today, the average per capita income of Latin American countries is one sixth of that of the United States, while the average of sub-Saharan Africa does not even reach $10 \%$ of the US. This situation has not changed significantly over the last half century.

Recent history, nevertheless, demonstrates that climbing the income ladder, though difficult, is not impossible. First Japan and then successive tiers of Asian NICs followed a development trajectory that is at odds with that of their counterparts in Latin American and sub-Saharan Africa (Szirmai, 2013). In five decades, the first tier of Asian NICs (Hong Kong, Rep. of Korea, Singapore and Taiwan) managed not only to surpass the income levels of previously richer Latin American NICs but also became part of the select group of high-income economies. The next tier of Asian NICs (Malaysia, Indonesia, Thailand and, more recently, China and Vietnam) started with income levels comparable to those of Africa in the 1950s. Sixty years later, these economies have substantially higher incomes than subSaharan Africa and are now approaching the income levels of Latin America, with the perspective of surpassing them in the coming decades. Similar trajectories seem to be in motion in other economies of South and South-East Asia, such as for instance India.

The way these Asian economies achieved such success has been matter of a long debate and has triggered a vast empirical and theoretical literature. What seems to be undisputed in this debate is the fact that this process took place in conjunction with a radical transformation of productive structures that entailed major shifts in the sectoral absorption of labour and radical improvements in the technological sophistication of producers. Structural change and technological upgrading was at the core of this process. 
The main goal of this thesis is to investigate these transformations in detail and provide a general framework that can be used to explore and explain success or failure in economic development. To address this goal, the thesis will examine from a theoretical and empirical perspective the time trajectory followed by different countries in two key dimensions: structural change and technological upgrading.

\subsection{Structural Change and Technological Upgrading}

Since the early work of development pioneers such as Albert Hirschman, Arthur Lewis and Raul Prebisch in the 1950s, one of the major concerns of development economics was the ability of the economic system to absorb the whole working population in productive activities. According to these theorists, the dualistic character of less advanced countries imposed important restrictions on their development potential. In their view, only overcoming that duality through a process of structural change would lead them out of poverty.

More than half a century later, this issue continues to be at the core of policy and academic debates. In many cases, the long expected transformation of poor rural societies into modern urbanized and industrial economies has left a bitter flavour. Huge urban conglomerations have absorbed increasing numbers of rural migrants who -instead of finding good-quality jobs in modern industries- ended up enlarging the pool of self-employed and informal workers in service activities. The sectoral structure of many countries has radically changed during these decades, but their dualistic nature has remained the same: labour markets are still sharply divided between a small fraction of good-quality, highly-paid jobs in modern industry and modern services and a large body of the working population employed in badquality, low-income activities, typically informal and in many cases oriented towards subsistence.

From a dual-economy perspective, this concern actually reflects the need for higher rates of labour absorption in the modern sector of the economy. In a globalized world, this goal could hardly be achieved unless that sector is international competitive. In fact, it could be argued that the long-run survival of any job opportunity created in the modern sector would rely heavily upon its capacity to face global competition.

It follows that the ability of the modern sector to absorb labour needs to be assessed together with its capacity to compete in world markets. This capacity, in turn, is ultimately shaped by the innovation and technological capabilities of the country. Though price competitiveness based on the exploitation of cheap labour might be a suitable mode of entry into international markets, there is a widespread consensus today that this is not a sustainable avenue towards development. Ulti- 
mately the factors that really matter for international competitiveness are quality upgrading, quality differentiation and technological change.

This thesis tries to develop this line of reasoning. The old question about creation of productive employment in dual economies is re-examined from a theoretical perspective that acknowledges the fundamental role played by innovation and technological capabilities in the process of development. By doing so, an important contribution of the thesis is to combine two strands of literature that have provided important insights in the development potential of less advanced nations, but without much communication between each other. On one hand, there is the approach, put forward by the development pioneers but also central to post-Keynesian and Latin American Structuralism, regarding the prime role of structural change in dual or highly heterogeneous economies. The shift of labour from traditional to modern activities as a major avenue towards development has always been at the core of these theoretical traditions. However, the specific channels by which the modern sector creates and absorbs new technologies have not been fully explored by them. In clear contrast, economic historians in the Catch-up tradition together with Evolutionary economists have given centre stage to the fundamental role played by technological upgrading in the process of development and the specific capabilities needed to reduce the technological gap with the leading economies of the world. The dualistic structure of developing countries, however, has not been given enough attention in these theoretical perspectives.

The approach proposed in this book combines these traditions and studies development from a perspective that puts both elements in the centre of attention: structural change and technological upgrading. The main message from the thesis is that the success of countries in their path towards economic development depends heavily on the emergence and dynamism of a modern sector capable of simultaneously absorbing an increasing share of the labour force and reducing the technological gap relative to the world frontier. Failure to do so eventually leads the economy towards low- or middle-income traps, in which only a small fraction of the population benefits from the gains of economic growth and technological progress.

\subsection{Research Approach}

The methodological strategy followed to address the main goal of the thesis combines different research methods. These methods can be broadly divided into two levels: theory and empirics.

At the theoretical level, the thesis develops a formal model of technological catch up in a context of dual and balance-of-payments restricted economies. This model lays the foundations for the subsequent empirical analysis. Hence, the proposed mathematical model, far from being a theoretical abstraction with little con- 
nection with real world phenomena, establishes clear bridges between different strands of literature and stylized facts observed in the process of economic development. In particular, the model provides insights into certain structural trajectories that are expected to occur if a series of theoretical postulates (assumptions) are true. These theoretical postulates are taken from different traditions of economic thought. Three strands of literature, in particular, are extensively used: the Latin American Structuralist, the Post-Keynesian and the Schumpeterian schools of thought. Building on these traditions, the model prepares the theoretical ground for the empirical analysis.

At the empirical level we construct a comprehensive dataset with information on value added, employment and productivity by broad sectors of the economy in a sample of 100 countries over the period 1950-2009 (depending on data availability). This data is used to operationalize and examine the temporal trajectories of the key variables of the theoretical model, and compare them across countries with different growth performance. In constructing this dataset, special attention is placed on the comparability of variables across time and space. The sectoral figures on value added and productivity are expressed in an international comparable currency using sector-specific PPP converters.

Descriptive tools are complemented with econometric panel data techniques to investigate the constructed dataset and evaluate some of the salient hypotheses arising from the reviewed literature and our model. In order to do so, the dataset is expanded to include variables that have been identified in the specialized literature as key determinants of economic growth. Another original contribution of this thesis is the construction of time series on manufacturing exports compatible with regular ISIC industry classifications (as opposed to trade classifications) and adjusted for their value added content.

Finally, in a more restricted sample of countries and a shorter period of time a more detailed examination of the sectoral dynamics is undertaken. For this part of the analysis the thesis proposes a number of complementary methods to characterize the sectoral patterns of structural change and technological catch up. These methods include an in-depth examination of the sectoral distributions of employment in the modern part of the economy and a modified shift-and-share technique that accounts for the contribution of different sectors to the aggregate technological catch up of the modern part of the economy.

\subsection{Structure of the Book}

The general approach briefly outlined above has been structured as follows.

In CHAPTER 2, we review a series of contributions from the literature that from a theoretical and empirical perspective have addressed the main issues that we 
will investigate in this thesis. That is, the role of structural change and technological upgrading in the process of economic development. The chapter not only presents the general ground on which the thesis will be elaborated, but also identifies a number of gaps in the literature that need further exploration and will constitute the main focus of our investigation.

Based on the theoretical contributions and the gaps identified, CHAPTER 3 develops a mathematical model of technological catch-up between countries. An original contribution of this model is that the follower economy is depicted as having a dual structure and a balance-of-payments restriction on economic growth, in line with the characterizations typically done to describe this sort of economies. Combining insights from different traditions of economic thought, the model is able to generate multiple equilibria in a simple and easily traceable fashion. The obtained equilibria, in turn, are interpreted as the contrasting outcomes which can be observed in records of historical experience as briefly summarized in the first paragraphs of this introduction. According to the model, depending on initial conditions and underlying parameter, an economy can successful catch up with the most advanced economies, by increasing the size of its modern sector and closing the modern sector's gap with the technological frontier. But it can also fail to do so and end up at intermediate stages, either at low or middle-income ranges, in a so-called development trap. The final outcome is determined by the dynamic interaction of structural change and technological upgrading in the process of economic growth.

The salient outcomes of the model are compared with patterns in the empirical data in CHAPTER 4. In order to do this a large dataset is constructed on employment, value added and other variables, broken down by sector and in units comparable across time and space. Using these variables, the chapter develops a new index of structural modernization to study economic development, that connects the main theoretical insights of the model with real world empirical trends. In short, the index calculates the productivity gap with respect to the world frontier in an aggregate of activities that is regarded as the modern part of the economy and weights it by the share of these activities in total labour force. Hence, it combines a technological dimension (the relative productivity) and a structural dimension (the size of the modern sector) thus providing a concise measure of the degree of modernity of an economy. The estimates of this index are used to explore the relationship between structural modernization and the aforementioned development traps. In analysing this relationship, the interactive nature of structural change and technological catch up is stressed. Important insights are obtained regarding the nature of low and middle-income development traps.

This line of research is explored further in CHAPTER 5, where the key variables constructed before are analysed within the general framework of growth regressions to explore their impact on economic growth. Econometric panel data 
techniques are used to estimate a variety of models and explore the role of these variables in driving economic growth. Following the theoretical underpinnings detailed in the first part of the thesis, this chapter also explores the role of variations in the sectoral composition of the modern part of the economy in this process. In particular, it explores several interactions between the explanatory variables and the shares of three broad sectors that jointly constitute the modern part of the economy: Manufacturing, Non-manufacturing industry and Modern market services. Furthermore, it analyses the role of exports and particular patterns of trade specialization in this process, giving special attention to the role played by manufacturing exports.

CHAPTER 6 investigates this last point in more detail, exploring the role of sectoral composition and structural change within the modern sector in a more disaggregated fashion. In order to do this, the chapter concentrates on a more restricted number of countries and a shorter period of time for which the required data is available. Looking at 30 countries over the period 1970-2010, it identifies some stylized patterns of structural change within the modern part of the economy and relates them to the contrasting outcomes in terms of successful development and middle-income traps identified in the previous chapters.

CHAPTER 7 concludes with a short summary of the main findings of the thesis and the main messages that can be derived from these findings. Furthermore, policy implications are discussed and lines for future research are proposed.

Five appendices with some technicalities complement the thesis. Perhaps the most important is Appendix $\mathrm{E}$ which details the procedures and sources used to build the dataset used in chapters 4 to 6 . 



\section{CHAP'TER 2.}

\section{Literature Review}




\subsection{Introduction}

One of the major concerns of economic development deals with the old question about why some countries manage to succeed in improving standards of living and moving progressively closer to living standards of the richest countries, while other countries get stuck at intermediate phases of development, either in very low levels of income or at middle income levels. Why do some countries manage to catch up with the world frontier successfully, while others fail to escape from development traps?

Several reasons have been highlighted in the literature to explain these divergent trends, ranging from capital accumulation and technological diffusion to the quality of institutions and geographical conditions. This thesis takes the perspective that failures ultimately reflect the inability of the economic system to undertake the transformations that are at the core of the development process. More specifically, the focus of the thesis is placed in two major transformations: the movement of labour from traditional to modern activities and the reduction of the technological gap with the world frontier in those modern activities. From this perspective, the success or failure of development should be analysed by looking simultaneously at the evolution of both dimensions through time.

This perspective is grounded on different strands of economic literature that have remarked the fundamental role played by structural change and technological upgrading in the process of development. This chapter provides an overview of this particular set of literature. In doing so, it also identifies the theoretical and empirical gaps that the thesis will try to fill.

The review starts in Section 2.2 with a general discussion on the idea of convergence and divergence between countries, and the related concept of development traps. Next, Section 2.3 details a number of theoretical contributions that have tried to explain these dynamics emphasizing the role of technology, structural change and the insertion of developing economies in world markets. Particular attention is given to various models of catch up that, from different theoretical perspectives, have formalized these ideas. The review of these models, in turn, provides the basic ground upon which we will build our own theoretical model in the next chapter. After this theoretical discussion, in Section 2.4 the review moves to a more empirical ground and evaluates the literature that has investigated the role of different sectors as drivers of economic growth. In particular, it discusses the hypothesis of manufacturing as the main engine of economic growth and a number of challenging views that postulates the emergence of modern services as new engines of growth. Section 2.5 explores further this line and analyses the literature that has specifically dealt with the heterogeneities that arise across different sectors and the role of structural change in such a context. Section 2.6 concludes the chapter summarizing 
the main research gaps that have been identified through the review and that will be addressed in the remaining of this book.

\subsection{Economic Growth and Development Traps}

\subsubsection{Convergence or divergence?}

Since the beginning of the economic discipline as an independent body of ideas, economists have been challenged by the question of why wealth differs so much across nations. This was a major concern for all classical economists, from Adam Smith and David Ricadro to Karl Marx. With the marginalist revolution and its main interest in efficient allocation, however, this issue was neglected for a long time. It was only by the second half of the $20^{\text {th }}$ century that the interest in economic growth and development revived, partially due to the new National Income and Product data, which for the first time allowed economists to measure economic growth at a national level (Nelson, 1996). Perhaps for this reason, the starting point for modern economic growth theory is usually set in the mid fifties with the formal mathematical models developed by Solow (1956) and Swan (1956) ${ }^{1}$.

A distinguishing characteristic of these models is their prediction regarding growth rate differentials among countries. Given the assumption of diminishing returns to capital, such models predict that economies with less capital per worker will have higher rates of return and higher growth rates. It follows that, in the long run, there should be a process of international convergence in the levels of per capita income. That is, the lower the starting level of per capita GDP relative to the long run equilibrium, the faster the growth rate. This convergence is said to be conditional because the long run equilibrium (or steady state) depends on the particular saving rate, population growth and position of the production function of each country (Barro and Sala-i-Martin, 1995).

Using different econometric techniques and convergence measures, an initial wave of empirical studies found evidence supporting this hypothesis at the country level (Barro, 1991; Baumol, 1986; Dowrick and Nguyen, 1989; Mankiw et al., 1992) and at the regional level (Barro and Sala-i-Martin, 1991; Cashin and Sahay, 1996; Cashin, 1995; Persson, 1997; Sala-i-Martin, 1996; Shioji, 2001).

At the same time, however, the hypothesis of convergence started to be challenged both from a theoretical and empirical point of view. The surge of endogenous growth models by the end of the 1980s gave analytical support for divergence trends among countries. In models such as Romer (1986), Lucas (1988) or Scott (1989), for example, new investments lead to technological progress in the form of

\footnotetext{
${ }^{1}$ Other contributions that are usually taken into account when describing the development of modern growth theory are Ramsey (1928), Harrod (1939) and Domar (1946).
} 
learning by doing. Consequently, the beneficial external effects of capital accumulation outweigh the detrimental consequences of increasing capital per worker. Hence, the marginal productivity of capital does not decline and rich countries stay rich while poor countries stay poor. In this type of models, then, convergence does not take place (Fagerberg, 1994).

At the empirical level, the main criticism to the evidence on convergence points out to the issue of cross-country heterogeneity, and to the fact that the standard convergence equation typically assumes that the same law applies to all countries (Castellacci, 2008). Once this assumption is relaxed, then the possibility of convergence clubs emerges. That is, groups of countries that share similar characteristics and similar initial conditions and therefore show identical long-run trends in their income behaviour (Bernard and Durlauf, 1995; Durlauf and Johnson, 1995). This, in turn, would imply the existence of multiple growth regimes across sets of countries. Using different techniques, several authors found evidence supporting this idea (Desdoigts, 1999; Dowrick and DeLong, 2003; Hobijn and Franses, 2000; Paap et al., 2005; Pritchett, 1997).

As we can see, the concept of convergence has been subject to large debate both at the theoretical and empirical ground. The general conclusion seems to be that evidence of convergence is, at best, restricted to sub-sample of countries.

Once the idea of convergence is set aside, the important notion of "development traps" emerges. That is, if there is no natural trend of all countries to converge to a similar per capita GDP levels or rates of growth, then some countries will get caught at low or intermediate levels while others will achieve the so desired convergence with the richest nations of the world. We turn now to review this notion.

\subsubsection{Development traps}

In clear contrast with the optimistic view of the earlier neoclassical growth models regarding income convergence among countries, a number of scholars have long ago postulated that there are certain traps into which countries might fall, resulting in failure to catch up with the advanced economies. Starting from RosenteinRodan's idea of the big push, most policy recommendations from the development pioneers in the 1950s and 1960s were, in a nutshell, strategies to escape the poverty trap 2 . The very concept of a low-income trap has been early formalized by Richard Nelson in his seminal model of capital accumulation and population growth in underdeveloped economies (Nelson, 1956). Many years later it gained renewed interest with the so called new growth theory and its emphasis on multiple equilibria ${ }^{3}$. In

\footnotetext{
${ }^{2}$ Closer to our days, the big-push idea has been revived in the policy recommendations of the Millennium Development Goals (Sachs, 2005)

${ }^{3}$ See Azariadis and Stachurski (2005) for a recent review of this kind of models.
} 
short, a poverty trap (hereafter, PT) refers to a situation in which there are selfreinforcing mechanisms that cause a country that is initially poor to remain poor.

Several empirical contributions have provided evidence regarding the prominence of this phenomenon. Quah (1996) finds evidence of a bi-modal distribution in cross-country per capita incomes, suggesting some earlier evidence on the existence of a poverty trap. That is, a number of countries caught at low incomes that does not seem to be converging to the standards of living of richer countries. More recently, Bloom et al. (2003) proposed a formal test for the existence of poverty traps. In this test the null hypothesis of existence of multiple equilibria is contrasted against the alternative that differences in per capita income reflect fundamental forces such as geography, climate or culture. The hypothesis is contrasted by looking at whether moving from a single relationship between the fundamental forces and economic growth, to multiple relationships improves significantly the model's fit. The authors find that this is actually the case and therefore take this as evidence of poverty traps.

Other authors have followed a more pragmatic approach, and defined the countries that would be caught in a poverty trap by looking at specific dimensions of the economic development. This is the case of Guillaumont (2009) who combines two indicators of structural handicap to assess the risk of countries to fall in the poverty trap. These indicators are the Human Assets Index (a composite index of health and education indicators) and the Economic Vulnerability Index (a composite index of exposure and size of natural and external shocks). In his view, a high Economic Vulnerability Index with a low Human Assets Index can be used to identify the risk of a poverty trap. This is, in fact, the procedure currently used by the UN to identify the Least Developed Countries (LDCs) 4 .

In recent years, the related notion of a middle-income trap (hereafter, MIT) has gained increasing attention both in academic and policy circles. First invoked by Gill and Kharas (2007) to stress that certain East Asian economies might not be able to move forward to a high-income status unless they undertake major shifts in their economic strategies, the concept has become increasingly popular, especially in Latin America and Developing Asia. Some theoretical arguments support this point of view. From the perspective of international specialization, middle-income economies face the challenge of moving from competitiveness in low-wage activities and routinized tasks to competitiveness in knowledge based production using cutting-edge technological innovations (Eeckhout and Jovanovic, 2012; Garrett, 2004; Jankowska et al., 2012; Lee, 2013). Failure to implement policies of transformation would strand middle-income economies between low-wage manufacturers and high-wage innovators. Their wages would be too high to compete with the low-

${ }^{4}$ See UNDESA (2008) for the details. 
wage competitors, while their technological capabilities would be too weak to compete with high-wage innovators. As Ohno (2009) clearly puts it, middle-income economies remain trapped in that income category when they are unable to break through the "glass ceiling" that separates the stage of industrial development where production remains under foreign guidance and the stage in which skills and knowledge are already internalized and locals can replace foreigners in all areas of production, including management, technology, design, factor operation, logistic, quality control and marketing.

Lee (2013) develops this line of arguments further and suggests that the emergence of middle-income traps is closely related to the success or failure of middle income countries to build up the necessary technological capabilities. In his view, middle income countries that fail to upgrade and diversify their economy towards sectors with short-cycle technologies are more likely to fall in this sort of traps. Short-cycle technologies where innovation is faster and existing knowledge rapidly becomes obsolete offer the best chances of outcompeting high-tech incumbent firms and countries. The transition from middle to high incomes involves a technological based specialization in sectors where there is a frequent emergence of new technologies which are not yet dominated by the advanced economies. Failure to achieve such specialization would doom these economies to remain in lower-wage activities which have few prospects for long-term success.

Jankowska et al. (2012) explore a related explanation for the emergence of middle-income traps. In their view, the limited income convergence of these countries is explained (at least partially) by their reduced capacity to engage structural transformations conducive to higher productivity. This conclusion is grounded on a detailed comparative analysis of the transformations that took place in the export structures of successful Asian economies and Latin American countries caught in the middle-income trap. In order to do so, the authors investigate a series of measures based on the so-called Product Space approach (Hausmann et al., 2007; Hidalgo et al. (2007): export diversification, export upgrading, export profile connectivity and degree of export clustering. The general conclusion is that while Asian economies managed to significantly improve their export profile, the Latin American economies failed to do so.

Though its theoretical foundations are still a matter for debate, many attempts have been made to empirically analyze the existence and prevalence of the MIT. Woo (2012) proposes a catching up index (CUI) based on the relative income with respect to the world leading economy (the US), and defines the MIT as a situation in which the value of the index remains in a middle band for a long period of time ${ }^{5}$. According to his estimates, five Latin American countries (Argentina, Brazil, Chile,

\footnotetext{
${ }^{5}$ In his analysis, the band is defined as a CUI that lies between $20 \%$ and $55 \%$.
} 
Mexico and Venezuela) are clearly caught in the MIT, while Malaysia is also "muddling" along in the trap. Using a similar perspective, Robertson and Ye (2013) put forth an approach based on time series analysis. In their view, a country would be caught in the MIT if the long-term forecast of its per capita income relative to the USA is time invariant and within a middle-income band ${ }^{6}$. In total, they identify 19 countries in the MIT for the year 2007. Felipe (2012) takes a different approach. Instead of looking at the relative income with respect to the US, he defines income thresholds in constant PPP dollars and extends the World Bank's classification of countries by income levels to the period 1950-20107. Then he calculates the median number of years that the countries of his sample have taken to "graduate" from the lower middle-income category to the upper middle-income category and from the upper middle-income category to the high-income category. Using these median numbers as cut-offs, he defines two traps: the lower-middle-income trap (LMIT) and the upper-middle-income trap (UMIT). In the first trap he includes all countries that, by 2010, have been classified as lower middle-income countries for longer than the median number of years needed by the group that graduated from this category. Similarly, in the second trap he includes all countries that, by 2010, have been classified as upper-middle income countries for longer that the median number of years needed by the group of countries that graduated from this category to the high income category. In total, he identifies 35 countries caught in the middleincome trap, of which 30 are in the lower-middle-income trap and five in the upper-middle-income trap.

Overall it seems that both the poverty and middle-income traps have been validated by the empirical literature. However, the question regarding why some countries fall in such traps while others manage to avoid them is still subject of debate. The scattered arguments provided by the contributions reviewed here suggest that technology and structural change play a fundamental role in this outcome. In what follows we further explore these lines of thought and review the main theoretical contributions that have studied the role of technological upgrading and structural change in the process of economic development.

\footnotetext{
${ }^{6}$ In their analysis, the band is defined as a relative per capita income lying between $8 \%$ and $36 \%$ of the one of the US.

${ }^{7}$ The World Bank distinguishes four income categories: low, lower-middle, upper-middle and high incomes. These categories are defined according to certain thresholds imputed on the per capita GNI calculated using the Atlas method, and have been published yearly from 1987 onwards.
} 


\subsection{Technological Gaps and the Dual Economy}

\subsubsection{Technological gap literature}

The idea that technology plays a central role in the process of economic growth would hardly be disputed by any economist nowadays. The specific ways in which new technologies are translated into the productive process and, more broadly, how their benefits can be reaped at national level, however, are still subject to debate.

A strand of literature that has significantly contributed to our understanding of these phenomena in the context of economic development is the so called catchingup literature ${ }^{8}$. This literature originates in a series of contributions that -from an economic historical perspective- investigated the process of catching-up in latecomer countries during the last two centuries, with special focus on the creation and international diffusion of new technologies (Castellacci, 2007). For the authors embedded in this tradition, technological differences are the prime cause of differences in per capita growth across countries. Development itself is seen as the process by which countries manage to master frontier technologies at the domestic level, and so, reduce the technological gap with the leaders and, eventually, take over that position.

The roots of this tradition can be traced to Veblen (1915) and Gerschenkron (1962) and their studies of latecomers to industrialization. Both have stressed the advantages of backwardness resulting from the fact that learning and imitation is typically cheaper and faster than original innovation at the frontier.

According to Gerschenkron, once the obstacles to industrialization had been removed, the opportunities inherent in industrialization vary directly with the backwardness of the country:

"Industrialization always seemed the more promising the greater the backlog of technological innovations with the backward country could take over from the more advanced country" (Gerschenkron, 1962, p. 8).

However, he also pointed out some difficulties that arise when trying to narrow the technological gap, such as the resistance to change and the increasing requirements for capital accumulation (Gerschenkron, 1962).

Following these lines of analysis, other authors have identified certain features that a country needs in order to close the gap with the technological leader and achieve catch up. Rejecting the implicit idea of the basic convergence hypothesis according to which international knowledge spillovers take place automatically, this strand of literature emphasizes the importance of capabilities of the receiving country to assimilate technological knowledge. In this sense, first Goode (1959) and then

\footnotetext{
8 A detailed review of this strand of literature can be found in Fagerberg and Godinho (2005) and Fagerberg et al. (2010).
} 
Cohen and Levinthal (1990) proposed the notion of absorptive capacity. According to the first author, societies at intermediate stages of development have many problems in adapting imported technologies and physical capital to their use. This leads to the conclusion that:

"... many underdeveloped countries do not have the capacity to absorb large amounts of physical capital even when it can be obtained from abroad on favourable terms. The lack of absorptive capacity is often due to inadequate supplies of suitable labour, which reflect past deficiencies of investment in human capital" (Goode, 1959, p. 149)'.

As we can see, the original formulation of the concept refers to the national level and is close related to the idea of human capital formation. In Cohen and Levinthal (1990), instead, the focus is at the firm level. In this case, absorptive capacity is defined as the firm's ability to identify, assimilate, and exploit knowledge from the environment. This formulation has been later extended to a broader definition of national absorptive capacity (Criscuolo and Narula, 2008; Dahlman and Nelson, 1995).

In a related strand of literature, Ohkawa and Rosovsky (1973) in their seminal study of Japan's development introduced the concept of social capability to designate those factors constituting a country's ability to import or engage in technological and organizational progress. In their view Japan had specific institutions that had enabled the absorption of technological and organizational progress of foreign origin.

This concept is further developed by Moses Abramovitz, who restates the simple formulation of the catching-up hypothesis in order to take into consideration both the backwardness of a country (technological gap) and its capabilities to assimilate the technology of the leading country (social capabilities). According to him,

"Countries that are technologically backward have a potentiality for generating growth more rapidly than that of more advanced countries, provided their social capabilities are sufficiently developed to permit successful exploitation of technologies already employed by the technological leaders" (Abramovitz (1986) p. 390)

Another qualification that this author makes regarding the simple formulation of the catching-up hypothesis is related to the technological congruence of the lagging country and the leader. In order to exploit a leader's path of technological progress, followers countries should not differ much from the leader in terms of factor supply, market size and resource endowment.

Taking all these elements together, this strand of literature provides an alternative view of the process of convergence and divergence among countries and, at the same time, identifies many of the forces that may explain the observed differences

\footnotetext{
${ }^{9}$ Similar arguments can be found in Myint (1980)
} 
in per capita growth. It is worth noting that most of this literature fits very well in what Nelson and Winter (1982) call appreciative theorizing as oppose to formal theorizing. That is, theorizing close to empirical work, mostly expressed verbally and representing the analyst's articulation of what he or she thinks is going on.

During the last decades, however, there have been many attempts to formalize these ideas within the general framework of mathematical growth models. The next section briefly summarizes some salient contributions in this line of work.

\subsubsection{Formal models of technological catch-up}

Early attempts to formalize this body of ideas within a coherent mathematical framework can be found in Fagerberg (1988a), (1988b) and Verspagen (1991), (1993). The models proposed in these contributions try to explain macroeconomic growth from a catch-up perspective. A technologically backward economy (the follower) has a technology-gap that separates it from a technologically advanced economy (the leader), and the changes over time in that gap ultimately determines the growth potential of the less developed economy. Among other things, the follower can diminish this gap by exploiting its backward position, imitating or using advanced technologies developed by the leader. This process, however, is not costless and depends on the specific degree of technological congruence and social capability of the follower country. Catch-up is, therefore, not guaranteed and the follower might even fall further behind.

More recently, some authors have tried to build a more comprehensive framework, integrating the basic ideas of the catch-up tradition into the macroeconomic setting of Post-Keynesian cumulative-causation-type models. Following previous developments in this line, Castellacci (2002) and León-Ledesma (2002) ${ }^{10}$ proposed models of catch-up in which demand-side factors play a more fundamental role than in the original contributions of the catch-up tradition. These models assume that growth is demand-led (in particular, export-led) and that there is a dynamic interactive process connecting the growth of aggregate demand and the growth of productivity. This process would emerge from two interrelated mechanisms: on one hand, the so called Kaldor-Verdoorn effect of increasing returns to scale which links productivity growth to demand growth ${ }^{11}$. On the other hand, the external causation mechanism that links demand growth with productivity growth through the effect of the latter on price-competitiveness and thus exports ${ }^{12}$. Therefore, an increase of output growth (due to export growth) would induce a higher increase in the growth

\footnotetext{
10 Both authors builds on previous contribution from Amable (1993), De Benedictis (1998) and Targetti and Foti (1997).

${ }^{11}$ Following Boyer (1988), this has been typically labelled "productivity regime".

12 The "demand regime", in Boyer's terminology.
} 
of productivity that would feed through into lower inflation. This in turn, would improve price competitiveness, allowing for higher exports and thus starting the process again in a cumulative-causation fashion. Within this framework, catch-up, as analysed in the traditional approach, can be retarded or stimulated by demandside factors.

Formalizations of this sort have proven to be extremely useful in investigating the complex interactions between supply and demand factors in the process of economic development, in contexts in which technological opportunities might lead to productivity gains that can feed back into higher demand and thus higher gains in productivity. Such a setting brings traditional models of catch-up much closer to the reality of developing economies, where demand factors play a fundamental role in the overall performance of the economy. Nevertheless, they still have at least two important limitations when depicting a follower economy that belongs to the developing world.

On one hand, they are based on an export-led framework that does not take into consideration a major bottle-neck to aggregate growth faced by developing economies, namely the increase in imported goods that takes place as countries develop. That is, the external balance of payment restriction is not explicitly taken into consideration. In a recent review of Post-Keynesian models of aggregate growth, Robert Blecker demonstrates that the equilibrium solution of export-led cumulative-causation (ELCC) models is not sustainable in the long-run precisely because they lack a plausible external restriction (Blecker, 2013). In his view, models of growth based on a balance of payment constraint (BOPC) in the tradition of Thirlwall and Dixon (1979) are better suited to deliver sustainable long-run equilibrium outcomes. It follows that expanding the models proposed in Castellacci (2002) and León-Ledesma (2002) to a context of a BOPC economy would not only provide a picture that is closer to the reality of developing countries but would also enable an equilibrium solution that is actually stable in the long run ${ }^{13}$.

On the other hand -and perhaps more fundamentally- the aggregate nature of these models disregards a salient feature of the developing world, namely, the dual character of their productive structures. When it comes to developing countries, an aggregate view of the country might result in misleading conclusions. A welldocumented fact about poor (and to a certain extent, middle-income) countries is the coexistence of modern, highly productive and technological advanced activities alongside low-productive, typically subsistence-oriented, traditional activities. The following section explores further this issue.

\footnotetext{
${ }^{13} \mathrm{It}$ is also interesting to notice that some of the earlier models of technological catch-up already introduced a BOPC in their formulation. See for example Fagerberg (1988a), (1988b) and a later revised version presented in Fagerberg (2007).
} 


\subsubsection{The dual economy and structural change}

In order to simplify the complexities of modern economies, many of the studies and approaches that we have seen so far, take a macroeconomic approach to growth. This macro approach, however, is not compatible with the idea of economic growth as a transformation and it "excludes from consideration the most pervasive of all the stylized facts of economic growth, structural change" (Metcalfe (2001) p. 581). As was pointed out by Kuznets (1971), high rates of productivity growth are inseparable from high rates of change in the production structure. Then, in order to represent realistically the growth paths of capitalist economies and to understand why growth rates differ over time and across countries, some level of disaggregation is essential in the analysis (Cornwall and Cornwall, 1994).

In fact, from early contributions in the literature on economic development (Chenery et al., 1986; Chenery and Taylor, 1968; Kuznets, 1966, 1971) to more recent studies on the sources of economic growth and catch up (Hidalgo and Hausmann, 2008; Lin, 2011; McMillan and Rodrik, 2011), a long tradition in economic thought links economic development with the process of transformation and upgrading of productive structures. That is, the progressive shift of the economy from the production of simple goods, typically labour- or natural resourceintensive to complex and more sophisticated goods, typically capital- and technology-intensive.

From this perspective, economic development can only be understood as a process of transformation. Early development economists have approached this issue by postulating the existence of a dualistic structure in the economies of the developing world. In their view, a distinguishing feature of less advanced countries is the co-existence of modern economic activities ${ }^{14}$, with high productivity using state of art technologies, alongside a set of activities with very low productivity, typically of informal nature and in many cases oriented towards subsistence. The classical models of dual economies à la Lewis ${ }^{15}$ have formally illustrated this point, stressing a fact that lies at the core of development: at early stages of development the key to reduce the gap with the advanced world lies in the reallocation of labour from the traditional to the modern part of the economy ${ }^{16}$. In these models, the modern part of the economy has typically been associated with urban industry

\footnotetext{
14 Often the modern sector is referred to as the modern capitalist sector, but this is not necessarily the case. State-owned firms can also be part of the modern sector.

15 The first model of a dual economy was formulated by Julius Herman Boeke, in his seminal work on the Indonesian economy and society (Boeke, 1930).

16 Obligatory references are Lewis (1954); Ranis and Fei (1961); Sen (1966). For recent reviews on dual models rooted in this tradition see Temple (2005) and Ranis (2012).
} 
(more specifically, with the manufacturing sector), as opposed to rural agriculture. This is a feature that has also been extensively studied in the particular case of Latin America by the so-called Latin American Structuralists. These authors have postulated the related concept of Structural Heterogeneity, according to which Latin American economies would be characterized by having sets of activities with very different levels of technological sophistication. In their view, the main challenge for these economies would lie in the reduction of this heterogeneity through the absorption of an increasing share of the labour force within the modern segments of the economy ${ }^{17}$.

The importance of the economic structure in development has also been emphasized in other strands of economic thought. Post-Keynesian authors, mainly working in the Kaldorian tradition, have argued that certain sectors (most prominently, manufacturing industries) are better suited to drive economic development (an important issue that will be addressed in detail in Section 2.4). Other authors also rooted in the Kaldorian tradition have emphasized the fundamental role of economic structure by looking at international trade dynamics, and the requirements of foreign exchange in the process of development. The aforementioned models of Balance-of-Payments constrained growth postulate that economic growth is ultimately determined by the relative size of the income elasticities of export and import demand $^{18}$. Therefore, structural shifts towards the production of goods with higher income elasticities would be at the core of successful development.

Structural change also lies at the core of the Evolutionary and Schumpeterian traditions of economic thinking. In these cases, however, the emphasis has not been on a single sector as major driver of economic growth, but rather on the role of technological change, regardless of where it takes place. From this perspective, in each epoch there are certain key technologies whose domain and application are so wide that the pattern of technical change of each country heavily depends on the national capabilities to master the production, imitation and innovation in this set of crucial knowledge areas (Cimoli et al., 2009; Cimoli and Dosi, 1995; Dosi et al., 1988; Mowery and Nelson, 1999). These core technologies would shape the overall absolute advantages and disadvantages of each country, and therefore, a proper technological dynamism would be hardly achieved without the construction of indigenous skills in this set of core technologies. Although certain activities within manufacturing have typically been singled out as the major drivers of technological change, the list of potential drivers is not restricted and includes a wide array of activities, rang-

\footnotetext{
${ }^{17}$ See Cimoli (2005) and ECLAC (2012) for recent reviews on this literature. The concept of structural heterogeneity is typically formulated from a multisectoral perspective but, in practise, Latin American Structuralists have also focus in 2-sectors models, as we will see below.

${ }^{18}$ See Thirlwall (2011) for a recent review of these models.
} 
ing from high-tech agriculture to modern services ${ }^{19}$. The focus here is typically on the distance to the technological frontier, and the capabilities needed to reduce the technological gap, regardless of the specific sector ${ }^{20}$.

In light of the above, recent contributions rooted in the Neo-Structuralist tradition have tried to combine the Post-Keynesian model of demand-led cumulative-causation growth with a Lewis-type model of dual economy (Cimoli et al., 2005; Ocampo et al., 2009a; Rada, 2007). The goal of these models is to formalize the forces behind dynamic structural change, employment and growth in a dual economy with an abundant labour surplus. The economy is divided in two sectors. An established modern or formal sector (that typically comprises industry along with parts of agriculture and services) coexists with a subsistence or informal sector in which production relies only on low-wage labour. The modern sector functions in a Kaldorian demand-led cumulative-causation manner. The subsistence sector, instead, has decreasing (or at best, constant) returns to scale, and has an institutionally-based gap with the real incomes of the modern sector ${ }^{21}$. The underlying idea is that labour that is not employed in the modern sector survives by finding some sort of economic activity in the informal sector. This part of the labour force is thus underemployed and constitutes a sort of reserve army. Interestingly, these models manage to capture different mechanisms by which demand growth, productivity growth and dynamic structural change are related to each other. Moreover, they address a fundamental issue of development already highlighted in the introduction of this thesis: the inability of the economic system to create enough productive employment. An important limitation, however, is that they only partially explore the role of innovation and technological catch-up in this process. In particular, neither the dynamics of the technological gap over time nor the possible productivity gains arising from international spillovers are modelled within these formulations. It follows that there is an interesting opportunity to integrate this line of research with the catch-up models discussed previously.

\subsubsection{First gap: a formal model of catch-up in dual economies}

In this thesis we try to reconcile these traditions in a single, simplified framework. Our point of departure is a model of technological catch-up along the lines of León-Ledesma (2002) and Castellacci (2002), in which the Post-Keynesian side is based on a Balance-of-Payments constrained model rather than an Export-led model. The main extension, however, lies in the characterization of the follower

\footnotetext{
${ }^{19}$ A good example in these lines can be found in Pérez (2010) and her proposal for a catching-up strategy in Latin America based on natural resources based production.

${ }^{20}$ See Fagerberg and Godinho (2005) and Fagerberg et al. (2010) for recent reviews on this literature.

${ }^{21}$ In the model proposed by Cimoli et al. (2005) the wage differential between the two sectors arises from an efficiency wage formulation.
} 
country as a dual economy. Accordingly, we split the developing economy into two sectors and we model the basic interactions among them along the lines proposed in Cimoli et al. (2005), Ocampo et al. (2009a) and Rada (2007).

As we will see in CHAPTER 3, a distinguishing feature of the proposed model is that multiple outcomes can be obtained depending on the initial conditions and underlying parameters. These outcomes, in turn, can be associated with different development traps that need to be overcome in order to achieve successful catch up with the world's leading economy. Therefore, this formalization gives interesting theoretical insights to explain the emergence of low and middle-income traps.

A series of recent papers has built models of similar inspiration. Botta (2009) presents a Structuralist North-South model of economic convergence, that also incorporates elements from the Post-Keynesian and Post-Schumpeterian literature. Interestingly, the model distinguishes between manufacturing and non-manufacturing industries and studies the role of industrialization in the process of catch-up. The share of manufacturing in total GDP is used as the key variable representing the productive structure and the movements in time of this endogenous variable determines the growth potential of the South. In a similar vein, Cimoli and Porcile (2010) and (2013) present models also rooted in the Neo-Structuralist tradition and try to integrate elements from the Post-Keynesian and Post-Schumpeterian schools within that framework. A distinguishing feature of these models is the use of a multi-sectoral framework -based on Ricardian-type trade models- according to which the productive structure of each economy (North and South) is represented by a continuum of goods with different technological characteristics. By means of this setting, the models are able to analyze the particular outcomes of certain trade specialization patterns on the growth, productivity and technological potential of the follower economy.

In all these models, however, the dynamic interactions between the degree of duality and the possibilities for catch-up are not fully explored. As we will see, the main contribution of our model relies precisely on the examination of this kind of interaction and its evolution along the process of economic development. Hence, the model proposed in this thesis contributes to the literature that has tried to bring together these related traditions in a coherent framework to analyze the basic problems of development.

\subsection{Sectoral Engines of Growth}

An important corollary of the previous discussion is that when it comes to developing countries, an aggregate perspective might result in misleading conclusions. These countries are characterized by extreme dualities, in which a modern sector coexists with a traditional one. 
So far, the discussion has been mainly theoretical and therefore what is exactly included in the modern sector has been left deliberately vague. As one moves from the theoretical formulation to the empirical analysis, however, a clear definition of the modern sector is needed. In this thesis we take the perspective that the modern sector is composed of those economic activities that a) have high relative productivity; and b) can act as drivers of economic development. In traditional development literature the latter has been typically associated with the industrial sector. A series of recent contributions, however, has started to challenge this perspective claiming that certain service activities could also be regarded as major engines of growth. In this section we review both perspectives, as they will provide us with more solid arguments to determine what should be included in the modern part of the economy in our empirical analysis.

\subsubsection{The role of Industry}

A large strand of literature, both at the theoretical and the empirical level, has stressed the importance of the industrial sector -in particular, manufacturing industries- as the main engine of economic growth. Even though we can trace this view back to Adam Smith, the literature typically points out the works of Nicholas Kaldor as initiating this tradition. According to this author, manufacturing is characterized by having static and dynamic increasing returns to scale. Statics returns relate to the size and scale of production units in this sector, while dynamic economies refer to learning by doing, induced technical change and external economies in production. These features lead to a positive relation between output growth and productivity growth in manufacturing with, in turn, implies that the faster the rate of growth of manufacturing, the faster will be the growth of GDP (Kaldor, 1967). Following this line, many authors have regarded manufacturing industries as the major engine of economic growth because they provide special opportunities for both embodied and disembodied technological progress (Szirmai, 2011). While the former is closely linked to the larger scope for capital accumulation (as long as rapid capital accumulation in manufacturing is associated with new capital goods that embody the latest state-of-art technology), the latter refers to changes in the knowledge of product and process technologies in firms and in the economy as a whole.

The key importance of manufacturing in technological progress is visible when we look at the distribution of $R \& D$ expenditures across major sectors of the economy. The available evidence suggests that the bulk of $R \& D$ is undertaken in the manufacturing sector ${ }^{22}$. Moreover, the intensity of $\mathrm{R} \& \mathrm{D}$ in manufacturing (that is,

\footnotetext{
22 The available data, however, might overestimate the share of manufacturing in total $\mathrm{R} \& \mathrm{D}$ due to the intrinsic problems in the measurement of R\&D investments and innovation in other sectors of the economy, more prominently in services. This issue is discussed in detail in Pilat (2001) and Young (1996).
} 
the sectoral $R \& D$ per unit of value added) industries is typically much higher than in any other sector of the economy (Lavopa and Szirmai, 2012a).

Besides accounting for the bulk of $\mathrm{R} \& \mathrm{D}$ investments, manufacturing industries would also generate important technological externalities for other sectors of the economy. As it was already emphasized in Cornwall (1977), this sector would enhance productivity growth through its linkages with the rest of the economy. The strong backward and forward linkages that characterize this sector also increase output and productivity in non-manufacturing sectors. This would constitute another important channel by which manufacturing industries would fuel overall economic growth. As it has been widely documented in the literature, R\&D investments have positive externalities that go far beyond the productivity gains achieved in the same sector. Several approaches have been proposed to empirically measure this type of spillovers, and in all cases, its important role in terms of increasing the total factor productivity of the economy has been highlighted 23 . More specifically, several studies have demonstrated the important technological spillovers of manufacturing over other sectors (see, for example, Park, 2004; Pieper, 2002; ten Raa and Wolff, 2000)

Another mechanism by which manufacturing industries would exert an special role is related to the alleviation of the balance of payments constraints that can hinder economic growth in developing countries (Palma, 2005; Tregenna, 2007, 2008).

Earlier references in this strand of research focused mainly on the important role of domestic manufacturing producing goods that otherwise would need to be imported and might cause shortage of foreign exchange leading to macroeconomic crisis (Prebisch, 1950; Singer, 1950; Singh, 1977). According to this view, in developing countries at early stages of development, agriculture might have a more important contribution to the balance of payment than manufacturing. However, as per capita income rises, the role of manufacturing in maintaining the external equilibrium becomes critical. Given the high income-elasticity of demand for manufacturing products, if this demand cannot be met from domestic sources, then there would be an increasing burden of manufactured imports on the trade balance.

Recent contributions tend to put more emphasis on the important role of manufacturing exports. Cimoli et al. (2010) and Gouvea and Lima (2010), for example, examine this issue based on Thirlwall's balance of payments constrained growth model in a multisectoral framework. Their findings suggest that manufacturing (especially technology-intensive industries) provides better opportunities to alleviate external restrictions due to a higher income-elasticity of demand for manufactured exports.

\footnotetext{
${ }^{23}$ See Wolff (2011) for a recent review on the literature on this topic.
} 
Regardless of the specific channel, the hypothesis that manufacturing constitutes the main engine of economic growth has been extensively tested in the empirical literature. Overall, the general conclusion seems to support the idea that manufacturing is the (or at least one of the) major engine(s) of economic growth. In what follows, we review this type of empirical literature. To order the exposition, we divide it in two broad groups.

The first group consists of a wide array of studies which have tested the socalled Kaldor laws for different countries, at different points in time and using different econometric tools. These laws have been first proposed by Nicholas Kaldor in his seminal work about the causes of the slow rate of growth in the United Kingdom (Kaldor, 1966), and can be summarized as follows (McCombie, 1983; Thirlwall, 1983):

$i$. The faster the growth rate of manufacturing output, the faster the growth rate of GDP;

ii. The faster the growth rate of manufacturing output, the faster the growth rate of manufacturing labour productivity (due to increasing returns);

iii. The faster the growth rate of manufacturing output, the faster the growth rate of nonmanufacturing labour productivity (due to reallocation of labour).

The verification of one or all of these laws constitutes a clear indication about the special role played by manufacturing in terms of economic growth. The first law, in particular, has been typically associated in the literature with the engine-ofgrowth hypothesis, according to which the main engine of economic growth would be the manufacturing sector.

The studies in the Kaldor tradition focus on the growth of the manufacturing sector. The second group of studies has focused, instead, on testing the impact that the size of the manufacturing sector (proxied by its share on total GDP or employment) has on the economic performance of the economy. In the following sections we review each group of contributions.

\section{Kaldor laws}

After Kaldor's seminal contribution, some early attempts to econometrically test his first law for the advanced economies can be found in Cornwall $(1977,1976)$ and Cripps and Tarling (1973). In general, these studies were based on the estimation of the following relationship using OLS techniques:

$$
\hat{Q}_{T}=\beta_{0}+\beta_{I} \hat{Q}_{m}
$$

where, $\hat{Q}_{T}$ and $\hat{Q}_{m}$ stands for total output (GDP) growth and manufacturing output growth respectively, and $\beta_{0}$ and $\beta_{I}$ are parameters to be estimated. In these early approaches, a positive and statistically significant coefficient $\beta_{I}$ was interpreted as evidence supporting the engine of growth hypothesis. The general con- 
clusion was that manufacturing was indeed the main engine of growth in advanced economies.

This approach, however, was later criticized because manufacturing output is a component of GDP, and thus $\hat{Q}_{m}$ and $\hat{Q}_{T}$ are positively related by definition. To solve this problem, other authors proposed to replace equation (2.1) for the following equation:

$$
\hat{Q}_{T}=\alpha_{0}+\alpha_{I}\left(\hat{Q}_{m}-\hat{Q}_{n m}\right)
$$

or directly:

$$
\hat{Q}_{n m}=\gamma_{0}+\gamma_{I} \hat{Q}_{m}
$$

where, $\hat{Q}_{n m}$ stands for the growth rate of the non-manufacturing sector (which can be further divided into agriculture and services). Equation (2.2) relates the overall rate of economic growth with the excess of the rate of growth in manufacturing over the rate of growth of non-manufacturing sector. Equation (2.3), on the other hand, directly relates the growth of non-manufacturing sector with the growth of manufacturing. If manufacturing is indeed the engine of growth, then $\alpha_{I}$ and/or $\gamma_{I}$ should be positive and significant.

Using these specifications several authors found empirical support for the engine of growth hypothesis in a wide arrange of contexts: country case studies (Tur$\mathrm{key}^{24}$, Greece ${ }^{25}$, U.S. ${ }^{26}$, South Africa ${ }^{27}$, Pakistan ${ }^{28}$ ), regional studies (Chinese regions $^{29}$, U.S. states ${ }^{30}$ ), and cross country studies (Asian NICS ${ }^{31}$, Africa ${ }^{32}$ and Developing countries $\left.{ }^{33}\right)$.

An alternative approach to solve the spurious relationship identified in equation (2.1) is based on the use of Instrumental Variables (IV) techniques. The IV approach would solve the endogeneity problems associated with equation (2.1), and thus correct possible biases in the estimated parameters. This approach was first proposed in Fagerberg \& Verspagen (1999), and subsequently used in other contri-

\footnotetext{
${ }^{24}$ Bairam (1991), period: 1925-1978.

${ }^{25}$ Drakopoulos and Theodossiou (1991), period: 1967-1988.

${ }^{26}$ Atesoglu (1993), period: 1965-1988.

${ }^{27}$ Millin and Nichola (2005), period: 1946-1998.

${ }^{28}$ Khan and Siddiqi (2011), period: 1964-2008.

${ }^{29}$ Hansen and Zhang (1996), period: 1985-1991.

${ }^{30}$ Bernat (1996), period: 1977-1990.

31 Mamgain (1999), period: 1960-1988, Singapore, South Korea, Indonesia, Thailand and Mauritius.

32 Wells and Thirlwall (2003), period: 1980-1996, 45 African countries.

33 Necmi (1999), period: 1960-1994, 45 Developing countries.
} 
butions, such as Kathuria \& Raj (2009) and Lavopa \& Szirmai (2012). In all cases, the general conclusion was that manufacturing is indeed the major engine of economic growth.

Other estimation techniques have also been used. Felipe (1998), explicitly specifies an underlying production function and estimates the externalities flowing from manufacturing to other sectors. Díaz-bautista (2003) and Tregenna (2007), in turn, based their estimations on Granger causality tests and also explore whether or not manufacturing explains the growth of other sector. In these cases manufacturing is found to either have a larger externality (Felipe, 1998) or cause the growth of the other sectors (Díaz-bautista, 2003). In her analysis of South Africa between 1970 and 2005 Tregenna (2007), however, finds that the direction of causality (according to the Granger test) goes from services to manufacturing and not the other way around.

Summing up, the evidence collected in this section in general seems to support the Kaldorian hypothesis that manufacturing is the main engine of growth. Using different estimation techniques, for different countries and different points of time, a large body of empirical literature has found that the manufacturing sector is the main driver of economic growth.

\section{Manufacturing shares}

A related strand of literature has tested the importance of manufacturing in the development process by focusing in the shares of this sector in total GDP instead of its growth rates.

This empirical strategy is adopted by Fagerberg \& Verspagen (2002) who examined the impact of manufacturing and services GDP shares on economic growth in three different periods (1966-72, 1973-83 and 1984-95), for a sample of 29 countries. They found that manufacturing has a positive and significant impact on economic growth, but mainly before 1973. Their interpretation of these results is that the first period offered special opportunities for catch-up through the absorption of mass production manufacturing techniques from the US. After 1973, however, information and communication technologies (ICTs) started to become more important as a source of productivity gains, and these technologies are no longer within the exclusive domain of manufacturing, but also operate in the service sector.

In a similar vein, Rodrik (2009) analysed the impact of the industrial GDP share on per-capita growth for a large sample of countries between 1960 and 2004, using instrumental variables techniques. He also found that the industrial share in GDP has a positive and significant impact on economic growth.

More recently, Szirmai \& Verspagen (2011) have also examined the relationship between the share of manufacturing in GDP and average growth rates of per capita GDP using panel data techniques for a sample of 90 countries between 1950 and 
2005. For the whole period, they found a moderate positive impact of manufacturing on economic growth in line with the engine of growth hypothesis. However, when the period is split into three subperiods (1950-70, 1970-90, 1990-2005), the direct effects of manufacturing on growth are only found for 1970-1990. This paper also provides interesting insights based on the inclusion of some interaction terms in the regressions. On one hand, it is found that the interaction between educational level and manufacturing shares has positive and significant effects on growth in all subperiods, suggesting that the role of manufacturing critically depends on the absorptive capacities of the country. On the other hand, it is found that the interaction between manufacturing shares and the GDP per capita relative to the USA (a proxy of technological gaps) has a significant negative sign in all three subperiods, implying that manufacturing is especially effective as a growth strategy in the early phases of economic development. Combining the two interaction terms in the regression leads to the conclusion that there is a positive effect of manufacturing on growth in countries with a highly educated workforce. This effect is found at different levels of income, but manufacturing has most effects on growth at low income levels. Such effects are found for different subperiods, but the paper also suggests that the route to growth via manufacturing is becoming more difficult over time. Ever greater amounts of human capital are required to achieve the same positive effects of expanding manufacturing.

\subsubsection{The role of Modern Services}

Two important trends of the last decades have led several authors to challenge the idea that manufacturing is the main engine of economic growth. In the first place, the phenomena of de-industrialization witnessed in advanced and in many developing economies have raised doubts about the capacity of manufacturing to drive economic development in the current context of globalization. In this sense, it has been suggested that the increasing competition in world trade (with rapid growth in exports from China) and the increasing requirements in terms of technological capacity to match the quality standards required by world markets, are making it increasingly difficult for developing countries to achieve rapid growth through industrialization, and especially through export-oriented activities (Sheehan, 2008).

In the second place, the so-called ICT revolution has conferred a renewed importance to certain industries within the service sector as major drivers of economic growth, casting doubts on Baumol's hypothesis that services are stagnant sectors in terms of productivity gains.

Spithoven (2000), for example, challenges the idea that services are less productive than manufacturing. He argues that many services (such as communications, transportation and health care) are as large-scale, as capital-intensive and as thoroughly grounded in technology, as manufacturing. Furthermore, he stresses that 
due to measurement problems, productivity in services might be underestimated while productivity in manufacturing might be overestimated.

Similar arguments are used to explain the fact that certain branches of services (mainly those related to ICTs) have shown rapid productivity growth in the last decades. Wölfl (2003) suggests that one possible reason for this dynamism is related to the presence of increasing returns to scale. In her view, ICT-related services might have increasing returns due to network effects on the production and use of ICT technologies. Eichengreen and Gupta (2011), Maroto and Rubalcaba (2008), and Maroto-Sánchez and Cuadrado-Roura (2009) also find that there are many service activities (such as financial intermediation, computer services, business services, communication, and legal and technical services) that have shown rapid dynamism in their productivity at levels comparable to those sectors traditionally characterised by higher productivity levels.

The positive impact of ICT services on overall productivity has also been highlighted by several empirical studies, both for the USA and the European Union (Bosworth and Triplett, 2007; Inklaar et al., 2005; O’Mahony and van Ark, 2003; Stiroh, 2001; Triplett and Bosworth, 2003; van Ark and Piatkowski, 2004).

In the light of these trends, some authors advocate for a service-led development strategy, in which services -instead of manufacturing- would be the main engine of growth. This strategy is typically grounded on the experience of India, where the explosive growth of ICT related services has been the main driver of rapid economic growth. In this line, Dasgupta and Singh (2005) argue that ${ }^{34}$

"... because of the new technological developments and other factors, services may in the future replace industry as the engine of growth, even in developing countries. In that sense, India may be regarded as pioneering a new development path which gives primacy to services rather than to manufacturing as the leading sector" (Dasgupta and Singh, 2005 p. 1037).

Recent studies aimed at testing the Kaldor's laws seem to support the idea that services are gaining importance in driving economic growth. Using different econometric techniques and different country-samples it has been found that certain segments of the service sector act as well as drivers of economic growth (Acevedo et al., 2009; Chakravarty and Mitra, 2009; Dasgupta and Singh, 2006; Felipe et al., 2009).

In this ongoing debate, there are also some strong counterarguments. In recent comparisons of the comparative performance of India and China it is argued that China by far outperforms India, especially because its growth is driven by manufacturing, while services play a more important role in India (see Ramani and Szirmai, 2014; Naudé et al., 2013).

${ }^{34}$ Similar arguments can be found in Joshi (2011); Mattoo (2009) 
It is also important to bear in mind that technological advances in software and ICT services are not possible without advances in ICT hardware (silicon technologies, data storage, data transport and data infrastructure), and that manufacturing, as we have previously documented, is still responsible for the greater part of $R \& D$ expenditures.

Most of the studies reviewed in this section also recognize the continued important role played by manufacturing industries. The general conclusion seems to be that new engines of growth are emerging but without necessarily replacing the old ones. It seems that the two-way interactions between services and manufacturing are of crucial importance (e.g. Andreoni and Lopez Gomez, 2012).

This conclusion has an important implication for the analysis that will be undertaken in this thesis. When examining the process of structural transformation and the particular evolution of the modern sector, our definition of that aggregate should consider not only the industrial sector (as in the classical approaches to structural change and dual economies) but also the set of services activities here regarded as potential engines of economic growth.

\subsubsection{Second gap: engines of economic growth}

The contrasting conclusions from the contributions reviewed in this section clearly indicate that the debate on the sectoral engines of growth is still open. The second part of this thesis will try to contribute to this debate by examining the particular role of manufacturing and services in the context of the two structural transformations that according to the proposed model are key to development. Moreover, the specific role of manufacturing exports in driving economic growth will be given special attention, as this has been a channel not sufficiently explored by the literature but with a key importance in our theoretical model. Both elements will be addressed in CHAPTER 5.

\subsection{Specialization Patterns and Economic Development}

Once it is acknowledged that certain sectors of the economy might act as engines of growth, the special role of structural change as a major driver of development emerges with clarity. A shift of resources - mainly labour- towards activities with higher levels of productivity and/or technological opportunities would provide an important bust to the overall wealth and dynamism of the economy.

An empirical approach that has been extensively used to address this issue is the so called shift-and-share technique. This technique provides a simple and rather intuitive way to disentangle the relative contributions of the changes that take place within and between the entities that compose an aggregate. It has been typically 
used to analyse the relative contribution of sectoral productivity gains and labour reallocation in the aggregate productivity growth of an economy

Using this approach several authors have investigated the importance of structural change in economic growth or productivity gains (de Vries et al., 2013; Hofman et al., 2014; Kucera and Roncolato, 2012; McMillan et al., 2014; McMillan and Rodrik, 2011; Ocampo et al., 2009b; Pieper, 2000; Timmer et al., 2014; Timmer and de Vries, 2009; van Ark and Timmer, 2003). Due to data constraints, all of them rely on a broad sectoral disaggregation, encompassing -at most- 10 broad sectors. Two general conclusions emerge from their analysis. On one hand, the special role of industry as a major driver of productivity gains is widely acknowledged. On the other hand the relative impact of the structural change component on aggregate productivity growth is typically much smaller than that of intra-sector productivity gains and, in many cases, only brings a marginal effect. Also interesting, however, many of these papers compare the successful experience of developing Asia with the less successful experience of Africa and Latin America, and conclude that the role of structural change is typically more important in the former than in the later. This would suggest that the comparative better performance of the Asian economies would be related (at least partially) to a stronger process of structural transformation.

One limitation of these approaches is that they concentrate mainly on manufacturing as a whole, conceiving structural change in a rather broad sense as meaning the shift from agriculture to manufacturing. Consequently, they have little to say about the possible impact of specialization and structural change within manufacturing on productivity growth (Fagerberg, 2000). As it was long ago emphasized by Salter (1960), and empirically shown by Dosi et al. (1990); Pavitt (1984); Robson et al. (1988); and Scherer (1982), the scope for technological progress and productivity advance differ markedly across industries. It follows that analysing the process of structural change at a higher level of disaggregation can notably improve our understanding of the main transformations that take place as countries develop and the important challenge that they face in avoiding falling in development traps.

There are notable exceptions that have analyzed, from this perspective, the process of structural change within manufacturing industries both in advanced economies (Castaldi, 2009; Peneder, 2003) and developing ones (de Vries et al., 2012; Fagerberg, 2000; Timmer and Szirmai, 2000; Wang and Szirmai, 2008). An interesting insight from this literature relates to the important role played by technological-intensive industries in driving aggregate productivity. Moreover, in this more disaggregated approaches the effects of the structural change component can be much larger than in the previous works.

The approach proposed in de Vries et al. (2012) is particularly interesting in this regard because it explicitly illustrates the importance of a more disaggregated ap- 
proach. In their analysis of the BRICs economies in the last two decades, they show that the contribution of the structural change component to total productivity growth actually depends on the number of sectors studied. In China and Russia, this component increases as they move from the broad 3 sectors to a more detailed disaggregation of 35 industries. In Brazil and India, instead, the opposite happens. This would suggest that the direction of the change is not determined a priory. From a theoretical point of view, however, it seems more accurate to use a higher level of disaggregation. This should reflect the fact that even within broad sectors the process of structural change towards activities with higher productivity is an important source of catch-up.

Regardless of the disaggregation used, an important gap in this literature is that it has been restricted to the analysis of sectoral contributions to productivity gains, without paying attention to the evolution of the technological gaps. That is, none of these contributions have taken into consideration the fact that productivity levels also move at different rates in the world's frontier and, for this reason, different sectors might play different roles in reducing the aggregate productivity gap. According to the theoretical underpinnings of this thesis (as detailed in the previous sections of this chapter) the aggregate productivity as compared to the world leader might actually be more important than the productivity level itself. Hence, an important contribution of this thesis will be to address this issue from a technological gap perspective.

A second point that has not been given enough attention relates to the differences between the sectors. As we have briefly explained in the previous section, according to some scholars, the degree of heterogeneity across sectors might also have important consequences for the development potential of countries. This perspective lies at the core of the Latin American Structuralist approach. According to these authors, in Latin America the classic rural-urban duality has been replaced by a new form of structural heterogeneity in which an export-oriented and highly productive group of sectors coexists with a set of low-productive activities oriented mainly to domestic markets (Pinto, 1971, 1976; Sunkel, 1978). Latin America then appears as a sort of a polarized economy, where groups of sectors with contrasting dynamics of accumulation, production and output growth coexist, and where a leading modern sector typically emerges as an enclave. Case studies for different Latin American countries confirm this stylized picture (Catela et al., 2012; Cimoli, 2005; ECLAC, 2010, 2012; Infante and Sunkel, 2009).

By looking at the so called structural change bonus, the literature previously reviewed has partially addressed this issue. However, the very fact that some countries might show larger degrees of heterogeneity than others has not attracted much interest. In view of this thesis, this very fact also constitutes a key element to characterize the development path followed by different economies. 
This point has been clearly illustrated by McMillan and Rodrik (2011). Examining the experience of 38 countries (29 developing and nine advanced) between 1990 and 2005 they find that inter-sectoral productivity gaps are widest for the poorest countries of the sample and tend to diminish as result of sustained economic growth. Using the coefficient of variation of the log of sectoral labour productivity as a measure of economy-wide productivity gaps, they find that this measure is negatively and highly significantly correlated with the average labour productivity of the country. When they compare the relative productivity of agriculture and nonagriculture sectors, however, they find a U-shaped relationship, suggesting that the inter-sector productivity gap might in fact be low at initial stages of development, increase at intermediate income-levels and drop again when economies reach highincome levels. Their interpretation of this result is that there are two key dynamics in the process of structural transformation: diversification (the emergence of new industries) and structural change (the movement of resources from traditional to newer industries). In their view, without the first dynamic, there is little that propels the economy, while without the second, productivity gains would not diffuse to the rest of the economy.

It follows that the process of structural change might tend to increase or reduce this heterogeneity, and the outcome would ultimately depend on how concentrated or dispersed the gains in sectoral productivity are. The latter becomes again an empirical question that has not been fully explored in these contributions.

An interesting approach to empirically investigate this issue further is proposed by Harberger (1998). This author proposes to examine the distribution of industry contribution to aggregate productivity growth and distinguish different patterns according to how dispersed or concentrated this distribution is. In particular, he distinguishes two main patterns: a mushroom pattern (in which only a few industries account for most of the aggregate productivity growth) and a yeast pattern (in which industries contribute more equally to productivity growth) ${ }^{35}$. This approach has been used to analyse the general patterns of structural change in Asian manufacturing (Timmer and Szirmai, 2000) and, more recently, to analyse the impact of ICT technologies on aggregate productivity growth (Inklaar and Timmer, 2007; van Ark and Smits, 2005). However, it has not been used to characterize the pattern of technological catch up.

\footnotetext{
35 This analogy comes from the fact that "while yeast causes bread to expand very evenly, mushrooms have the habit of popping up, almost overnight, in a fashion that is not easy to predict" (Harberger, 1998, p. 6).
} 


\subsubsection{Third gap: sectoral heterogeneities and aggregate catch-up}

From our previous discussion it follows that there are two important gaps in the literature that has addressed the role of structural change on economic development from a sectoral perspective. The first is that this literature has typically analyzed structural change using a broad definition of sectors. In most cases, the examination of the role of structural change has been done distinguishing no more than ten broad sectors of the economy. However, the productivity bonus typically associated with structural change also occurs within these broad sectors. Specifically, there are large heterogeneities within industry and services that should also be considered when analysing this type of effects.

The second gap refers to the measure that has been typically used in almost all empirical approximations to this issue. The focus has always been placed on the contributions of different sector to aggregate productivity gains, without taking into consideration the fact that these contributions would also depend on the potential gains that each sector might have, given their technological characteristics and the movements of the world frontier. In this sense, an examination of the contribution of each sector to the reduction of the technological gap (proxied by the relative productivity with respect to the world's frontier) would be a natural extension that might add interesting insights on this type of analysis. This is particularly important in the context of this thesis, in which, as we have previously detailed, the evolution of technological gaps are taken as prime elements in explaining the success or failure of countries in their path towards development.

\subsection{Final Remarks}

In this chapter an argument has been developed connecting different strands of literature that address decisive topics for developing economies. Starting from the general discussion of convergence and divergence among countries, and the related concept of development traps, the review has moved to a number of theoretical contributions that have tried to explain the main forces behind these trends. The key role of technological upgrading and structural change has been highlighted and several empirical issues regarding the sectoral composition of developing economies have been summarized.

The review has also revealed some gaps in the literature that deserve further research. In particular, there are at least three related issues that remain unexplored or have attracted little interest. These will be the main focus of this thesis.

The first issue is a theoretical one, and is related to the fact that the formalisation of the technological gap literature has not paid enough attention to the dual character of developing economies. Moreover, insufficient effort has been devoted to introduce some of the distinguishing macroeconomic characteristics of this type 
of economies. One characteristic that stands out is the so called Balance-ofPayments restriction. CHAPTER 3 of this thesis will address this gap and propose a formal model of technological catch-up in which the follower economy has a dual economic structure and a binding restriction on its external accounts. As we will show, this model is able to provide interesting insights about the ultimate reasons why some developing countries are caught in low or middle-income traps while other manage to successfully catch up with the world's leading economies. The validity of this theoretical formulation will be further examined from an empirical perspective in CHAPTER 4, where the salient outcomes of the model will be contrasted with real-world data.

The second issue refers to the specific role of different sectors in driving the structural transformation that according to the model are key to achieving successful catch up. This will be addressed in CHAPTER 5, in which the ongoing debate on sectoral engines of growth will be fully integrated into our analysis and where the specific role of manufacturing and modern services will be compared. Moreover, one channel by which manufacturing would exert a special role will be further examined: the role of manufacturing exports. This mechanism is perhaps one of the least explored in the empirical literature and deserves special attention in this thesis due to the prime place given to the alleviation of balance of payments constraints to fuel economic growth.

The third issue, in turn, refers to the important heterogeneities that can be observed within the modern part of the economy. As we have just stated, these heterogeneities will be addressed in this thesis from an original viewpoint that focuses on the contribution of different sectors to the reduction of the aggregate technological gap. This will be the main goal of CHAPTER 6, where some stylized patterns of structural change and technological catch up will be examined from this perspective. 


\section{CHAPTER 3. \\ Technological Catch Up in a Balance-of-Payments Constrained Dual Economy}




\subsection{Introduction}

In this chapter we present a theoretical model of technological catch up between countries. This theoretical formalization provides the basic ground upon which we will build the empirical analysis undertaken in the remaining chapters of the thesis. As such, it is intended to be simple enough as to capture the main analytical mechanisms at play in the process of catch up while maintaining a clear empirical traceability. The original contribution of the model lies in the characterization of the follower economy as a dual economy that has a binding constraint on its external accounts. Following the literature reviewed in the previous chapter, both conditions seem to depict very closely the reality faced by most developing countries. Their inclusion in a formal model thus constitutes an important contribution and, at the same time, it provides a clearer connection with the empirical analysis that will be done afterwards.

The model combines elements from Post-Keynesian, Neo-Schumpeterian and LatinAmerican Structuralist literature to explore the factors that ultimately determine the possibilities of a developing economy to surpass its dual character and enter a path of successful catch up with the advanced economies. In the model, the developing economy is characterized by two distinguishing features. The first feature is the presence of an extended traditional/informal sector (i.e., a large portion of its labour force is working in extremely low productive activities that use obsolete technologies and mainly produces for its own subsistence). The second feature is the existence of an important degree of technological backwardness in the nontraditional sectors (i.e., a significant technological gap in the modern activities as compared to the advanced economies).

The focus of the model is on the dynamical interaction between both features in the process of economic development. From this perspective, successful development entails a joint improvement in both dimensions up to the point at which modern activities not only become dominant but also manage to catch up with the world frontier. That is, they manage to close the technological gap while absorbing most of the workers from the traditional sector.

The chapter is organized as follows. In the next section we present the building blocks of the model and in Section 3.3 we analyse the dynamic behaviour of the system. In addition, we study the viability conditions and stability properties of the multiple equilibria obtained. Section 3.4 brings the mathematical formalization to a more tangible ground. By means of simple simulation it presents a set of structural trajectories that might shed light on the various obstacles that developing economies need to overcome before entering on a successful development path. Finally, in Section 3.5 we present the main conclusions that can be derived from the analy- 
sis and several lines along which our model could be extended. A mathematical appendix with some technicalities of the model is included at the end of the thesis.

\subsection{The Model}

Following the literature reviewed in the previous chapter, we propose a model in which a developing, technologically-backward economy tries to catch-up with an advanced, technologically-leading economy. The model is written from the perspective of the developing country that is also generically denoted as the South, the follower or the domestic economy. The advanced economy, in turn, is generically denoted as the North, the leader or the foreign economy, and is identified by the superscript $f$.

Besides being technologically backward, the follower has a dual productive structure. A low-productive traditional sector (identified with the subscript $S$ ), that is mainly oriented towards subsistence, coexists with a modern, high-productive, capitalist sector (identified with the subscript $M$ ). The model works with the simplifying assumption that each of these sectors produces a unique, homogeneous good. In reality, of course, these sectors are representing a wide set of heterogeneous activities producing very different goods. The traditional sector would typically encompass two broad sets of activities: subsistence agriculture and urban informal services. The remaining sectors (non-subsistence agriculture, industry and formal services) would all be contained within the modern sector aggregate. Although this heterogeneity within each broad sector is not explicitly modelled, it is implicitly captured by the various parameters that define the behaviour of the economy ${ }^{36}$.

Since the focus of the model is placed on the dynamic behaviour of the southern economy along time, the setting is built in terms of the growth rates of a number of key variables. In particular, two variables stand out: the share of workers in the modern sector (denoted by the Greek letter $\lambda$ ) and the relative stock of technological knowledge in the modern sector as compared to the leading economy (denoted by the Greek letter $\rho$ ). The success or failure of the follower economy will ultimately be determined by the movement in time of these variables. Successful economic development will entail a joint increase in both variables up to the point where the modern sector not only becomes dominant ( $\lambda$ gets closer to one) but also manages to catch up with the technological frontier ( $\rho$ gets closer to one). This, however, would not be the only possible outcome of the model. Intermediate situations in which one or both of these variables remain trapped in a low level equilibrium are also possible.

Before entering into the detailed specification of the model, it is worth stressing some of the prime assumptions regarding the functioning of each sector.

\footnotetext{
36 This point will be developed further in the next sections.
} 


\section{Modern sector}

The modern sector is composed by firms that produce for the domestic and external demand and set prices applying a mark-up rule over unit labour cost. Wages in the sector, in turn, are in part determined by the size of the traditional sector that acts as a "reserve army". For this reason, increases in the share of labour in the modern sector will lead to higher pressures on wage inflation that might eventually erode price-competitiveness at the international level.

The technology used by the modern sector has increasing returns to scale on labour. Productivity gains in this sector also depend on the growth of the technological knowledge applied to production. This knowledge, in turn, is assumed to depend in three major factors (that will be explained in detail later): a) domestic technological efforts; b) international spillovers; and c) induced innovations due to the modernization of the economy.

Finally, the sector is assumed to have a binding restriction on external accounts. That is, the rhythm of production is determined by the availability of foreign exchange. Since it is further assumed that there is no accumulation of financial capital, this implies that exports in this sector should grow at exactly the same rate as imports. Export potential, in turn, is assumed to depend on price and non-price factors. While the first are determined by the dynamics of wages and productivity, the second are directly determined by the level of technological sophistication of the sector, as captured by the technology gap. In particular, it is assumed that the income-elasticity of export demand has an endogenous component that depends negatively on the gap. The greater the distance to the technological frontier, the lower the income elasticity of the products that a country can produce.

\section{Traditional sector}

The traditional sector, in contrast, is assumed to produce for its own demand, using only labour. Therefore, it does not provide any demand-push effect on the modern sector. The level of productivity (and thus, average income) is very low (by definition, lower than in the modern sector), and for this reason the workers of this sector are always willing to move to the modern sector if there are working opportunities there. The technology in use has non-increasing returns to scale. Income per worker will thus tend to increase -or at least, remain constant- when labour is absorbed by the modern sector. Last but not least, it is assumed that there is no interaction between this sector and the foreign economy. That is, there are neither imports nor exports from this sector.

This short summary of the main assumptions provides the ground to specify the detailed setting of the model. We start by describing the functioning of the modern sector, then we describe the functioning of the traditional sector and in the next section we study the dynamic properties of the model. 


\subsubsection{Economic growth in the modern sector}

Following conventional BOPC growth models, our point of departure to characterize the dynamic functioning of this economy is the external restriction. Ruling out the possibility of financial capital movements, net income payments and unilateral transfers, this restriction states that, in the long run, the value of exports should equal the value of imports ${ }^{37}$. Since the traditional sector is not involved in trade, total imports and total exports in the South will be equivalent to the value of exports and imports of the modern sector. Therefore, the restriction (expressed in domestic prices) can be stated as follow:

$$
P_{M} * X_{M}=e * P_{M}^{f} * M_{M}
$$

where, $P$ stands for prices, $X$ and $M$ are the quantities of exports and imports, $e$ is the nominal exchange rate, the subscript $M$ represents the modern sector and the superscript $f$ represents the foreign economy.

Since our interest relies on the dynamic behaviour of the economy, our focus will be placed in the dynamic version of this restriction, according to which the value of exports should growth at the same rate than the value of imports. Logdifferentiation of equation (3.1) yields:

$$
\hat{P}_{M}+\hat{X}_{M}=\hat{e}+\hat{P}_{M}^{f}+\widehat{M}_{M}
$$

where, a hat over the variable represents the rate of growth.

Next, we introduce the specific equations for the growth rates in the volume of exports and imports. Following the literature, we assume that both rates are determined by changes in relative prices (real exchange rate) and income. That is,

$$
\begin{aligned}
& \hat{X}_{M}=\eta\left(\hat{e}+\hat{P}_{M}^{f}-\hat{P}_{M}\right)+\varepsilon \hat{Z} \\
& \widehat{M}_{M}=-v\left(\hat{e}+\hat{P}_{M}^{f}-\hat{P}_{M}\right)+\chi \widehat{Y}_{M}
\end{aligned}
$$

where, $\eta$ and $v$ are the price elasticities of demand for exports and demand for imports respectively; $\varepsilon$ and $\chi$ are the income elasticities of demand for exports and demand for imports; $\hat{Z}$ stands for the growth rate of foreign income, $\hat{Y}_{M}$ represents

\footnotetext{
${ }^{37}$ International capital flows could be easily incorporated into the analysis. Following Thirlwall and Hussain (1982) an extra term capturing the net capital inflows could be included in equation (3.1). Since our focus is on the dynamic version of the restriction, in such a case, our implicit assumption would be that these capital flows remain constant in the long run (i.e., there is no explosive accumulation of external debt or international reserves). A more sophisticated (and realistic) alternative would be to define the external constraint in terms of a stable (and sustainable) level of current account deficit to GDP ratio, as it is done, for example, in Moreno-Brid (1998) or McCombie and Thirlwall (1997).
} 
the growth rate of output in the modern sector ${ }^{38}$ and the term within brackets $\left(\hat{e}+\hat{P}_{M}^{f}-\hat{P}_{M}\right)$ provides the rate of real currency depreciation.

Equations (3.3) and (3.4) are conventional equations for the growth rate of exports and import demand. Exports will depend positively on real currency depreciation and world income while imports will depend negatively on real currency depreciation and positively on the domestic income of the modern sector.

Making use of equations (3.3) and (3.4) in our dynamical external restriction (equation (3.2)) and solving for the growth rate of modern sector output yields:

$$
\hat{Y}_{M}^{b p}=\frac{\overbrace{(\eta+v-1)}^{a}\left(\hat{e}+\hat{P}_{M}^{f}-\hat{P}_{M}\right)+\varepsilon \hat{Z}}{\chi}=\frac{a\left(\hat{e}+\hat{P}_{M}^{f}-\hat{P}_{M}\right)+\varepsilon \hat{Z}}{\chi}
$$

Equation (3.5) represents the conventional BOP constrained growth rate. It basically states that the output growth of the modern sector will depend positively on price competitiveness (as captured by the term: $a\left(\hat{e}+\hat{P}_{M}^{f}-\hat{P}_{M}\right)$ ) and foreign income growth (as captured by the term $\varepsilon \hat{Z}$ ), and negatively to its appetite for imports (as captured by the income-elasticity of imports, $\chi$ ).

If the parameter $a$ is positive, then the Marshall-Lerner condition holds and increases in the rate of real depreciation will put the modern sector on a higher growth path. If, however, $a=0$ or relative PPP is assumed (that is: $\hat{e}+\hat{P}_{M}^{f}-\hat{P}_{M}=$ 0 ), then the first part of the numerator becomes zero and equation (3.5) boils down to the so called Thirlwall's law:

$$
\hat{Y}_{M}^{b p}=\frac{\varepsilon}{\chi} \hat{Z}
$$

In this case, only changes in income elasticities or world income growth would have an impact in modern sector growth. Throughout this chapter, however, we will assume that the Marshall-Lerner condition holds $(a>0)^{39}$ and we will not impose any PPP condition ${ }^{40}$. Therefore output growth in the modern sector will also be affected by changes in price competitiveness.

\footnotetext{
${ }^{38}$ It is important to remember that, by construction, we are assuming that the acquisition of foreign goods (import demand) is only done by domestic agents involved in the modern sector. For this reason, the growth of imports is only related to the output growth of the modern sector.

39 The empirical evidence regarding the validity of this condition is mixed. A detailed recent review can be found in Bahmani et al. (2013). According to their analysis, in 56 of the 91 cases reviewed the condition holds. However, the authors also emphasize that many of these studies would not satisfy further significant tests.

40 The validity of the PPP condition has also been long debated in the literature. In a recent review, Blecker (2013) concludes that PPP seems to hold only in the very long-run (half century or more) and mainly between countries that are structurally similar. The dynamics that we are interested to
} 
An important feature of our model is that both elements (income elasticity and price competitiveness) will ultimately depend on the two key variables defined in the introduction of this chapter: $\rho$ and $\lambda$. In what follows we introduce the dynamic equations for the various components that affect the growth rate stated in equation (3.5) and build a linear system that ultimately depends on these state variables.

To begin with, we endogenize the income elasticity of export demand $(\varepsilon)$. Inspired in Neo-Schumpeterian and Neo-Structuralist literature, we assume that this elasticity depends negatively on the technological gap of the modern sector $\left(G_{M}\right)^{41}$. That is:

$$
\varepsilon=\xi-\psi G_{M}
$$

where, $\xi>0$ represents the income-elasticity of the state-of-art version of the good exported by the modern sector and $\psi>0$ represents the penalty on that income-elasticity brought by the technological backwardness of the South.

The rationale behind equation (3.6) is that a certain good can be produced using a wide array of technologies, ranging from state-of-art technologies $\left(G_{M}=0\right)$ to technologies that are completely obsolete by international standards $\left(G_{M}=1\right)$. These technologies, in turn, will affect the characteristics of the good. In particular, we assume that the quality and nature of goods that an economy can produce changes as it come closer to the frontier. Since the demand elasticity of high quality and sophisticated goods tends to be higher than that of low quality goods, then a negative relationship can be traced between the income elasticity of exports and the technological gap. In a way, the term $\psi G_{M}$ captures the ability of the country to achieve better quality and higher product differentiation in that particular exporting good.

The technological gap $\left(G_{M}\right)$, in turn, is defined as one minus the relative stock of technological knowledge of the South as compared to that of the leading economy $(\rho)$. That is,

$$
\begin{aligned}
& G_{M}=1-\rho \\
& \rho=\frac{T_{M}}{T_{M}^{f}}
\end{aligned}
$$

where $T$ stands for the stock of technological knowledge.

analyze in this chapter are more likely to take place in periods that are shorter than half a century and between very dissimilar countries. Therefore, not assuming PPP seems to be more in line with the available empirical evidence on the issue.

41 This is an standard hypothesis in this type of literature. See for example, Cimoli et al. (2010); Cimoli and Porcile (2013); Dosi et al. (1990); Gouvea and Lima (2010) 
Next, we introduce an equation for the dynamics of prices in the modern sector. Following Post-Keynesian literature, we assume that prices in this sector are set by adding a mark-up over unit labour cost. The growth rate of prices will thus be represented by:

$$
\hat{P}_{M}=\hat{\tau}+\widehat{W}_{M}-\hat{R}_{M}
$$

where $\hat{\tau}$ stands for the rate of change in (one plus) the mark-up over unit labour cost, $\widehat{W}_{M}$ represents the rate of wage inflation in the modern sector and $\hat{R}_{M}$ stands for the rate of growth of productivity in the modern sector ${ }^{42}$.

Following most literature on this topic, we assume that the mark-up is exogenously determined (by institutional factors) and constant in the medium/long run. Therefore the rate of change in the mark-up $(\hat{\tau})$ will be equal to zero. Wage inflation in the modern sector $\left(\widehat{W}_{M}\right)$, instead, will be endogenous to the model. In particular, it is assumed to depend negatively on the relative size of the traditional sector. As long as the traditional sector is large, wage inflation will be small. However, as the modern sector expands and absorb workers from the traditional sector, pressures for wage increases will start to grow, partly eroding the price competitiveness advantage that the South might have at initial levels of development. The following equation captures this dynamical behaviour:

$$
\widehat{W}_{M}=\omega+\theta \lambda
$$

where $\omega$ represents wage inflation exogenous to the model (due to, for example, institutional factors not explicitly modelled) and $\theta$ is a positive parameter that captures the sensitivity of wage inflation to modern's sector share on total employment ${ }^{43}$.

42 Note that the difference between wage inflation and productivity growth is equivalent to the growth rate of unit labour cost.

${ }^{43}$ This particular way of modeling the wage dynamics of the modern sector has the great advantage of being intuitively and extremely simple in its mathematical formulation. However, it might not reflect accurately the dynamics of countries at very initial levels of developments, where the traditional sector is so large that changes in its relative size will have marginal or no impact on the wage level of the modern sector. In fact, the effects of $\lambda$ on $\widehat{W}_{M}$ might be better described in a non-linear fashion. A simple way to incorporate this issue would be to distinguish two phases in the development path of the economy as it is done, for example in Fei and Ranis (1997). In a first phase, $\theta$ would be equal to zero and wages in the modern sector would only depend on the exogenous parameter $\omega$. After certain turning point in the level of $\lambda$ the economy would enter in a second phase in which $\theta$ would become positive. Under this setting, the functioning of the economy would be different depending on whether it has already surpassed the turning point or not. Intuitively the main difference with our current formulation would be that in the first phase the economy will -ceteris paribus- grow faster because it will be better suited to exploit its price-competiveness. 
Plugging equations (3.6) to (3.10) in (3.5) we get a new expression for the BOPC growth rate of output that depends on our state variables $(\rho$ and $\lambda)$, the productivity growth of the modern sector and a set of exogenous variables:

$$
\begin{aligned}
\hat{Y}_{M}^{b p} & =\frac{a \overbrace{\left(\hat{e}+\hat{P}_{M}^{f}-\omega\right)}^{b}-a \theta \lambda+[\overbrace{(\xi-\psi)}^{f}+\psi \rho] \hat{Z}+a \hat{R}_{M}}{\chi} \\
& =\frac{(a b+f \hat{Z})+(\psi \hat{Z}) \rho-(a \theta) \lambda+a \hat{R}_{M}}{\chi}
\end{aligned}
$$

where $f=(\xi-\psi)$ stands for the income elasticity of the less technological sophisticated version of the good exported by the modern sector (good produced with $\rho=0)$ and $b=\left(\hat{e}+\hat{P}_{M}^{f}-\omega\right)$ encompasses the set of pressures for real exchange depreciation that are exogenous to the model ${ }^{44}$.

Looking at the numerator of Equation (3.11) we can already notice that the BOPC growth rate of the modern sector depends positively on the relative stock of technology, the growth rate of labour productivity and the set of exogenous variables affecting price-competitiveness and export demand. The share of the modern sector in total employment, instead, has a negative impact and therefore brings a counterbalancing effect that reduces the growth rate of output as the economy develops.

Using equation (3.11) and bearing in mind that, by definition, the growth rate of employment should be identical to the growth rate of output minus the growth rate of labour productivity $\left(\widehat{N}_{M} \equiv \widehat{Y}_{M}-\widehat{R}_{M}\right)$, we can derive an expression for the rate of growth of employment in the modern sector that is compatible with the external restriction:

$$
\widehat{N}_{M}^{b p}=\frac{(a b+f \hat{Z})+(\psi \hat{Z}) \rho-(a \theta) \lambda-(\chi-a) \hat{R}_{M}}{\chi}
$$

In order to fully characterize the modern sector, we still need to define the factors that determine productivity growth. Following Castellacci (2002) and LeónLedesma (2002) we assume that productivity gains in this sector are ruled by three main elements: embodied technological progress (proxied by the InvestmentOutput ratio, $k)^{45}$, increasing dynamic returns on labour (the so called Kaldor-

\footnotetext{
${ }^{44}$ Since the term $b$ includes the rate of nominal depreciation of the domestic currency $(\hat{e})$, it has a very important role from a policy perspective. The management of the nominal exchange rate by the monetary authority will have an impact on the whole dynamic of the system through this term. Comparative-static exercises at the final section of the chapter will illustrate further this point.

45 This ratio, in turn, is used as a proxy for the growth rate of capital stock (assuming that the output to capital stock ratio and the rate of depreciation are constant in the long run). Embodied techno-
} 
Verdoorn effect) and improvements in the domestic technological knowledge $\left(\widehat{T}_{M}\right)$. That is:

$$
\widehat{R}_{M}=\mu k+\gamma_{M} \widehat{N}_{M}+\alpha \widehat{T}_{M}
$$

where $\mu, \gamma_{M}$ and $\alpha$ are positive parameters that capture the sensitivity of productivity gains to capital intensification, labour growth ${ }^{46}$ and domestic technological knowledge growth respectively.

Following the catch-up literature, the growth rate of the stock of technological knowledge is assumed to depend on R\&D domestic innovation efforts and on international spillovers stemming from the diffusion of technological knowledge generated by the leader. While the former is taken as exogenous to the model (represented by the parameter $\zeta$ ), the latter is assumed to depend positively on the size of the technological gap (as captured by the term $\left.\sigma G_{M}\right)^{47}$. In addition to these elements, our model also incorporates a Hicksean induced-innovation channel in line with recent Post-Keynesian models on economic growth (See for example, Naastepad, 2005; Palley, 2012, 2013). According to this literature, the rate of growth in the technological knowledge also depends on the availability of resources in the economy, and hence, a positive relationship can be established between the rate of employment and the rate of technological progress. In our model, this channel is represented by a positive relationship between the share of labour in the modern sector and the growth rate of technological knowledge (as captured by the term $\beta \lambda$ ): the absorption of labour in the modern sector reduces the size of the reserve army

logical progress might be better captured using more specific variables (accounting, for example, for the quality of the capital stock). Here, however, we preferred to keep the original formulation of the referred models.

46 The parameter $\gamma_{M}$ is equivalent to the traditional $K$ - $V$ coefficient on output growth but in terms of employment growth. Equation (3.13) could also be expressed with increasing dynamic returns on output. In that case, we would have: $\hat{R}_{M}=\phi_{k} k+\phi_{L} \hat{Y}_{M}+\phi_{T} \widehat{T}_{M}$, which would look very similar to the equations used in Castellacci (2002) and León-Ledesma (2002). Both equations are in fact equivalent, and the relationship between their parameters can be described as follows: $\phi_{k}=\mu /\left(1+\gamma_{M}\right) ; \phi_{L}=$ $\gamma_{M} /\left(1+\gamma_{M}\right) ; \phi_{T}=\alpha /\left(1+\gamma_{M}\right)$. Since our focus in the following sections will be placed on employment absorption, we prefer to express this equation in terms of employment growth rather than output growth. A discussion on the various forms of modelling the $K-V$ effect can be found in Pieper (2003).

${ }^{47}$ Given this formulation, the larger is the gap, the larger is the growth rate of technological knowledge due to international spillovers. It is important to highlight that this relationship is assumed to be linear. Previous literature on this issue has also incorporated non-linear specifications for the spillovers in order to capture the fact that for extremely large technological gaps the imitation of technologies might no longer be possible (see Castellacci, 2002); Verspagen, 1991, (1993). 
and therefore induces firms to increase their rates of innovation. The following equation summarizes these channels ${ }^{48}$ :

$$
\widehat{T}_{M}=\zeta+\beta \lambda+\sigma G_{M}
$$

Combining equations (3.13) and (3.14) and replacing $G_{M}$ for its definition, we get a new expression for the growth rate of productivity in the modern sector:

$$
\widehat{R}_{M}=\mu k+\gamma_{M} \widehat{N}_{M}+\alpha[\overbrace{(\zeta+\sigma)}^{d}-\sigma \rho+\beta \lambda]=\mu k+\gamma_{M} \widehat{N}_{M}+\alpha(d-\sigma \rho+\beta \lambda)
$$

where $d=(\zeta+\sigma)$ is a positive parameter representing the autonomous technological knowledge accumulation in the South.

The introduction of a Kaldor-Verdoorn coefficient in equation (3.13) give rise to the so called "cumulative causation" mechanism according to which an increase in the equilibrium growth rate of employment in equation (3.12) will lead to an increase in productivity growth that will reinforce the original increase in employment (through the last term of equation (3.12)) restarting the cycle. This cumulative cycle has been approached in the literature as an interactive process between two regimes: the demand regime (DR) and the productivity regime (PR). Taken together, these regimes constitute a system of two linear equations that in our case would be represented as follows:

$$
\begin{aligned}
& \widehat{N}_{M}^{D R}=\frac{(a b+f \hat{Z})+(\psi \hat{Z}) \rho-(a \theta) \lambda}{\chi}-\frac{(\chi-a)}{\chi} \widehat{R}_{M} \\
& \widehat{N}_{M}^{P R}=-\frac{(\mu k+\alpha d)-\alpha \sigma \rho+\alpha \beta \lambda}{\gamma_{M}}+\frac{1}{\gamma_{M}} \widehat{R}_{M}
\end{aligned}
$$

To be stable, this system requires the (absolute) value of the slope of PR to be larger than the (absolute) value of the slope of $\mathrm{DR}^{49}$. That is:

\footnotetext{
48 This equation is also based on the corresponding equations used by Castellacci (2002) and LeónLedesma (2002). The main difference is that our equation explicitly considers the dual character of this economy by introducing the term $\beta \lambda$. However, to keep things simple, it does not consider the effects of output growth and cumulative output on technological knowledge growth (as is the case in León-Ledesma, 2002) and the international spillovers are introduced in a linear fashion (instead of the non-linear specification used in Castellacci, 2002).

49 To see this, we can introduce a lag structure in the equation DR, solve the system and analyze the stability of the equilibrium as if it was a single difference equation. In that case, the eigenvalue of the corresponding equilibrium would be: $\left[-(\chi-a) \gamma_{M} / \chi\right]$. It follows that the solution will be stable if and only if the absolute value of this expression is smaller than one. That is, if: $\left|-(\chi-a) \gamma_{M} / \chi\right|<1$, that is equivalent to the condition stated in the text.
} 


$$
\left|\frac{1}{\gamma_{M}}\right|>\left|-\frac{(\chi-a)}{\chi}\right| \Rightarrow \chi>\left|(\chi-a) \gamma_{M}\right|
$$

If Condition 1 holds, this setting for the dynamical behaviour of the modern sector will deliver stable equilibrium values for its output, employment and productivity growth that will ultimately depend on the state variables of our model ( $\rho$ and $\lambda)$.

It is interesting to notice that the condition will always hold if $\gamma_{M}$ is less than one and $\chi$ is larger than $a$. That is, if the increasing returns of labour are lower than one and the Marshall-Lerner condition is positive but lower than the incomeelasticity of imports. Both assumptions seem to be in line with the literature, and therefore, in what follows we will assume that they hold ${ }^{50}$. This will already ensure that, if the dynamic behaviour of the state variables is stable, the final solution of the system will also be stable.

Solving the linear system formed by the DR and PR, and replacing the results in equation (3.11), we get the equilibrium values for output, productivity and employment growth in the modern sector:

$$
\begin{gathered}
\hat{Y}_{M}^{*}=\frac{\left(1+\gamma_{M}\right)(a b+f \hat{Z})+a(\mu k+\alpha d)}{g}+\frac{\left(1+\gamma_{M}\right) \psi \hat{Z}-a \alpha \sigma}{g} \rho \\
+\frac{a \alpha \beta-a \theta\left(1+\gamma_{M}\right)}{g} \lambda \\
\hat{R}_{M}^{*}=\frac{\gamma_{M}(a b+f \hat{Z})+\chi(\mu k+\alpha d)}{g}+\frac{\gamma_{M} \psi \hat{Z}-\chi \alpha \sigma}{g} \rho+\frac{\chi \alpha \beta-a \theta \gamma_{M}}{g} \lambda \\
\widehat{N}_{M}^{*}=\frac{(a b+f \hat{Z})-(\chi-a)(\mu k+\alpha d)}{g}+\frac{\psi \hat{Z}+(\chi-a) \alpha \sigma}{g} \rho-\frac{(\chi-a) \alpha \beta+a \theta}{g} \lambda
\end{gathered}
$$

where $g=\chi+(\chi-a) \gamma_{M}$

Since $g$ is equivalent to the numerator of the slope differential between the DR and PR, it will always be positive. Moreover, since we have assumed that $\chi>a$ (in order to ensure that condition 1 holds), we can already notice that our state variables will have counterbalancing effects in the capacity of the modern sector to absorb labour: while increases in $\rho$ will always lead to higher labour demand, increases in $\lambda$ will always contract the growth rate of labour in the modern sector. This is so

\footnotetext{
${ }^{50}$ Regarding the first assumption, most studies find a K-V coefficient (in output terms) of about 0.3 to 0.5 , that would correspond to a coefficient in terms of employment growth lower than 1 . As for the second condition, Wu (2008), for example, provides estimates for $a$ and $\chi$ in a sample of 35 countries, and his results show that in 17 of the 23 countries where the Marshall-Lerner condition holds, $\chi$ is larger than $a$.
} 
because the assumption that $\chi$ is larger than $a$ implies that the negative impact of productivity gains on labour absorption cannot be compensated by the positive impact of the increasing demand due to improved price-competitiveness ${ }^{51}$.

\subsubsection{Economic growth in the traditional sector}

As mentioned before, a distinguishing feature of the southern economy in our model is the presence of a large traditional sector employing an important portion of the labour force. In fact, we work under the simplifying assumption that the labour force not employed in the modern sector finds some way of survival in the traditional sector. Therefore, our model resembles a full-employment model, but with the important remark that a major share of the labour population is underemployed in low-productive activities ${ }^{52}$.

The dynamical behaviour of this sector is modelled in an extremely simplified fashion (in line with, for example, Ocampo et al., 2009a). We assume nonincreasing returns to scale, with labour as the only input. In addition, we assume an exogenous growth rate in total labour force, and thus, labour growth in this sector is obtained as a residual. Under this setting, the whole dynamics of this sector is driven by the dynamics of labour growth in the modern sector (as stated in equation (3.18)).

The following equation represents the growth rate of productivity in the traditional sector:

$$
\widehat{R}_{S}=\iota+\gamma_{S} \widehat{N}_{S}
$$

where the subscript $S$ identifies the traditional sector, $\iota$ is a positive parameter reflecting autonomous productivity gains in this sector and $\gamma_{S}$ is the equivalent of $\gamma_{M}$ for the traditional sector (that is, the sensitivity of productivity to changes in labour growth). In our setting, we assume that $\gamma_{S}$ is non-positive, reflecting the fact that this sector -as opposed to the modern sector- does not benefit from increasing returns to labour.

By definition, the growth rate of total labour force can be derived as a weighted average of the sectoral growth rates of employment, with weights given by the re-

\footnotetext{
51 To see this we should bear in mind that while productivity gains (by definition) have a one-to-one negative impact on labour growth, the positive impact on output (and thus labour) growth is partially restrained by the relative increase of imports associated with output (and thus income) growth. The positive impact of productivity gains on output growth is, according to equation (3.11), equal to $(a / \chi)$. If $\chi>a$, then this effect will always be lower than one, and therefore the net effect on employment absorption will be negative.

${ }^{52}$ From this perspective, unemployment could also be seen as an extreme case of under-employment with productivity equal to zero. Using this broad definition, unemployed population would also be included within the traditional sector.
} 
spective shares on total employment. Bearing this fact in mind and assuming that total labour force grows at an exogenous rate $n$, then the growth rate of labour in the traditional sector can be obtained as a residual:

$$
\widehat{N}_{S}=\frac{1}{(1-\lambda)}\left(n-\lambda \widehat{N}_{M}\right)
$$

Finally, since by definition output growth should be identical to the sum of productivity and employment growth, combining equations (3.19) and (3.20) we can obtain an expression for the growth rate of output in the traditional sector. This equation depends on the growth rate of employment in the modern sector, and thus, on the state variables of our model:

$$
\widehat{Y}_{S}=\iota+\frac{\left(1+\gamma_{S}\right)}{(1-\lambda)}\left(n-\lambda \widehat{N}_{M}\right)
$$

As we can see, increases in the labour absorption of the modern sector (as captured by $\widehat{N}_{M}$ ) might have a positive or negative impact on the output growth of the traditional sector depending on the magnitude of the decreasing returns on labour $\left(\gamma_{S}\right)$. If $\left|\gamma_{S}\right|$ is lower than one, then the term $\left(1+\gamma_{S}\right)$ will be positive and an acceleration of labour absorption in the modern sector will always have a negative impact on traditional output growth. If, however, these returns are larger than the unity (in absolute terms) then $\left(1+\gamma_{S}\right)$ will be negative and the impact will be positive: the increase of productivity due to the migration of workers to the modern sector more than compensate the reduction of labour force. The last possibility seems quite implausible, and therefore in what follows we will work under the assumption that $\left|\gamma_{S}\right|<1^{53}$.

Regardless of the assumptions imposed to this parameter, what really matters is that the dynamics of the traditional sector will ultimately depend on the growth rate of labour in the modern sector, and therefore, on the state variables of our system. Hence, to understand the dynamics of the southern economy we need to analyze the dynamical behaviour of $\rho$ and $\lambda$.

\subsection{Dynamical Behaviour}

According to the setting proposed in the previous section, the dynamic behaviour of the South will ultimately depend on the level of the relative stock of technological knowledge $(\rho)$ and the share of the modern sector in total employment $(\lambda)$. Hence,

\footnotetext{
${ }^{53} \mathrm{It}$ is worth noting, however, that the assumptions imposed to this parameter will not have any relevant impact on the dynamic behaviour of the whole system.
} 
to examine this behaviour, we need to analyze the movement in time of these state variables. Recalling their definition,

$$
\begin{gathered}
\rho=\frac{T_{M}}{T_{M}^{f}} \\
\lambda=\frac{N_{M}}{L}
\end{gathered}
$$

it follows that the growth rate of these variables will be given by:

$$
\begin{aligned}
& \hat{\rho}=\widehat{T}_{M}-\widehat{T}_{M}^{f} \\
& \hat{\lambda}=\widehat{N}_{M}-\widehat{L}
\end{aligned}
$$

To close the system we need to specify a dynamic equation for the growth of technological knowledge in the leading economy $\left(\widehat{T}_{M}^{f}\right)$. For this purpose we make use of the same specification than in the South, but with two important remarks: since, by definition, the technological gap of the leader equals zero, the "catchingup" term disappears. In addition, since in the leading economy the modern sector is already dominant (in an extreme case, we could assume that $\lambda^{f}$ equals one), the leader will typically get a larger bonus for the induced innovation channel than the South (unless, of course, the South manages to completely catch-up with the North). Technological accumulation in the North will thus be given by the following expression:

$$
\widehat{T}_{M}^{f}=\zeta^{f}+\beta^{f} \lambda^{f}
$$

where $\zeta^{f}$ and $\beta^{f}$ are positive parameters capturing the domestic innovation efforts in the leading economy and the sensitivity of technological growth to modern sector labour share.

Plugging equations (3.14), (3.18) and (3.25) into equations (3.23) and (3.24), and rearranging terms we get a dynamic system that describes the movements in time of our state variables:

$$
\begin{aligned}
& \left\{\begin{array}{l}
\dot{\rho}=\rho\left(d-\widehat{T}_{M}^{f}-\sigma \rho+\beta \lambda\right) \\
\dot{\lambda}=\lambda\left[\frac{(a b+f \hat{Z})-(\chi-a)(\mu k+\alpha d)-n g}{g}+\frac{\psi \hat{Z}+(\chi-a) \alpha \sigma}{g} \rho-\frac{(\chi-a) \alpha \beta+a \theta}{g} \lambda\right]
\end{array}\right. \\
& \text { or, using the capital letters } A \text { to } F \text { to simplify the notation: } \\
& \left\{\begin{array}{l}
\dot{\rho}=\rho(A+B \rho+C \lambda) \\
\dot{\lambda}=\lambda(D+E \rho+F \lambda)
\end{array}\right.
\end{aligned}
$$


In the context of our model, each of these terms has an important economic meaning (see Table 3.1).

Table 3.1. Definition and interpretation of each term in the dynamic system

\begin{tabular}{|c|c|c|}
\hline Term & Definition & Economic interpretation \\
\hline$A$ & $\left(d-\widehat{T}_{M}^{f}\right)$ & $\begin{array}{l}\text { Growth of the relative technological knowledge due to exogenous components (do- } \\
\text { mestic investment in } R \& D \text { minus technological growth in the frontier), assuming } \\
\text { that the South is benefiting from all the potential spillover from the North. }\end{array}$ \\
\hline$B$ & $(-\sigma)$ & $\begin{array}{l}\text { Deceleration in the growth rate of relative technological knowledge due to diminish- } \\
\text { ing advantages of backwardness (decreasing technological gap). }\end{array}$ \\
\hline $\mathrm{C}$ & $(\beta)$ & $\begin{array}{l}\text { Acceleration in the growth rate of relative technological knowledge due to the ex- } \\
\text { pansion of the modern sector (increasing labour share). }\end{array}$ \\
\hline$D$ & \multicolumn{2}{|c|}{$\begin{array}{l}\text { Growth of the modern sector share in total labour force due to exogenous components. These can be } \\
\text { further divided into four terms: }\end{array}$} \\
\hline \multirow{6}{*}{$(\chi$} & $\frac{a b}{g}$ & $\begin{array}{l}\text { Labour absorption due to exogenous real exchange depreciation (brought by } \\
\text { changes in nominal exchange rate depreciation, foreign inflation and/ or domestic } \\
\text { "institutional" inflation). }\end{array}$ \\
\hline & $f \hat{Z}$ & \multirow{4}{*}{$\begin{array}{l}\text { Labour absorption due to increases in world income, assuming the minimum } \\
\text { potential export elasticity (maximum gap-penalty on income elasticity of exports) } \\
\text { Labour release due to productivity gains resulting from capital intensification and } \\
\text { autonomous technological knowledge accumulation (assuming all potential spill- } \\
\text { overs). }\end{array}$} \\
\hline & $g$ & \\
\hline & $a)(\mu k+\alpha d)$ & \\
\hline & $g$ & \\
\hline & $(-n)$ & Deceleration of sector's share growth due to total labour force expansion. \\
\hline
\end{tabular}

E Acceleration in modern sector's absorption of labour due to increasing technological sophistication (decreasing technological gap). This can be further divided into two terms:

$(\chi-a) \alpha \sigma \quad$ Labour absorption due to productivity growth deceleration brought by diminishing $g$ advantages of backwardness.

$\psi \hat{Z} \quad$ Labour absorption due to income elasticity improvements brought by increasing $\frac{\bar{Z}}{g} \quad$ technological sophistication of exports.

F Deceleration of labour absorption due to the expansion of the modern sector (increasing labour share). This can be further divided into:

$-\frac{a \theta}{g} \quad$ Labour release due to real appreciation brought by wage-inflationary pressures.

$-\frac{(\chi-a) \alpha \beta}{g} \quad \begin{aligned} & \text { Labour release due to productivity growth acceleration brought by the expansion of } \\ & \text { the modern sector (increasing induced-innovations). }\end{aligned}$ 


\subsubsection{Equilibrium points}

If we keep the previous assumptions that the Marshall-Lerner condition holds $(a>0)$ but weakly (so that $a<\chi)$, and we further assume that the KaldorVerdoorn effect is less than one $\left(\gamma_{M}<1\right)$, then we can already determine the signs of all terms except $A$ and $D$ :

$$
\mathrm{A} \gtrless 0 ; \mathrm{B}<0 ; \mathrm{C}>0 ; \mathrm{D} \gtrless 0 ; \mathrm{E}>0 ; \mathrm{F}<0
$$

Bearing this information in mind, we turn now to solve the system, find the potential equilibria and analyze their dynamic properties under different parameter conditions.

To find the equilibrium points (steady states) of the system, we set $\dot{\rho}=0$ and $\dot{\lambda}=0$ and solve for $\rho$ and $\lambda$. The resulting equilibrium points are detailed in Table 3.2 .

Table 3.2. Equilibrium points

\begin{tabular}{ccc}
\hline Equilibrium & $\rho^{*}$ & $\lambda^{*}$ \\
\hline $\boldsymbol{E}_{\mathbf{1}}$ & $\rho_{1}^{*}=0$ & $\lambda_{1}^{*}=0$ \\
$\boldsymbol{E}_{\mathbf{2}}$ & $\rho_{2}^{*}=-\frac{A}{B}$ & $\lambda_{2}^{*}=0$ \\
$\boldsymbol{E}_{\mathbf{3}}$ & $\rho_{3}^{*}=0$ & $\lambda_{3}^{*}=-\frac{D}{F}$ \\
$\boldsymbol{E}_{\mathbf{4}}$ & $\rho_{4}^{*}=\frac{C D-A F}{B F-C E}$ & $\lambda_{4}^{*}=\frac{A E-B D}{B F-C E}$ \\
\hline
\end{tabular}

The last equilibrium is the most interesting. Graphically, this equilibrium is reached in the intersection of the isoclines for which $\dot{\rho}=0$ and $\dot{\lambda}=0$. That is, the intersection of:

$$
\begin{aligned}
& \lambda=-\frac{A}{C}-\frac{B}{C} \rho \\
& \lambda=-\frac{D}{F}-\frac{E}{F} \rho
\end{aligned}
$$

$(\rho$-insocline $)$

$(\lambda$-insocline $)$

The remaining equilibria would typically be characterized as being nonmeaningful in economic terms and therefore, ignored. In the context of our model, however, these equilibria are also interesting because they can be associated with different traps that need to be overcome in the process of development. The first 
equilibrium, for example, would represent a low-income trap, in which an exporting modern sector has not yet emerged and the stock of domestic technological knowledge is negligible as compared with the advanced world. The other two equilibria would represent intermediate stages in which either there is some accumulation of technological knowledge that has not yet given rise to a modern exporting sector $\left(E_{2}\right)$ or there is a modern exporting sector that uses technologies that are extremely far from the leading economy $\left(E_{3}\right)$. In graphical terms, $E_{1}$ is the origin while $E_{2}$ is the $\mathrm{x}$-intercept of the $\rho$-insocline and $E_{3}$ is the y-intercept of the $\lambda$-insocline (See Figure 3.1).

Figure 3.1. Graphical representation of the equilibria

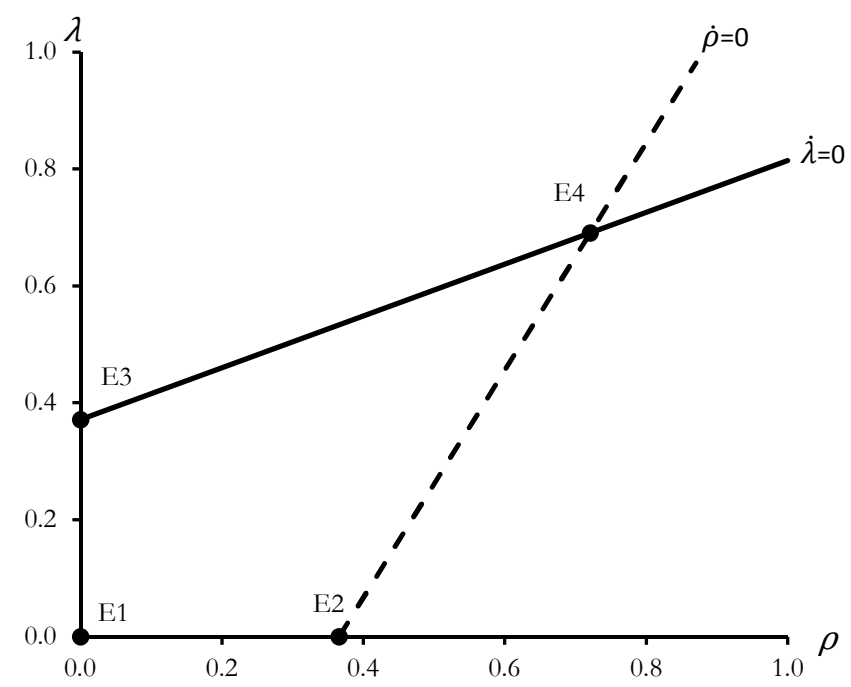

In what follows, our analysis will focus on the Equilibrium 4, but looking at the dynamic properties of all the equilibria taken together.

Before entering in the dynamic analysis, we need to establish a set of conditions that ensures the economic viability of Equilibrium 4. By definition, $\rho$ and $\lambda$ should be positive and less or equal than one. Therefore, we need to impose four "viability conditions": 
Table 3.3. Viability conditions

\begin{tabular}{cc}
\hline Condition & \\
\hline$V C 1$ & $\rho_{4}^{*}>0$ \\
$V C 2$ & $\lambda_{4}^{*}>0$ \\
$V C 3$ & $\rho_{4}^{*} \leq 1$ \\
$V C 4$ & $\lambda_{4}^{*} \leq 1$ \\
\hline
\end{tabular}

The first two viability conditions will be met if and only if the numerator and denominator of $\rho_{4}^{*}$ and $\lambda_{4}^{*}$ have the same sign. VC3 and VC4, instead, require that the absolute value of the denominator is larger than the absolute value of the numerator.

In APPENDIX $A$, at the end of this thesis, we demonstrate that, given the signs of the terms that are already known, these conditions can be met under six different set of restrictions. Each set is defined by a different combination in the sings of the terms $A$ and $D$ and the sign of the slope differential between the isoclines. The following table summarizes these sets and the particular conditions needed:

Table 3.4. Viability conditions under different restrictions on the signs of $A, D$ and the slope differential

\begin{tabular}{|c|c|c|c|c|c|c|c|c|c|}
\hline \multicolumn{6}{|c|}{ Sub-Cases } & \multicolumn{4}{|c|}{ Viability Conditions } \\
\hline & \multirow{2}{*}{$A$} & \multirow{2}{*}{$D$} & \multicolumn{3}{|c|}{ (Slopes) } & \multirow[b]{2}{*}{$V C 1$} & \multirow[b]{2}{*}{$V C 2$} & \multirow[b]{2}{*}{$V C 3$} & \multirow[b]{2}{*}{$V C 4$} \\
\hline & & & $\dot{\rho}=0$ & & $\dot{\lambda}=0$ & & & & \\
\hline $\begin{array}{c}\text { Case } \\
1.1\end{array}$ & + & + & $-\frac{B}{C}$ & $>$ & $-\frac{E}{F}$ & n.a. & n.a. & $(\mathrm{BF}-\mathrm{CE}) \geq(\mathrm{CD}-\mathrm{AF})$ & $(\mathrm{BF}-\mathrm{CE}) \geq(\mathrm{AE}-\mathrm{BD})$ \\
\hline $\begin{array}{c}\text { Case } \\
1.2\end{array}$ & + & - & $-\frac{B}{C}$ & $>$ & $-\frac{E}{F}$ & $(\mathrm{CD}-\mathrm{AF})>0$ & $(\mathrm{AE}-\mathrm{BD})>0$ & $(\mathrm{BF}-\mathrm{CE}) \geq(\mathrm{CD}-\mathrm{AF})$ & $(\mathrm{BF}-\mathrm{CE}) \geq(\mathrm{AE}-\mathrm{BD})$ \\
\hline $\begin{array}{c}\text { Case } \\
1.3\end{array}$ & - & + & $-\frac{B}{C}$ & $>$ & $-\frac{E}{F}$ & $(\mathrm{CD}-\mathrm{AF})>0$ & $(\mathrm{AE}-\mathrm{BD})>0$ & $(\mathrm{BF}-\mathrm{CE}) \geq(\mathrm{CD}-\mathrm{AF})$ & $(\mathrm{BF}-\mathrm{CE}) \geq(\mathrm{AE}-\mathrm{BD})$ \\
\hline $\begin{array}{c}\text { Case } \\
2.1\end{array}$ & - & - & $-\frac{B}{C}$ & $<$ & $-\frac{E}{F}$ & n.a. & n.a. & $(\mathrm{BF}-\mathrm{CE}) \geq(\mathrm{CD}-\mathrm{AF})$ & $(\mathrm{BF}-\mathrm{CE}) \geq(\mathrm{AE}-\mathrm{BD})$ \\
\hline $\begin{array}{c}\text { Case } \\
2.2\end{array}$ & + & - & $-\frac{B}{C}$ & $<$ & $-\frac{E}{F}$ & $(\mathrm{CD}-\mathrm{AF})>0$ & $(\mathrm{AE}-\mathrm{BD})>0$ & $(\mathrm{BF}-\mathrm{CE}) \geq(\mathrm{CD}-\mathrm{AF})$ & $(\mathrm{BF}-\mathrm{CE}) \geq(\mathrm{AE}-\mathrm{BD})$ \\
\hline $\begin{array}{c}\text { Case } \\
2.3\end{array}$ & - & + & $-\frac{B}{C}$ & $<$ & $-\frac{E}{F}$ & $(\mathrm{CD}-\mathrm{AF})>0$ & $(\mathrm{AE}-\mathrm{BD})>0$ & $(\mathrm{BF}-\mathrm{CE}) \geq(\mathrm{CD}-\mathrm{AF})$ & $(\mathrm{BF}-\mathrm{CE}) \geq(\mathrm{AE}-\mathrm{BD})$ \\
\hline
\end{tabular}


In the table we distinguish two broad groups of conditions. In the first group (Case 1 ), the slope of the $\rho$-insocline is larger than the slope of the $\lambda$-insocline (as in the example presented in Figure 3.1). Within this group three further sub-cases are detailed according to different combinations in the sign of the terms $A$ and $D$ for which the viability conditions can be met $^{54}$. In the second group, instead, the slope of the $\lambda$-insocline is larger. The sub-cases again distinguish different combinations for the signs of $A$ and $D$. The following figure illustrates each of these cases:

${ }^{54}$ Notice that in this case a scenario in which the terms $A$ and $D$ are simultaneously negative could never satisfy the viability conditions and thus it is not included in the table. 
Figure 3.2. Graphical representation of the different cases
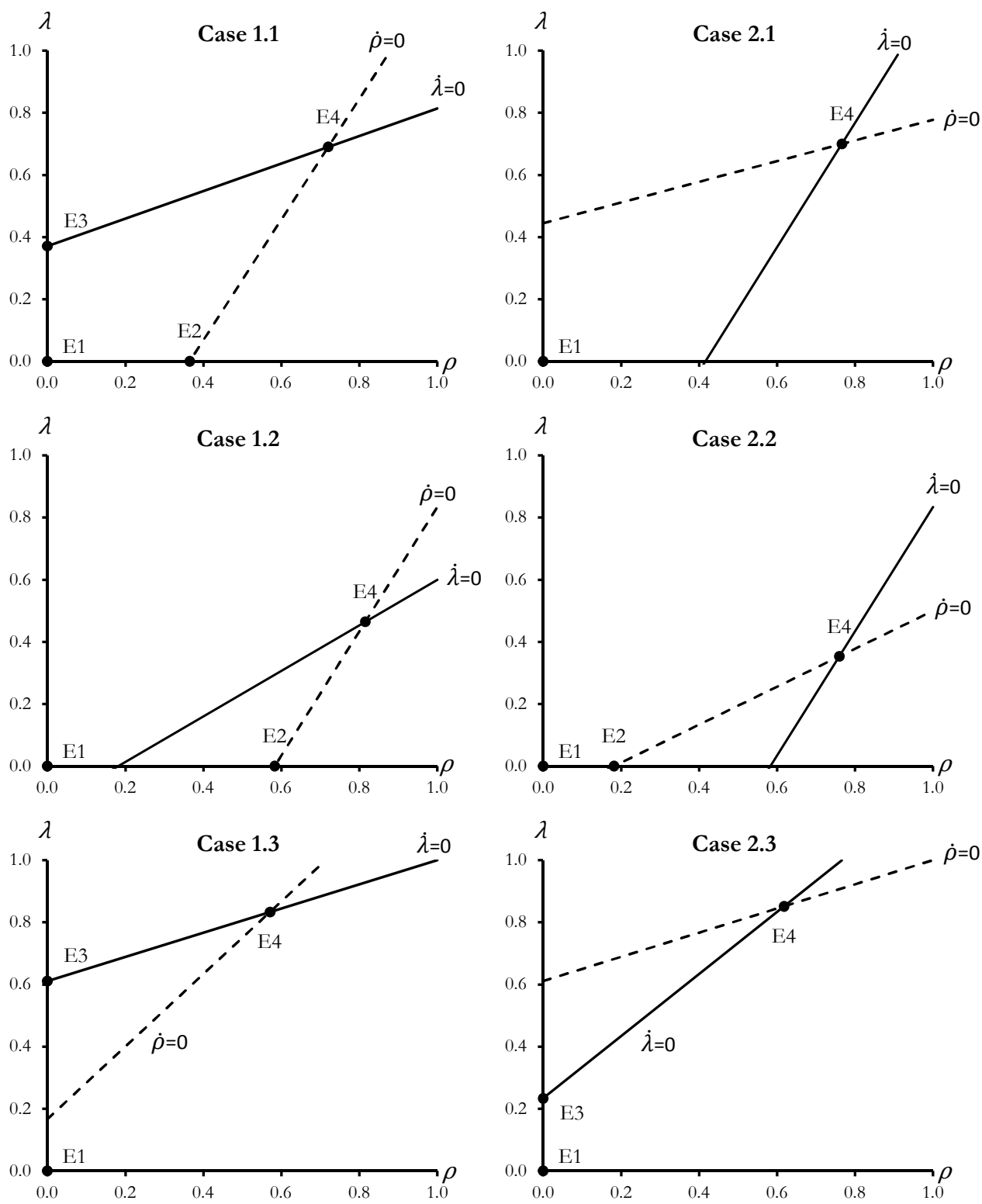

\subsubsection{Dynamic properties}

We turn now to analyze the stability properties of each equilibrium under the different sets of restrictions defined in Table 3.4. Interestingly, if the viability conditions are met, it can be shown that the stability of the fourth equilibrium will only 
depend on the sign of the slope differential. If the slope of the $\rho$-insocline is larger than the slope of the $\lambda$-insocline (Case 1), then the equilibrium will be stable. Otherwise, it will be a saddle point ${ }^{5}$.

The remaining equilibria will never be stable when Equilibrium 4 is stable. If this equilibrium is not stable, however, at least one of the remaining equilibria will be stable. In particular, in Case 2.1, the first equilibrium will be stable, in Case 2.2 the second equilibrium will be stable and in Case 2.3, the third equilibrium will be stable ${ }^{56}$. The following table summarizes these results:

Table 3.5. Stability properties of the equilibria under different cases

\begin{tabular}{|c|c|c|c|c|c|c|c|c|c|}
\hline \multicolumn{6}{|c|}{ Sub-Cases } & \multicolumn{4}{|c|}{ Equilibria } \\
\hline & \multirow{2}{*}{$A$} & \multirow{2}{*}{$D$} & \multicolumn{3}{|c|}{ (Slopes) } & \multirow[b]{2}{*}{ Eq. 1} & \multirow[b]{2}{*}{ Eq. 2} & \multirow[b]{2}{*}{ Eq. 3} & \multirow[b]{2}{*}{ Eq. 4} \\
\hline & & & $\dot{\rho}=0$ & & $\overline{\dot{\lambda}=0}$ & & & & \\
\hline $\begin{array}{c}\text { Case } \\
1.1\end{array}$ & + & + & $-\frac{B}{C}$ & $>$ & $-\frac{E}{F}$ & Unstable & Saddle & Saddle & Stable \\
\hline $\begin{array}{c}\text { Case } \\
1.2\end{array}$ & + & - & $-\frac{B}{C}$ & $>$ & $-\frac{E}{F}$ & Saddle & Saddle & Unstable & Stable \\
\hline $\begin{array}{c}\text { Case } \\
1.3 \\
\end{array}$ & - & + & $-\frac{B}{C}$ & $>$ & $-\frac{E}{F}$ & Saddle & Unstable & Saddle & Stable \\
\hline $\begin{array}{c}\text { Case } \\
2.1\end{array}$ & - & - & $-\frac{B}{C}$ & $<$ & $-\frac{E}{F}$ & Stable & Saddle & Saddle & Saddle \\
\hline $\begin{array}{c}\text { Case } \\
2.2\end{array}$ & + & - & $-\frac{B}{C}$ & $<$ & $-\frac{E}{F}$ & Saddle & Stable & Saddle & Saddle \\
\hline $\begin{array}{c}\text { Case } \\
2.3\end{array}$ & - & + & $-\frac{B}{C}$ & $<$ & $-\frac{E}{F}$ & Saddle & Saddle & $\underline{\text { Stable }}$ & Saddle \\
\hline
\end{tabular}

Another feature worth noting about Table 3.5 is that in most cases the non-stable equilibria are actually saddle points. That is, points that exhibit both stability and instability at the same time. In the vicinity of these points there are trajectories moving towards and away from them. However, there is only one trajectory that will lead the economy to that steady state. All other trajectories, even if they move towards that attractor for some time, will eventually turn and move away. The fact that Equilibrium 4 constitutes a saddle point in Case 2 (see last column of Table 3.5) is therefore quite interesting from policy perspective. It means that there might be a feasible trajectory to the good equilibrium but it is very difficult to bit it. This contrast with the Case 1, in which reaching the good equilibrium is much easier: it just requires that the economy moves out from the basis of attraction of the other low-income traps. The following figure illustrates these contrasting situations.

\footnotetext{
55 See Appendix A.1 for the formal demonstration.

${ }^{56}$ See Appendix A.2 for the formal demonstration.
} 
Figure 3.3. Illustrative trajectories under different stability properties in Eq. 4
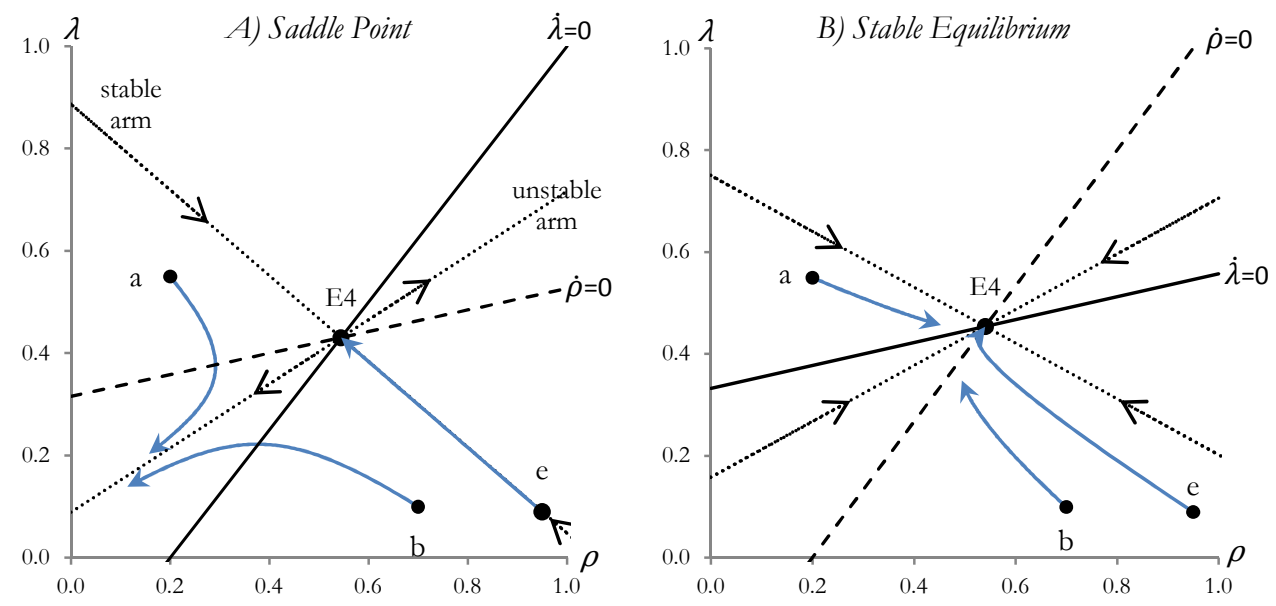

Panel A on Figure 3.3 illustrates a situation in which the Equilibrium 4 is a saddle point (Case 2.1). Besides the regular isoclines (equations for which the movement of the state variables is zero), the figure also shows the so-called separatrices (dotted lines). These lines, which also pass through the steady-state, determine the direction of any trajectory moving in the vicinity of the equilibrium. One of them (the stable arm) has arrows pointing towards the equilibrium, while the other (the unstable arms) is pointing away from it. Due to these counterbalancing forces, the only way to reach the steady state is to be posited exactly on the stable arm. Any initial condition not situated in this arm, will lead the economy away from the steady state. This is illustrated in the figure by the trajectories starting in points $a$ and $b$. As we can see, after initially heading towards the steady state, these trajectories bend and move towards the origin. The trajectory starting at the initial conditions depicted by point $e$, instead, manages to move smoothly towards the steady state. From a policy point of view, this would mean that if the economy starts with a very small modern sector (as represented, for example, in points $b$ and $e$ ) and the good equilibrium is a saddle point, this equilibrium will only be reachable if the technological gap is extremely low. Specifically, for a modern sector that employs only $10 \%$ of the labour force, the relative technological knowledge should be exactly $95 \%$ of that of the leading economy in order to hit the stable path towards the equilibrium. Anything smaller will lead the economy towards a low-income poverty trap (as shown by the path starting in $b$ ).

In clear contrast, Panel B presents a situation in which the Equilibrium 4 is stable (Case 1.1). In such a case, regardless of the initial conditions the economy will al- 
ways head towards the steady state. We can see, therefore, that in this case the trajectories starting with the initial conditions $a$ and $b$ will also move towards the steady state, significantly reducing the technological gap (trajectory starting in $a$ ) or expanding the share of the modern sector (trajectory starting in $b$ ).

\subsubsection{Economic interpretation}

We focus now on the economic meaning of the various conditions that determine the different cases detailed in the previous section. These cases result from different combinations in the signs of the slope differential and the terms $A$ and $D$. Recalling the definition of $B, C, E$ and $F$ (see Table 3.1), it is possible to see that the sign of the slope differential will be determined by the following expression:

$$
\left(-\frac{B}{C}\right)-\left(-\frac{E}{F}\right)=\frac{(a \theta \sigma-\beta \psi \hat{Z})}{\beta[\alpha \beta(\chi-a)+a \theta]}
$$

Under the assumption that $\chi>a$ the denominator will always be positive and the sign of the expression will ultimately be determined by the numerator. This means that Equilibrium 4 will be stable (Case 1) if and only if:

$$
a \theta \sigma>\beta \psi \hat{Z}
$$

If this condition does not hold, then the equilibrium will be a saddle point (Case 2).

In order to get a better understanding of the economic meaning of this condition, we can re-write it as follows:

$$
\frac{\sigma}{\beta}>\frac{\psi \hat{Z}}{a \theta} \Rightarrow \frac{(-\sigma)}{\beta}<\frac{\psi \hat{Z}}{(-a \theta)}
$$

We can notice that the terms on the left-hand-side are related to the growth rate of technological knowledge, while the terms in the right-hand-side are related to the growth rate of output in the modern sector. In particular, $(-\sigma)$ captures the negative impact of the relative stock of technological knowledge on the growth rate of technological knowledge (due to decreasing advantages of backwardness as the gap is reduced) and $\beta$ captures the positive impact of the share of the modern sector on the growth rate of technological knowledge (the induced-innovation channel). On the other side, $\psi \hat{Z}$ reflects the "direct" positive impact of the relative stock of technological knowledge on the growth rate of output in the modern sector ${ }^{57}$ and $(-a \theta)$

\footnotetext{
57 That is, without considering the "indirect" impact of $\rho$ on output growth through relative-price changes brought by its effects on productivity growth.
} 
captures the "direct" negative impact of the labour share of the modern sector on the growth rate of output in the modern sector due to wage-inflation ${ }^{58}$.

In the light of these definitions, we can see that the condition is actually stating that the (direct) effect of $\rho$ as compared to the (direct) effect of $\lambda$ should be larger in the growth rate of technological knowledge than in the growth rate of output. This will always be the case if in each equation $\left(\widehat{Y}_{M}\right.$ and $\left.\widehat{T}_{M}\right)$ the negative effect prevails. For this to happen, we need that the coefficients $\sigma$ and $a$ (combined with $\theta$ ) are sufficiently large. Both coefficients play a key role in our model. The first one is capturing the scope by which the South can benefit from international technological spillovers (either in the form of technological transfer or directly via imitation). Since the absorptive capabilities of the South are not explicitly modelled in our technological knowledge equation (as it would be the case, for example, if we use a non-linear specification for the spillovers in line with Verspagen, 1991, 1993), these capabilities would be implicitly captured by $\sigma$. Increasing absorptive capacity would then increase $\sigma$ and thus contribute to the stability of Equilibrium 4.

The coefficient $a$, on the other hand, is representing the so-called MarshalLerner condition, and therefore is capturing the cumulative effects of changes in the real exchange rate on competitiveness and long-run growth. We can see that the larger the size of this coefficient, the more likely that the equilibrium will be stable. In an extreme case (that we might call "strong Marshal-Lerner"), it is possible to show that if $a$ is larger than $\chi$ and the difference $(a-\chi)$ is larger than $(\psi \hat{Z} / \alpha \sigma)$, then the slope of the $\lambda$-insocline will be negative and the fourth equilibrium will always be stable. However, a strong Marshal-Lerner condition seems to be against most findings in the literature ${ }^{59}$ and therefore we will keep the assumption that $a$ is positive but smaller than $\chi$.

We turn now to analyze the distinction between the sub-cases (1, 2 and 3$)$. As we have already shown, each sub-case will depend on the particular sign of $A$ and D.

Recalling the definition of $A$ (see Table 3.1), we can see that this term will be positive if and only if:

$$
d>h \Rightarrow(\zeta+\sigma)>\left(\zeta^{f}+\beta^{f} \lambda^{f}\right)
$$

Bearing in mind that $\zeta^{f}(\mathrm{R} \& \mathrm{D}$ investment in the leading economy) will be typically larger than $\zeta$, and that $\lambda^{f}$ will be typically close to one, it is possible to assume that $A$ will always be negative at early stages of development. Only an extremely

\footnotetext{
58 That is, without considering the "indirect" impact of $\lambda$ on output growth through relative-price changes brought by its effects on productivity growth.

59 See footnote 46.
} 
high value for $\sigma$ could revert this situation (which would require, as we mentioned before, very high levels of domestic absorptive capabilities).

The term $D$, on the other hand, will be positive if:

$$
\begin{aligned}
& (a b+f \hat{Z})>(\chi-a)(\mu k+\alpha d)+n g \Rightarrow \\
& a b+(\xi-\psi) \hat{Z}>(\chi-a)[\mu k+\alpha(\zeta+\sigma)]+n\left[\chi+(\chi-a) \gamma_{M}\right]
\end{aligned}
$$

That is, it will be positive if the autonomous forces leading to labour absorption in the modern sector (exogenous real depreciation and world income growth) more than compensate the autonomous forces leading to labour release (productivity gains resulting from capital intensification and exogenous technological accumulation) and the increase in total labour force.

At initial stages of development, $D$ will typically be negative due to the combined effect of high population growth $(n)$ and low income elasticity of demand for exports with poor technological sophistication $(\xi-\psi)$. As a country develops, $D$ will typically turn sign and become positive because the negative effect of $n$ diminishes while the effects of capital intensification and exogenous technological accumulation remain low. At a certain stage of development, however, $D$ might turn sign again: if domestic investments in capital and R\&D rise significantly and/or absorptive capabilities are significantly improved, while income elasticity remain low (or increase less rapidly), $D$ will become negative again.

As we will see in the next section, the analogies that can be drawn between the signs of $A$ and $D$ and the different stages of development will be very useful in understanding, from an economic point of view, the dynamical behaviour of the model proposed.

To finish the characterization of the equilibria in the model, we state now the four viability conditions in terms of $A, D$ and the deep parameters of the model:

$$
\begin{aligned}
& \beta g D+[a \theta+(\chi-a) \alpha \beta] A>0 \\
& \beta[g D-(\chi-a) \alpha \sigma-\psi \hat{Z}]+[a \theta+(\chi-a) \alpha \beta](A-\sigma) \leq 0 \\
& \sigma g D+[\psi \hat{Z}+(\chi-a) \alpha \sigma] A>0 \\
& \sigma[g D-(\chi-a) \alpha \sigma-a \theta]+[\psi \hat{Z}+(\chi-a) \alpha \sigma](A-\beta) \leq 0
\end{aligned}
$$

As we can see, the viability conditions are actually imposing some lower and upper boundaries to the relative sizes of the terms $A$ and $D$. 


\subsection{Trajectories and Development Traps}

\subsubsection{Structural trajectories}

An interesting feature of the model proposed in this chapter is that it is able to reproduce, in a very simplified fashion, different structural trajectories which are in line with a long strand of appreciative theorizing on economic development. In order to exploit this feature, we present now a series of simulations that, based on the system form by equations (3.26) and (3.27), can illustrate this sort of trajectories and provide some intuition on the general conditions that need to be met in order to achieve success in the process of economic development.

In this regard, it is important to emphasize that the various scenarios defined before by looking at the signs of $A, D$ and the slope differential (Cases 1.1 to 2.3) can actually be associated with different stages of development, and the multiple equilibria of the model can be associated with different sorts of low- and middleincome traps that need to be overcome before entering in a successful path towards economic development. That is, a path in which the economy manages to expand the modern sector and, at the same time, reduce significantly the technological gap.

At very early stages of development, the economy would be dominated by the traditional sector and the stock of technological knowledge would be negligible when compared with the advanced world. In terms of our model, the economy would be situated very close to the basin of attraction of Equilibrium 1 and, eventually, it will end up in a poverty trap where $\rho$ and $\lambda$ will be equal to zero. This equilibrium would be stable and therefore the economy will tend to stay in this trap unless an exogenous shock changes some of the underlying parameters that describe the functioning of the economy. As we have previously seen, Equilibrium 1 will be stable if and only if the terms $A$ and $D$ are simultaneously negative. Such a situation can be represented as follows: 
Figure 3.4. Initial stage

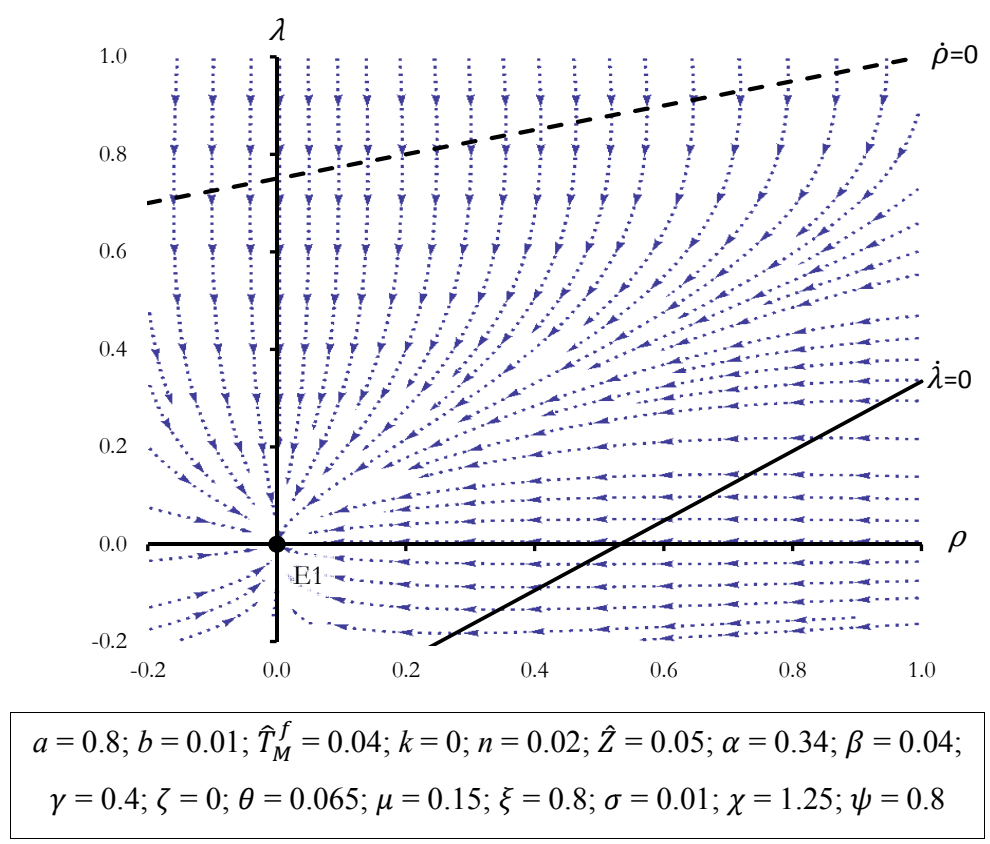

This figure presents the usual isoclines in the space $(\rho ; \lambda)$ and the corresponding relevant equilibrium. In addition, it shows the slope field of the system. That is, the direction of all possible trajectories starting from any point in the bi-dimensional plane of the state variables. This field provides a straightforward rule to determine the stability of the various equilibria: if an equilibrium is stable, then in the vicinity of that equilibrium all arrows should point towards it (as in Equilibrium 1 in Figure 3.4). Below the figure we also detail the specific parameter-values used to build it. ${ }^{60}$

Under this particular set of parameters, the model illustrates an economy that at initial levels of technological development- has little or no foreign demand for its products. In particular, we assume that $\xi=\psi$, and thus the income elasticity for export demand is equal to zero. In such a situation, regardless of how fast the world income is increasing (in the simulation we assume an increase of $5 \%$ ) the term $D$ will probably be negative. Therefore, the absence of enough external demand will

\footnotetext{
${ }^{60}$ All the figures presented in this section have been calculated using Wolfrand Mathematica 8.0. The software scripts are available upon request.
} 
make the existence of a modern sector nonviable ${ }^{61}$. Furthermore, by being at very initial stages of technological development the difference between the autonomous increase in domestic and foreign technology will be so large that the term $A$ will be negative as well. In such a situation (terms $A$ and $D$ being simultaneously negative and the slope differential also being negative) the first equilibrium will be stable and regardless of the initial conditions the economy will end up in this poverty trap.

To escape from this equilibrium either $A$ and/or $D$ should become positive. That is, either the domestic investments on technological accumulation and the absorptive capacity of the economy should raise enough to surpass the technological growth of the North (thus turning positive the term $A$ ) and/or the autonomous forces leading to labour absorption in the modern sector should raise enough as to counterbalance the exogenous growth of total labour force (which would turn positive the term $D$ ). If the intensity of these changes is not as strong as to revert the instability of the good equilibrium, the economy will end up in an intermediate equilibrium that might also be associated with a low (or medium)-income trap. In the first case (increase in domestic technological capabilities) the economy will move towards the Equilibrium $2\left(\rho_{2}^{*}>0 ; \lambda_{2}^{*}=0\right)$ : the traditional sector will continue to be dominant, but the technological gap will be reduced. In the second case, the economy will move towards the Equilibrium $3\left(\rho_{3}^{*}=0 ; \lambda_{3}^{*}>0\right)$ : a modern exporting sector will emerge, but using obsolete technologies in international terms. The following figures illustrate each of these scenarios 62 .

\footnotetext{
${ }^{61}$ In this setting, even if there is some initial external demand for the good produced by the economy, since the income elasticity of export demand equals zero the exporting sector will not grow or will grow very slowly. Thus, it will not be able to absorb the increasing labour force and in the medium/long run the traditional sector will become dominant.

62 In each figure, the parameters that have changed with respect to the previous situation are underlined.
} 
Figure 3.5. Big-push on technological investments

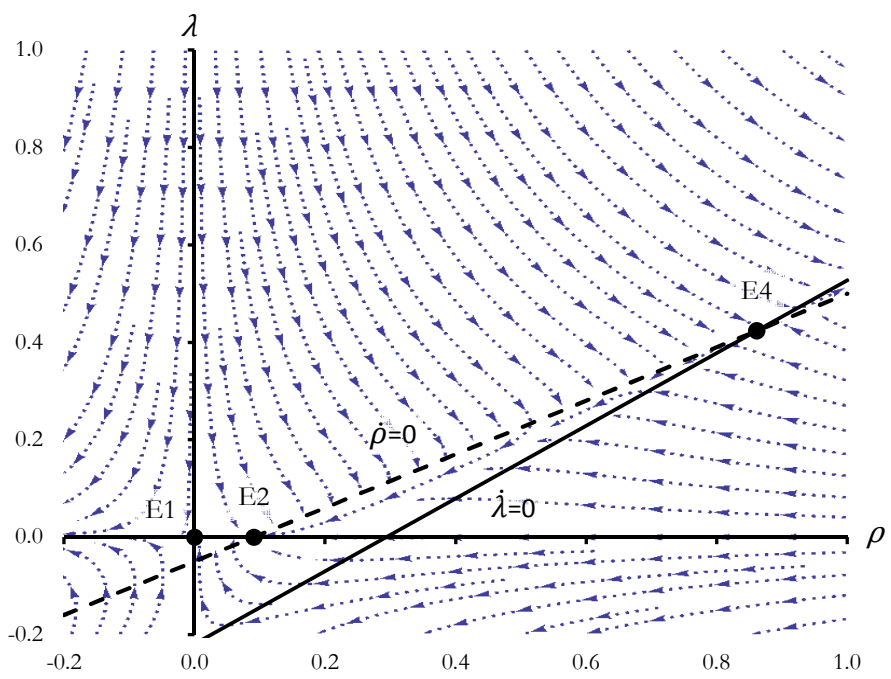

$a=0.8 ; b=0.01 ; \widehat{T}_{M}^{f}=0.04 ; k=0 ; \underline{n=0.01} ; \hat{Z}=0.05 ; \alpha=0.34 ; \beta=0.04$; $\gamma=0.4 ; \zeta=0.02 ; \theta=0.065 ; \mu=0.15 ; \xi=0.8 ; \underline{\sigma=0.02} ; \chi=1.25 ; \psi=0.8$

Figure 3.6. Emergence of a modern exporting sector

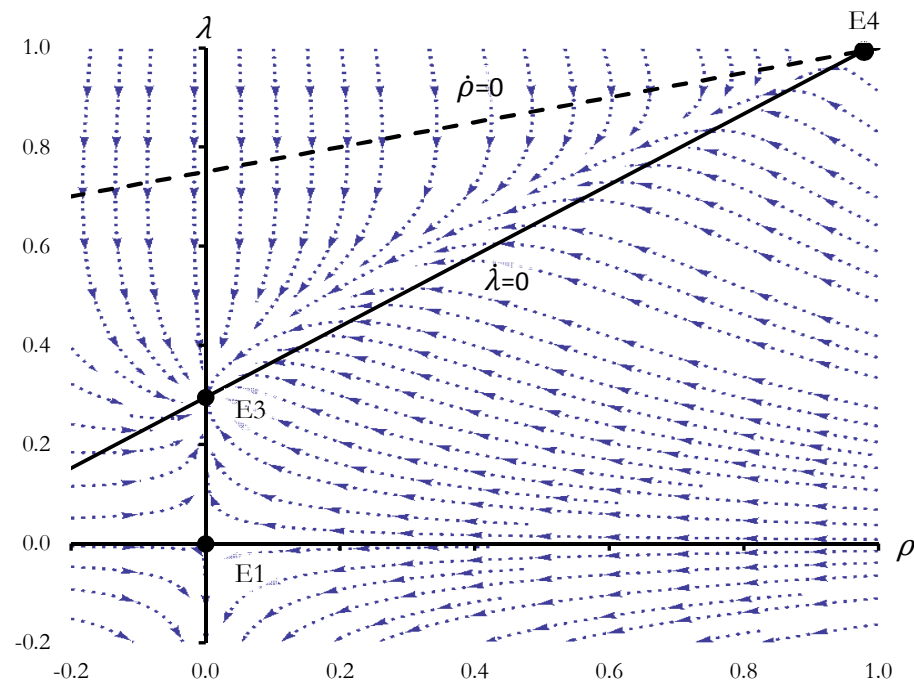

$a=0.8 ; b=0.01 ; \widehat{T}_{M}^{f}=0.04 ; k=0 ; \underline{n=0.01} ; \hat{Z}=0.05 ; \alpha=0.34 ; \beta=0.04$; $\gamma=0.4 ; \zeta=0 ; \theta=0.065 ; \mu=0.15 ; \xi=1.3 ; \sigma=0.01 ; \chi=1.25 ; \psi=0.8$ 
Starting from the set of parameters that defined Figure 3.4, in Figure 3.5 we have simulated a simultaneous increase of $\zeta$ and $\sigma$ (a "big-push" on technological investments) and a decrease in $n$ (the well-known decrease in population growth that goes hand to hand with economic development). In Figure 3.6, instead, we have simulated an increase of $\xi$ (the autonomous income demand elasticity for exports) together with the decrease of $n$.

From these potential trajectories, the most reasonable would be the one represented by Figure 3.6. This trajectory is actually quite in line with the historical path followed by many developing countries, in which the emergence of a modern sector was typically associated with an exogenous shock that provided increasing export opportunities for the domestic production (in terms of our model, an increase in $\xi$ so that, $\xi>\psi)^{63}$. Other things equal, such an event will move the curve $\dot{\lambda}=0$ upwards eventually turning positive the sign of the term $D$ (and thus the y-intercept of this curve, as shown in Figure 3.6). In the example this is reinforced by a decrease in the growth rate of total labour force. Both factors lead to an increasing participation of the modern sector in the absorption of total labour. At early phases of this process, however, it is not surprising that the technology at use is obsolete in international terms, as compared with the world frontier.

The other case, instead, could be associated with a "big-push" in technological investments that succeeds in reducing the technological gap. This push, however, is unable to translate the increasing technological capabilities into the creation of a dynamic modern sector. In a way, demand factors (mainly related to a low income elasticity of exports) play against the final outcome of this trajectory. In terms of the figure, this is represented by a movement downwards of the $\rho$-insocline, up to a point in which $A$ becomes positive (and thus the x-intercept of this curve). We can notice now the emergence of a stable equilibrium (the Equilibrium 2 in our previous discussion) on the horizontal axis.

Once the economy reaches any of these intermediate equilibria, the challenge becomes different. To escape this sort of development traps, the role of absorptive capacities and export performance become fundamental. If, for example, the economy manages to significantly increase the domestic absorptive capacity (or move towards sectors where imitation is easier) and at the same time increases the share

${ }^{63}$ Think, for example, in the experience of the East and Southeast Asian economies during the postwar period. Geostrategic events (as Richard Stubbs put its) significantly helped these economies to find markets for their emerging manufacturing industries. The Korean war gave a huge boost to Japan's and Hong Kong's exports and, later, the Vietnam war boosted the sales of emerging manufacturing exports from Japan, South Korea, Taiwan and Singapore (Stubbs, 1999, 2005). In terms of our model, these exogenous shocks would have given new export opportunities that, in turn, boosted the emergence and consolidation of a modern exporting sector. 
of exportable goods with lower gap-punishment on demand (that is, goods with high income-elasticity of demand regardless of the degree of technological sophistication), then it might enter into a dynamic path towards the good equilibrium. This process will typically take place together with an intensification of the capital-output ratio $(k)$ and an increase in $\mathrm{R} \& \mathrm{D}$ expenditures $(\zeta)$ that will lead to higher productivity gains and -ceteris paribus- would decrease the capacity of the modern sector to absorb labour. Therefore, the increase in exports should be large enough to more than compensate this negative impact in labour absorption.

In terms of our model, starting from Figure 3.6, this story could be reflected as a simultaneous increase in $\sigma$ (which would be associated with an increase in the domestic absorptive capacity), $k$ and $\zeta$ together with a decrease in $\psi$ (the gappunishment on income elasticity of exports). Figure 3.7 shows this new scenario.

Figure 3.7. Path towards successful development

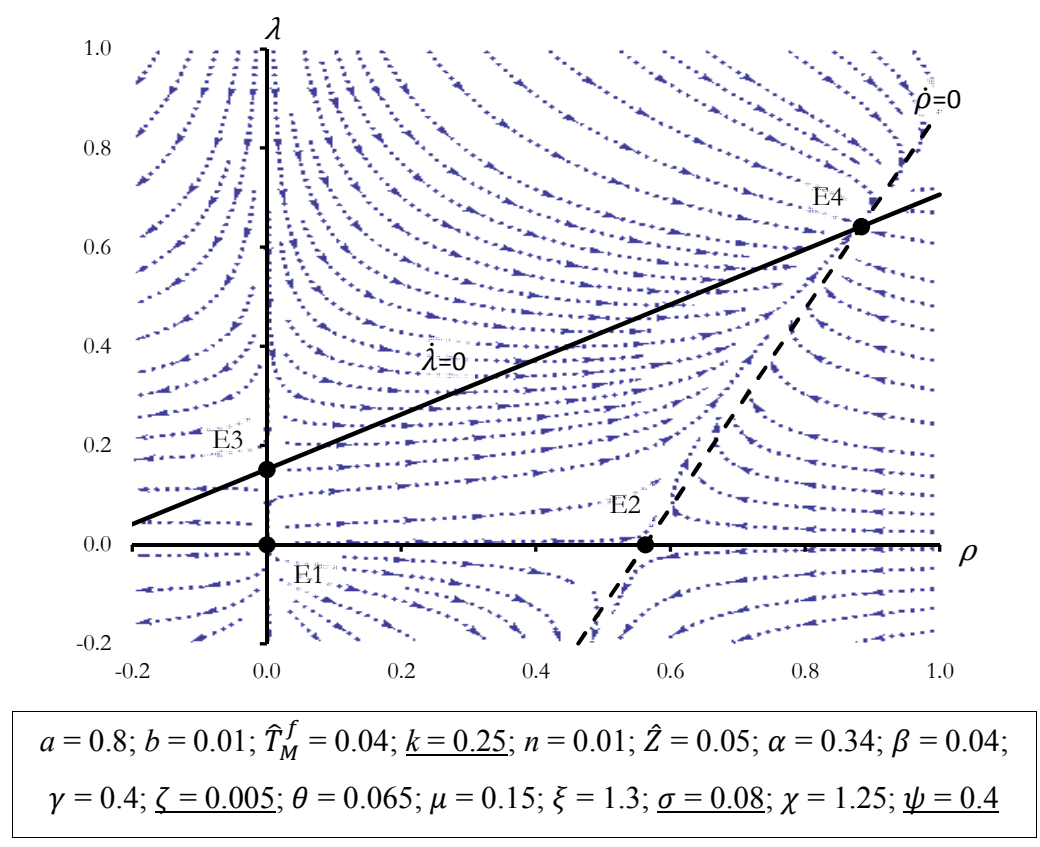

As we can see from Figure 3.7, if there are no further changes in the parameters, the economy will move towards a good equilibrium, in which the modern sector becomes dominant $(\lambda=0.64)$ and the technological gap is significantly reduced $(\rho=0.88)$. It follows that the structural trajectory described by the transition from Figure 3.4 to Figure 3.6 and then to Figure 3.7 can be characterized as a story of successful development. Such a trajectory would schematically illustrate the experi- 
ence of the East and Southeast Asian economies. As it has been extensively documented by the literature, during the post-war period these economies managed to improve significantly their absorptive capacities and increase their stock of technological knowledge ${ }^{64}$. In parallel -and perhaps more importantly- they also managed to transform they economic structures towards the production of goods with higher degrees of technological sophistication and higher income-elasticity of demand in world markets ${ }^{65}$. That is, they managed to simultaneously achieve a significant increase of $\sigma$ and a reduction of $\psi$. In the light of our model, these transformations would have been at the core of their successful developmental path.

Once the economy manages to undertake the specific transformations needed to ensure the stability of Equilibrium 4, the particular attractor towards which it moves will depend on the specific values of the remaining parameters. Hence, it is important to examine how marginal changes in these parameters will impact on the equilibrium values of the state variables.

\subsubsection{Comparative statics}

The following table summarizes the impact that changes in the deep parameters of the model would have on the equilibrium values of the state variables in the vicinity of Equilibrium 4 (assuming that it is stable and economically viable). It presents the sign of the partial derivative of $\rho_{4}^{*}$ and $\lambda_{4}^{*}$ with respect to each parameter of the model. Marginal increases of parameters that present a positive (negative) sign will improve (harm) the steady state of the Southern economy.

${ }^{64}$ See for example Cimoli et al. (2009); Hobday (1995); Kim and Nelson (2000)

65 Gouvea and Lima (2010) provide interesting evidence in this regard. Using a multi-sectoral BOPC model they show that the acceleration of growth in the Asian tigers (as compared to Latin America) was primarily due to their increasing specialization in those goods for which the income-elasticity of exports was higher. 
Table 3.6. Comparative statics in the vicinity of Equilibrium 4 (sign of the partial derivatives with respect to the deep parameters of the model).

\begin{tabular}{ccc}
\hline Parameter & $\boldsymbol{\rho}_{\mathbf{4}}^{*}$ & $\boldsymbol{\lambda}_{\mathbf{4}}^{*}$ \\
\hline$a$ & $?(+)$ & $?(+)$ \\
$b$ & + & + \\
$\hat{T}_{M}^{f}$ & - & - \\
$k$ & - & - \\
$n$ & - & - \\
$\hat{Z}$ & + & + \\
$\alpha$ & - & - \\
$\beta$ & $?(+)$ & + \\
$\gamma$ & - & - \\
$\zeta$ & + & + \\
$\theta$ & - & - \\
$\mu$ & - & - \\
$\xi$ & + & + \\
$\sigma$ & + & $?(+)$ \\
$\chi$ & - & - \\
$\psi$ & - & $(-)$ \\
\hline
\end{tabular}

Note: The interrogation mark identifies those cases in which the sign of the derivative is undetermined under the assumptions already defined throughout the model. Between brackets it is specified the sign that these derivatives will take under some additional conditions. See Appendix A.3 for the details.

Looking at the table, the first feature that stands out is the homogeneity of signs between the state variables. Under the setting proposed, the impact of marginal changes in the parameters will typically go in the same direction both for $\rho_{4}^{*}$ and $\lambda_{4}^{*}$. Only in very few cases, changes in the values of one parameter might have an opposite impact on the equilibrium values of the state variables ${ }^{66}$. In general terms, all signs are in line with the intuition and the literature on this topic. Increases in the size of the Marshall-Lerner condition (a), the exogenous rate of currency depreciation $(b)$, the growth rate of foreign income $(\hat{Z})$ and the autonomous part of the income elasticity $(\xi)$ will all have a positive effect on the growth rate of output and, through this demand channel, on the equilibrium values of the state variables. Improvements on domestic absorptive capacities $(\sigma)$, local investments in $\operatorname{R} \& \mathrm{D}(\zeta)$ and the size of the induced innovation coefficient $(\beta)$ would also have a positive

${ }^{66}$ These would be the cases in which the additional conditions for $a$ and $\beta$ (in the case of $\rho_{4}^{*}$ ) and $\sigma$ and $\psi$ (in the case of $\lambda_{4}^{*}$ ) are not met. See Appendix A.3 for the details. 
impact on the equilibrium values, in this case, through their direct effect on the rate of accumulation of technological knowledge and their indirect effect on competitiveness and export demand.

Increases in the remaining parameters would have negative impact on the equilibrium values. Higher income elasticity for imports $(\chi)$ would erode the net effects of any force that increases output, thus diminishing labour absorption and technological accumulation in the modern sector. Higher values in the invest-output ratio $(k)$, or the sensitivity of productivity to captialization $(\mu)$, in turn, would accelerate productivity gains and lower the rates of labour absorption in the modern sector, decreasing the equilibrium values of $\rho_{4}^{*}$ and $\lambda_{4}^{*}$. The same is true for the dynamic returns to scale parameter $\left(\gamma_{M}\right)$ and the sensitivity of productivity gains to the technological stock growth $(\alpha)$.

Higher levels of technological accumulation in the leading economy $\left(\widehat{T}_{M}^{f}\right)$ and rapid growth of the total labour force $(n)$ would also tend to diminish the equilibrium values, due to their respectively negative effects on the relative technological stock and the share of the modern sector in total employment. In a similar vein, higher sensitivity of wages in the modern sector to the size of the reserve army $(\theta)$ would erode price-competitiveness of exports more rapidly and thus impact negatively on the equilibrium. Finally, a higher penalty to technological backwardness in the export elasticity $(\psi)$ will tend to diminish the demand for exports and therefore would also have a negative impact on the equilibrium values.

In the cases of $a, \beta, \sigma$, and $\psi$ it is important to notice that the direction of the effects might not always be as described above. In the appendix we detail the specific additional conditions needed to get this particular impact. In most cases, these conditions are not very restrictive and thus likely to hold.

The effect of marginal changes in the deep parameters of the model can be illustrated by looking at two phenomena that have attracted special attention in the economic development literature in recent years: the acceleration of global technological change and the movements in the real exchange rates.

Figure 3.8 presents the case of a developing economy that, starting from an equilibrium position, face simultaneously an acceleration of technological change in the global economy (modelled as an increase in the technological knowledge growth rate of the leading economy, $\hat{T}_{M}^{f}$ ) and an acceleration of the rate of real appreciation of its domestic currency (modelled as a reduction of $b$, that could either respond to an increase in the rate of autonomous inflation, $\omega$, or a reduction in the rate of nominal depreciation, $\hat{e})$. Other things equal, the first phenomena will make the term $A$ fall and this will be reflected by a movement to the left of the $\rho$-isocline. In addition, the real appreciation would decrese the term D and therefore the $\lambda$ isocline will move downwards, as shown in the figure. The result of this two com- 
bined effect will be extremely harmful for the Southern economy. As we can see, the new equilibrium E4' will entail a significantly lower share of labour in the modern sector and a much wider technological gap.

Figure 3.8. Acceleration of global technological change and real appreciation of the domestic currency

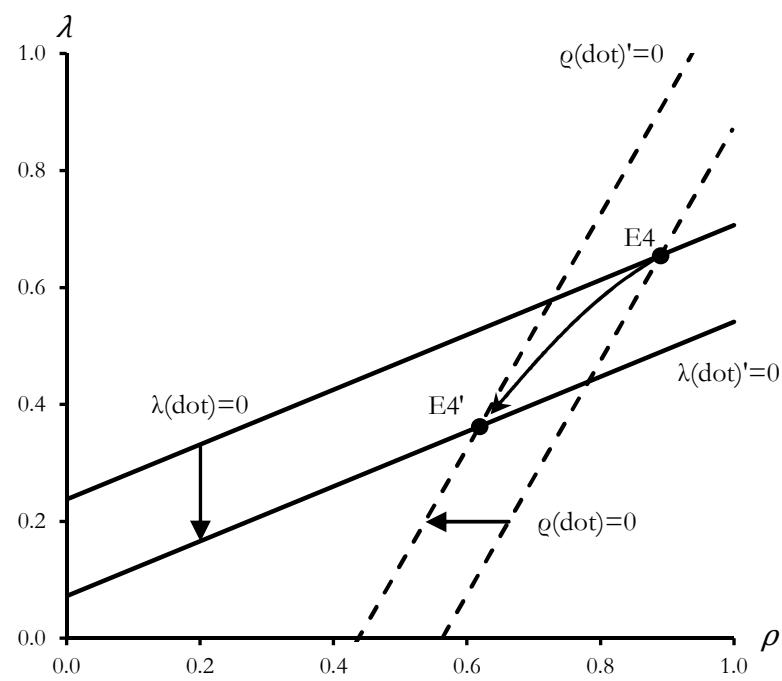

A trajectory as the one presented in Figure 3.8 could be associated, for example, to the experience of Latin America during the 1980s and 1990s where various episodes of strong real appreciation of domestic currencies (due to high inflation or stabilization policies anchored on appreciated nominal exchange rates) together with a failure to tap into the global acceleration of technological growth brought by the ICT-revolution, dramatically hampered the possibility of these countries to sustain a process of structural modernization and technological catch up. The empirical evidence presented in the next chapters of this thesis will illustrate in more detail this sort of trajectories.

\subsection{Final Remarks}

The productive absorption of labour has been long identified as one of the major challenges of developing economies. From the development pioneers back in the post-war period to the flagship publications of major international organization nowadays, this has been and continues being in the centre of the development agenda. 
Despite its centrality, this issue has not been fully acknowledged in theoretical research about the sources and dynamics of economic growth. This chapter tried to make a modest contribution in this line by setting up a model of catch-up among countries in which the dual character of developing economies and the important challenges to absorb labour in the modern part of the economy stands out as one of the major features. By examining the dynamic interaction between technological catch-up and structural change, the model provides interesting insights on the different structural trajectories that an economy might follow in the process of economic development. Furthermore, it is able to deliver economically meaningful multiple equilibria in a simple linear setting. Hence, it can be easily solved and yields clear traceability of the main forces involved.

Interestingly, the multiple equilibria of the model can be associated with different types of development traps that need to be overcome in order to enter in a path towards successful development. Simple simulations of the model illustrated this feature. After surpassing an initial poverty trap -whether due to the emergence of a modern exporting activity or due to some boost in the domestic technological capabilities- the Southern economy would typically be attracted towards another bad steady state. In order to rectify this tendency, two fundamental transformations would be needed: a radical improvement in the export performance and a radical enhancement in the domestic absorptive capabilities. Failure to achieve any of these transformations will ultimately lead the developing economy to one of the remaining development traps.

It remains open, however, the question about how exactly these transformation take place. The successful experience of East and Southeast Asian economies suggest that a key element in this process is the upgrading of the modern sector towards the production of goods with higher degrees of technological sophistication and higher income-elasticity of demand in world markets. In the simplified framework proposed here this sort of dynamics could not be explicitly modelled. For this reason, an interesting extension of the model would be the introduction of a multi-sectoral structure within the modern sector of the Southern economy. Such an extension could shed new light in this issue and improve the analytical interpretation of the major results of the model. One way to do so would be to model the modern sector as producing a continuum of goods with different technological characteristics, as it is done, for example, in Cimoli and Porcile (2013). Alternatively, the modern sector could be modelled using a dynamic Input-Output framework, in line, for example, with Los and Verspagen (2006).

A second line in which the model could be extended would be the inclusion of non-linearities in some of its building functional relations. This could significantly improve its capability to depict more closely the reality of certain economic phenomena. One step in this line would consist in introducing a non-linear specifica- 
tion for the international spillovers in the equation of technological knowledge accumulation. Following Verspagen (1991) and (1993), such a setting would capture better the ideas of the original catching-up theorists. Under this setting, the specific role of absorptive capacities and technological congruence at different stages of development could be fully explored. Preliminary simulations in this line give a richer set of possible outcomes when it comes to analyse the structural trajectories followed by the domestic economies. In particular, a non-zero low-level equilibrium also emerge, which might very well depict the reality of emerging economies that have been trapped at middle-income levels.

Another step in this line would be the introduction of a retardation mechanism in the Kaldor-Verdoorn coefficient according to which the size of this parameter would decrease as the economy develops. This is the approach used in Rada (2007), where the $K-V$ coefficient depends (in a non-linear fashion) on the share of the modern sector in total employment. Such a setting would yield a more realistic pattern in the growth rate of output as countries become richer. If this coefficient diminishes with the size of the modern sector share, then more advanced economies would have a lower premium in terms of increasing returns to scale and -other things equal- a lower rate of output growth.

In a similar vein, the distinction of two phases in the dynamical behaviour of wages in the modern sector would capture better the reality of countries at very initial levels of development, where the reserve army is so large that changes in the relative size of the modern sector have marginal or no impacts on wage inflation. Such a distinction will bring the model closer to the tradition of Lewis-type models in which modern sector wages start increasing only after certain turning point in the relative size of modern sector.

It follows that the model proposed can provide a well suited starting point for future research. As we have briefly detailed, some interesting extensions can be built upon the ground set by this model. Nevertheless, it should be emphasized that extending the model in any of these lines will significantly increase its complexity and reduce the intuitive traceability of the main forces involved, which has been one of the major concerns of this chapter.

In what follows we will examine from an empirical perspective the salient features of this model. In particular, we will study the dynamics of the two key variables of the model (the share of labour and the technological gap of the modern sector) in a large sample of countries over the last 60 years. Moreover, we will explore the connections that exist between this dynamical behaviour and the emergence of low and middle-income traps. 
CHAPTER 4.

Structural Modernisation and Development Traps 


\subsection{Introduction}

This chapter investigates, from an empirical perspective, the salient features of the model proposed in the previous chapter. In particular, it analyses the two transformations that according to the model would be at the core of successful development. That is, the movement of labour from traditional to modern activities and the reduction of the technological gap in the modern part of the economy.

In order to do so, it proposes a new index that captures the major attributes of these complex and multifaceted dimensions in a parsimonious fashion. On one hand, structural change is studied as the change in the share of labour force employed in modern sectors of the economy. On the other hand, the degree of technological catch-up is analysed in terms of changes in labour productivity in the modern sectors relative to labour productivity at the international frontier. The new index combines changes along these two dimensions.

The study of changes over time in both dimensions provides a useful device to characterize the structural trajectories followed by different countries in the process of development. Moreover, the comparative analysis of their movements gives an indication of the reasons why some countries fail to achieve long-run sustained development. The cross-country comparisons undertaken in this chapter suggest that countries that fall into low or middle-income traps are countries that have failed to achieve a proper transformation along each of these dimensions.

The analysis is carried out on a newly constructed dataset that, combining information from various sources, provides unbalanced data for 100 countries over the period 1950-2009 on employment, labour force and value added in broad sectors of the economy (10 major aggregates of the ISIC rev. 3), with value added converted into a common currency using industry-specific converters. By means of this dataset, internationally comparable measures of sectoral labour productivity and employment shares in total labour force are constructed and used for the analysis of the two dimensions introduced above.

The chapter is structured as follows. Section 4.2 describes the main data sources and procedures used to construct the dataset and specifies the main indicators used throughout the chapter. It also describes the statistical criteria used to determine whether countries are caught in some kind of development trap. Section 4.3 introduces the data and prepares the ground for the analysis of development traps in Section 4.4 and the analysis of the structural trajectories followed by a selected number of countries in Section 4.5. Finally, Section 4.6 concludes. A methodological appendix with details regarding the construction of the dataset is included at the end of the thesis. 


\subsection{Empirical Approach}

\subsubsection{An index of structural modernisation}

Following the theoretical underpinning detailed in the previous chapter, we examine two interrelated dimensions that are at the core of the development process: structural change and technological catch up. In a purely theoretical exercise, the first dimension would be captured by the share of labour population working in the modern part of the economy. The technological dimension, in turn, would be captured by the relative level of technological knowledge of the modern part of the economy compared to that of the world frontier. Yet, to empirically capture these dimensions we need operational definitions that allow for analysis with the available data. Hence, part of the theoretical soundness needs to be sacrificed in order to have a measurable variable based on real data widely available through time and across countries.

The first dimension is relatively easy to operationalise. There are long datasets covering employment characteristics in almost all countries (of course, with different degrees of reliability, but typically good enough to get a stylized picture). The main challenge here lies in determining what exactly should be included as the modern part of the economy. This is especially problematic due to the lack of highly disaggregated data by sector for long periods in developing countries. For this reason, our definition of the modern sector will be restricted to an aggregate of broad sectors. In particular, the comparable data at hand (to be described in more detail in Section 4.2.3) only allows for a distinction of 10 major sectors as detailed in the following table: 
Table 4.1. Sectoral disaggregation and definition of Modern Market Activities (MMA)

\begin{tabular}{|c|c|}
\hline ISIC rev 3 & Sector \\
\hline AtB & Agriculture, Hunting, Forestry and Fishing \\
\hline $\mathrm{C}$ & Mining and Quarrying \\
\hline $\mathrm{D}$ & Manufacturing \\
\hline $\mathrm{E}$ & Electricity, Gas and Water \\
\hline $\mathrm{F}$ & Construction \\
\hline $\mathrm{GtH}$ & Wholesale and Retail Trade and Restaurants and Hotels \\
\hline I & Transport, Storage and Communication \\
\hline JtK & Financing, Insurance, Real Estate and Business Services \\
\hline 70 & Real Estates \\
\hline LtQ & Community, Social and Personal Services \\
\hline $\mathrm{CtF}+\mathrm{I}+\mathrm{JtK}-70$ & Modern Market Activities (MMA) \\
\hline AtB, GtH, 70, LtQ & Non-Modern Activities (NMA) \\
\hline
\end{tabular}

Ideally each sector of the economy should be divided between its modern and traditional components. Take the case, for example, of agriculture. It is clear that small scale subsistence agriculture should be included in the traditional sector. Modern and highly mechanized agricultural activities oriented towards exports, instead, should be considered as part of the modern economy. By the same token, extremely profitable retailers (such as IKEA or Wal-Mart) should be considered part of the modern sector as opposed to informal street vendors (both included in Sector $G t H)^{67}$. The availability of reliable data allowing for such distinctions, however, would make the analysis only feasible for a few advanced economies. As a second best solution, our approach identifies those sectors that are predominantly composed of what can typically be considered as modern activities. Following our previous discussion regarding the sectoral engines of economic growth (Chapter 2, Section 2.4), the natural candidates are: Industry (that is, Mining, Manufacturing, Utilities and Construction) and international tradable services (that is, Transport and Telecommunications and Financial and Professional Services $\left.{ }^{68}\right)$. These sectors can be re-

\footnotetext{
${ }^{67} \mathrm{~A}$ detailed discussion on the heterogeneity of this sector in the context of developing countries can be found in de Vries (2010)

${ }^{68}$ Professional Services are actually a component of the sector $K$ in the ISIC classification. In order to calculate this component, we subtract from this sector the industry number 70 (Real Estates). When building the data we only considered those countries for which this distinction could be made at least in the GDP figures. If this distinction was not possible in the employment data, we included as
} 
garded as modern both from a static and dynamic perspective. On the one hand, they typically have higher levels of productivity than the rest of the economy (static advantage). On the other hand, and perhaps more fundamentally, they also present a higher potential for technological upgrading and productivity gains. Henceforth, these activities will be grouped together under the label Modern Market Activities (MMA), and will be associated with the modern part of the economy. The other sectors are categorised as non-Modern Market Activities ${ }^{69}$. Our key variable to analyse structural change will be, therefore, the number of workers in the modern sector as percentage of total labour force. Following the nomenclature of our model, it will be denoted with the Greek letter Lambda. That is:

$$
\lambda_{t}^{i}=\frac{N_{M, t}^{i}}{L_{T, t}^{i}}
$$

Where $N_{M}$ stands for employment in MMA, $L_{T}$ for the total labour force, the subscript $t$ represents the time and the superscript $i$ the country.

It is important to stress the fact that the denominator is defined in terms of the total labour force, and thus also includes the unemployed population. The rationale behind this is that workers that do not find any job opportunity in the labour market should also be considered as part of the "traditional" or unproductive sector ${ }^{70}$.

The second dimension (technological knowledge) is much more difficult to capture, since it refers to a complex concept that cannot be directly measured. Following the standard literature on this issue, this dimension will be proxied by the relative labour productivity of the domestic modern sector compared to the same sector in the world leading economy. This, of course, is a crude measure of technological performance. In particular, it does not distinguish between the development of new technologies and the more extensive use of already existing ones (embodied technological change through capital intensification) ${ }^{71}$. In this sense, we assume that labour productivity indirectly reflects the level of technological knowledge embedded in the production of those goods that are produced within the MMA aggregate. But we should keep in mind that our operational definition for this dimension en-

MMA the whole sector $K$. This, however, should not introduce an important bias, since employment in Real Estates (as opposed to Value Added) is typically negligible.

${ }^{69}$ Note that this aggregate not only includes activities such as traditional small holder agriculture or informal sector services, but also productivity resistant sectors such as government or restaurants. These are not strictly 'traditional', but they are included here because they do not have the potential to drive aggregate growth through their productivity dynamics.

${ }^{70}$ See McMillan and Rodrik (2011) for an enlightening discussion on this issue. Note that our nonmodern sector is broader than the "traditional" sector in older dual economy models.

${ }^{71}$ A detailed discussion on the use of labour productivity as a proxy for technological capabilities can be found in Szirmai (2015), chapter 4. 
tails a broader conceptualization of technological change than in CHAPTER 3. In particular, productivity gains due to capital intensification will also be considered as technological improvements. Hence, our key variable to analyse the technological dimension is the relative labour productivity of the modern activities with respect to the world frontier. Following again the nomenclature of our model, it will be denoted with the Greek letter Rho. That is:

$$
\rho_{t}^{i}=\frac{P_{M, t}^{i}}{P_{M, t}^{f}}
$$

Where $P_{M}$ stands for the labour productivity in modern activities and the superscript $f$ stands for the frontier or leading economy.

The use of this proxy, however, is not without difficulties. First and foremost, the aggregate to be compared should be composed by exactly the same set of activities in the domestic and the leading economy. Therefore, especial care should be taken when building the dataset in order to work with comparable sectoral aggregates. In addition, the corresponding measures of labour productivity should be valued in a currency that is internationally comparable. Since the goal is to compare specific parts of the economy, from the production side, it is important to use sector-specific conversion ratios. In order to address this second problem, the productivity measures are first calculated at sectoral level in local currency units (LCU) and then converted into an international currency using the multilateral industry of origin PPP convertors published in Inklaar and Timmer $(2012)^{72}$. The resulting figures at PPP dollars are then aggregated into the MMA sectoral aggregate to estimate the corresponding index of relative labour productivity.

For every country of our sample we start by estimating the value added per worker (at current local currency units) in each sector that is part of the MMA aggregate, for the benchmark year 2005:

$$
P_{j, l c u}^{i}=\frac{Y_{j, l c u}^{i}}{N_{j}^{i}}
$$$$
\mathrm{j}=\mathrm{C}, \mathrm{D}, \mathrm{E}, \mathrm{F}, \mathrm{I}, \mathrm{JtK}-70
$$

where, $Y$ stands for the sectoral value added and the subscript $j$ identifies each of the six sectors that compose the MMA aggregate (as detailed in Table 4.1). The subscripts $l c u$ in $P$ and $Y$ indicate that these measures are expressed in local currency units.

\footnotetext{
72 In fact, these are expenditure PPP convertors that have been adjusted to match as closer as possible with industry of origin PPPs. In particular, trade and market margins have been peeled off and specific corrections have been done to account for the relative prices in intermediate (domestic and imported) goods.
} 
Then we convert these figures into international dollars using the sector-specific convertors of each country $\left(P P P_{j}^{i}\right)$ :

$$
P_{j}^{i}=\frac{P_{j, l c u}^{i}}{P P P_{j}^{i}} \quad \quad \mathrm{j}=\mathrm{C}, \mathrm{D}, \mathrm{E}, \mathrm{F}, \mathrm{I}, \mathrm{JtK}-70
$$

These figures at 2005 international dollars are then back cast and extrapolated using the corresponding growth rates of sectoral labour productivity in order to cover as many years as possible within the period 1950-2009.

Once the sectoral productivities have been calculated for each country/year, we estimate our measures of labour productivity in the modern market activities, simply as a weighted sum, using the sectoral shares in total MMA employment as weights:

$$
P_{M, t}^{i}=\sum_{j} s_{j, t}^{i} P_{j, t}^{i} \quad \quad \mathrm{j}=\mathrm{C}, \mathrm{D}, \mathrm{E}, \mathrm{F}, \mathrm{I}, \mathrm{J}, \mathrm{K}-70
$$

where $s_{j, t}^{i}$ stands for the share of employment of sector $j$ in total employment of MMA in country $i$ for the year $t$.

Finally, to compute our index of relative productivity in MMA, we need to estimate the world technological frontier at every point of time. This is done by identifying the country that has the highest $P_{M, t}^{i}$ in each year:

$$
P_{M, t}^{f}=\max \left(P_{M, t}^{i}\right)
$$

Dividing the domestic productivity in modern activities by the frontier value yields the relative productivity of each country in each year as specified in equation (4.2).

The fact that we compute the frontier in this way entails that the leading economy is not necessarily always the same one. Moreover, the leader might not have the highest productivity in every single sector that composes the MMA aggregate. Since this aggregate also includes heterogeneous activities, the leader might have the highest productivity not because it represents the frontier in every sector, but because its sectoral composition is heavily oriented towards the sectors with the highest productivity in absolute terms (in which it should represent the frontier or be close to it). In this chapter, we do not distinguish these effects (structural composition as opposed to sector-specific catch up), since we only look at the aggregate of modern market activities. This, however, is a very important point that will be addressed in detail in CHAPTER 6. 
Using these two indicators we derive our measure of structural modernization by simple multiplication:

$$
\Omega_{\mathrm{t}}^{\mathrm{i}}=\lambda_{t}^{i} * \rho_{t}^{i}
$$

The index of structural modernization $(\Omega)$ proposed in this chapter is thus the relative productivity of modern activities weighted by their share in total labour force. Interestingly, the proposed index not only combines the dimensions previously described, but also assigns different degrees of importance in the final value depending on the relative levels of each dimension. Since the components of the index are two positive values that can only range between 0 and 1 , the resulting index is convex to the origin. That is, it will always reward balanced situations (e.g. situations in which the relative size of the modern activities and their technological gap are not very different) and penalize situations in which only one of this dimensions is large while the other is very small. Therefore, a country that either has a very large modern sector that is completely behind in terms of technological sophistication, or an extremely productive modern sector that accounts for only a minor part of the economy will typically rank lower according to this index than an economy that has a medium-size MMA with a relatively large (but not extreme) technology gap. The following figure illustrates this feature and introduces the main graphical tools that will be used throughout this chapter:

Figure 4.1. Structural Modernization Landscape: Level curves and structural trajectories

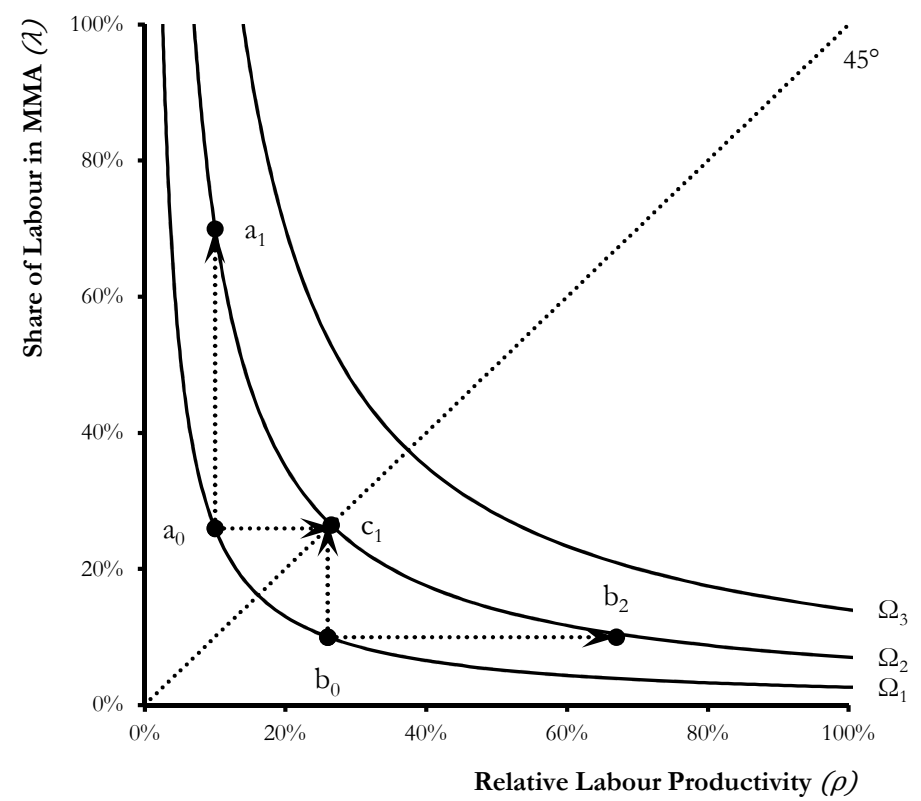


The figure shows what we will from now on refer to as the Structural Modernization Landscape. Each point in the landscape gives a certain combination of values for the two dimensions of our structural modernization index. That is, a value for the share of modern activities in total labour force $(\lambda)$ and a value for the relative labour productivity of these activities with respect to the leading economy $(\rho)$. The different curves in the landscape $\left(\Omega_{1}<\Omega_{2}<\Omega_{3}\right)$ give different combinations of $\lambda$ and $\rho$ for which the structural modernization index has the same value. Hence, they represent the level curves (or contours) of the structural modernisation index. In the landscape we have also drawn five points, indicating different positions in which an economy could be at different points of time. The movement from one point to another (from $a_{0}$ to $a_{1}$, for example) will hereafter be referred to as a structural trajectory. The trajectory indicates the main structural changes in a given economy between two (or more) points in time. Finally, the landscape is divided in two major areas by the 45 degree line.

Given the convexity of the index, on the left-hand side of the diagonal increases in $\rho$ are relatively more important than increases in $\lambda$ and the other way around on the right-hand side. This is illustrated in a comparison of structural trajectories $\left(a_{0} ; a_{1}\right)$ and $\left(a_{0} ; c_{1}\right)$. Starting from $a_{0}$ the change needed in $\lambda$ to increase the structural modernization index from $\Omega_{1}$ to $\Omega_{2}$ is much larger (in percentage points) than the change needed in $\rho$. The opposite holds on the right side of the 45 degree line, as the comparison between trajectories $\left(b_{0} ; b_{1}\right)$ and $\left(b_{0} ; c_{1}\right)$ illustrates. The position of a country at either side of the diagonal provides a rough indication of the dimension that it needs to improve most urgently to increase its level of structural modernisation. However, it should be noted that the weights given to $\rho$ and $\lambda$ in the construction of the index are somewhat arbitrary. If fact, we are working with the (implicit) assumption that the effort needed to improve each of these dimensions is comparable. If, instead, improving one dimension (for example, expanding the modern sector) would demand more efforts than improving the other dimension (for example, reducing the technological gap), then the dimension that is more difficult to improve (in the example, $\lambda$ ) should receive more weight in the index. Since we do not have a metric to measure these relative efforts we decided to keep the simplest weighting scheme possible and assign equal weights to the each of the two variables $^{73}$. Therefore, the position in the landscape will be taken as an indicative (but not conclusive) element in what follows. As we will show in Sections 4.4 and

\footnotetext{
$73 \mathrm{~A}$ more general formulation of the index would be given by the following expression: $\Omega_{\mathrm{t}}^{\mathrm{i}}=\left(\lambda_{t}^{i}\right)^{a} *\left(\rho_{t}^{i}\right)^{b}$ where $a$ and $b$ would indicate the weights give to each variable in the construction of the index. In Equation (4.7) we assume that $a=b=1$.
} 
4.5, this graphical tool is useful to characterize the development path followed by different economies in international comparisons and across time.

\subsubsection{Defining the development traps}

One goal of this chapter is to study the structural trajectories (in the terms described above) of those countries that are caught in a certain development trap (either a poverty trap or a middle-income trap). Therefore, an operational definition of those traps and an analytical metric to classify countries in low, middle and high incomes is needed. From the various perspectives reviewed in CHAPTER 2, Section 2.2.2, this chapter builds on the one developed by Felipe (2012).

Our metric to classify countries by income category heavily relies on the classification used by the World Bank. For more than three decades, this organization has been publishing a country classification by income category that encompasses four major categories: low, lower-middle, upper-middle and high incomes. These categories are defined in terms of the per capita gross national income (GNI) of each country estimated using the so-called Atlas method. The income categories have been historically defined based on the relationship that exists between GDP per capita and other summary variables of well-being such as poverty incidence or infant mortality. The original thresholds have been then updated every year to incorporate the effects of international inflation and therefore they remain constant in real terms over time (World Bank, 2014).

Unfortunately, the threshold levels of GDP per capita used by the World Bank are only published since 1987. In order to cover a longer time span (in particular, to extend the analysis back to 1950 onwards), a procedure is needed to calculate the income thresholds on the basis of an international comparable measure available for the whole period. Our income measure is the GNI per capita at constant PPP dollars of 2005 from the World Bank World Development Indicators ${ }^{74}$. Like Felipe (2012) we define the PPP income thresholds in 2005 constant PPP dollars in such a manner as to get the maximum correspondence between the country classifications based on our method and the country classifications based on the original World Bank methods for the period 1987-2013. This is done ad-hoc, experimenting different threshold levels and checking the number of coincidences obtained along that period. The thresholds identified using this procedure yield a $90 \%$ of coincidence in the classification of countries as compared to the original classification published by the World Bank. These thresholds are subsequently used for all years of our period (1950-2013).

\footnotetext{
74 This dataset starts in 1960. Therefore, three additional sources have been used to expand its coverage both along time and across countries. See Appendix E.1 for the details.
} 
The identified thresholds are the following (in 2005 PPP dollars): low income (less than 2.250 PPP dollars), lower-middle income (between 2.250 and 7.249 PPP dollars), upper-middle income (between 7.250 and 14.999 PPP dollars) and high income (15.000 PPP dollars and above). Next, by means of these thresholds, we determine the yearly income category of each country between 1950 and 2013. In many cases, the income category varies from year to year due to cyclical movements in per capita GNI. To avoid these fluctuations in the yearly income classification, we eliminate isolated downturns ${ }^{75}$ and only upgrade the income classification of a country if it does not fall back into a lower category in the remaining years of the period 1950-2013. According to this rule, a country can only graduate once from a given income category to the one above it during the period studied ${ }^{76}$. Therefore it is possible to pinpoint the exact year in which this change takes place. More important for our procedure, it is possible to unambiguously calculate the number of years that each country of our sample has been classified as low, lower-middle, upper-middle and/or high income economy during the period.

Once this is calculated we can develop an operational definition of middleincome traps. Our approach is based on Felipe (2012), but with some modifications. As stated in CHAPTER 2, Section 2.2.2, Felipe uses the median number of years needed to graduate for the countries that actually graduated from one category to another within the period of analysis, as a benchmark. Any country that is classified as a middle-income country for more than the median number of years, is considered to be caught in a middle-income trap. One disadvantage of this procedure is that it might overestimate the number of countries really caught in the MIT. An economy that takes a few more years than the median to graduate to a higher income category can hardly be considered trapped. To minimize this potential misclassification, we use a more conservative approach: instead of using the median duration of graduation, we take the average number of years needed to graduate by the upper quartile of the distribution of countries that have graduated to a higher income category between 1950 and 2013. We only consider a country as trapped if it has been in a given category more years than the slowest $25 \%$ of countries that managed to make the transition during the period under analysis.

A second adjustment to the Felipe's procedures deals with the countries that have transited to their current income category within a time frame that is shorter than the corresponding threshold. These countries would be classified as not

\footnotetext{
75 These are defined as drops in a category for only one or two years in a window of 5 years.

${ }^{76} \mathrm{It}$ is important to notice that by using this procedure we are excluding the possibility of a country following a falling behind trajectory. That is, a country first upgrading to a higher income category and later slipping back to a lower income category for a long period of time. Even though this only happens rarely (in our sample it can be observed especially in some transition economies after the fall of the Soviet Union), we aim at including this type of trajectories as well in future work.
} 
trapped per definition. However, in reality these countries might have also fallen into a middle-income trap. Whether this is the case depends on the speed of economic growth they will show in the years to come. If they do not grow fast enough, they will be also captured in the MIT. In order to incorporate these cases, we project the number of years that these countries would need to graduate from their current income category to the next one under the assumption that they will maintain the growth rate of the last two decades ${ }^{77}$. If the estimated number of years in that a country is projected to stay in the same income category exceeds the benchmark duration, this country will also be classified as being caught in the MIT. Since the classification is based on a projection, in our analytical sections we will carefully distinguish both situations (i.e., the countries actually trapped and those that might be potentially trapped according to our projections of future growth). These procedures apply to middle-income traps. We distinguish a lower-middle-income trap (a country takes too long to graduate from the lower middle income to upper middle income category) and an upper middle-income trap (the country takes too long to graduate from the upper middle-income category to the high income category).

Finally, an operational definition is also needed for the poverty trap -countries that are trapped in the low-income category (Felipe's procedures only apply to middle-income traps). In this case, we had to use a slightly different procedure than for the countries in the middle-income trap. Since there is no income category below low-incomes, we do not know when a country entered the low-income category. Therefore, we can also not calculate how long it takes for a country to graduate to the lower-middle income category. However, assuming that growth rates of the past two decades will be maintained, we can project the number of years that the current poor countries will need to surpass this income category. Having estimated the number of years to graduation for all the low-income countries of our sample, we can again examine the corresponding distribution and establish a threshold to distinguish between low-income countries in the way to becoming middle-income economies and low-income countries actually trapped in poverty. Our criterion here is to include in the Poverty Trap all countries located in the upper quartile of this distribution ${ }^{78}$.

Summing up, a country is considered to be in a lower-middle-income trap (LMIT) if, in 2013, it has been in that category for more years than the average needed by the slowest countries that graduated from that category between 1950 and

\footnotetext{
77 That is, the estimated number of years is calculated taking the average annual growth rate of per capita GNI observed between 1993 and 2013. The projections have also been done using the average growth rates of other periods (1998-2008, 2003-2013 and 2010-2013) and the results do not change significantly.

78 Other measures have also been explored. Using the median or the average of the distribution plus half standard deviation also yields similar results.
} 
2013. By the same token, a country is considered to be in a upper-middle-income trap (UMIT) if in 2013 it was already categorized as upper-middle income country for more years than the average of the slowest countries that managed to graduate to high incomes between 1950 and 2013. A country is projected to be in a LMIT if the estimated number of years that it will be in that category (assuming the same growth rate of the last two decades) is larger than the benchmark previously defined. Similarly, a country is projected to be in the UMIT if the estimated number of years that it will be in that category (once more, assuming the same growth rate of the last two decades) is larger than the corresponding benchmark. Finally, a country is considered to be in a poverty trap (PT) if the projected number of years needed to surpass the low-income category lies at the upper quartile of the distribution of projected years needed to graduate for all the low-income countries of our sample.

\subsubsection{The dataset}

One of the contributions of this chapter is the construction of a very large data set with international comparable data on employment and value added by sector (10 sectors previously defined) and unemployment. These are the variables required for the construction of the modernisation index described above.

In short, the dataset contains information for 100 countries over the period 1950-2009. The coverage for each individual country, however, varies significantly in accordance to data availability. On average, the number of years covered is 30 . In order to minimize potential noise in the estimates, all variables have been calculated as averages over five-year periods, starting in 1950 and ending in 2009. Thus we have a total of twelve periods, covering the last six decades.

This dataset has been constructed using a wide array of sources. The approach, in all cases, was to build a benchmark estimate for the year 2005 using the best available information and then extrapolate these estimates to the other years using indices of growth at constant prices (in the case of value added) or employment, at sectoral level. The benchmark estimates for 2005 were first calculated in current LCU and then converted (at sectoral level) into PPP international dollars using the sector-specific ratios estimated by Inklaar and Timmer (2012).

For 42 countries for which the data was available, these estimates have been done at a larger disaggregation of 35 -industries ${ }^{79}$. For the remaining countries, sector specific conversion factors at the 10 broad sectors previously detailed were used.

\footnotetext{
${ }^{79}$ The higher sectoral disaggregation of these countries will be "exploited" in the analysis of structural change within MMA undertaken in CHAPTER 6.
} 
Due to international comparability, information quality and data disaggregation, the following sources have been given priority when constructing the figures on sectoral value added and employment (in this order) ${ }^{80}$ :

1) World Input-Output Database (WIOD) ${ }^{81}$

2) Asia, EU and World KLEMS Databases (KLEMS) ${ }^{82}$

3) OECD Structural Analysis Database (STAN) $)^{83}$

4) Groningen Growth and Development Centre, 10 Sector Database $(\text { GGDC10s) })^{84}$

5) Asian Productivity Organization Database (APO) $)^{85}$

Using these sources it is possible to cover a total of 76 countries (35 advanced and 41 developing economies). Given the overrepresentation of advanced economies, several additional sources have been used to increase the number of developing economies included in the sample:

1) Asian Development Bank Key Indicators for Asia and the Pacific Database (KIAP) 86

2) EUROSTAT Database (Modules for non-EU countries) ${ }^{87}$

3) United Nations Economic Commission for Latin America and the Caribbean Statistical Database (CEPALSTAT) ${ }^{88}$

4) United Nations Economic Commission for Africa: UNECA (2005)

5) United Nations Statistical Division, National Accounts Database ${ }^{89}$

\footnotetext{
${ }^{80}$ For certain countries these sources have been complemented with information directly published by the National Statistics Institute (NSI) or other contributions that have specifically dealt with this issue. NSI data has been used for Argentina, Chile and Vietnam. In the cases of Brazil, China and India we have also used the dataset put forth in de Vries et al. (2012). Finally, data for Turkey was complemented with the dataset built by McMillan and Rodrik (2011).

81 Available at www.wiod.org. See Timmer (ed) (2012) for details.

82 Available at asiaklems.net, euklems.net and worldklems.net respectively.

83 Available at stats.oecd.org

${ }^{84}$ Available at www.ggdc.net. See Timmer et al. (2014) for details.

85 Available at www.apo-tokyo.org/about/measurement.html

86 Available at www.adb.org/data/statistics

87 Available at epp.eurostat.ec.europa.euu. In particular, we used the data referred to these subsets of countries: Southern European Neighbourbood Policy countries (MED), Candidate countries and potential candidates (CPC), and Eastern European Neighbourbood Policy countries (ENP).

88 Available at www.estadisticas.cepal.org

${ }^{89}$ Available at unstats.un.org
} 
6) International Labour Organization, Key Indicators of the Labour Market Database (KILM8) 90

Using these additional sources we managed to build a consistent and international comparable dataset that encompasses 100 countries (36 advanced and 64 developing countries). The details on the specific sources and procedures used for each country/period and the final coverage for that country are presented in APPENDIX E, at the end of the thesis.

As we have already stressed before, our index to capture structural change is based on the number of workers in modern market activities as percentage of total labour force. This means that the denominator of our index includes not only employed but also unemployed population. Hence, figures for the unemployed population are also needed. Since the most widely available indicator in this regard is the unemployment rate, our strategy to estimate these figures is to make use of this rate and the total employment figures calculated before. Recalling that the unemployment rate is defined as the share of unemployed population over total labour force,

$$
u_{t}^{i}=\frac{U_{T, t}^{i}}{L_{T, t}^{i}}
$$

where $U_{T, t}^{i}$ stands for the total number of unemployed people in country $i$, in year $t$. Then by simple algebraic manipulation we can obtain an expression for the unemployed population that depends on the variables that we actually have ${ }^{91}$ :

$$
U_{T, t}^{i}=\frac{u_{t}^{i}}{1-u_{t}^{i}} N_{T, t}^{i}
$$

where $N_{T}$ stands for the total number of employed people.

In order to estimate the unemployed population, therefore, significant efforts were devoted to construct long series of unemployment rates that were comparable both across countries and over time. This was not an easy task and in many cases the results should be interpreted with some caution. Still, the trends seem to be in line with historical records. In building these series, we also made use of a wide array of sources (see Section Appendix E.3 for the details).

Unfortunately, in many countries the constructed series of unemployment rates cover a shorter period than our estimates for sectoral employment and value added. Therefore, for the country/years in which data on employment was available but no data on the unemployment rate could be gathered (typically developing countries in the 1960s and 1970s), the unemployed population was back cast using the growth

\footnotetext{
${ }_{90}$ Available at www.ilo.org/kilm

${ }_{91} \frac{U_{T, t}^{i}}{L_{T, t}^{i}}=\frac{U_{T, t}^{i}}{N_{T, t}^{i}+U_{T, t}^{i}} \Rightarrow u_{t}^{i}\left(N_{T, t}^{i}+U_{T, t}^{i}\right)=U_{T, t}^{i} \Rightarrow u_{t}^{i} N_{T, t}^{i}=\left(1-u_{t}^{i}\right) U_{T, t}^{i} \Rightarrow U_{T, t}^{i}=\frac{u_{t}^{i}}{1-u_{t}^{i}} N_{T, t}^{i}$
} 
rates of total employment, under the assumption that the unemployment rates have not changed significantly during these years.

\subsection{Structural Change and Development}

Structural change has been typically analysed as the changes that take place in the sectoral structure of employment or output as countries develop. Following the classical models of dual-economy, in this chapter we take the perspective that employment is the key variable to look at. As we have previously stated, this emphasis comes from the understanding that the crux of development lies on the capacity of the economic system to productively absorb an increasing number of its labour force in the modern sector.

The emphasis in the development literature has been typically placed on industry (or more restrictively, on manufacturing). In order to also incorporate modern services we rather focus on the aggregate of modern market activities. Figure 4.2 compares the evolution of both shares as countries get richer ${ }^{92}$. It presents the relationship between the level of per-capita GNI at constant 2005 PPP dollars (x-axis) and the corresponding share of industry and MMA on total labour force (y-axis). Each dot in the figure shows the average values of one country over a five-year period between 1950 and 2009. Three vertical lines crossing the horizontal axis divide the figure in the income categories previously defined: low $(L)$, lower-middle $(L M)$, upper-middle $(U M)$ and high $(H)$ incomes. In all figures presented in this section we also include the fitted curves obtained by locally weighted regressions (lowess) ${ }^{93}$. These curves facilitate the visualization of the main patterns that can be derived from the data, without imposing any prior specification on the nature of the relationship ${ }^{94}$.

\footnotetext{
92 All figures presented in this section exclude the United States (because it is taken as the benchmark for comparison in the productivity measures) and two outliers: Iran and Venezuela. These outliers presented extremely high levels of relative productivity in MMA exclusively due to their abundance of oil.

${ }^{93}$ Lowess stands for "locally weighted scatterplot smoothing" and is a non-parametric method to fit a smooth curve. In short, it fits polynomial regressions to localized subsets of the data and joins them together. By doing so, it gives smaller weights to the observations that are more distant from each subset. Therefore, the shape of the fitted curve at high (low) values of the explanatory variables is not affected by the points corresponding to low (high) values. See Cleveland (1979) for the details and Carmignani and Mandeville (2010) and Eichengreen and Gupta (2011) for recent applications of this method in the analysis of structural change.

${ }^{94}$ All fitted curves have been calculated using Stata 13.0 with the default options (bandwidth of 0.8 and Tricube Weighting Scheme). Other bandwidths and weighted schemes were also explored and gave similar results.
} 
Figure 4.2. Share of labour force in Modern Market Activities (MMA) and Industry by levels of per capita Gross National Income (GNI), at constant PPP dollars of 2005. Five year averages between 1950 and 2009 for 97 countries.

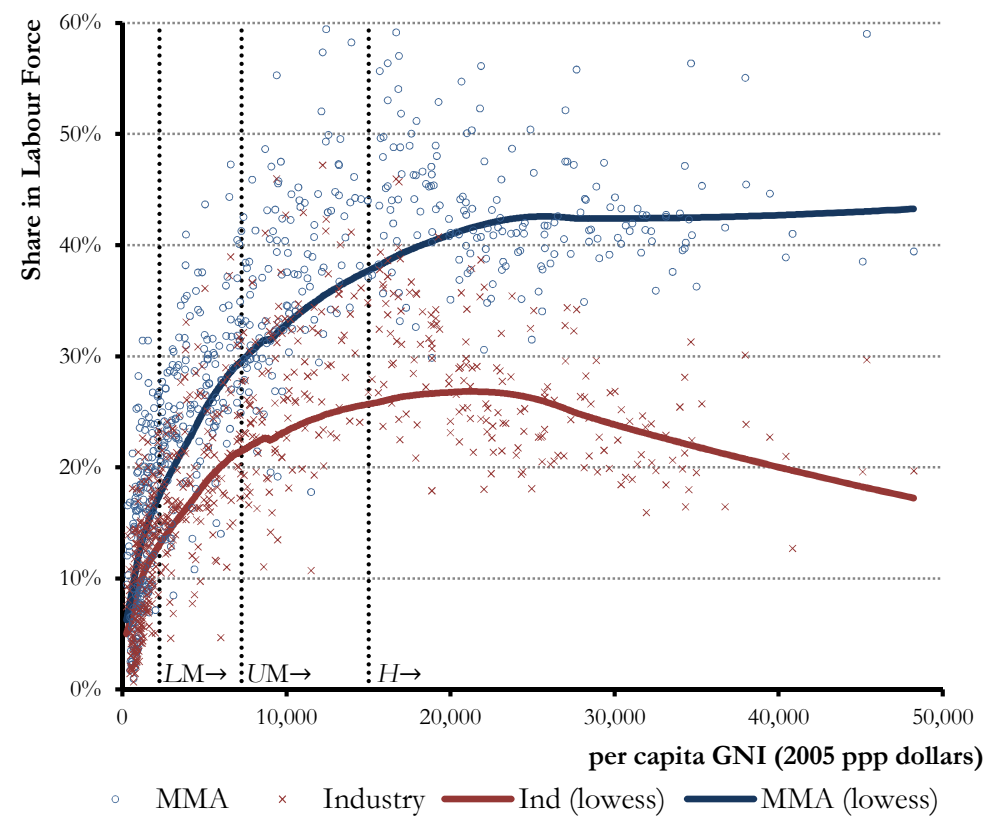

For industry, the figure clearly illustrates the well documented inverted-U shape as country develops. The fitted curve for the share of the industrial labour force grows steadily at initial and medium levels of incomes, reaches a maximum at about 21.000 dollars and then starts declining. Perhaps more interestingly, the figure suggests a different pattern in the MMA aggregate. At initial and medium levels of incomes, it also grows steadily but at a faster pace, pointing to the increasing importance of non-industrial modern activities. Then, it gradually decelerates and at about 22.000 dollars it reaches a plateau and stays at a relatively steady level. Hence, in clear contrast with Industry, the aggregate of modern activities does not show any clear turning point. According to the fitted curve, this steady level would be around $42 \%$ of total labour force.

This contrasting behaviour is explained by the dynamics of the modern services, whose share continues to grow even at very high levels of income, partially (or totally, depending on the case) counterbalancing the decline in industry.

The fact that beyond a certain point the share of modern activities in total labour force bends and becomes flatter indicates that above a certain level of income, structural composition no longer varies with income. Once a country has graduated to the high-income category, further increases in the share of the modern sector are no longer correlated with income. Other factors seem to become more important. 
The figure also shows that almost no country achieves high income levels without having a modern sector of at least 35 to $40 \%$ of the labour force. However, a large modern sector is not sufficient for achieving high incomes. There are many country observations in middle-income ranges with a labour share in modern activities larger than $40 \%$.

As we have previously stated an important part of the story still missing in Figure 4.2 is the size of the technological gap. Therefore, it is important to look simultaneously at how far each economy is from the world technological frontier in the production of these goods (that is, once the traditional and non-market sectors are excluded). As stated in Section 4.2.1, our proxy variable to analyze this phenomenon is the relative labour productivity with respect to the world frontier that, according to our estimates, in all years considered is the United States. The following figure presents the relationship between this variable and the level of per capita income:

Figure 4.3. Relative labour productivity in Modern Market Activities (MMA) by levels of per capita Gross National Income (GNI), at constant PPP dollars of 2005. Five year averages between 1950 and 2009 for 97 countries.

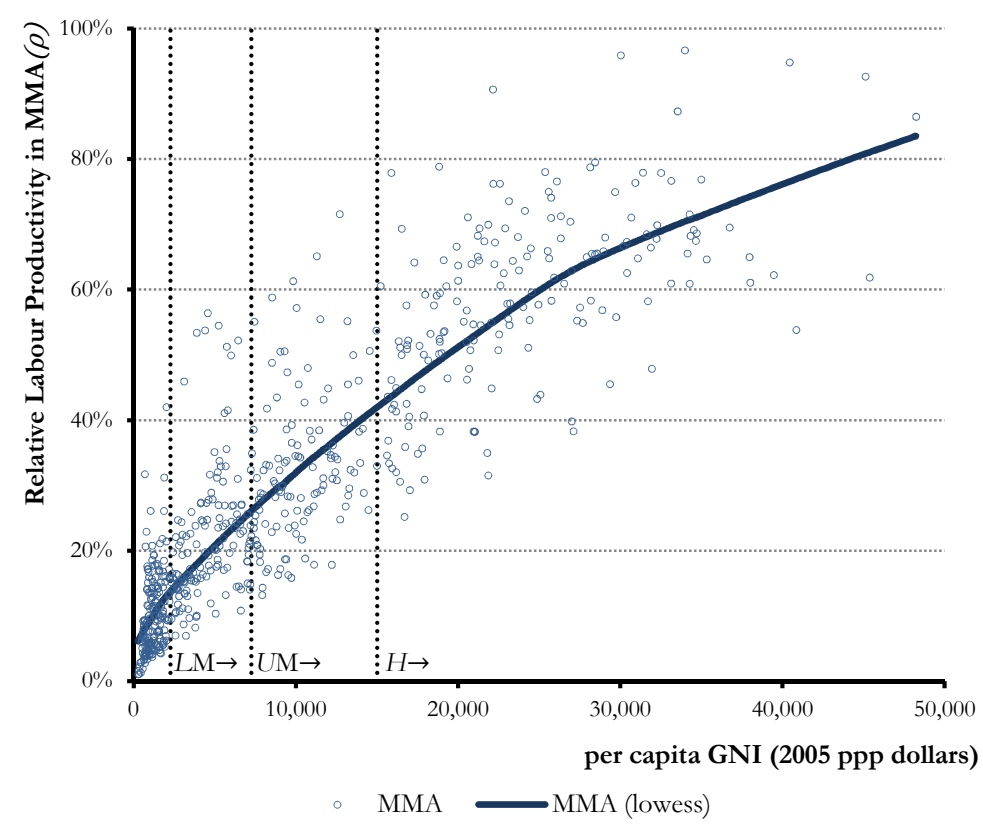

Not surprisingly, Figure 4.3 presents evidence of a very strong positive correlation between our proxy of relative technological knowledge in modern activities and the 
level of incomes ${ }^{95}$. Moreover, this remains positive even at upper middle and high levels of income, providing further evidence on the fundamental role that technological catching up plays once the low and lower-middle income ranges are surpassed.

The evidence presented in the previous figures provides support for the idea that an index of development that combines both features (the relative importance of the modern activities in total labour force and their distance to the technological frontier) is well suited to capture the complex dimensions of structural transformation in a single measure. The following figure presents the relationship between our index of structural modernization and the level of per capita incomes in our sample of countries.

Figure 4.4. Structural modernization index by levels of per capita Gross National Income (GNI), at constant PPP dollars of 2005. Five year averages between 1950 and 2009 for 97 countries.

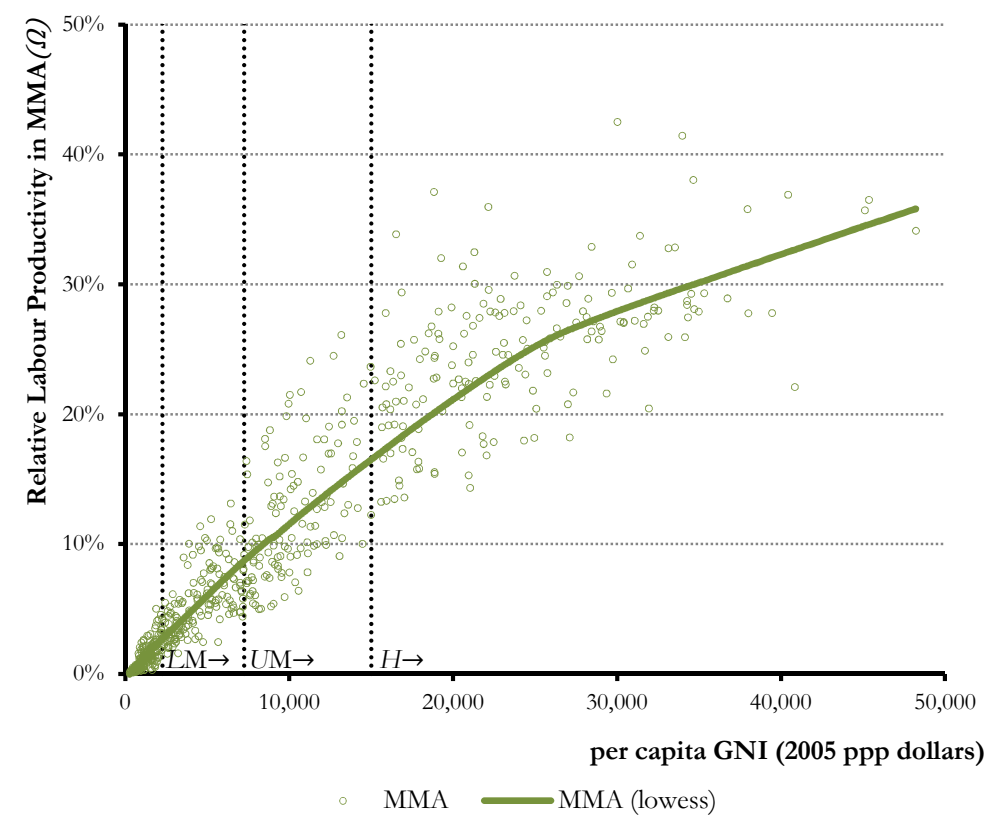

\footnotetext{
${ }^{95}$ It should be noted, however, that part of this high correlation is explained by the fact that richer countries have, at the same time, higher levels of capital-intensity. As we mentioned in Section 4.2.1, our proxy variable (relative productivity) captures a broad concept of technological change that also includes capital intensification.
} 
As we can see, a clear positive and slightly decreasing relationship can be observed between our index of structural modernization and the level of incomes. Again, this relationship seems to grow steadily, at a very similar rate across low, lower-middle and upper-middle ranges of income. Once the economy has surpassed the 25.000 dollars of per capita income, the slope of the fitted curve seems to decrease slightly, but the positive relationship stays quite strongly. As further indications of this positive correlation, we have explored the goodness of fit when imposing a quadratic functional form on the relationship, and it yields a very good fit, with an R-square of about $0.90^{96}$.

In what follows we will use the two main components of our index of structural modernization to study in more detail the countries caught in some sort of development trap. In particular, we will try to address the following research questions: a) Are certain regions of the $(\lambda, \rho)$ landscape associated with low- and middleincome traps? And if so: b) Is it possible to establish a typology of countries according to their position in that landscape?

\subsection{Development Traps}

In a first approximation, the figures presented in the previous section could be interpreted as reflecting a series of structural transformations that countries would typically undertake in their transition from low to middle and then high-income status. As we have previously stated, however, some observations in these figures could also represent countries that are unable to make such transformations and therefore cannot move upward in the income ladder.

Both situations are actually coexisting in the figures and can only be disentangle by means of a proper and manageable definition of low and middle-income traps. As we have detailed in Section 4.2.2, in this chapter we use a modification of the approach developed by Felipe (2012) and we define these traps according to the number of years that a country has been categorized within a certain income level. Following the procedure already explained we have identified the following thresholds: 31 years for the upper-middle-income trap, 41 years for the lower-middleincome trap and 27 years for the poverty trap ${ }^{97}$.

Thus, any country that in 2013 has been classified as upper-middle income for more than 31 years is categorized as being in the upper-middle-income trap. By the

\footnotetext{
${ }^{96}$ Interestingly, if we impose a quadratic relationship to the previous figure we also get a very good fit, but with a lower R-square (0.81). This would suggest that our index of modernization is better suit to capture the transformations that take place as countries get richer.

${ }_{97}$ The detailed tables and corresponding distributions used to define these thresholds can be found at Appendix B.1.
} 
same token, any country that in 2013 has been classified as a lower middle-income country for more than 41 years is categorized as being in the lower middle-income trap. As we have previously explained, we also consider the cases of those countries that have recently turned into a new income category but, given their slow growth rate in the last decades, are likely to be trapped as well in one of these middleincome traps. In these cases, we project the total number of years that they will be in that particular income category by using the average annual growth rate of the period 1993-2013. If that number is greater than the corresponding threshold, the country is also included among the trapped group.

Finally, all countries that in 2013 are classified as low-income and, according to our projections, will take more than 27 years to graduate from this category are considered as being caught in a poverty trap.

Using this procedure in our sample of 100 countries we have identified 52 countries that have successfully transited to a higher income level category during the period under analysis and do not show evidence of being currently trapped in that category. These successful cases are summarized in the following transition matrix. 
Table 4.2. Transition matrix for countries that have successfully improved their income category between 1950-2013 and are unlikely to be in the middle-income trap. 52 countries.

Ending Year

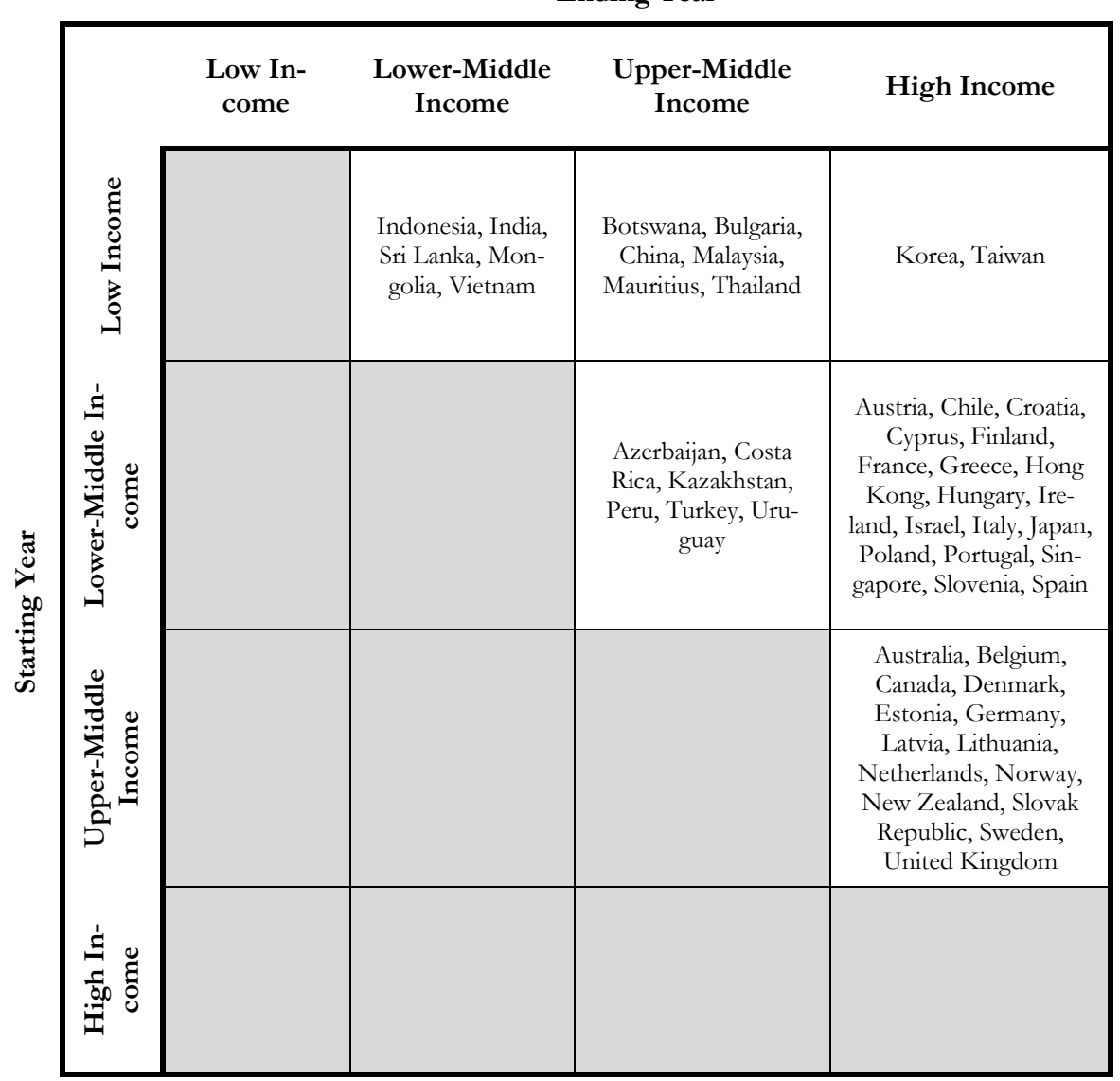

Each cell in the matrix lists those countries that have transited from the category stated in the rows to the category stated in the columns. Since we are only looking at successful cases (i.e., countries that improve their category), all countries that would fall in or below the main diagonal are not considered. Within these countries, the most successful are the ones that managed to move the greatest number of categories. These are the countries in the most upper-right cell: Korea and Taiwan. These are the only two economies in our sample that transited from low to high income status within the period studied. Next, we have countries that have climbed two categories, either moving from low to upper-middle income status (Botswana, Bulgaria, China, Malaysia, Mauritius and Thailand) or from low-middle to highincome status (Chile, Hong Kong, Israel, Japan, Singapore and thirteen other European countries). Finally, we have a series of 26 countries that have climbed up 
one category during the period. Perhaps the most interesting among them are those that have managed to escape from the poverty trap and today do not seem to be trapped at lower-middle income levels: Indonesia, India, Sri Lanka, Mongolia and Viet-Nam. Not surprisingly, all of them are located in Asia.

Contrasting with the successful cases, there are 30 countries of our sample that could be characterized as being caught in some sort of low- or middle-income trap. The following table lists these cases ${ }^{98}$ :

Table 4.3. Countries in a development trap. 2013, 30 countries.

\begin{tabular}{lll}
\hline Poverty Trap (9) & $\begin{array}{l}\text { Low Middle- } \\
\text { Income Trap (10) }\end{array}$ & $\begin{array}{l}\text { Upper Middle- } \\
\text { Income Trap (11) }\end{array}$ \\
\hline Kenya & Bolivia & Argentina \\
Madagascar & Egypt* & Brazil* \\
Malawi & Jordan & Colombia* \\
Mali & Moldova* & Ecuador* \\
Nepal & Morocco* & Macedonia \\
Niger & Namibia & Mexico \\
Rwanda & Pakistan* & Romania \\
Togo & Philippines* & Russia \\
Zambia & Ukraine* & Serbia \\
& Yemen* & South Africa \\
& & Venezuela \\
\hline
\end{tabular}

Note: the asterisk identifies countries that have been characterized as being in the MIT based on the projected number of years that they would still need to graduate from their current income category. See Table B. 3 in Appendix B.1 for the details.

The lists of countries detailed in each column of Table 4.3 are quite consistent with the secondary literature on country development performance. Starting form the last column, we note that many countries usually associated with the upper-middleincome trap are included in this group. Among the most invoked, we can mention Argentina, Brazil, Mexico, and South Africa. The same holds for countries that are

98 The remaining 18 countries of our dataset not included in Table 4.2 and Table 4.3 are: a) countries that had high income status right from the early 1950s (Switzerland and the United States), or from the beginning of our series of per capita GDP (Czech Republic); b) countries that have not change their category but does not seem to be trapped at middle incomes (Georgia); and c) countries that had low incomes in 2013 but according to our projections will surpass this category faster than the corresponding threshold used to determine the poverty trap (Bangladesh, Burkina Faso, Cambodia, Cameroon, Ethiopia, Ghana, Kyrgyz Republic, Lesotho, Mozambique, Nigeria, Senegal, Sierra Leone, Tanzania and Uganda). 
typically associated with the lower-middle-income trap, such as Bolivia, Jordan and Morocco. Regarding the poverty trap, although the countries identified also match with regular characterizations on this matter ${ }^{99}$, the number seems quite small. This is partially explained by the fact that the sample of countries included in our dataset is very likely biased towards the most successful countries within this category. Countries most likely trapped at low incomes are, at the same time, countries with the worst data on national accounts statistics and sectoral employment. Hence, many of these countries might have been excluded from our analysis simply because there was not enough available information to build the indicators needed for our structural characterization ${ }^{100}$. Therefore, the nine countries presented in the table should be considered as representative of a much broader universe of countries. Also note that we have used conservative thresholds for defining a trap, because we want to exclude countries that are slowly but steadily growing out of poverty.

Having disentangled the successful and unsuccessful cases that were presented together in the previous section, we can now focus on the latter in order to get a first impression on the importance of structural modernization in order to escape from poverty and middle-income traps. With this purpose, the next figure reproduces Figure 4.4 but only for those countries that are in some kind of development trap (i.e., the countries listed in Table 4.3). The importance of structural transformation stands out more clearly when we superimpose three thresholds indicating the minimum values of the structural modernization index that, according to our historical records, need to be surpassed in order to move from one income category to another. These thresholds are defined as the lowest value of $\Omega$ recorded across all countries of each income category (excluding low incomes) in the whole panel (that is, including also all observations between 1950 and 2009): 0.016 (lowest value recorded in the lower-middle income category), 0.05 (lowest value recorded in the upper-middle income category), and 0.13 (lowest value recorded in the high-income category) ${ }^{101}$.

\footnotetext{
${ }^{99}$ All of them, for example, are classified as Chronically Deprived or Chronically Partially Deprived countries by Anderson (2007) in a cluster analysis over 130 non-OECD countries between 1960 and 2003. With the only exception of Kenya, they are also classified as Least Developed Countries (LDCs) by the UN.

100 The following countries (not included in our dataset due to lack of information on sectoral employment and value added) would also fall into the category of poverty trap applying our criteria to their per capita GNI figures: Benin, Burundi, Central African Republic, Congo, Côte d'Ivoire, Dem. Rep. of Congo, Eritrea, Guinea, Guinea-Bissau, Haiti, Syrian Arab Republic and The Gambia.
}

101 These thresholds correspond to the following observations: $\Omega_{1}$, Vietnam in the period 2005-09; $\Omega_{2}$, Bulgaria in the period 2000-05; and $\Omega_{3}$, Lithuania in the period 2005-09. 
Figure 4.5. Structural modernization index by levels of per capita GNI at constant PPP dollars of 2005. Average values between 2005 and 2009 for countries in low or middle-income traps.

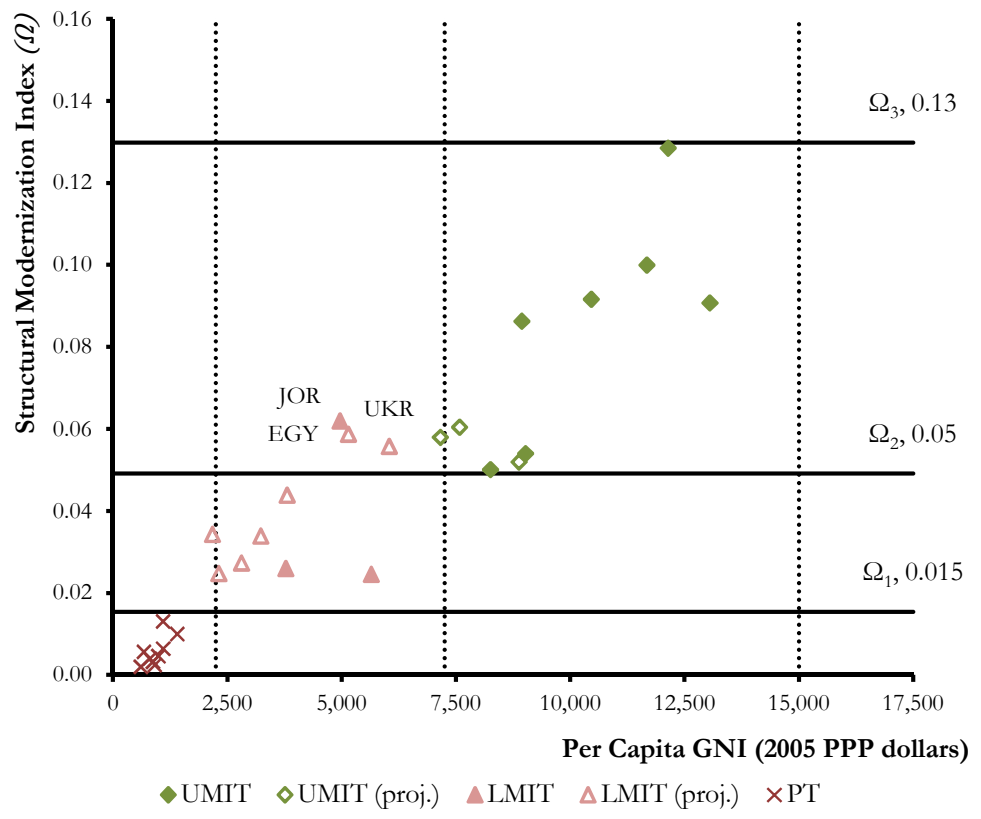

The observations of the figure are now divided in three broad groups in correspondence with the type of trap in which they are caught. For the middle-income traps, a further distinction is made between the countries that are actually in the trap and those that would potentially be trapped according to our income projections.

As we can see, all countries caught in a poverty trap have an $\Omega$ index lower than 0.016. In the case of the countries in the lower-middle-income trap, the threshold value of 0.05 seems to constitute more a necessary but not sufficient condition to escape from this situation. Three out of ten countries have an index value larger than the corresponding threshold, but nevertheless remained trapped in the lowermiddle income category in 2013 (Egypt, Jordan and Ukraine). Finally, in the case of the upper-middle-income trap, the threshold limit of 0.14 seems to be a clear barrier for the countries trapped in this situation. In this case, all countries lie below that limit. It follows that a common feature shared by almost every country that we have identified as being caught in a development trap is that they have been unable to achieve the necessary level of structural modernization.

This aggregate picture indicates the importance of structural modernization in the process of development. However, it says little about the relative importance of each dimension. A more accurate view can be obtained by looking at the structural modernization landscape (as introduced in Figure 4.1). The next figure depicts this 
landscape for the period 2005-2009 in the case of the countries caught in a development trap. It also includes the high-income economies to illustrate the position in the landscape occupied by successful countries.

Figure 4.6. Structural modernization landscape. Average values between 2005 and 2009 for high income countries and countries in a development trap.

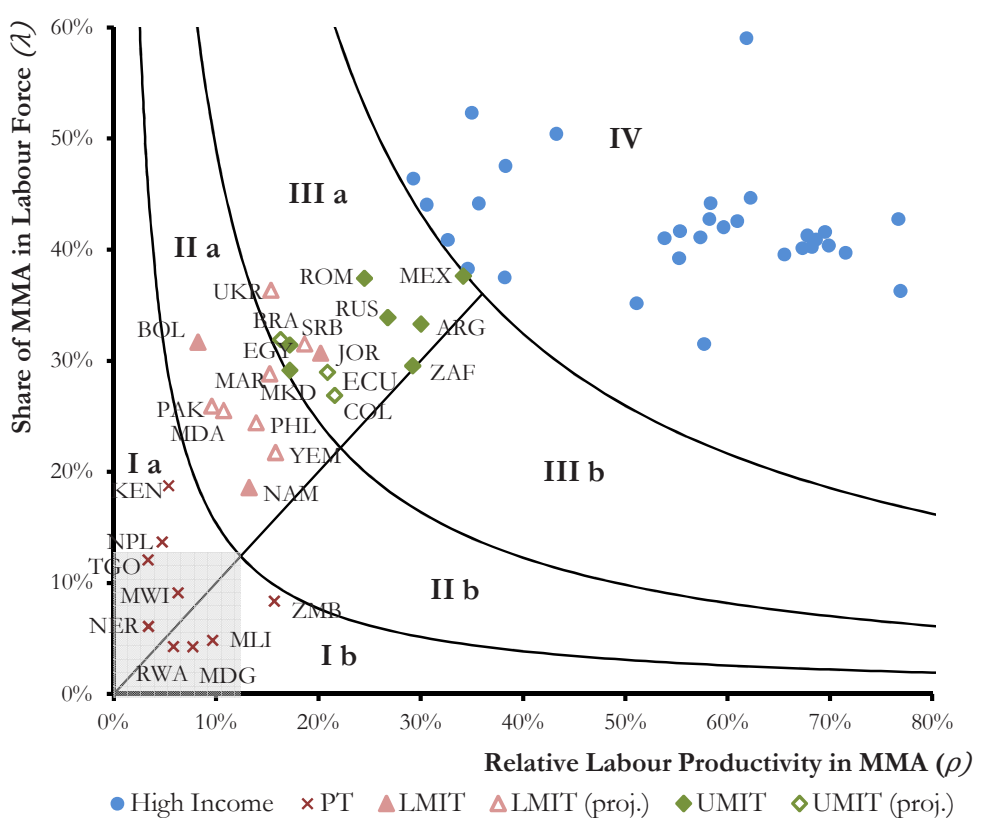

This figure is illustrative of a series of important characteristics that are worth exploring in detail. It provides graphical evidence about the interactive nature of structural change and technological catch-up in the context of economic development. In particular, it illustrates how different countries might get caught in a developmental trap if they are not able to perform a radical transformation of their productive structures. The figure has been divided in four regions based on the level curves (contours) of the structural modernization index that correspond to the thresholds presented in Figure 4.5. As explained before, each curve indicates the (observable) minimum value of $\Omega$ needed to move from one income-category to the next one. All regions below the third level curve have been further separated in two sub-regions by the 45 degree line, in order to stress the different relative importance of each dimension in achieving higher modernization level. To the left of this line (sub-regions $a$ in the figure), increases of $\rho$ would "pay off" more than increases in $\lambda$ in terms of the impact that this would have in $\Omega$. To the right of this line (sub-regions $b$ ), instead, increases of $\lambda$ would have a larger relative impact on 
the resulting index. The figure also distinguish a grey area in which both dimensions ( $\rho$ and $\lambda$ ) would be simultaneously lower than the minimum average needed to arrive to the first level curve. As we will see, this region is particularly interesting because it would contain the economies at the earliest stage of development.

Now, looking at each region we can find interesting clustering of cases. Starting from the upper right corner of the landscape (the peak of the three dimensional mountain), we can see that all high-income economies are located in Region VI. This, of course, is an outcome obtained by construction since the corresponding level curve has been constructed using the lowest level of $\Omega$ exhibited across all high income observations of our panel. Exactly at the opposite side of the landscape, in Region I (the foot of the mountain), we find all the countries identified as being caught in a poverty trap. Within this group, it is possible to differentiate three stylized cases. First, there are six countries (Mali, Malawi, Madagascar, Niger, Rwanda and Togo) in which the modern sector not only employs a negligible share of total labour force but also presents an extreme gap with respect to the world frontier. These are the countries located in the shaded region of the figure. Undoubtedly, these countries face the largest challenge ahead in terms of structural modernization. Secondly, there are two cases (Kenya and Nepal) that though having a very low index of structural modernization have a relatively large modern sector. These are the countries located in the non-shaded part of Region Ia. Contrasting with this case, a third stylized situation is illustrated by Zambia, which presents an extremely small modern sector but one that is relatively closer to the technological frontier, and thus is located in the non-shaded part of Region IIa.

Between these two extremes of the landscape, we find all countries caught in a middle-income trap. The countries that are identified as being caught in the lowermiddle-income trap are mostly located in the Region IIa. In these countries, the modern sector has expanded sufficiently to escape the poverty trap, but the technological distance to the world frontier is still extremely large. Three special cases are Jordan, Egypt and Ukraine that have managed to enter in the next region of the landscape in terms of the modernisation index but are still trapped in the lowermiddle income category. From a structural perspective, their economies are more similar to those countries situated at upper-middle income levels.

Most countries identified as caught in the upper-middle-income trap, in turn, are located in (or at the border of) the Region IIIa. These countries are in an intermediate situation. They already managed to surpass the poverty and lower-middleincome traps but did not succeed in going further. These economies already have a medium-sized modern sector that, in many cases, is comparable in size to that of the advanced economies. The main challenge, hence, seems to be especially in the technological dimension: these countries need to reduce the technological gap with the world frontier in their modern activities. The only exception to this rule might 
be Argentina and South Africa, which are located in Region IIIb, though very close to the 45 degree line. In these economies, the expansion of the modern sector would be at least as important as the reduction of the technological gap.

The following table lists all countries identified as being in a development trap, according to their location in Figure 4.6:

Table 4.4. Countries in a development trap by regions of the structural modernization landscape. 20052009. 29 countries ${ }^{102}$

\begin{tabular}{|c|c|c|c|}
\hline Ia & I $b$ & II $a$ & III $a$ \\
\hline Kenya (L) & Madagascar (L) ${ }^{\dagger}$ & Bolivia (LM) & Argentina (UM) \\
\hline Malawi (L) ${ }^{\dagger}$ & $\operatorname{Mali}(\mathrm{L}) \dagger$ & Namibia (LM) & Brazil (UM) \\
\hline Niger $(L) \dagger$ & Rwanda (L) $†$ & Morocco (LM) & Colombia (UM) \\
\hline Nepal (L) & Zambia (L) & Moldova (LM) & Ecuador (UM) \\
\hline \multirow[t]{9}{*}{$\operatorname{Togo}(\mathrm{L}) \dagger$} & & Pakistan (LM) & $\operatorname{Mexico}(\mathrm{UM})$ \\
\hline & & Philippines (LM) & Macedonia (UM) \\
\hline & & Yemen (L) & Romania (UM) \\
\hline & & & Russia (UM) \\
\hline & & & Serbia (UM) \\
\hline & & & South Africa (UM) \\
\hline & & & Egypt (LM) \\
\hline & & & Jordan (LM) \\
\hline & & & Ukraine (LM) \\
\hline
\end{tabular}

Note: Between brackets we detail the income category (L=Low, LM=Lower-Middle, $\mathrm{UM}=\mathrm{Upper-Middle).} \mathrm{The} \mathrm{dagger}(\dagger)$ indicates low-income countries located in the shaded area of Region I.

The localization of the various countries in Figure 4.6 stresses once more a very important point already highlighted earlier in this chapter. One of the main challenges in the process of economic development seems to be how to move from Region I to Region IV in the structural modernization landscape without getting trapped in between. As we will see in the next section, this is a challenge that only a few countries have managed to accomplish in the recent economic history.

Interestingly, the various regions of this figure can also be associated with the basins of attraction of the multiple equilibria found, from a theoretical perspective, 102 As stressed before (see footnote 87 ) Venezuela is excluded from the figures because it presents and
extremely high level of relative productivity in MMA mostly explained by the oil sector. 
in the CHAPTER 3. The dynamical solution of that model yields four equilibria that can be stable or unstable depending on certain conditions in the underlying parameters. In particular, at very early stages of development, an equilibrium located at the origin would typically be stable. The basin of attraction of this equilibrium could easily be associated with the shaded part of Region I in Figure 4.6, and therefore, it makes a lot of sense to find here most of the countries caught in the poverty trap. The next two equilibria correspond to situations in which only one of the variables is different from zero. Therefore, the basis of attraction of these equilibria could easily be associated with the non-shaded areas of Regions I and with Region II. Countries trapped in the lower-middle-income trap (or even in the poverty trap) would be typically (given the underlying parameters) be attracted towards these two equilibria, as it seems to happen in Figure 5. The last equilibrium of the model (the good equilibrium), instead, is characterized by having positive values in both dimensions and therefore it would typically fall somewhere within Regions III and $I V$. The exact point in which it would fall will depend on the underlying parameters. As customary in this type of models higher levels of absorptive capabilities, domestic efforts in R\&D investments or income-elasticity of export demand will typically increase the equilibrium values and therefore tend to move the equilibrium towards Region $I V$. Higher levels of price inflation, income-elasticity of import demand or labour force growth, instead, would decrease the equilibrium values and therefore move the equilibrium towards Region III. Perhaps more interestingly, for economies trapped within Regions I or $I I$, the theoretical model would provide interesting insights about broad economic strategies needed to overcome the obstacles driving the economy towards the bad equilibria and to escape from these regions. In short, this strategy would entail a radical transformation in export performance grounded on a structural shift towards the production of goods with higher income elasticity of demand in world markets and a radical improvement in the domestic absorptive capabilities of the domestic economies in order to tap into the global flows of technological knowledge. Both transformations would turn the good equilibrium stable thus enabling the economy to move away from the basin of attraction of the low-level equilibria ${ }^{103}$.

Given the clear match between regions and income-status (most countries trapped in low or lower-middle incomes being in regions I and II, and most countries trapped in upper-middle incomes being in Region III ${ }^{104}$, it is possible to derive a typology of countries caught in some sort of development trap according to the

\footnotetext{
103 See CHAPTER 3, Section 3.4.

104 The only exceptions are the three countries categorized as being in the LMIT but posited in Region IIIa (Egypt, Jordan and Ukraine).
} 
dimension (in our 2-dimensional landscape) that they need to improve more radically in order to escape from the trap:

Table 4.5. Typology of countries based on the regions of the structural modernization landscape

\begin{tabular}{|c|c|c|c|}
\hline & \multicolumn{2}{|c|}{ In order to surpass } \\
\hline & & $\begin{array}{c}\text { Low- or Lower-Middle- } \\
\text { Income Trap }\end{array}$ & $\begin{array}{c}\text { Upper-Middle-Income } \\
\text { Trap }\end{array}$ \\
\hline \multirow{3}{*}{$\begin{array}{c}\text { Needs to } \\
\text { improve }\end{array}$} & $\begin{array}{l}\text { Technological } \\
\text { accumulation }\end{array}$ & Regions Ia and IIa & Region IIIa \\
\hline & $\begin{array}{l}\text { Labour Ab- } \\
\text { sorption }\end{array}$ & Regions Ib and IIb & Region IIIb \\
\hline & Both & Region I & - \\
\hline
\end{tabular}

Looking at Table 4.4 and Table 4.5 would suggest, for example, that the main challenge in countries such as Argentina and South Africa would be related to increase the size of the modern sector whereas in Brazil, Mexico and Russia, for example, it would be more urgent to improve the degree of technological sophistication of the already existing modern activities.

The cross-country approach used in this section provides an interesting starting point to analyse economic development. But the picture we obtain is still rather stylized and provides little insights on the particular structural trajectories followed by different countries. To overcome this limitation, in the following section we focus on a selected number of countries -each of them representative of one of the different situations described above- and we analyse their evolution through the structural modernization landscape in the last four or five decades.

\subsection{Structural Trajectories}

In this section we present the structural trajectory of a series of countries that can be regarded as representative of the various development outcomes that have been identified so far. Two broad groups are analysed. First, what we call "successful trajectories". These are economies that have improved their income category during the period and do not present evidence of being currently caught in any sort of development trap. Within this group we present six countries selected from Table 4.2. The criterion here has been to pick two cases from each of the right-most upper cells of the table. The second group illustrates what we call "unsuccessful trajectories" and is composed by economies that have been identified as being currently 
caught (or projected to be caught) in some sort of development trap. Within this group we also present six countries selected from Table 4.3. In this case, we chose two cases for each income trap.

\subsubsection{Success stories}

Examples of successful trajectories include the following: Korea and Taiwan (which managed to move from low to high incomes during the period); Hong Kong and Singapore (which managed to move from lower-middle to high incomes); and China and Thailand (which managed to move from low to upper-middle incomes). To analyse the structural trajectories we present a set of figures with the corresponding structural modernization landscape and the position of each country in different points of time, starting (when the data is available) in 1960 and ending in 2009. In all cases, the points in the figures represent averages across five-year periods around the year indicated next to the observation. The landscapes have been divided in the various regions defined in Figure 4.6, which -as we will see- provide useful insights on the interpretation of the trajectories observed.

Figure 4.7. Structural trajectories (five year averages). Rep. of Korea and Taiwan

a) Rep. Of Korea (1960-2009)

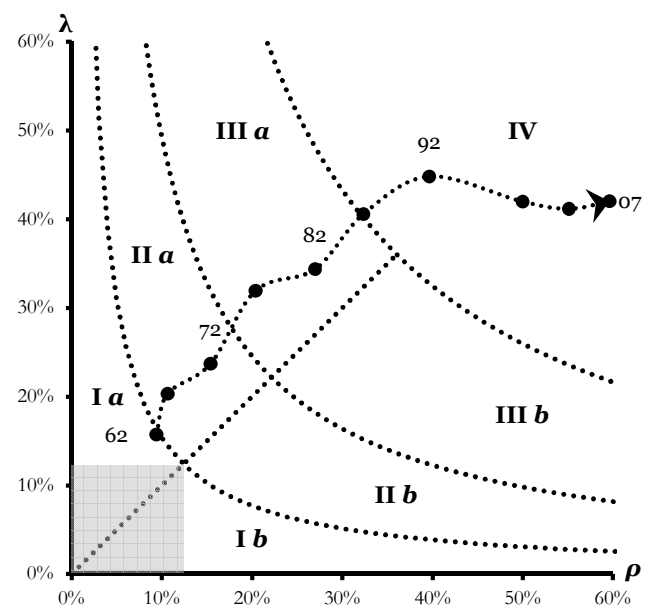

b) Taiwan (1960-2009)

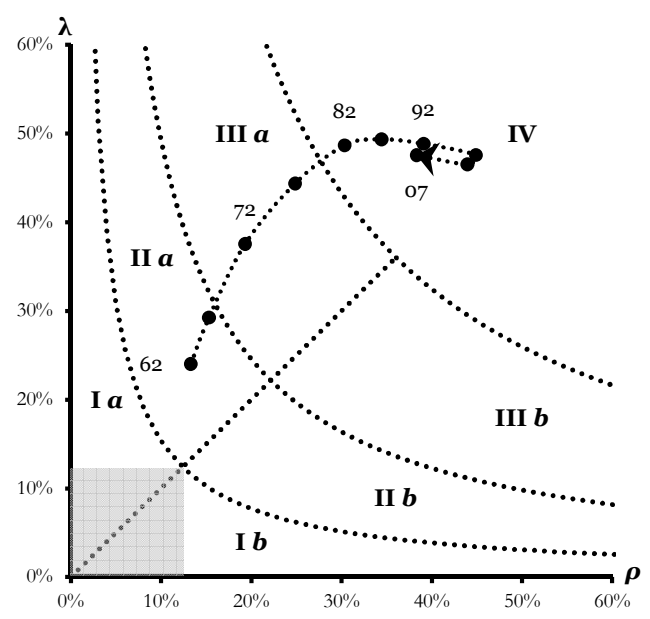

Panel $a$ in Figure 4.7 depicts the structural trajectory of Korea between 1960 and 2009. Undoubtedly, this is one of the most astonishing trajectories within our sample of countries during the period considered. In the early 1960s Korea was a lowincome economy situated at the border of the worst region of the landscape. Both the share in total labour force and the relative labour productivity of modern market activities were extremely low. In a time span of three decades, this economy 
managed to transform its structure radically moving from the lower bound of Region IIa to the centre of Region IV and attaining by the second half of the 1990s the status of high-income economy. The trajectory resembles a straight diagonal crossing Regions IIa and IIIa to end up at a level of $45 \%$ of total labour force in the modern activities by the early 1990s and keep that level with a significant reduction of the technological gap in the years to come.

The trajectory of Taiwan (panel b) illustrates another of the most successful stories in our sample. Starting from Region IIa (with a modern sector that was comparatively larger than the one of Korea, but equally far from the technological frontier), this economy also managed to simultaneously increase the size of its modern sector and reduce the technological gap at a very rapid pace, moving in ten years to Region $I I I a$, and ten years later to Region $I V$. In a quarter century, Taiwan radically transformed its structure and became a high-income economy. Contrasting with Korea, however, this economy could not maintain its rate of catch-up. After 2000 it started to lose some ground with respect to the world frontier.

Next we present the cases of four economies that managed to climb two income categories during the period under consideration. We start with the remaining Asian tigers: Hong Kong and Singapore. In this case, our data start in the 1970s. Figure 4.8 shows the corresponding trajectories.

Figure 4.8. Structural trajectories (five year averages). Hong Kong and Singapore

a) Hong Kong (1970-2009)

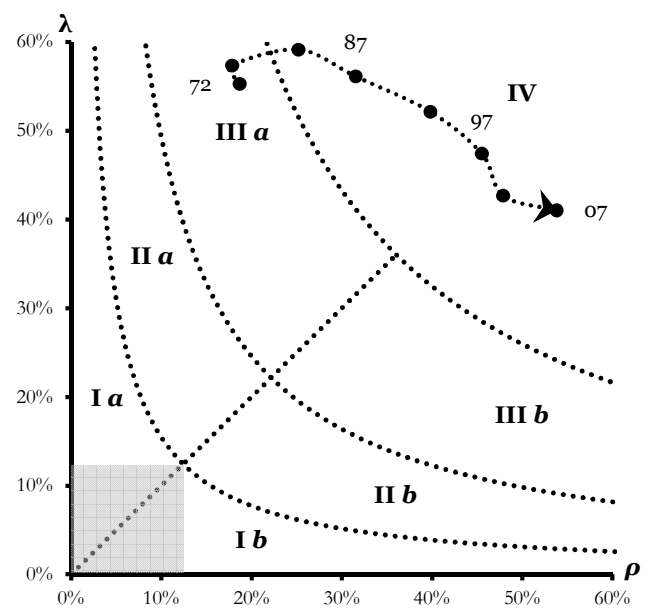

b) Singapore (1970-2009)

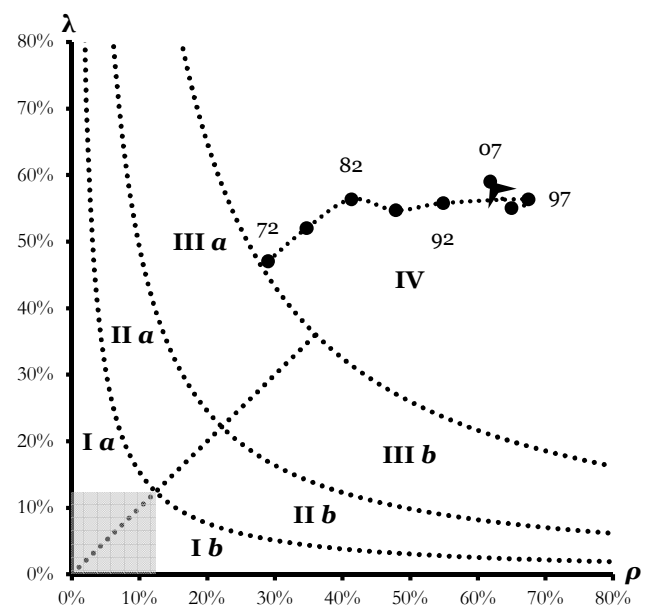

Both economies were categorized as lower-middle income in the early 1960s (not shown in the figure) and had already managed to achieve high incomes by the be- 
ginning of the 1980s. As we can see, by the early 1970s they already had a very large modern sector and their main achievement was to significantly reduce the technological gap with the world frontier. Actually, in the case of Hong Kong we can see a steady decline in the share of modern activities in total labour force, mainly driven by the sharp drop in manufacturing shares. In Singapore, in contrast, the share of modern activities continues to grow until the early 1980s and later stays at the same level. Since 1995 the Singapore economy has been falling behind in a technological sense, though it is still increasing the size of the modern sector.

The last two successful economies that we present are also situated in East Asia: China and Thailand. Both economies started the period as low-income economies and managed to climb up to upper-middle-income economies. The challenge for these economies is now to graduate from this income category, and avoid the trajectory followed by the trapped economies that we will analyse in the next section.

Figure 4.9. Structural trajectories (five year averages). China and Thailand

a) China (1960-2009)

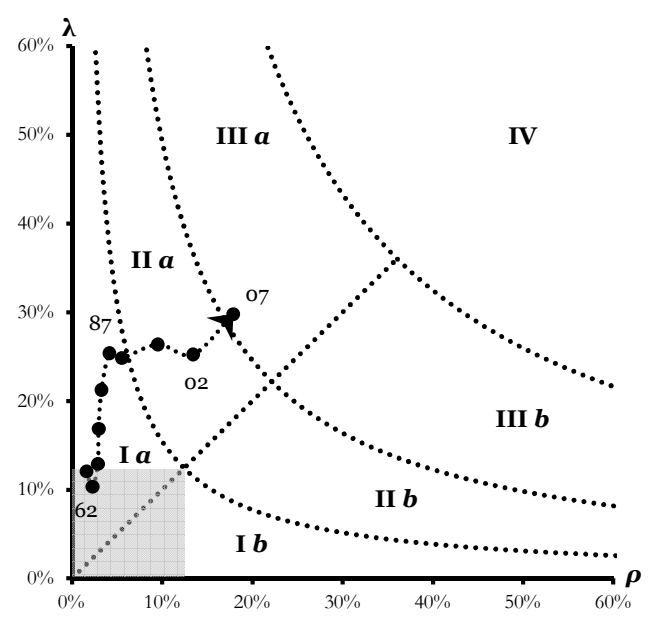

b) Thailand (1960-2009)

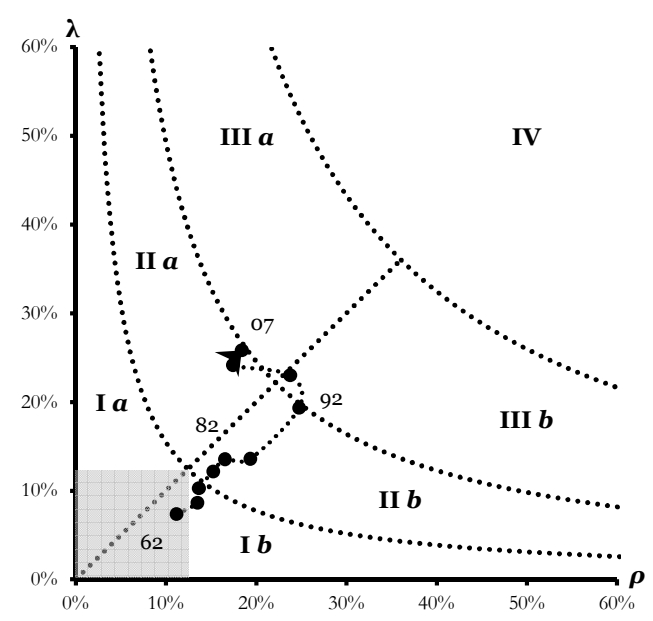

Figure 4.9 clearly shows the important achievements of China, especially during the last 25 years. Between 1960 and 1970 this economy was stuck in the worst region of the landscape. After this year, however, a dramatic shift in the structure of employment leads to a steady increase in the relative size of the modern sector, that in 15 years increases by more than 10 percentage points. During the next 15 years, the expansion of the modern sector stops but in a context of rapid catch up with the world frontier. Finally, in the last years, this economy combines a steady increase along both dimensions. Between endpoints, the Chinese economy has managed to 
move from Region Ia to Region IIIa, in a clear successful structural transformation trajectory. The case of Thailand also provides a good illustration of a successful trajectory. Starting at very low levels in the 1960s, this economy slowly managed to increase the size of the modern sector and reduce the technological gap. By the second half of the 1980s absorption of labour force in the modern sector accelerated substantially and by the mid 1990s Thailand entered into Region IIIa. During the 1990s and 2000s Thailand managed to maintain its upward trend but lost some ground in terms of technological catching-up. As in the case of China, this economy now faces the challenge of maintaining the pace of the structural modernization to go beyond Region III and avoiding falling in the upper-middle-income trap.

Having reviewed some of the most representative successful cases, we turn now to analyse the structural trajectories of a number of countries that, according to our empirical analysis, have fallen in some sort of development trap.

\subsubsection{Unsuccessful trajectories}

The unsuccessful trajectories are illustrated with two cases from each income trap: Brazil and South Africa (upper-middle-income trap), Bolivia and Philippines (lowermiddle-income trap) and Malawi and Zambia (poverty trap).

Our first pair of unsuccessful stories illustrates the upper-middle-income trap and clearly shows cases in which the economy has been caught in one region of the landscape with great difficulties in moving forward for a very long period. Although this trajectory is illustrated with the cases of Brazil and South Africa, other countries (such as Argentina or Colombia) also present similar trajectories. 
Figure 4.10. Structural trajectories (five year averages). Brazil and South Africa

a) Brazil (1960-2009)

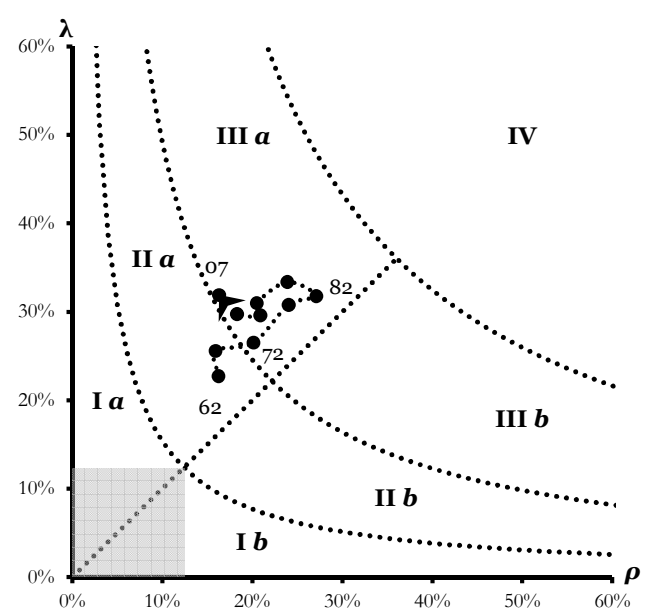

b) South Africa (1960-2009)

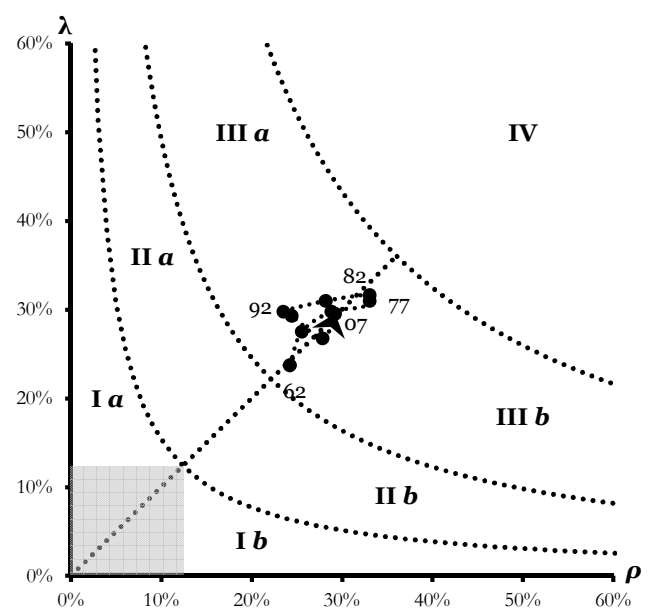

For almost half a century the two economies presented in Figure 4.10 have been trapped in Region III of the landscape. The economy of Brazil showed an impressive structural modernization between 1960 and 1980 (the so called Brazilian miracle). During these years the economy managed to move from Region IIa to the upper right corner of Region IIIa, significantly increasing the size of the modern sector and improving the degree of technological sophistication. From the 1980s onward, however, there has been a steady increase in the technological gap, while the size of the modern sector was maintained. By the end of the 2000s the technology gap was almost as large as it was in the early 1960s. A similar story can be told about South Africa. Looking at panel $b$ of the figure, we see that it also showed an important structural modernization between 1960 and 1980, but then fell behind. By the early 1990s, the relative productivity in the modern sector was even lower than in the early 1960s. During the 1990s and 2000s this tendency of declining relative productivity was reversed. But the recovery in productivity performance went hand in hand with a decreasing share of modern activities in the total labour force (mainly due to extremely high and increasing rates of unemployment). At the end of the period this country was almost at the same point as in the late 1980 s.

We turn now to the cases of Bolivia and Philippines, two countries trapped at lower-middle income levels and with a similar tendency to move towards the upper-left corner of Region Ila (see Figure 4.11). The structural trajectory of these economies is also quite similar. Till the late 1970s, these economies were moving progressively from Region II to Region III. From the 1980s onward, however, they started to lag behind in technological terms (a leftward movement in the landscape) 
although they continued to increase the size of their modern sectors. This is especially true for Bolivia, where the modern sector jumped from less than $20 \%$ in the late 1980s to more than 30\% today. In both cases, however, the direction of the trajectory seems to be towards the upper-left corner of Region IIa, which would clearly indicate the great difficulties that these economies face in order to move upwards in the structural modernization landscape. If structural modernization is indeed the key to escape from middle-income traps, then these trajectories provide warning signals about prospects of these economies to escape the lower-middleincome trap. In terms of our model, these economies seem to be attracted towards the development trap represented by Equilibrium 3 .

Figure 4.11. Structural trajectories (five year averages). Bolivia and Philippines

a) Bolivia (1960-2004)

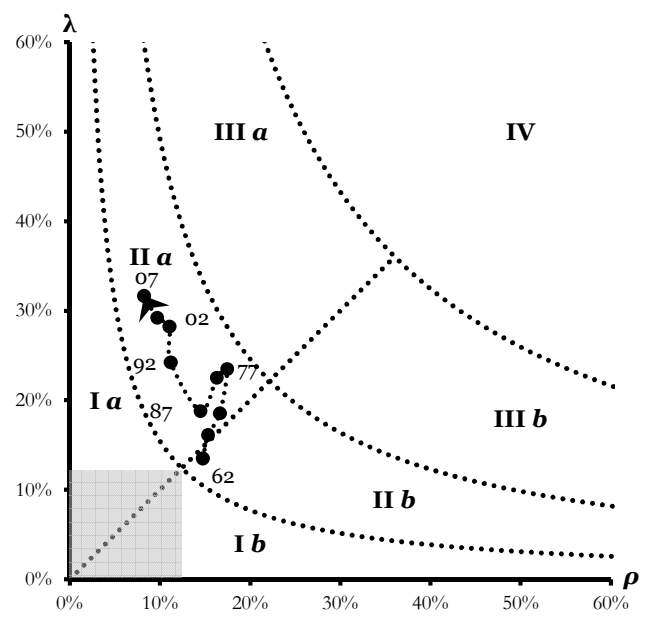

b) Philippines (1970-2009)

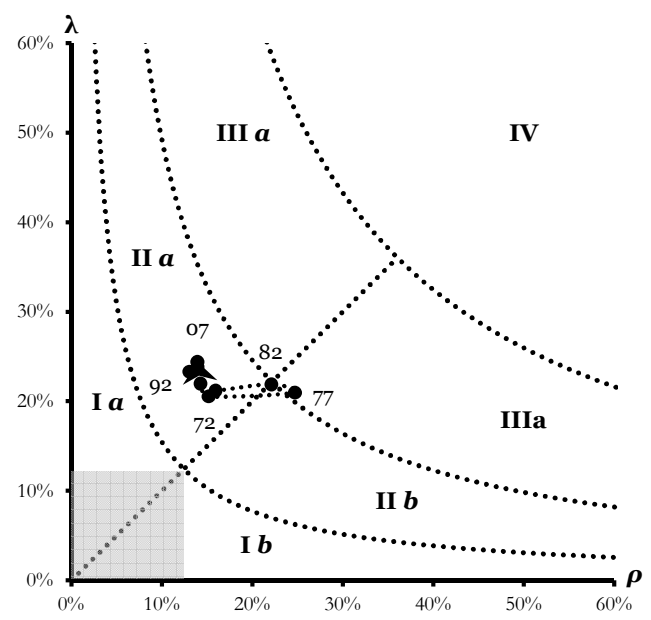

The last pair of countries that we discuss is not only caught in the poverty trap but also face difficulties in moving away from the shaded part of Region I. The perspectives for these countries are therefore the least optimistic ones (see Figure 4.12). This type of trajectory is illustrated with the cases of Malawi and Zambia, but it should be kept in mind that other countries such as Madagascar, Mali, Niger or Rwanda would probably present similar trajectories ${ }^{105}$.

\footnotetext{
105 Unfortunately we have not been able to collect the necessary data to build similar figures for these countries. In particular, data on employment by sector before the 2000 s are rarely available. Nevertheless, the available data for the last period shows that all of them are located in the shaded are of Region I, as illustrated in Figure 4.6.
} 
Figure 4.12. Structural trajectories (five year averages). Ethiopia and Tanzania

a) Malawi (1965-2009)

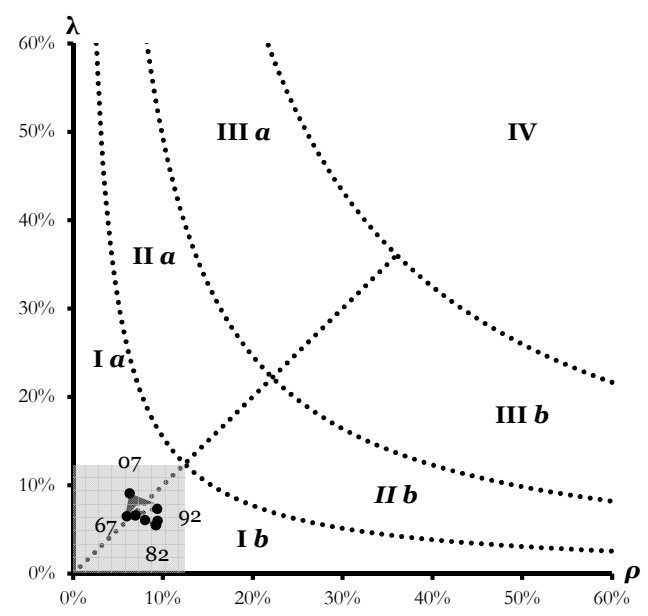

b) Zambia (1965-2009)

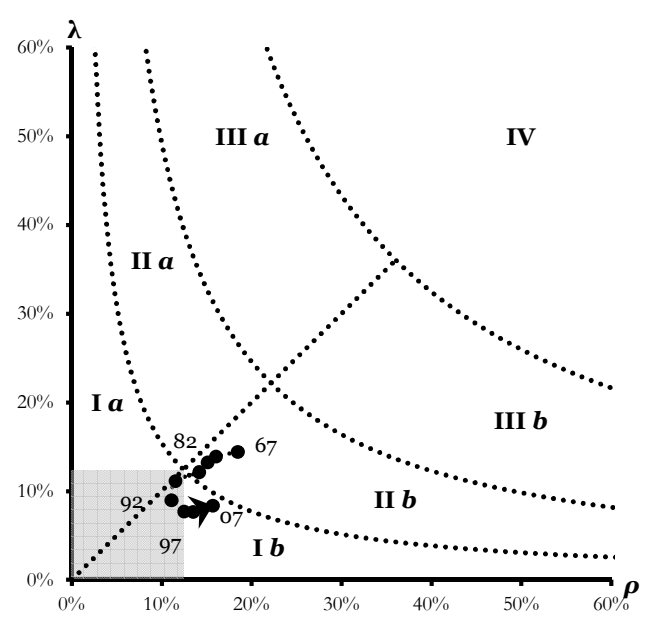

As we can see, these economies have been trapped in the very bottom of Region I at least for the last four decades. In such a situation, the main challenge ahead seems to be the development of a modern sector capable of absorbing an increasing share of the labour force. The case of Zambia in the first decades after the independence is particularly discouraging. Between 1965 and 1990, the relative size of the modern sector showed a significant reduction while its technological gap was increasing steadily, in a trajectory directed right towards the worst region of the landscape. The situation seems to have improved in the last decade, though the modern sector still represents a modest portion of the economy.

\subsection{Final Remarks}

In this chapter we have proposed a new index to analyse the process of structural transformation that unfolds as countries develop. This index has been theoretically grounded in the model developed in CHAPTER 3. It has been calculated for a large sample of countries over a long period of time, and the results have been used to shed new light on the reasons why some countries might be caught in development traps.

Our findings highlight the fundamental role played by the structural modernization of the economy in the process of economic development and, at the same time, stress the important risks associated with the lack of such transformation. In short, countries that have not managed to move forward in the structural upgrading 
of their productive systems, ended up being stuck in different sorts of low- or middle-income traps.

This chapter should be considered as an exploratory first step in the broader research programme of this thesis. Some interesting questions are deliberately left open for further exploration in the upcoming chapters. Two in particular stand out. The first relates to how our structural modernisation variables impact on economic growth. In the theoretical model there are several channels by which these variables might affect the growth rate of the economy. Depending on the counterbalancing forces of these channels, the net effect might be positive or negative and will typically depend on the particular stage of development that the economy is. Therefore, an investigation of these issues in the general context of the literature that has examined the determinants of growth and the sectoral engines of economic development would be a natural extension for the analysis here undertaken. In fact, this is precisely the aim of the next chapter.

The second question has to do with the composition of the modern sector and the changes that take place within this aggregate as countries develop. As stated in CHAPTER 2, a long strand of literature has stressed that the very nature of technological catch up is itself closely tied to the upgrading of the economy towards activities that are more technology intensive. The broad sectoral disaggregation used in this chapter, unfortunately, does not allow us to study the effects of such changes. The structural composition of the modern sector itself and its structural transformation along time will definitely affect the size of the aggregate technological gap of the modern sector. Therefore, an exploration of the sectors that make up the modern market aggregate and their changes over time would significantly improve our understanding of why some countries manage to rapidly close the technological gap while other lag further behind. This is another avenue of research that we will explore in the next chapters of the thesis. While CHAPTER 5 will already address this issue at a somehow aggregate level (distinguishing only 3 broad sectors within MMA), CHAPTER 6 will go much further and use a broader disaggregation to characterize the general patterns of structural change within the modern sector. 


\section{CHAP'TER 5.}

Structural Modernisation, Trade Specialization and Economic Growth. The Role of Manufacturing. 


\subsection{Introduction}

The previous chapters have explored some of the key transformations that take place as countries develop from a theoretical and empirical perspective. In doing so, the main focus has been placed on what we have labelled the process of structural modernisation. That is, the simultaneous expansion and technological catch up of the modern sector of the economy. The empirical examination of how these two dimensions evolved along time in a large sample of countries during the last 50 years provided some interesting insights. In short, we found that the countries that ended up caught in a development trap have been, at the same time, countries that have been unable to perform such structural transformation.

In this chapter we bring the analysis of structural modernisation into a more general discussion on the determinants of economic growth. In particular, we propose a more exhaustive approach that fully exploits the panel nature of the dataset previously constructed, in order to explore the specific role played by our key variables in the process of economic development. Following the theoretical foundations specified in CHAPTERS 2 and 3, we also explore the role of different sectoral compositions of the modern part of the economy in driving economic growth. Furthermore, we analyse the role of exports and particular trade specializations in this process.

Our point of departure is a panel-data growth regression that includes as regressors the explanatory variables that are typically identified as relevant by PostKeynesian and Neo-Schumpeterian traditions, as suggested in the model proposed in CHAPTER 3. These range from supply side factors (such as education, capital formation and population) to demand side factors (such as import and export demand and real exchange rate dynamics). This baseline regression is then augmented in order to incorporate the variables that have been identified as key for development throughout the previous chapters: the share of labour in modern market activities and the relative productivity of these activities with respect to the world frontier.

As stressed in our theoretical discussion, the aggregate of MMA activities is itself very heterogeneous and an important source of the differences in cross-country performance relates to the composition of this aggregate. In order to account for this fact, this chapter also examines the growth impact of the broad sectors that jointly constitute the modern part of the economy.

In the examination of the growth determinants undertaken in this chapter, special attention will be placed on the specific role of exports and the impact of different patterns of trade specialization. According to our theoretical model, these issues should be of prime importance. As explained in CHAPTER 3, the nexus between the dynamics of the modern sector and aggregate economic growth hinges upon 
the capacity of the former to drive exports. As we will see in the second part of this chapter, exports play a fundamental role, but not all exports have the same impacts. The value added content of exports and the particular set of goods exported seem to be at the core of the export-growth link. Moreover, the interactions of exports with other explanatory variables seem to be at least as important as the level of exports itself.

The findings of this chapter suggest that the technological upgrading of the manufacturing sector and the shift towards the production of goods with higher income elasticity are two key elements in fostering economic growth and helping economies to avoid or escape from low and medium-level development traps, confirming some of the key messages obtained at the previous chapters of this thesis.

The chapter is structured in two major parts. In the first part, we examine the relationship between our structural modernisation variables and economic growth, we study the impact of the modern sector's composition and we explore the interaction of various explanatory variables with that composition. Building on the findings of the first part, the second part investigates the relationship between export structures and economic growth. In doing so, the main focus is placed on the particular role played by manufacturing exports and by certain specialization patterns within this broad aggregate of industries. Finally, in Section 5.4 we present some concluding remarks. An appendix with details on the construction of the data and a series of robustness check on the econometric regressions is included at the end of the thesis.

\subsection{Structural Modernisation and Economic Growth}

\subsubsection{Approach}

The main goal of this chapter is to study the determinants of economic growth from the perspective detailed along the thesis. That is, including the variables typically included in growth regressions side by side with the variables that define the structural modernization index. Moreover, we also explore the impact of the different sub-sectors that integrate the modern aggregate. In particular, we study whether some sectors are more prone to act as engines of growth than others. Following our discussion on the sectoral engines of growth (CHAPTER 2, Section 2.4.1), we pay special attention to the role of manufacturing as compared to other two subsectoral aggregates: non-manufacturing industry (NMI)106 and modern market services (MMS).

Our approach exploits the panel nature of the dataset constructed in the previous chapter and uses specific techniques that account for unobserved country char-

106 That is, Mining, Utilities and Construction. 
acteristics by including either fixed or random effects. This approach is inspired and follows quite closely the approach proposed in Szirmai and Verspagen (2011) to study the role of manufacturing in economic growth (see CHAPTER 2, Section 2.4.1). However, it has been adapted to incorporate the key variables studied in the previous chapters of this thesis, and extended to include other variables related to the external growth channel.

Our point of departure is the following regression:

$$
\hat{y}_{t}^{i}=a_{0}+a_{1} \rho_{t_{1}}^{i}+a_{2} \lambda_{t_{1}}^{i}+b C_{t_{1}}^{i}+v^{i}+u_{t}^{i}
$$

Where $\hat{y}_{t}^{i}$ stands for the growth rate in per capita gross national income in country $i$ during the five year period $t, \rho_{t_{1}}^{i}$ is the corresponding index of relative labour productivity in the MMA in the first year of that period, $\lambda_{t_{1}}^{i}$ is the share of labour in modern activities in the first year of that period and $C$ is a vector of explanatory variables that includes five time-variant regressors and two time-invariant regressors. The time-variant variables are: LNPOP (logarithm of population), EDU (years of education), INV (gross capital formation as percentage of GDP), OPEN (degree of openness) and UNDERV (undervaluation of the real exchange rate). The timeinvariant regressors, in turn, are CLIMATE (climate zones: dummy variable that takes 1 if half or more of the country's area is in temperate zones) and RICHNR (abundance of natural resources: dummy variables that takes 1 if the country has an above average natural resource endowment ${ }^{107}$ ). The time-variant regressors are all evaluated at the first year of each five-year period. Finally, $v^{i}$ is a fixed term that accounts for the country-specific effects (the unobserved individual effects) and $u_{t}^{i}$ denotes the remainder of the disturbance.

The majority of the variables included in $C$ are typically included in most economic growth regressions and do not deserve further explanation ${ }^{108}$. Perhaps the less common are UNDERV and RICHNR. The first variable is included in light of the importance that the dynamics of real exchange rates have in our theoretical model. As we have seen, one of the main channels by which technological change feeds up into economic growth has to do with the external channel, and this, in turn, is mediated by the real exchange rate. At the empirical ground, several authors have emphasized the important role of real exchange rates in fostering or restraining economic growth. Perhaps the most influential has been Rodrik (2008), who shows that episodes of undervaluation are strongly associated with more rapid economic growth, using panel data techniques on a sample of 188 countries between 1950 and 2005. Our measure of undervaluation mimics the one proposed by this

107 The procedures used to calculate this variable are explained below.

108 In Section E.4 of APPENDIX E we provide the detailed definition of each variable and the data sources used to construct them. 
author and provides the real exchange rate adjusted for the so called BalassaSamuelson effect. That is, it adjusts the relative price of tradables to non-tradables for the fact that the relative price of non-tradables tend to be higher as countries grow rich. This index is constructed in a way that is comparable across countries and over time. Whenever it exceeds unity, it indicates that the domestic currency is undervalued $^{109}$.

The variable RICHNR, in turn, is included in order to account for the fact that our sample includes countries that are very heterogeneous in terms of their endowments of natural resources. This might have important implications on their economic structures and needs to be controlled. The variable has been constructed on the basis of a data series on natural capital recently released by the World Bank $^{110}$. It takes value 1 if the country had an above average per-capita natural capital in 2005 and 0 otherwise. Using this procedure, 15 countries of our sample have been classified as natural resource rich economies ${ }^{111}$.

Following the standard literature on growth regressions ${ }^{112}$, our expectation is that all these regressors with the only exception of LNPOP and RICHNR will enter with a significant and positive sign ${ }^{113}$.

In the cases of $\rho$ and $\lambda$, the expected sign will depend on counterbalancing forces that might lead to a positive or a negative impact. According to our theoretical model, an increase in $\rho$ would have a positive impact on growth via improved export dynamism but, at the same time, a negative impact due to the decreasing advantages of backwardness (catching up bonus for countries far from the technological frontier). That is, the closer a country is to the frontier, the less it can benefit from imitation and technologies created by the leader. In a similar vein, an increase of $\lambda$ would have a positive impact on growth through its positive effects on domestic innovation capabilities (the induced-innovation channel explained in CHAPTER 3). At the same time, however, it will have a negative impact on the competitiveness of the economy due to the higher wage-pressures that would be triggered by the reduction of the "reserve army". The final signs of both variables, thus, remain an empirical question that will be addressed in this chapter.

\footnotetext{
${ }^{109}$ See APPENDIX E, Section E.4.4 for a detailed explanation on how this index is calculated.

110 World Bank (2010). Dataset available at: http://data.worldbank.org/data-catalog/wealth-ofnations

111 The countries are: Australia, Brazil, Canada, Chile, Denmark, Ecuador, Finland, Iran, Netherlands, Norway, New Zealand, Russia, Sweden, United States and Venezuela

112 As summarized, for example, in Durlauf et al. (2005).

${ }^{113}$ In the cases of size and natural resources the literature has found mixed evidence. See Alesina et al. (2005) and Frankel (2012) for recent reviews on these issues.
} 
As we have previously detailed, this chapter will also examine the role of different subsectors within the modern sector. In order to do so, Equation (5.1) will be augmented in the following way:

$$
\hat{y}_{t}^{i}=a_{0}+a_{1} \rho_{t_{1}}^{i}+a_{2} \lambda_{t_{1}}^{i}+a_{3} S_{j, t_{1}}^{i}+b C_{t_{1}}^{i}+v^{i}+u_{t}^{i} ; j=M A N, N M I, M M S
$$

where $s_{j}$ stands for the share of subsector $j$ in total labour employed by the modern sector ${ }^{114}$. Given data constraints, we have been able to distinguish only three broad sectors within the modern market activities aggregate: Manufacturing (MAN), NonManufacturing Industry (NMI) and Modern Market Services (MMS).

The inclusion of the sectoral shares in total labour employed by the modern sector aims at capturing (at least broadly) the particular composition of this sector. A positive and significant sign in any of the coefficients associated with $s_{j}$ will be interpreted as evidence of an engine-of-growth type effect in that particular sector. Given the literature reviewed in CHAPTER 2 and the results of previous works in this line, we expect a positive and significant coefficient in the case of manufacturing.

Equations (5.1) and (5.2) will be estimated using panel data techniques. However, to identify the best suited technique, it is necessary to give a first look at the data.

\subsubsection{Data}

Our dataset builds on the dataset prepared for CHAPTER 4 with some additional variables calculated from different sources. The details on how this data has been constructed are presented in APPENDIX E. Here, instead, we report some summary statistics of the variables included in our dataset (see Table 5.1).

The table provides some interesting insights regarding the structure of our dataset. It lists the mean, minimum value, maximum value, standard deviation and number of observations of each variable used in the models that will be tested in this section.

\footnotetext{
${ }^{114}$ Note that we run the model described by regression (5.2) separately for each subsector. We proceed in this way to avoid potential biases due to multicollinearity between the regressors while, at the same time, we control for the size of the modern sector (as captured by the coefficient $a_{2}$ )
} 


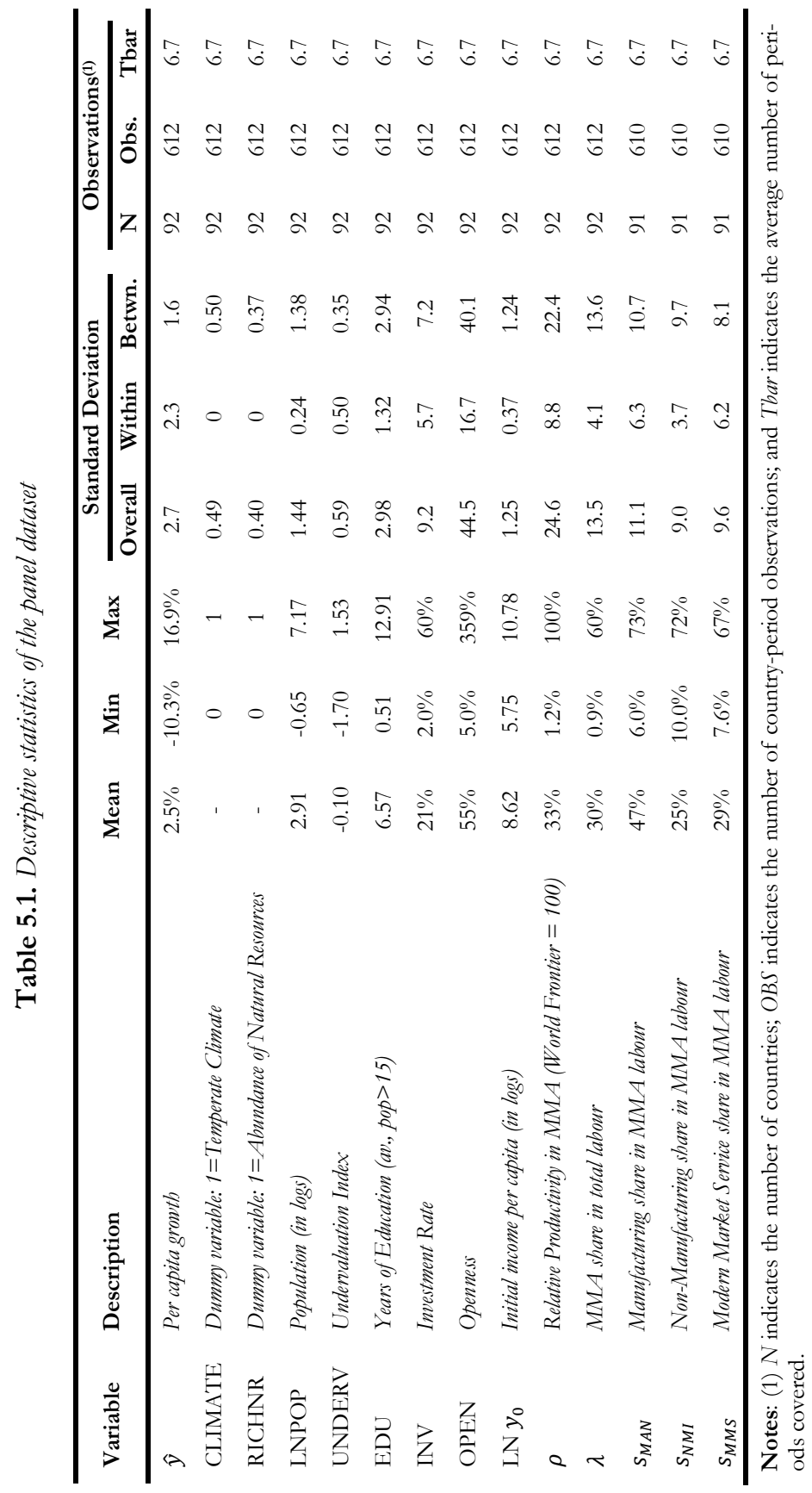


Before entering into the details, it is important to notice some facts about the coverage of our dataset. As we have previously explained, the time spam covered ranges from 1960 to 2009 and the units of observation are five year periods. Therefore, the total number of periods covered should be 10 . The average number of periods covered, however, is 6.7 indicating that there are many missing data. This results from the fact that many of our explanatory variables were not available for all countries in all years. Moreover, from the sample of 100 countries analysed in CHAPTER 4, eight countries had been dropped because they did not have complete information for all variable in any period ${ }^{115}$. Nevertheless, the number of observations included is still quite high, reaching more than 600 country-period combinations.

Looking at the third column of the table we can see that the average growth rate in per capita income throughout all periods and countries has been $2.5 \%$. The highest growth rate in our sample has been recorded by Botswana in the period 19701974 (17\% annual growth), while the most dramatic recession is observed in Rwanda in the period 1990-1994, with a yearly fall in per capita income of about $10 \%$. In terms of the key variables related to structural modernisation we can see that the modern sector employs, on average, $30 \%$ of the labour force, and the largest value has been recorded by Great Britain in 1960 (60\% of total labour force). The relative labour productivity in MMA, in turn, has an average value of $33 \%$. Last but not least, we can also observe a great variability in the composition of the modem sector. On average, manufacturing is the largest sub-sector, employing almost half of the modern's sector workers. Modern services are the second largest with $29 \%$ average share, and non-manufacturing industry represents the smallest subsector (with an average share of $25 \%$ ). However, there are many countries in which either modern services or non-manufacturing industry are the largest sub-sector. The extreme cases are Sierra Leona in 2005 (where non-manufacturing industry employed $72 \%$ of the modern sector's labour) and Hong Kong in 2005 (where modern services accounted for $67 \%$ of all workers in the modern sector).

Given the panel structure of the dataset, the standard deviation is broken down into two dimensions: deviation within countries over time and deviation between countries. While the within component is much larger than the between component in the dependent variable, in all regressors (with the only exception of UNDERV) the between component dominates. Therefore, the explanatory variables are relatively more volatile between countries than within countries. As suggested in Szirmai and Verspagen (2011) this specific feature of our dataset implies that we cannot rely purely on fixed effect estimations, as they eliminate the between com-

\footnotetext{
115 These countries are: Azerbaijan, Burkina Faso, Cyprus, Georgia, Madagascar, Macedonia, Romania
} and Serbia. 
ponent completely. A technique that also accounts for this type of variation in the regressors would thus be preferred.

The natural candidate for this would be the random effects technique because it includes both a within and a between element. However, this technique assumes exogeneity of all regressors and the random individual effect, an assumption that would be difficult to meet in our case. An alternative estimator that could be regarded as being in a middle point between the fixed and the random effect models is the estimator proposed by Hausman and Taylor (1981). This estimator assumes that only some of the regressors are endogenous and the strictly exogenous regressors are used as instruments for the endogenous ones.

In order to implement the Hausman-Taylor (HT) technique, we first need to identify the variables that should be treated as endogenous. To do so, we follow an approach proposed by Jacob and Osang (2007) and also used in Szirmai and Verspagen (2011). This approach consists on running individual regressions of our dependent variable against each explanatory variable using fixed and random effects and then performing a Hausman (1978) test to examine whether the hypothesis that the random effects estimator is consistent and efficient fails to be rejected. If this hypothesis cannot be rejected, then the fixed effect model would be preferred indicating evidence of correlation between the explanatory variable being tested and the residual (endogeneity). The following table summarize the results of this test applied to each variable listed before: 
Table 5.2. Hausman's (1978) specification test for the explanatory variables

\begin{tabular}{lccccc}
\hline Variable & N & Obs. & $\chi^{2}$-stat & p-value & Endog. \\
\hline CLIMATE & 92 & 612 & - & - & \\
RICHNR & 92 & 612 & - & - & \\
LNPOP & 92 & 612 & 1.1 & 0.292 & \\
UNDERV & 92 & 612 & 0.0 & 0.856 & \\
EDU & 92 & 612 & 11.8 & 0.001 & 1 \\
INV & 92 & 612 & 0.5 & 0.460 & \\
OPEN & 92 & 612 & 2.4 & 0.125 & \\
$L N y_{0}$ & 92 & 612 & 25.1 & 0.000 & 1 \\
$\rho$ & 92 & 612 & 15.3 & 0.000 & 1 \\
$\lambda$ & 92 & 612 & 6.4 & 0.012 & 1 \\
$s_{M A N}$ & 91 & 610 & 3.6 & 0.056 & \\
$s_{N M I}$ & 91 & 610 & 0.1 & 0.818 & \\
$s_{M M S}$ & 91 & 610 & 2.8 & 0.093 & \\
\hline
\end{tabular}

Applying this procedure in our explanatory variables leads to the identification of five endogenous explanatory variables: $E D U, L N y_{0}, \rho, \lambda$ and $\rho_{M M S}$. Hence, in what follows these variables will be treated as endogenous when applying the HT estimator.

Summing up, our dataset covers a very large sample of countries over a long (but varying) period of time. The variability between countries is in most regressors much larger than the variability within countries, over time. Therefore, an estimator that accounts for this type of variability is needed. Given the strong indication of endogeneity in some of our explanatory variables, the estimator to be used also needs to correct for this potential bias. For these reasons, our preferred estimator is the HT. Hence all regressions of this chapter will be run using this estimator. As a robustness check of the desirability of this estimator over the fixed and random effect estimators, we have performed a pre-test estimation proposed by Baltagi et al. (2003) in all our estimated models. These authors suggest performing two sequential Hausman (1978) specification tests. First, the standard Hausman test based on a fixed effect versus a random effect model. If this test is not rejected, then the random effect model would be the preferred one. If the test is rejected, they propose performing a second Hausman test based on the difference between the fixed effect and the HT estimator. If this test is not rejected, then the choice of strictly exogenous variables for the HT estimator is taken as correct and the HT estimator would be the preferred one. Otherwise, only the fixed effect estimator will be efficient and consistent. In all our models the first test is rejected while the second test 
is not rejected suggesting that the HT estimator is indeed the best model to use in our case $\mathrm{e}^{116}$.

\subsubsection{The role of modern market activities}

In this section we present the results obtained when we estimate the models detailed in equations (5.1) and (5.2), using the HT estimator. The following table summarizes the main results.

116 The results of these tests are reported in Table C. 3 of APPENDIX C. 
Table 5.3. Determinants of growth. The role of modern market activities. Hausman-Taylor estimates for the period 1960-2009

\begin{tabular}{|c|c|c|c|c|c|c|}
\hline & Model 0 & Model 1 & Model 2 & Model 3a & Model 3b & Model 3c \\
\hline Constant & $\begin{array}{l}0.140^{* * *} \\
(0.027)\end{array}$ & $\begin{array}{l}0.000 \\
(0.008)\end{array}$ & $\begin{array}{l}0.008 \\
(0.012)\end{array}$ & $\begin{array}{c}0.026^{*} \\
(0.013)\end{array}$ & $\begin{array}{l}0.016 \\
(0.013)\end{array}$ & $\begin{array}{l}-0.024 \\
(0.015)\end{array}$ \\
\hline CLIMATE & $\begin{array}{l}0.016 \\
(0.008)\end{array}$ & $\begin{array}{l}0.011 \\
(0.006)\end{array}$ & $\begin{array}{l}0.015 \\
(0.010)\end{array}$ & $\begin{array}{l}0.015 \\
(0.010)\end{array}$ & $\begin{array}{l}0.015 \\
(0.011)\end{array}$ & $\begin{array}{l}0.017 \\
(0.011)\end{array}$ \\
\hline RICHNR & $\begin{array}{l}0.015 \\
(0.011)\end{array}$ & $\begin{array}{l}0.011 \\
(0.008)\end{array}$ & $\begin{array}{l}0.015 \\
(0.013)\end{array}$ & $\begin{array}{l}0.016 \\
(0.013)\end{array}$ & $\begin{array}{l}0.015 \\
(0.014)\end{array}$ & $\begin{array}{l}0.020 \\
(0.014)\end{array}$ \\
\hline LNPOP & $\begin{array}{l}0.003 \\
(0.002)\end{array}$ & $\begin{array}{l}0.002 \\
(0.002)\end{array}$ & $\begin{array}{l}0.004 \\
(0.003)\end{array}$ & $\begin{array}{l}0.004 \\
(0.003)\end{array}$ & $\begin{array}{l}0.004 \\
(0.003)\end{array}$ & $\begin{array}{l}0.004 \\
(0.003)\end{array}$ \\
\hline UNDERV & $\begin{array}{l}0.016^{* * *} \\
(0.004)\end{array}$ & $\begin{array}{l}0.014 * * * \\
(0.004)\end{array}$ & $\begin{array}{l}0.018^{* * *} \\
(0.004)\end{array}$ & $\begin{array}{l}0.015^{* * *} \\
(0.004)\end{array}$ & $\begin{array}{l}0.019 * * * \\
(0.004)\end{array}$ & $\begin{array}{l}0.016^{* * *} \\
(0.004)\end{array}$ \\
\hline EDU & $\begin{array}{l}0.004^{* *} \\
(0.001)\end{array}$ & $\begin{array}{l}0.001 \\
(0.001)\end{array}$ & $\begin{array}{l}0.002 \\
(0.001)\end{array}$ & $\begin{array}{l}0.004^{*} \\
(0.001)\end{array}$ & $\begin{array}{l}0.002 \\
(0.001)\end{array}$ & $\begin{array}{l}0.003 \\
(0.001)\end{array}$ \\
\hline INV & $\begin{array}{l}0.071^{* * *} \\
(0.016)\end{array}$ & $\begin{array}{l}0.058^{* * *} \\
(0.015)\end{array}$ & $\begin{array}{l}0.067^{* * *} \\
(0.016)\end{array}$ & $\begin{array}{l}0.061^{* * *} \\
(0.016)\end{array}$ & $\begin{array}{l}0.072^{* * *} \\
(0.017)\end{array}$ & $\begin{array}{l}0.072^{* * *} \\
(0.016)\end{array}$ \\
\hline OPEN & $\begin{array}{l}0.023^{* * *} \\
(0.006)\end{array}$ & $\begin{array}{l}0.018^{* * *} \\
(0.005)\end{array}$ & $\begin{array}{l}0.022^{* * *} \\
(0.006)\end{array}$ & $\begin{array}{l}0.024^{* * *} \\
(0.006)\end{array}$ & $\begin{array}{l}0.022^{* * *} \\
(0.006)\end{array}$ & $\begin{array}{l}0.027 * * * \\
(0.006)\end{array}$ \\
\hline$L N y_{0}$ & $\begin{array}{l}-0.021^{* * *} \\
(0.004)\end{array}$ & & & & & \\
\hline$\Omega$ & & $\begin{array}{l}-0.149^{* * *} \\
(0.027)\end{array}$ & & & & \\
\hline$\rho$ & & & $\begin{array}{l}-0.043^{* * *} \\
(0.011)\end{array}$ & $\begin{array}{l}-0.035^{* *} \\
(0.011)\end{array}$ & $\begin{array}{l}-0.044^{* * *} \\
(0.011)\end{array}$ & $\begin{array}{l}-0.039 * * * \\
(0.011)\end{array}$ \\
\hline$\lambda$ & & & $\begin{array}{l}-0.097 * * * \\
(0.025)\end{array}$ & $\begin{array}{l}-0.132^{* * *} \\
(0.027)\end{array}$ & $\begin{array}{l}-0.096^{* * *} \\
(0.024)\end{array}$ & $\begin{array}{l}-0.138^{* * *} \\
(0.027)\end{array}$ \\
\hline$S_{M M S}$ & & & & $\begin{array}{l}-0.064^{* *} \\
(0.022)\end{array}$ & & \\
\hline$S_{N M I}$ & & & & & $\begin{array}{l}-0.035 \\
(0.023)\end{array}$ & \\
\hline$S_{M A N}$ & & & & & & $\begin{array}{l}0.069^{* * *} \\
(0.019)\end{array}$ \\
\hline p75_90 & $\begin{array}{l}-0.006 \\
(0.004)\end{array}$ & $\begin{array}{l}-0.007 \\
(0.004)\end{array}$ & $\begin{array}{l}-0.004 \\
(0.004)\end{array}$ & $\begin{array}{l}-0.007 \\
(0.004)\end{array}$ & $\begin{array}{l}-0.004 \\
(0.004)\end{array}$ & $\begin{array}{l}-0.005 \\
(0.004)\end{array}$ \\
\hline p90_09 & $\begin{array}{l}0.004 \\
(0.006)\end{array}$ & $\begin{array}{l}0.001 \\
(0.006)\end{array}$ & $\begin{array}{l}0.003 \\
(0.006)\end{array}$ & $\begin{array}{l}0.001 \\
(0.006)\end{array}$ & $\begin{array}{l}0.004 \\
(0.006)\end{array}$ & $\begin{array}{l}0.005 \\
(0.006)\end{array}$ \\
\hline Rho & 0.684 & 0.47 & 0.789 & 0.784 & 0.809 & 0.82 \\
\hline Obs. & 612 & 612 & 612 & 610 & 610 & 610 \\
\hline Countries & 92 & 92 & 92 & 91 & 91 & 91 \\
\hline
\end{tabular}

${ }^{*} \mathrm{p}<0.05, * * \mathrm{p}<0.01, * * * \mathrm{p}<0.001$ 
The first model in Table 5.3 presents our baseline estimation. It provides the results of a growth regression that includes the variables typically used by the literature. These are the variables encompassed in $C_{t_{1}}^{i}$ in equation (5.1) plus one additional variable aimed at capturing the catching up potential of less developed countries (the initial per capita GNI, in logs). In all models we have also included period dummies to capture specific time effects. Following the literature, we distinguished three sub-periods that would have different characteristics: 1960-1974, 1975-1989 and 1990-2009.

As we can see, most variables are significant and have the expected sign. Undervaluation, Education, Investment and Openness all contribute positively and significantly to the rate of per capita growth. Initial incomes, instead, enters with a negative and significant coefficient, in line with the catching-up hypothesis. The remaining variables do not show any significant impact on growth ${ }^{117}$.

The next two models (second and third column of the table) augment this baseline by including our structural modernisation variables. In model 1, we include the structural modernisation index $(\Omega)$ as defined in the previous chapter. In model 2, we include separately the two variables that compose the index. That is, the share of labour in the modern sector $(\lambda)$ and the relative productivity of this sector as compared with the world frontier $(\rho)$. In both cases, the variable $\mathrm{LNy}_{0}$ is no longer included since the catching-up component is already captured by $\rho$. As we can see, the estimated coefficient of the structural modernisation index is negative and highly significant. In terms of our theoretical model, this evidence would indicate that the negative effects of structural modernization on economic growth dominate, on average, over the positive effects. A similar conclusion is obtained when we enter the two variables that compose the index separately: both enter with a negative and highly significant coefficient. This means that the larger the size of the modern sector and the closer it is to the world frontier, the less rapid the economy will grow.

From the discussion of the previous chapter, this seems to be a rather counterintuitive result. A major message from CHAPTER 4 was that countries caught at low or middle income traps are, at the same time, countries that have been unable to perform the proper transformations in terms of $\lambda$ and $\rho$. Hence, a positive effect of these variables on economic growth would have been expected. On second

\footnotetext{
117 In Appendix C.2, Table C. 4 we explore how these results would change if we use alternative regressors for $C_{t_{1}}^{i}$. In particular, we investigate what happens if we use the growth rate of capital per worker (instead of INV), the growth rate of terms of trade (instead of UNDERV), an alternative measure of human capital (instead of EDU) and an alternative measure of relative incomes. The main results obtained in this section also hold when these alternative variables are used.
} 
thoughts, however, this result is not surprising. All the standard literature on catchup finds a negative relation between growth rates and relative incomes (or productivity) with the world frontier. Interpreted from this perspective, the negative effect of $\rho$ would actually be reflecting the decrease in the advantages of backwardness as countries develop ${ }^{118}$. In a similar vein, the negative effect of $\lambda$ would be reflecting the fact that as the modern sector becomes dominant, the potential growth-bonus derived from structural change tends to diminish.

Taken together, these results would be indicative of the fact that less developed countries have a higher scope to exploit the advantages of backwardness. Therefore, as countries modernize the growth rate tends to decrease. Once this is acknowledged an important question that emerges is whether there are other forces that might counterbalance the deceleration that occurs in growth rates as countries achieve their structural modernisation.

As explained before, one important element to consider while evaluating the role of the modern sectors has to do with its sectoral composition. To explore this fact, columns 3 to 5 in Table 5.3 augment the previous model by including separately the shares of modern-market services, non-manufacturing industry and manufacturing in the total workforce employed by the modern sector. The results are quite remarkable. While modern services enter in the regression with a negative and significant coefficient, manufacturing enters with a positive and highly significant sign. Non-manufacturing industry also shows a negative sign but the coefficient is not statistically significant. These results suggest counterbalancing effects of different sectoral compositions. The growth deceleration typically associated with a larger modern sector is partially compensated for by the particular sector structure that characterizes the modern sector. The larger the share of manufacturing, the lower this deceleration will be. In contrast, the relative size of modern services is negatively correlated with growth.

Our results thus provide further evidence supporting the idea that manufacturing is the main engine of economic growth. In clear contrast with recent literature that highlights the emergence of modern services as new engines of growths, our regressions suggest that a process of structural modernisations heavily based upon this type of activities would entail a burden rather than a benefit in terms of the growth potential of countries ${ }^{119}$.

118 In fact, comparing models 1 and 2 we can see that our measure of relative productivity in the modern sectors seems to capture better the catch up potential of developing countries than the initial level of per capita incomes: the coefficient associated with $\rho$ almost double (in absolute terms) the coefficient of LNy0.

119 This conclusion might be biased by the fact that modern services are more present in already advanced countries and/or appear at late stages of development (when big spurts of growth are rare). As a robustness check to explore this potential pitfall we have run models $3 \mathrm{a}$ to $3 \mathrm{c}$ including income 
Since non-manufacturing industry also presents a negative sign, it seems that the distinguishing factor has to do with the relative size of manufacturing. Therefore, in all upcoming regressions we will use model $3 \mathrm{c}$ as our baseline model. The relative size of manufacturing will thus be taken as a rough indicator of the sectoral composition of the modern sector.

As a robustness check of this result, we have also explored what happens if we enter directly the shares of each sector in total labour force (thus excluding $s_{j}$ and replacing $\lambda$ by the corresponding $\lambda_{j}$ ). Under this setting, the main results hold: modern market services and non-manufacturing industry show a negative and significant coefficient while manufacturing enters with a positive sign. The significance of the latter, however, drops and the coefficient now becomes not significant ${ }^{120}$. The remaining variables show the same sign and significance levels (see Table C. 5 in APPENDIX C).

For a better understanding of the particular role of the composition of the modern sector in economic growth we introduce some interaction terms between the labour share of manufacturing and the remaining explanatory variables. We can explain the role of these interactions taking the example of the interaction between the share of manufacturing $\left(s_{M A N}\right)$ and the size of the modern sector $(\lambda)$. Using as a benchmark the model of equation (5.2) for the case of manufacturing, the augmented model would be:

$$
\hat{y}_{t}^{i}=a_{0}+a_{1} \rho_{t_{1}}^{i}+a_{2} \lambda_{t_{1}}^{i}+a_{3} s_{M A N, t_{1}}^{i}+a_{4} \lambda_{t_{1}}^{i} s_{M A N, t_{1}}^{i}+b C_{t_{1}}^{i}+v^{i}+u_{t}^{i}
$$

As we can see, the effect of the size of the modern sector is now mediated also by its composition. In such a case, the total effect of $\lambda$ on economic growth will be given by the following expression:

$$
\frac{\partial \hat{y}_{t}^{i}}{\partial \lambda_{t_{1}}^{i}}=a_{2}+a_{4} s_{M A N, t_{1}}^{i}
$$

level slope dummies for the corresponding sectoral shares. If the role of modern services would change in the process of development we would expect to find different slopes (negative at initial levels but positive at high income ranges). However, we found a quite stable pattern across income levels: the interacted slopes in the case of modern services enter in all cases (low, medium and high incomes) with a negative coefficient (though it is only significant for high incomes). In the case of manufacturing, instead, the three groups enter with a positive and highly significant coefficient. See Table C. 6 in APPENDIX C.

${ }^{120} \mathrm{~A}$ possible explanation for the non-significance of the manufacturing share coefficient is that the model defined in this way might suffer from multicollinearity. This would result from the fact that the three shares are, by definition, highly correlated. 
That is, the effect will depend on the particular share of manufacturing in the modern sector. If the term $a_{4}$ is positive and significant, then the larger the share of manufacturing, the more positive the effect of $\lambda$ on aggregate growth. However, as we have already seen, $a_{2}$ is negative and highly significant. The net effect, then, will depend on the result of this two counter-balancing forces.

A similar procedure can be done for each of our explanatory variables. Here in particular, we are interested on the interaction with the explanatory variables that have a significant impact on growth according to our model 3.c. That is, $\lambda, \rho, \mathrm{UN}$ DERV, EDU, INV and OPEN. The following table reports the results of augmenting the model with the interaction of $s_{M A N}$ with each of these variables: 
Table 5.4. Determinants of growth: the effect of $M M A$ composition including interactions with explanatory variables. 1960-2009, Hausman-Taylor estimates

\begin{tabular}{|c|c|c|c|c|c|c|}
\hline & Model 4a & Model 4b & Model 4c & Model 4d & Model 4e & Model 4f \\
\hline Constant & $\begin{array}{c}0.055^{* *} \\
(0.018)\end{array}$ & $\begin{array}{l}-0.008 \\
(0.016)\end{array}$ & $\begin{array}{l}-0.016 \\
(0.015)\end{array}$ & $\begin{array}{l}0.021 \\
(0.018)\end{array}$ & $\begin{array}{l}-0.023 \\
(0.018)\end{array}$ & $\begin{array}{l}-0.010 \\
(0.017)\end{array}$ \\
\hline CLIMATE & $\begin{array}{l}0.011 \\
(0.008)\end{array}$ & $\begin{array}{l}0.015 \\
(0.010)\end{array}$ & $\begin{array}{l}0.017 \\
(0.012)\end{array}$ & $\begin{array}{l}0.014 \\
(0.010)\end{array}$ & $\begin{array}{l}0.017 \\
(0.011)\end{array}$ & $\begin{array}{l}0.018 \\
(0.012)\end{array}$ \\
\hline RICHNR & $\begin{array}{l}0.010 \\
(0.011)\end{array}$ & $\begin{array}{l}0.017 \\
(0.013)\end{array}$ & $\begin{array}{l}0.021 \\
(0.016)\end{array}$ & $\begin{array}{l}0.016 \\
(0.013)\end{array}$ & $\begin{array}{l}0.020 \\
(0.015)\end{array}$ & $\begin{array}{l}0.020 \\
(0.016)\end{array}$ \\
\hline LNPOP & $\begin{array}{l}0.005 \\
(0.003)\end{array}$ & $\begin{array}{l}0.004 \\
(0.003)\end{array}$ & $\begin{array}{l}0.005 \\
(0.003)\end{array}$ & $\begin{array}{l}0.004 \\
(0.003)\end{array}$ & $\begin{array}{l}0.004 \\
(0.003)\end{array}$ & $\begin{array}{l}0.006 \\
(0.004)\end{array}$ \\
\hline UNDERV & $\begin{array}{l}0.017^{* * *} \\
(0.004)\end{array}$ & $\begin{array}{l}0.016^{* * *} \\
(0.004)\end{array}$ & $\begin{array}{l}0.044^{* * *} \\
(0.009)\end{array}$ & $\begin{array}{l}0.016^{* * *} \\
(0.004)\end{array}$ & $\begin{array}{l}0.016^{* * *} \\
(0.004)\end{array}$ & $\begin{array}{l}0.017^{* * *} \\
(0.004)\end{array}$ \\
\hline EDU & $\begin{array}{l}0.005^{* * *} \\
(0.001)\end{array}$ & $\begin{array}{c}0.003^{*} \\
(0.001)\end{array}$ & $\begin{array}{c}0.003^{*} \\
(0.001)\end{array}$ & $\begin{array}{l}-0.003 \\
(0.002)\end{array}$ & $\begin{array}{l}0.003 \\
(0.001)\end{array}$ & $\begin{array}{l}0.002 \\
(0.001)\end{array}$ \\
\hline INV & $\begin{array}{l}0.056^{* * *} \\
(0.016)\end{array}$ & $\begin{array}{l}0.066^{* * *} \\
(0.016)\end{array}$ & $\begin{array}{l}0.068^{* * *} \\
(0.016)\end{array}$ & $\begin{array}{l}0.066^{* * *} \\
(0.016)\end{array}$ & $\begin{array}{l}0.067 \\
(0.049)\end{array}$ & $\begin{array}{l}0.068^{* * *} \\
(0.016)\end{array}$ \\
\hline OPEN & $\begin{array}{l}0.028^{* * *} \\
(0.006)\end{array}$ & $\begin{array}{l}0.027^{* * *} \\
(0.006)\end{array}$ & $\begin{array}{l}0.027 * * * \\
(0.006)\end{array}$ & $\begin{array}{l}0.027 * * * \\
(0.006)\end{array}$ & $\begin{array}{l}0.027^{* * *} \\
(0.006)\end{array}$ & $\begin{array}{l}0.011 \\
(0.009)\end{array}$ \\
\hline$\rho$ & $\begin{array}{l}-0.012 \\
(0.011)\end{array}$ & $\begin{array}{l}-0.083^{* * *} \\
(0.025)\end{array}$ & $\begin{array}{l}-0.040^{* * *} \\
(0.011)\end{array}$ & $\begin{array}{c}-0.027^{*} \\
(0.011)\end{array}$ & $\begin{array}{l}-0.039 * * * \\
(0.011)\end{array}$ & $\begin{array}{l}-0.035^{* *} \\
(0.011)\end{array}$ \\
\hline$\lambda$ & $\begin{array}{l}-0.469 * * * \\
(0.061)\end{array}$ & $\begin{array}{l}-0.140^{* * *} \\
(0.026)\end{array}$ & $\begin{array}{l}-0.155^{* * *} \\
(0.027)\end{array}$ & $\begin{array}{l}-0.166^{* * *} \\
(0.027)\end{array}$ & $\begin{array}{l}-0.139 * * * \\
(0.028)\end{array}$ & $\begin{array}{l}-0.150^{* * *} \\
(0.027)\end{array}$ \\
\hline$S_{M A N}$ & $\begin{array}{l}-0.118^{* * *} \\
(0.032)\end{array}$ & $\begin{array}{l}0.032 \\
(0.024)\end{array}$ & $\begin{array}{l}0.065^{* * *} \\
(0.018)\end{array}$ & $\begin{array}{l}-0.032 \\
(0.029)\end{array}$ & $\begin{array}{c}0.067^{*} \\
(0.027)\end{array}$ & $\begin{array}{l}0.032 \\
(0.024)\end{array}$ \\
\hline$s_{M A N} * \lambda$ & $\begin{array}{l}0.641 * * * \\
(0.098)\end{array}$ & & & & & \\
\hline$s_{M A N} * \rho$ & & $\begin{array}{c}0.115^{*} \\
(0.052)\end{array}$ & & & & \\
\hline$s_{M A N} *$ UNDERV & & & $\begin{array}{l}-0.060^{* * *} \\
(0.017)\end{array}$ & & & \\
\hline$s_{M A N} * \mathrm{EDU}$ & & & & $\begin{array}{l}0.017 * * * \\
(0.004)\end{array}$ & & \\
\hline$S_{M A N} * \mathrm{INV}$ & & & & & $\begin{array}{l}0.011 \\
(0.109)\end{array}$ & \\
\hline$s_{M A N} *$ OPEN & & & & & & $\begin{array}{c}0.050^{*} \\
(0.020)\end{array}$ \\
\hline p75_90 & $\begin{array}{c}-0.010^{*} \\
(0.004)\end{array}$ & $\begin{array}{l}-0.006 \\
(0.004)\end{array}$ & $\begin{array}{l}-0.008 \\
(0.004)\end{array}$ & $\begin{array}{c}-0.009 * \\
(0.004)\end{array}$ & $\begin{array}{l}-0.005 \\
(0.004)\end{array}$ & $\begin{array}{l}-0.006 \\
(0.004)\end{array}$ \\
\hline p90_09 & $\begin{array}{c}-0.003 \\
(0.006)\end{array}$ & $\begin{array}{l}0.003 \\
(0.006)\end{array}$ & $\begin{array}{l}0.003 \\
(0.006)\end{array}$ & $\begin{array}{l}0.000 \\
(0.006)\end{array}$ & $\begin{array}{l}0.005 \\
(0.006)\end{array}$ & $\begin{array}{l}0.003 \\
(0.006)\end{array}$ \\
\hline Rho & 0.727 & 0.796 & 0.848 & 0.804 & 0.821 & 0.855 \\
\hline Obs. & 610 & 610 & 610 & 610 & 610 & 610 \\
\hline Countries & 91 & 91 & 91 & 91 & 91 & 91 \\
\hline
\end{tabular}

${ }^{*} \mathrm{p}<0.05,{ }^{* *} \mathrm{p}<0.01,{ }^{* * *} \mathrm{p}<0.001$ 
Our results suggest that in almost all cases, the interaction with the share of manufacturing in MMA is highly significant (the only exception is INV). Therefore, the effect of all explanatory variables is in a way mediated by the particular composition of the modern sector. In all cases except UNDERV the interaction shows a positive sign, suggesting that the larger the relative size of manufacturing, the stronger the positive effect of that particular variable on growth. In the cases of $\lambda$ and $\rho$ this positive interaction counterbalances the negative direct effect obtained for these variables in the first set of regressions. In EDU and OPEN, instead, it reinforces the positive effect ${ }^{121}$. In the case of UNDERV the interaction shows a negative and significant sign, suggesting that the positive effect of undervaluation on growth diminishes with the relative size of manufacturing. This is an unexpected result that deserves further investigation.

The results summarized in Table 5.4 can be better illustrated by plotting the corresponding marginal effect of each explanatory variable, as described in equation (5.4). That is, by looking at the total effect on growth at different relative size of manufacturing.

121 The coefficient associated with EDU in model $4 \mathrm{c}$ actually turns negative when the interaction term is introduced, but the combined effect is positive for most ranges of the manufacturing share (see Figure 5.1). 
Figure 5.1. Marginal effect of different explanatory variables on growth, when interacted with share of Manufacturing in $M M A$
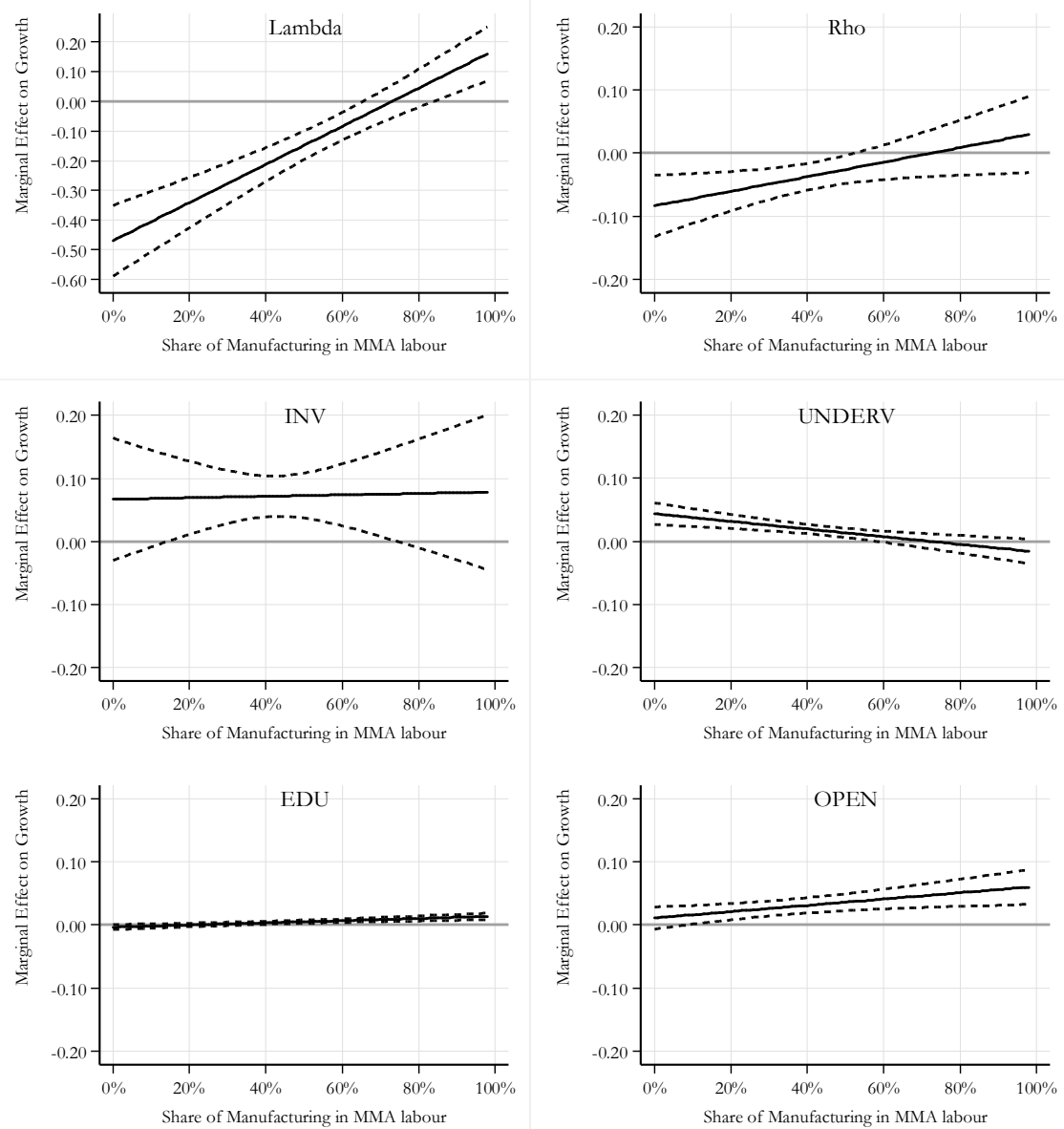

Each panel of Figure 5.1 presents the marginal effect of one of the explanatory variables on economic growth, at different relative sizes of manufacturing $\left(s_{M A N}\right)$. The solid lines show the marginal effect while the dashed lines show the $95 \%$ interval of confidence. For all ranges of $s_{M A N}$ in which the lower bound of the interval is above zero, the marginal effect of the variable is positive and significant. For all ranges in which the upper bound is below zero, the marginal effect is negative and significant. If the zero line lies between the upper and lower bound, then the marginal effect is not statistically significant. For the sake of clarity, the y-axis range in the first figure is much wider than in the remaining ones, so it should be stressed that the size and variability of the marginal effect in this particular variable is much larger. 
The first two panels illustrate with clarity how the effect of $\lambda$ and $\rho$ on economic growth change dramatically depending on the composition of the modern sector. A large modern sector has a negative effect on growth, but this effects diminishes as the manufacturing share increases and turns positive if that share exceeds $80 \%$ (point in which the lower bound of the confidence interval crosses the zero axis). In the same way, the marginal effect of the technology gap of the modern sector on growth is negative but decreases as the manufacturing share grows and becomes zero if that share exceeds $60 \%$. Hence, in an extreme case, if manufacturing completely dominates the modern sector, then the effect of both variables is positive. An expansion of the modern sector and a reduction of the technological gap would increase (instead of retract) the speed of growth. Such a situation, however, would be quite implausible. As detailed in Table 5.1, the average share of manufacturing in our panel dataset is about $50 \%$, and the maximum ever achieved is $73 \%$. Nevertheless, these results would again confirm our previous conclusion that countries with a modern sector strongly based on manufacturing would suffer a lower penalization on their growth rates as they achieve their structural modernization.

Looking at the remaining panels of the figure we can also notice that the positive impact of EDU and OPEN on growth depends on the share of manufacturing in the modern sector. At very low levels of $s_{M A N}$, these variables have a negligible (or even negative) impact on growth. Their positive impact starts when manufacturing represents at least $20 \%$ of the modern sector, and it increases as this relative size grows.

The negative slope of UNDERV, instead, is more difficult to interpret. It might be reflecting the effect of a third variable that we are not explicitly considering in this set of regressions. This outcome could be driven, for example, by an increase in the relative importance of imported goods as manufacturing becomes dominant. This would be an extended phenomenon in low and middle income countries where the process of industrialization typically brings increasing requirements of capital goods that are not domestically produced and thus need to be imported from abroad. If these increasing requirements for imported goods are not offset by an equivalent increase in domestic exports, then the external restriction might become binding and the growth rates would tend to diminish (eventually leading to a Balance of Payments crisis). In such a context, a real devaluation of the domestic currency might erode (instead of stimulate) the growth potential of the economy under examination, as reflected in the negative slopes of the corresponding interaction term. Note, however, that it is only at extremely large relative sizes of manufacturing that the marginal effect of UNDERV becomes negative. 


\subsection{Export Structure and Economic Growth}

One of the major messages of the previous section relates to the special role that manufacturing would play in the process of economic development. In line with a large strand of literature that highlights the positive growth enhancing characteristics of this sector, our previous discussion suggests that a structural modernisation heavily based upon manufacturing would be better able to avoid the slowdown in the rate of growth that takes place as countries expand their modern sector and approach to the technological frontier.

An important channel by which manufacturing might be exerting this special role is through its export potential. Therefore, in the remaining of this chapter we will explore the specific impact of international trade on economic growth, and the particular role played by manufacturing exports.

\subsubsection{Approach}

Our point of departure is the model described by Equation (5.2), using the share of manufacturing on total MMA labour as a proxy for the composition of the modern sector. That is, the model $3 \mathrm{c}$ in Table 5.3. In all regressions of this section, this baseline model will be modified in order to explore further the positive and significant impact found in the term OPEN. This variable will be sequentially replaced by other variables related to merchandise exports and their composition.

An important challenge when evaluating the role of exports of particular sectors in economic growth has to do with the different classifications used by trade and national accounts data. Trade data is typically classified on a product base, whereas national accounts, instead, focus on broad sectors. Since our analysis so far has been based on a national accounts perspective, particular attention needs to be devoted to classify our trade variables in a comparable manner. This is especially relevant when defining what particular set of exported goods should be regarded as part of the manufacturing sector. The definition typically used is based on the Standard International Trade Classification (SITC) and only includes headings 5 to 8 (that is: chemicals, basic manufactures, machinery and transport equipment, and miscellaneous manufactured goods) and sometimes excludes subheadings 68 (nonferrous metals) and 667 (Pearls and precious and semiprecious stones). Therefore it does not include within manufacturing, for instance, any processed food or beverage products. In many developing countries this type of goods accounts for an important share of manufacturing production and export ${ }^{122}$.

\footnotetext{
${ }^{122}$ Interestingly, this issue gave rise to some debate during the late 80 s and early 90 s but was later disregarded. To the best of our knowledge, there is not recent literature dealing with this topic. For the earlier references, see: Hill (1986) and Yeats (1991), (1992).
} 
Besides the classification issue, another problem that arises when analysing the role of exports is related to their composition. Most studies on this issue refer to total exports, regardless of the value added content of these exports. In a context of an increasing fragmentation of production, this may introduce an important bias in the estimations, especially when the focus is on the impact of exports on overall economic growth.

In this chapter, important efforts have been devoted to overcome these limitations. Therefore, the export variables constructed are based on the ISIC classification of manufacturing and consider not only gross value of exports but also the value added content of exports. In order to do so, the original data published at 5 and 6 digits of the SITC (rev 1 and 2) by UN-COMTRADE was converted into 4 digit levels of the ISIC rev 2. Subsequently sector-specific Value Added-Gross Output ratios have been applied to the manufacturing export figures of each country to obtain a rough estimate of their value added content. These ratios have been calculated using the UNIDO INDSTAT database and other complementary sources. The next subsection provides further details.

Being aware of the fact the manufacturing sector is itself composed by a set of very heterogeneous industries, we will also explore the role of different specialization patterns within manufacturing exports. These patterns are defined using two alternative criteria in correspondence with the key features highlighted in our theoretical model: their technological content and their average income elasticity of demand.

In order to classify manufacturing exports according to their technological content, we use the standard OECD classification originated in Hatzichronoglou (1997) and revised in OECD (2003). Based on this classification we distinguish four sectoral groups: high-tech, medium high-tech, medium low-tech and low-tech. The following table summarize the ISIC sectors included in each group: 
Table 5.5. Classification of Manufacturing exports by technology intensity

\begin{tabular}{|c|c|}
\hline $\begin{array}{l}\text { High- } \\
\text { technology }\end{array}$ & $\begin{array}{l}\text { Aerospace (ISIC code: } 3845) \text {; Computers and office macbinery (ISIC code: } \\
\text { 3825); Electronics and communications (ISIC code: } 3832 \text { ); Pharmaceuti- } \\
\text { cals (ISIC code: } 3522 \text { ); Scientific instruments (ISIC code: } 385 \text { ) }\end{array}$ \\
\hline $\begin{array}{l}\text { Medium-high- } \\
\text { technology }\end{array}$ & $\begin{array}{l}\text { Motor vehicles (ISIC code: } 3843 \text { ); Electrical machinery (ISIC code: } 383 \text { - } \\
\text { 3832); Chemicals (ISIC code: } 351+352-3522) \text {; Other transport equip- } \\
\text { ment (ISIC code: } 3842+3844+3849) \text {; Non-electrical machinery (ISIC } \\
\text { code: } 382-3825 \text { ) }\end{array}$ \\
\hline $\begin{array}{l}\text { Medium-low- } \\
\text { technology }\end{array}$ & $\begin{array}{l}\text { Rubber and plastic products (ISIC code: } 355+356 \text { ); Shipbuilding (ISIC } \\
\text { code: } 3841 \text { ); Other manufacturing (ISIC code: } 39 \text { ); Non-ferrous metals } \\
\text { (ISIC code: } 372 \text { ); Non-metallic mineral products (ISIC code: } 36 \text { ); Fabri- } \\
\text { cated metal products (ISIC code: } 381 \text { ); Petroleum refining (ISIC code: } \\
\text { 353+354); Ferrous metals (ISIC code: } 371 \text { ) }\end{array}$ \\
\hline $\begin{array}{c}\text { Low- } \\
\text { technology }\end{array}$ & $\begin{array}{l}\text { Paper printing (ISIC code: } 34) \text {; Textiles and clothing (ISIC code: } 32 \text { ); } \\
\text { Food, beverages, and tobacco (ISIC code: } 31 \text { ); Wood and furniture (ISIC } \\
\text { code: } 33 \text { ) }\end{array}$ \\
\hline
\end{tabular}

Source: Own elaboration based on Hatzichronoglou (1997) and OECD (2003)

From a Post-Keyenesian perspective, however, the most important feature when evaluating the impact of certain exported good in economic growth is the income elasticity of export demand. If a low-tech sector has a high income elasticity of demand, then it might have a higher impact on growth than a more technological sophisticated sector with lower income elasticity. In order to account for this feature as well, we also explore a sectoral classification based on the average income elasticity shown by different groups of exports throughout the period under consideration. This classification is defined on the basis of the sectoral income elasticities of export demand estimated by Gouvêa and Lima (2013). Using panel data techniques in a sample of 90 countries for the period 1965-1999, these authors estimate sectoral elasticities of exports and imports to study the empirical validity of Thirlwall's Balance of Payments Constrained growth model. Their results are reported using Leamer's 11 sectors classification and show elasticity values that range from a lowest level of 0.174 to a maximum level of 2.376. On the basis of these results, we have distinguished three sectoral groups: high income elasticity (sectors with estimated average elasticity higher than 2), medium income elasticity (estimated elasticity ranging between 1 and 2) and low income elasticity (estimated elasticity below 
1). The following table presents this sectoral classification, reports the estimated elasticities of Gouvêa and Lima (2013) and summarizes the ISIC manufacturing codes included in each group ${ }^{123}$ :

Table 5.6. Classification of Manufacturing exports by average level of income elasticity

\begin{tabular}{|c|c|c|c|}
\hline & $\begin{array}{c}\text { Sectoral group } \\
\text { (Leamer classification) }\end{array}$ & $\begin{array}{l}\text { Estimated } \\
\text { elasticity }(1)\end{array}$ & $\begin{array}{l}\text { ISIC codes included }{ }^{(2)} \\
\text { (only manufacturing) }\end{array}$ \\
\hline \multirow{3}{*}{$\begin{array}{l}\text { High Income } \\
\text { Elasticity }\end{array}$} & Macbinery & 2.376 & $382,383,384,385$ \\
\hline & Labour-intensive industries & 2.163 & $\begin{array}{l}322,324,332,342,356 \\
361,362,369,381,390\end{array}$ \\
\hline & Petroleum & 2.096 & 353,354 \\
\hline \multirow{4}{*}{$\begin{array}{l}\text { Medium In- } \\
\text { come Elasticity }\end{array}$} & Capital intensive industries & 1.544 & $\begin{array}{l}321,323,355,371,372, \\
381\end{array}$ \\
\hline & Chemical industries & 1.640 & 351,352 \\
\hline & Forest products & 1.103 & 331,341 \\
\hline & Animal products & 1.021 & $3111-2,3114$ \\
\hline \multirow{2}{*}{$\begin{array}{l}\text { Low Income } \\
\text { Elasticity }\end{array}$} & Tropical agriculture & 0.681 & $3113,3118-9,113$ \\
\hline & Cereals & 0.174 & $3115-7,312,314$ \\
\hline
\end{tabular}

Source: Own elaboration based on Gouvêa and Lima (2013)

(1) Estimates taken from Gouvêa and Lima (2013), Table 1, page 246.

(2) The imputation of ISIC sectors into Leamer's Sectors has been done based on a correspondence table elaborated by Hidalgo et al. (2007) and available at www.chidalgo.com/productspace

Comparing both classifications we can see that there is an important overlap between the average technological content and the average income elasticity. All hightech sectors except Pharmaceuticals have, according to Gouvêa and Lima (2013) estimates, also high levels of income elasticity. The same seems to be true for medium-high-tech sectors. The main differences occur at lower levels of technological content. As we can see, some sectors previously identified as low-or medium-lowtech fall into the high-income elasticity group (Furniture, Non-metallic products, Petroleum, Plastic products, Printing and Wearing apparel). In a similar vein, several low-tech sectors fall into the medium-income elasticity group (such as, for example, Dairy products, Paperproducts, Textiles and Wood products). It follows that analysing the composition of exports by means of one or the other classification would probably deliver different results.

123 We should note that some groups of the Leamer classification include also non-manufacturing goods. These are the cases of Petroleum, Forest products, Animal products, Tropical agriculture and Cereals. Since the original source makes no distinction between manufacturing and non-manufacturing goods the estimated elasticities presented in Table 5.7 for these groups might be underestimated. In future research we aim at building our own elasticity estimates excluding non-manufacturing goods. 
We turn now to briefly describe the procedures followed to build our data and the main descriptive statistics of the new variables that will be analysed in the remaining of this section.

\subsubsection{Data}

The following steps summarize the procedure used to construct our trade variables. In the APPENDIX $\mathrm{E}$ we describe with further detail the specific sources used for each country and variable.

i) Structure of exports. We estimated the structure of exports at 4-digit levels of the ISIC rev 2 for each country/year of our sample using information from UN-COMTRADE (accessed towards the WITS online tool124). Given the long span of our analysis, we used the information published according to the SITC rev. 1 and SITC rev. 2 at the highest available level of disaggregation (5 and 6 digits, depending on the product/country) and we converted it into ISIC codes using specific concordance tables ${ }^{125}$. In most countries, this information starts in 1962 and continues until 2010.

ii) Exports at current dollars. We estimated figures at current dollars multiplying the structure of exports by the total value of merchandise exports at current dollars published by UNCTAD for each country/year. For a few countries (Belgium, Indonesia and Panamá), UNCTAD data was not available for the whole period and therefore we used comparable data published by the WTO.

iii) Value Added of exports. We estimated the value added of manufacturing exports multiplying the exports of each sector by the value added-gross output ratio of the nearest 3 digit sector ${ }^{126}$. These ratios were calculated using information from three main sources: OECD, UNIDO and ECLAC ${ }^{127}$.

124 World Integrated Trade Solution (http://wits.worldbank.org/wits/)

125 Three concordances have been elaborated: from SITC rev. 1 to SITC rev. 2 (based on Feenstra, 1996), from SITC rev. 1 to ISIC rev. 2 (based on UN, 1971), and from SITC rev. 2 to ISIC rev. 2 (based on the WITS concordance, available online). When building these concordances, we faced an important difficulty: while a one on one correspondence between SITC and ISIC rev. 2 is only achievable using disaggregated data at 6 digit level of the SITC, in the starting years many products/countries only provide the information at lower levels of disaggregation. To overcome this difficulty, we generated an algorithm that imputes the structure of the first year with available data at 6 digits into the corresponding group at lower level of disaggregation for all the previous years. That is, if the data at 6 digit level for a certain group of goods for a certain country was only available after 1970, during the sixties, we used the proportions of 1970 to break down the data for earlier years.

126 Unfortunately, value added-gross output ratios at higher level of disaggregation were only available for very few countries and years. To avoid biases in our data, we preferred to use ratios disaggregated at 3 digit-level for all countries.

${ }^{127}$ See Table E. 6 in APPENDIX E for the details. 
iv) Groups of exports. Using our figures at 4-digit level of the ISIC rev. 2, we constructed 3 broad groups of exports following the standard classifications of agriculture, mining and manufacturing sectors ${ }^{128}$. As explained above, within manufacturing, we have further explored two alternative classifications of industries: a) by technological intensity (see Table 5.5); and b) by average level of income elasticity of export demand (see Table 5.6).

v) Exports as percentage of GDP. Finally, for each country/year we divided our estimates of gross exports and exported value added at current dollars by the GDP. The information on GDP at current dollars was mainly taken from the WDI database. For some countries, however, this database does not cover all the period under analysis and thus it was complemented with data from the Penn World Tables, version 8.

Using this procedure we constructed estimates of manufacturing exports (total and value added) at the aggregate level and disaggregated by technology group and elasticity group for our sample of countries between 1960 and 2009. Due to data constraints, however, not all countries are represented in each 5-year interval (see APPENDIX E)

Before analysing the main descriptive statistics derived from this dataset, it is important to emphasise some of its limitations. First, the correspondences between trade data and industrial data are never exact, and therefore, important assumptions regarding product structures within certain STIC codes have been necessary (see footnote 116). Thus, the disaggregation by ISIC categories (especially at high levels) is only approximate.

Second, the procedure to estimate the value added content of exports using domestic value added output ratios is rough. It should be understood as a first approximation given the data at hand. At the conceptual level, it only captures part of what the recent literature has referred to as "trade in value added" 129 . According to this literature, not only the domestic value added content of a particular export is important, but also the value added of all domestic suppliers which have contributed to the production of that particular good. In this regard, our approach is limited since it includes only the "direct" value added of exports, but leaves behind the "indirect" domestic value added generated, which may represent the most important share of domestic exported value added. The lack of input-output tables for all

\footnotetext{
${ }^{128}$ Note that we defined these groups in accordance to the ISIC classification. Therefore, all agricultural products that have been further processed into manufacturing are treated as manufacturing exports. This is the case, for example, of all processed food exports that are integrated into the ISIC rev. 2 major group 311-312, Food Manufacturing.

${ }^{129}$ See Stehrer (2012) for a recent review on this literature.
} 
countries in our sample, however, made it impossible to capture both the direct and the indirect effects of exports on value added for the long time span considered here.

Finally, our empirical approximation relies on a strong assumption: the ratio of value added to gross output of an exported good produced in a specific sector should be equal to the value added output ratio of all goods produced in that sector. Once more, however, for the majority of the cases, this does not seem to be a too extreme assumption.

Given these limitations, we should interpret our results with caution. Nevertheless, even with these limitations, the variables constructed offer an interesting opportunity to include trade features into the examination of structural modernisation and economic growth.

That being said, we present now some descriptive statistics of our trade variables. 


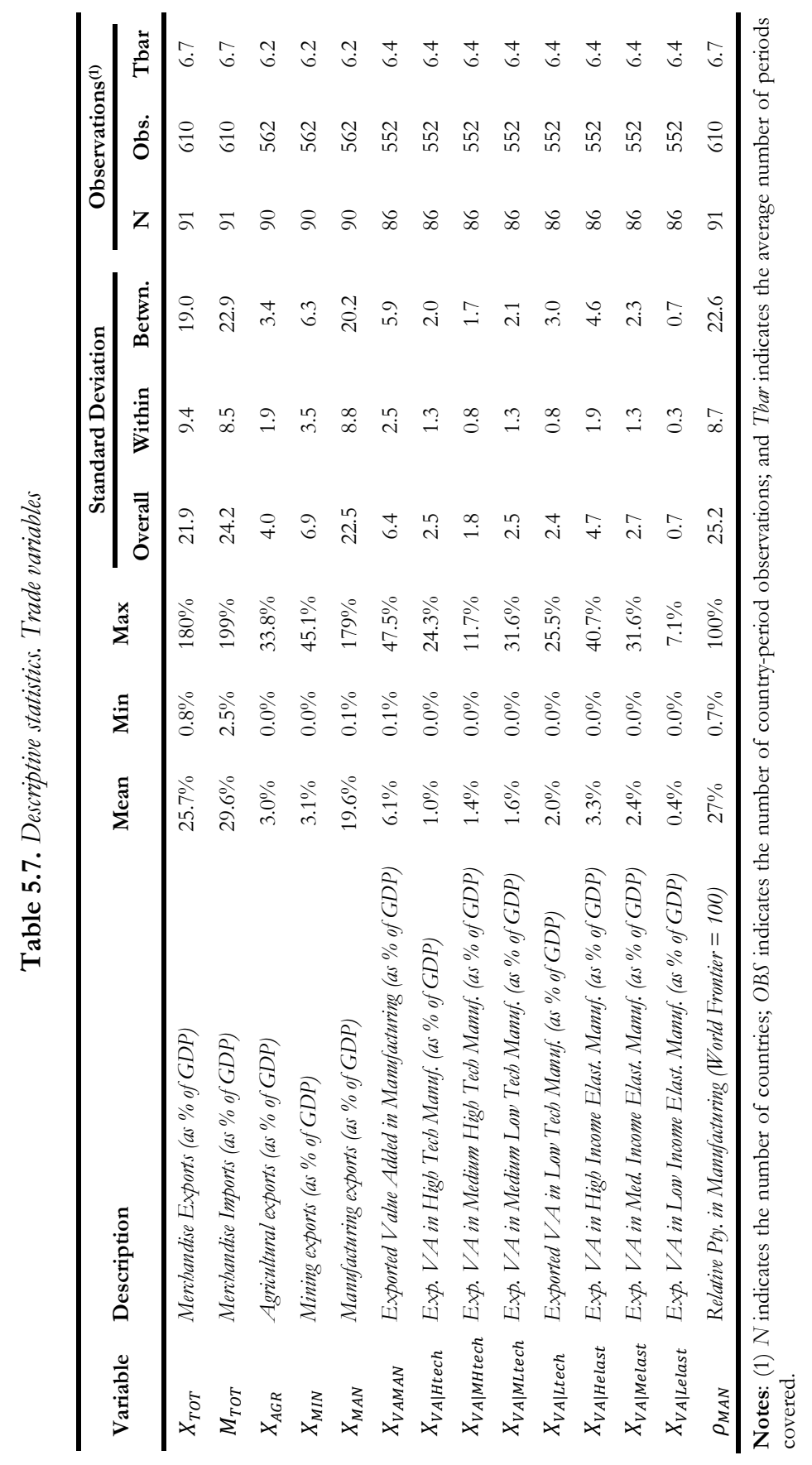


To begin with, we should emphasize that the coverage of our trade variables (once they are opened by sectors) is lower than the coverage of the variables examined in the previous section. Therefore, the regressions undertaken in this section will be done over a smaller sample, in which about 50 observations have been $\operatorname{lost}^{130}$ (see last three columns of the table).

Looking at the third column of the table we can see that manufacturing exports (defined according to the ISIC classification) are by far the most important component within total exports. Their share in GDP is, on average, six time larger than the share of mining and agricultural exports. Our estimates also suggest that, on average, the value added content of manufacturing exports is only 30\% of their total value. The average share in GDP by technological intensity groups is quite balanced (ranging from 1\% to $2 \%$ ) but the average share by elasticity group is mostly dominated by the high and middle income groups. Manufacturing exports with low income elasticity only represent (on average) $0.4 \%$ of the GDP.

In line with the discussion of our previous regressors, in the trade variables the standard deviation between countries is also more pronounced than the deviation over time within the same countries. Therefore, the Hausman-Taylor estimate will be, once more, our preferred technique to analyse the impact of these variables on economic growth. As was done previously, before applying this technique we need to identify the endogenous variables. In this case, the Hausman specification tests indicate that six variables should be treated as endogenous: $X_{T O T}, X_{M A N}, X_{V A M A N}$, $X_{V A \mid \text { Hech }}, X_{V A \mid \text { MHtech }}$ and $X_{V A \mid \text { Helast }}$ (see Table 5.8).

\footnotetext{
${ }^{130}$ As a robustness check, the estimates undertaken so far have also been run over this restricted sample and the results remained almost unchanged. Hence, we do not expect this loss of observations to bring an important bias in our estimates.
} 
Table 5.8. Hausman's (1978) specification test for the explanatory trade variables

\begin{tabular}{lccccc}
\hline Variable & $\mathbf{N}$ & Obs. & $\chi^{2}$-stat & p-value & endog. \\
\hline$X_{\text {TOT }}$ & 91 & 610 & 5.2 & 0.023 & 1 \\
$M_{\text {TOT }}$ & 91 & 610 & 0.6 & 0.451 & \\
$X_{\text {AGR }}$ & 90 & 562 & 2.6 & 0.108 & \\
$X_{\text {MIN }}$ & 90 & 562 & 0.1 & 0.734 & \\
$X_{\text {MAN }}$ & 90 & 562 & 8.6 & 0.003 & 1 \\
$X_{V A M A N}$ & 86 & 552 & 4.8 & 0.028 & 1 \\
$X_{V A \mid \text { Htech }}$ & 86 & 552 & 11.0 & 0.001 & 1 \\
$X_{V A \mid \text { MHtech }}$ & 86 & 552 & 10.3 & 0.001 & 1 \\
$X_{V A \mid \text { MLtech }}$ & 86 & 552 & 0.5 & 0.460 & \\
$X_{V A \mid \text { Ltech }}$ & 86 & 552 & 2.7 & 0.099 & \\
$X_{V A \mid \text { Helast }}$ & 86 & 552 & 9.0 & 0.003 & 1 \\
$X_{V A \mid \text { Melast }}$ & 86 & 552 & 0.0 & 0.872 & \\
$X_{V A \mid \text { Lelast }}$ & 86 & 552 & 0.5 & 0.478 & \\
$\rho_{\text {MAN }}$ & 91 & 610 & 3.2 & 0.072 & \\
\hline
\end{tabular}

We turn now to analyse the results.

\subsubsection{Trade and manufacturing}

Our first set of regressions explores the role of various trade variables on economic growth. The base run replicates our preferred model of the last section (without interaction terms) but applied to the restricted sample with available data on the trade variables (that is, to 562 instead of 610 observations). The next models introduce exports as explanatory variable instead of openness (Model 5), and then disaggregate them by major sectors (Models 6 and 7). 
Table 5.9. Determinants of growth. The role of exports

\begin{tabular}{|c|c|c|c|c|}
\hline & Model 3c & Model 5 & Model 6 & Model 7 \\
\hline Constant & $\begin{array}{l}-0.021 \\
(0.016)\end{array}$ & $\begin{array}{l}-0.018 \\
(0.016)\end{array}$ & $\begin{array}{l}-0.027 \\
(0.017)\end{array}$ & $\begin{array}{l}-0.029 \\
(0.017)\end{array}$ \\
\hline CLIMATE & $\begin{array}{l}0.017 \\
(0.012)\end{array}$ & $\begin{array}{l}0.019 \\
(0.012)\end{array}$ & $\begin{array}{l}0.018 \\
(0.012)\end{array}$ & $\begin{array}{l}0.018 \\
(0.012)\end{array}$ \\
\hline RICHNR & $\begin{array}{l}0.016 \\
(0.015)\end{array}$ & $\begin{array}{l}0.016 \\
(0.015)\end{array}$ & $\begin{array}{l}0.012 \\
(0.016)\end{array}$ & $\begin{array}{l}0.012 \\
(0.016)\end{array}$ \\
\hline LNPOP & $\begin{array}{l}0.005 \\
(0.003)\end{array}$ & $\begin{array}{l}0.005 \\
(0.003)\end{array}$ & $\begin{array}{l}0.005 \\
(0.004)\end{array}$ & $\begin{array}{l}0.006 \\
(0.004)\end{array}$ \\
\hline UNDERV & $\begin{array}{l}0.012^{* * *} \\
(0.004)\end{array}$ & $\begin{array}{l}0.012^{* * *} \\
(0.004)\end{array}$ & $\begin{array}{l}0.013^{* * *} \\
(0.004)\end{array}$ & $\begin{array}{l}0.012^{* * *} \\
(0.004)\end{array}$ \\
\hline EDU & $\begin{array}{l}0.003 \\
(0.001)\end{array}$ & $\begin{array}{l}0.003 \\
(0.001)\end{array}$ & $\begin{array}{c}0.003^{*} \\
(0.001)\end{array}$ & $\begin{array}{c}0.003^{*} \\
(0.001)\end{array}$ \\
\hline INV & $\begin{array}{c}0.043^{* *} \\
(0.017)\end{array}$ & $\begin{array}{c}0.053 * * \\
(0.017)\end{array}$ & $\begin{array}{c}0.052^{* *} \\
(0.017)\end{array}$ & $\begin{array}{l}0.056^{* * *} \\
(0.017)\end{array}$ \\
\hline$\rho$ & $\begin{array}{l}-0.035^{\text {*** }} \\
(0.011)\end{array}$ & $\begin{array}{l}-0.039 * * * \\
(0.011)\end{array}$ & $\begin{array}{l}-0.035^{* *} \\
(0.011)\end{array}$ & $\begin{array}{l}-0.034^{* *} \\
(0.011)\end{array}$ \\
\hline$\lambda$ & $\begin{array}{l}-0.122^{* * *} \\
(0.026)\end{array}$ & $\begin{array}{l}-0.127^{* * *} \\
(0.026)\end{array}$ & $\begin{array}{l}-0.121^{* * *} \\
(0.026)\end{array}$ & $\begin{array}{l}-0.133^{* * *} \\
(0.027)\end{array}$ \\
\hline$S_{M A N}$ & $\begin{array}{l}0.075^{* * *} \\
(0.018)\end{array}$ & $\begin{array}{l}0.076^{* * *} \\
(0.018)\end{array}$ & $\begin{array}{l}0.080^{* * *} \\
(0.018)\end{array}$ & $\begin{array}{l}0.083^{* * *} \\
(0.018)\end{array}$ \\
\hline OPEN & $\begin{array}{l}0.019 * * \\
(0.006)\end{array}$ & & & \\
\hline$X_{\text {TOT }}$ & & $\begin{array}{c}0.037 * * \\
(0.011)\end{array}$ & & \\
\hline$X_{A G R}$ & & & $\begin{array}{l}0.067 \\
(0.046)\end{array}$ & $\begin{array}{l}0.054 \\
(0.052)\end{array}$ \\
\hline$X_{M I N}$ & & & $\begin{array}{c}0.073^{* *} \\
(0.024)\end{array}$ & $\begin{array}{c}0.067^{* *} \\
(0.025)\end{array}$ \\
\hline$X_{M A N}$ & & & $\begin{array}{l}0.035^{* *} \\
(0.012)\end{array}$ & \\
\hline$X_{V A M A N}$ & & & & $\begin{array}{l}0.142^{* * *} \\
(0.040)\end{array}$ \\
\hline p75_90 & $\begin{array}{c}-0.010^{*} \\
(0.004)\end{array}$ & $\begin{array}{c}-0.009 * \\
(0.004)\end{array}$ & $\begin{array}{c}-0.010^{*} \\
(0.004)\end{array}$ & $\begin{array}{c}-0.010^{*} \\
(0.004)\end{array}$ \\
\hline p90_09 & $\begin{array}{l}0.000 \\
(0.006)\end{array}$ & $\begin{array}{l}0.001 \\
(0.006)\end{array}$ & $\begin{array}{l}0.001 \\
(0.006)\end{array}$ & $\begin{array}{l}-0.001 \\
(0.006)\end{array}$ \\
\hline Rho & 0.865 & 0.865 & 0.877 & 0.88 \\
\hline Obs. & 562 & 562 & 562 & 552 \\
\hline Countries & 90 & 90 & 90 & 86 \\
\hline
\end{tabular}

${ }^{*} \mathrm{p}<0.05,{ }^{* *} \mathrm{p}<0.01,{ }^{* * *} \mathrm{p}<0.001$ 
Restricting the sample does not seem to affect our estimates in any significant way: the results shown in the first model of the table are almost identical to those of the previous section. Perhaps the only important change is that the period dummy for 1975-1990 now becomes highly significant. The negative sign of this period dummy would be reflecting the oil crisis and debt crisis that took place during those years.

Now, when we replace OPEN by $X_{T O T}$ we can see that the latter enters with a positive and significant coefficient that is much larger than the corresponding coefficient for openness. Interestingly, if $X_{\text {TOT }}$ is further broken down into its three main components, manufacturing and mining enter with a positive and significant coefficient while agriculture enters with a non-significant coefficient. However, the coefficient of mining exports almost duplicates that of manufacturing. This surprising result seems to be driven by the fact that we are considering gross exports instead of their value added content. Once we make the appropriate adjustment to value added we can see that exports of manufacturing value added is the component with the highest level of significance and has by far the largest coefficient ${ }^{131}$.

Overall, the results of Table 5.9 demonstrate the important role played by exports in driving economic growth. However, they suggest that not all exports have the same growth-enhancing effect. Manufacturing exports, mainly when adjusted by their value added content, are the export component that shows the highest correlation with economic growth in our sample of countries for the period under consideration. Also interesting, we can see that the positive impact of manufacturing's share on MMA employment $\left(s_{\text {MAN }}\right)$ remains positive and highly significant even when we introduce variables capturing the role of manufacturing exports. This suggests that there are other channels through which manufacturing is exerting a positive impact on growth. As stated in CHAPTER 2, Section 2.4.1, these would be mainly related to the larger opportunities for technological progress that this sector provides as compared to the other sectors of the MMA.

Given the well-known diversity of industries that composes manufacturing, it is important to investigate whether this positive effect is driven by some specific set of industries within this aggregate. We explore this issue by looking at the growth impact of different manufacturing groups, following two alternative classifications: first we distinguish manufacturing exports according to the technological intensity of the industries to which they belong. Second we distinguish these exports according to the average level of income elasticity in their export demand (see Table 5.10).

\footnotetext{
${ }^{131}$ It should be noted, however, that the adjustment for value added content is only done for manufacturing exports. The shares of agriculture and mining exports over GDP still refer to gross exports. Unfortunately, we could not find comparable value added-gross output ratios for these sectors to make the same adjustment that we have done for manufacturing exports.
} 
Each column in Table 5.10 presents a different model in which $X_{V A M A N}$ has been replaced by the exported value added-GDP ratio of one particular group of manufacturing industries. The first four columns detail the results for the exports by technological intensity while the last three columns detail the results by level of income elasticity.

Looking first at the technological categories we find a somewhat surprising result. Only the low tech categories enters to the regression with a positive and significant coefficient. High tech and medium-high tech manufacturing, instead, enter with a non-significant coefficient. On second thoughts this is not so implausible. It might be reflecting the fact that many low income countries find their first road towards catch up by exporting low-tech products. Furthermore, even if some sectors are classified as being low-tech their impact on growth might still be important due to two complementary reasons. On one hand, they might have a high income elasticity of demand (as it seems to be the case in some labour-intensive industries according to our classification). On the other hand, they might be reflecting a specialization within the broad set of sectors encompassed in that particular group that does show a higher degree of technological sophistication and thus, higher dynamism in world markets.

The first hypothesis is partially confirmed when we look at the second part of the table (models 9e to 9g). In this case, only the exports of high and medium income elasticity enter with a positive and significant coefficient. Manufacturing exports coming from sectors with low income elasticity, instead, enter with a negative sign, although it is not statistically different from zero. 
Table 5.10. Determinants of growth: the role of different manufacturing value added exports groups

\begin{tabular}{|c|c|c|c|c|c|c|c|}
\hline & Model 9a & Model 9b & Model 9c & Model 9d & Model 9e & Model 9f & Model 9g \\
\hline Constant & $\begin{array}{l}-0.016 \\
(0.017)\end{array}$ & $\begin{array}{l}-0.016 \\
(0.017)\end{array}$ & $\begin{array}{l}-0.026 \\
(0.018)\end{array}$ & $\begin{array}{l}-0.016 \\
(0.016)\end{array}$ & $\begin{array}{l}-0.019 \\
(0.017)\end{array}$ & $\begin{array}{l}-0.027 \\
(0.018)\end{array}$ & $\begin{array}{l}-0.014 \\
(0.017)\end{array}$ \\
\hline CLIMATE & $\begin{array}{l}0.013 \\
(0.013)\end{array}$ & $\begin{array}{l}0.013 \\
(0.013)\end{array}$ & $\begin{array}{l}0.015 \\
(0.014)\end{array}$ & $\begin{array}{l}0.013 \\
(0.012)\end{array}$ & $\begin{array}{l}0.017 \\
(0.012)\end{array}$ & $\begin{array}{l}0.014 \\
(0.013)\end{array}$ & $\begin{array}{l}0.013 \\
(0.013)\end{array}$ \\
\hline RICHNR & $\begin{array}{l}0.005 \\
(0.016)\end{array}$ & $\begin{array}{l}0.006 \\
(0.016)\end{array}$ & $\begin{array}{l}0.006 \\
(0.017)\end{array}$ & $\begin{array}{l}0.007 \\
(0.016)\end{array}$ & $\begin{array}{l}0.010 \\
(0.016)\end{array}$ & $\begin{array}{l}0.007 \\
(0.017)\end{array}$ & $\begin{array}{l}0.004 \\
(0.016)\end{array}$ \\
\hline LNPOP & $\begin{array}{l}0.004 \\
(0.004)\end{array}$ & $\begin{array}{l}0.004 \\
(0.004)\end{array}$ & $\begin{array}{l}0.006 \\
(0.004)\end{array}$ & $\begin{array}{l}0.007 \\
(0.004)\end{array}$ & $\begin{array}{l}0.005 \\
(0.004)\end{array}$ & $\begin{array}{l}0.006 \\
(0.004)\end{array}$ & $\begin{array}{l}0.004 \\
(0.004)\end{array}$ \\
\hline UNDERV & $\begin{array}{l}0.012^{* *} \\
(0.004)\end{array}$ & $\begin{array}{l}0.013^{* * *} \\
(0.004)\end{array}$ & $\begin{array}{l}0.012^{* * *} \\
(0.004)\end{array}$ & $\begin{array}{l}0.011 * * \\
(0.004)\end{array}$ & $\begin{array}{l}0.013^{* * *} \\
(0.004)\end{array}$ & $\begin{array}{l}0.011 * * \\
(0.004)\end{array}$ & $\begin{array}{l}0.013^{* * *} \\
(0.004)\end{array}$ \\
\hline EDU & $\begin{array}{c}0.003^{*} \\
(0.001)\end{array}$ & $\begin{array}{c}0.003^{*} \\
(0.001)\end{array}$ & $\begin{array}{c}0.004 * \\
(0.001)\end{array}$ & $\begin{array}{l}0.003^{*} \\
(0.001)\end{array}$ & $\begin{array}{c}0.003^{*} \\
(0.001)\end{array}$ & $\begin{array}{l}0.004^{*} \\
(0.001)\end{array}$ & $\begin{array}{l}0.004^{*} \\
(0.001)\end{array}$ \\
\hline INV & $\begin{array}{c}0.053^{* *} \\
(0.017)\end{array}$ & $\begin{array}{l}0.053 * * \\
(0.017)\end{array}$ & $\begin{array}{l}0.056^{* * *} \\
(0.017)\end{array}$ & $\begin{array}{c}0.043^{*} \\
(0.017)\end{array}$ & $\begin{array}{c}0.050^{* *} \\
(0.017)\end{array}$ & $\begin{array}{l}0.060^{* * *} \\
(0.017)\end{array}$ & $\begin{array}{c}0.052 * * \\
(0.017)\end{array}$ \\
\hline$\rho$ & $\begin{array}{l}-0.029 * * \\
(0.011)\end{array}$ & $\begin{array}{l}-0.030^{* *} \\
(0.011)\end{array}$ & $\begin{array}{l}-0.028^{*} \\
(0.011)\end{array}$ & $\begin{array}{l}-0.022 * \\
(0.011)\end{array}$ & $\begin{array}{l}-0.032^{* *} \\
(0.011)\end{array}$ & $\begin{array}{l}-0.030^{* *} \\
(0.011)\end{array}$ & $\begin{array}{l}-0.029 * * \\
(0.011)\end{array}$ \\
\hline$\lambda$ & $\begin{array}{l}-0.103^{* * *} \\
(0.026)\end{array}$ & $\begin{array}{l}-0.106^{* * *} \\
(0.027)\end{array}$ & $\begin{array}{l}-0.122 * * * \\
(0.026)\end{array}$ & $\begin{array}{l}-0.110^{* * *} \\
(0.025)\end{array}$ & $\begin{array}{l}-0.116^{* * *} \\
(0.026)\end{array}$ & $\begin{array}{l}-0.127^{* * *} \\
(0.027)\end{array}$ & $\begin{array}{l}-0.103^{* * *} \\
(0.026)\end{array}$ \\
\hline$S_{M A N}$ & $\begin{array}{l}0.066^{* * *} \\
(0.019)\end{array}$ & $\begin{array}{l}0.067^{* * *} \\
(0.018)\end{array}$ & $\begin{array}{l}0.076^{* * *} \\
(0.018)\end{array}$ & $\begin{array}{l}0.049^{* *} \\
(0.018)\end{array}$ & $\begin{array}{l}0.070^{* * *} \\
(0.018)\end{array}$ & $\begin{array}{l}0.080^{* * *} \\
(0.018)\end{array}$ & $\begin{array}{l}0.063^{* * *} \\
(0.018)\end{array}$ \\
\hline$X_{A G R}$ & $\begin{array}{l}0.032 \\
(0.054)\end{array}$ & $\begin{array}{l}0.029 \\
(0.052)\end{array}$ & $\begin{array}{l}0.033 \\
(0.052)\end{array}$ & $\begin{array}{l}0.017 \\
(0.051)\end{array}$ & $\begin{array}{l}0.051 \\
(0.052)\end{array}$ & $\begin{array}{l}0.038 \\
(0.052)\end{array}$ & $\begin{array}{l}0.033 \\
(0.053)\end{array}$ \\
\hline$X_{M I N}$ & $\begin{array}{l}0.049 \\
(0.025)\end{array}$ & $\begin{array}{c}0.050^{*} \\
(0.025)\end{array}$ & $\begin{array}{c}0.057^{*} \\
(0.025)\end{array}$ & $\begin{array}{c}0.050^{*} \\
(0.024)\end{array}$ & $\begin{array}{l}0.061 * \\
(0.025)\end{array}$ & $\begin{array}{c}0.054 * \\
(0.024)\end{array}$ & $\begin{array}{l}0.047 \\
(0.025)\end{array}$ \\
\hline$X_{V A \mid \text { Htech }}$ & $\begin{array}{l}0.024 \\
(0.078)\end{array}$ & & & & & & \\
\hline$X_{V A \mid M H t e c h}$ & & $\begin{array}{l}0.085 \\
(0.130)\end{array}$ & & & & & \\
\hline$X_{V A \mid M L t e c h}$ & & & $\begin{array}{l}0.180 * * \\
(0.065)\end{array}$ & & & & \\
\hline$X_{V A \mid \text { Ltech }}$ & & & & $\begin{array}{l}0.432^{* * *} \\
(0.104)\end{array}$ & & & \\
\hline$X_{V A \mid \text { Helast }}$ & & & & & $\begin{array}{l}0.135^{*} \\
(0.054)\end{array}$ & & \\
\hline$X_{V A \mid \text { Melast }}$ & & & & & & $\begin{array}{l}0.195 * * \\
(0.066)\end{array}$ & \\
\hline$X_{V A \mid \text { Lelast }}$ & & & & & & & $\begin{array}{l}-0.142 \\
(0.248)\end{array}$ \\
\hline p75_90 & $\begin{array}{l}-0.011^{* *} \\
(0.004)\end{array}$ & $\begin{array}{c}-0.010^{*} \\
(0.004)\end{array}$ & $\begin{array}{l}-0.011^{* *} \\
(0.004)\end{array}$ & $\begin{array}{l}-0.013^{* *} \\
(0.004)\end{array}$ & $\begin{array}{c}-0.010^{*} \\
(0.004)\end{array}$ & $\begin{array}{l}-0.011^{* *} \\
(0.004)\end{array}$ & $\begin{array}{l}-0.011^{* *} \\
(0.004)\end{array}$ \\
\hline p90_09 & $\begin{array}{l}-0.001 \\
(0.006)\end{array}$ & $\begin{array}{l}-0.001 \\
(0.006)\end{array}$ & $\begin{array}{l}0.000 \\
(0.006)\end{array}$ & $\begin{array}{l}-0.006 \\
(0.006)\end{array}$ & $\begin{array}{l}0.000 \\
(0.006)\end{array}$ & $\begin{array}{l}-0.001 \\
(0.006)\end{array}$ & $\begin{array}{l}-0.001 \\
(0.006)\end{array}$ \\
\hline Rho & 0.886 & 0.884 & 0.903 & 0.879 & 0.875 & 0.895 & 0.887 \\
\hline Obs. & 552 & 552 & 552 & 552 & 552 & 552 & 552 \\
\hline Countries & 86 & 86 & 86 & 86 & 86 & 86 & 86 \\
\hline
\end{tabular}

${ }^{*} \mathrm{p}<0.05,{ }^{*} * \mathrm{p}<0.01, * * * \mathrm{p}<0.001$ 
An interesting way of exploring the second hypothesis consists in interacting each export group with the degree of catch up that the corresponding sector has with respect to the world frontier. Following the theoretical model detailed in CHAPTER 3, we could imagine that the impact of each export group on growth will depend positively on how close it is from the world technological frontier. Sectors that are close to the frontier are expected to produce more sophisticated goods across all export groups. In order to investigate this point, we detail a last set of regressions in which we interact the variables corresponding to each export group with the relative labour productivity in manufacturing industries $\left(\rho_{\text {MAN }}\right)$. The latter is taken as a proxy of the size of the technology gap of this sector with respect to the world frontier. Ideally this interaction should be done with the relative productivity of each sectoral group (high tech manufacturing, medium-high tech manufacturing, etc.), but the data at hand does not allow for such level of disaggregation in our production variables. As a second best solution, we interact with $\rho_{\text {MAN }}$. A positive and significant interaction term would be taken as evidence of this type of phenomena. That is, it will reveal that the growth impact of that particular export group depends on the distance to the frontier of the domestic manufacturing producers. The closer to the frontier, the higher the positive impact on growth.

The results of these set of regressions are summarized in the following figures (the corresponding results are reported in APPENDIX C, Table C. 1 and Table C. 2). Each figure depict the marginal effect of the corresponding manufacturing value added export group by level of manufacturing relative productivity. 
Figure 5.2. Marginal effect of manufacturing value added exports in different technology intensity groups, by level of relative productivity in manufacturing.
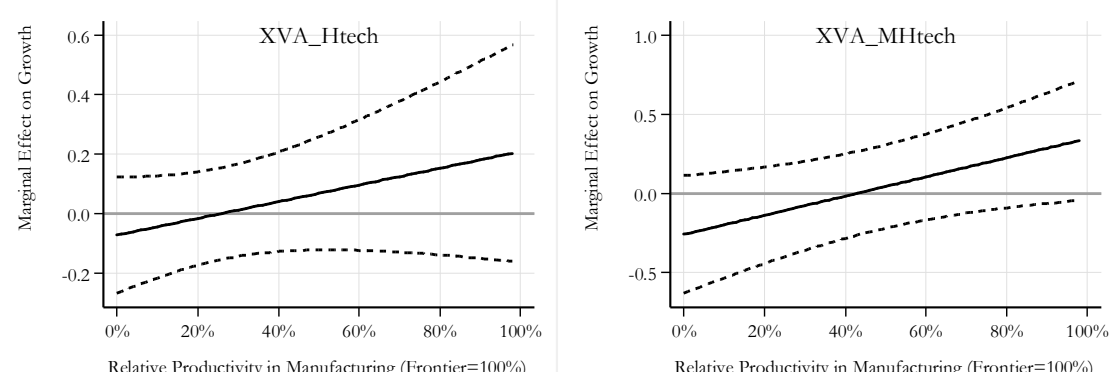

Relative Productivity in Manufacturing (Frontier $=100 \%$ )
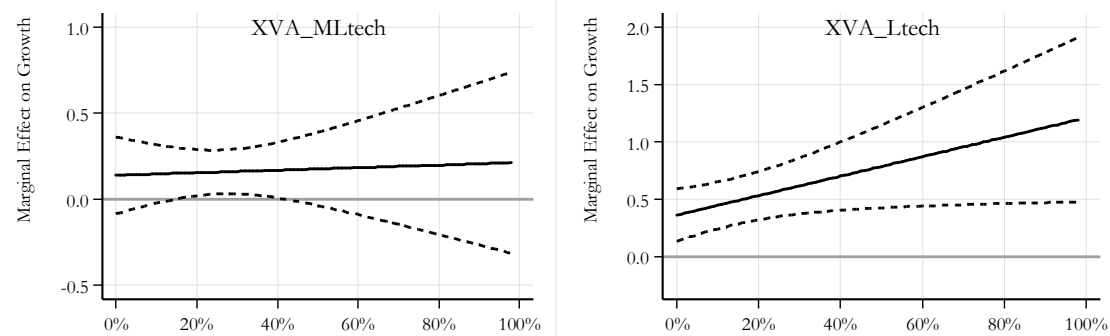

Relative Productivity in Manufacturing (Frontier $=100 \%$ ) 
Figure 5.3. Marginal effect of manufacturing value added exports in different income elasticity groups, by level of relative productivity in manufacturing.
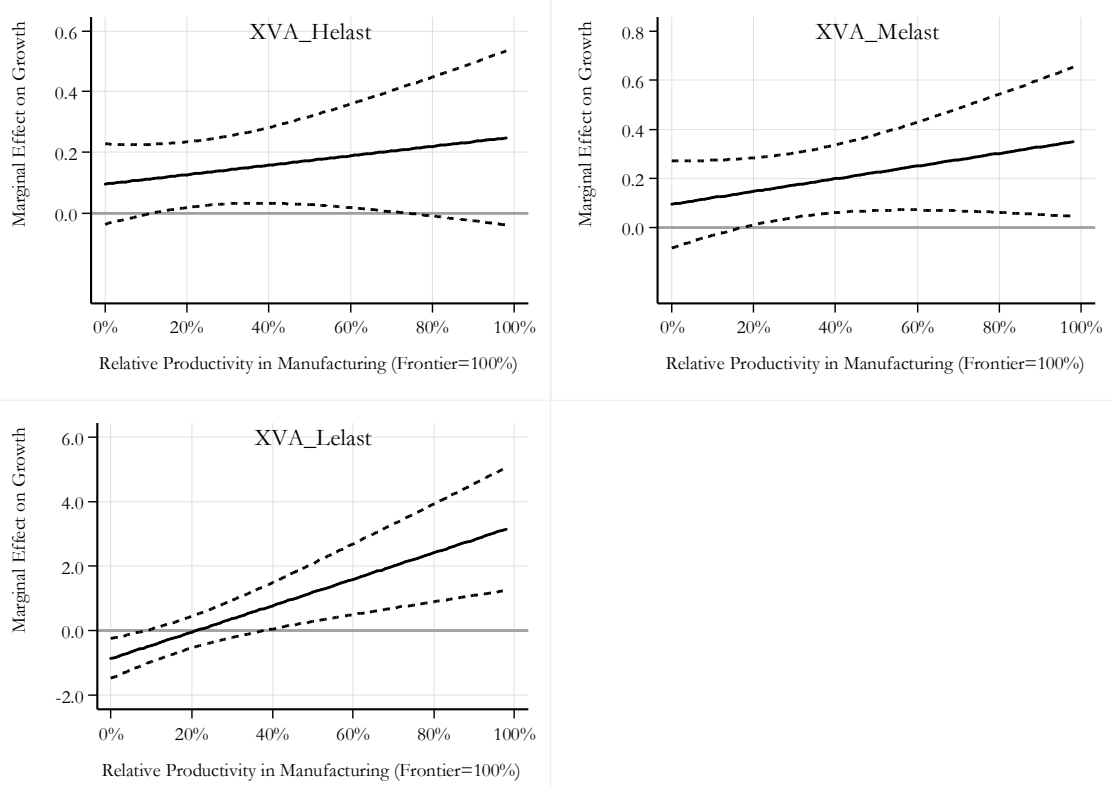

As we can see, in three of the four technological categories, the lower significance boundary lies below the zero axis for all ranges of manufacturing relative productivity. This indicates that the results do not significantly deviate from zero. The only exception is the low-tech category, where the interaction has the expected positive slope and is highly significant in all ranges of $\rho_{M A N}$.

Perhaps more telling are the figures for the income-elasticity groups. In this case, all groups present a positive and significant effect on growth that increases with the level of $\rho_{M A N}$. Also interesting, at very low levels of $\rho_{\text {MAN }}$ exports in industries with low income elasticity actually have a negative impact on growth. This negative impact, however, is rapidly reversed at higher levels of relative productivity.

\subsection{Final Remarks}

In this chapter we have investigated various channels through which the process of structural modernisation could have an impact on aggregate economic growth. This has been done within the general framework of panel data growth regressions. The standard model of growth typically tested in most empirical work has been augmented in order to include the key variables that constitute the centre of attention 
of this thesis. That is, we have explored the impact that an expansion of the modern sector and its catch up to the world frontier has on average growth rates in our sample of countries during the last five decades.

From the results of the previous chapter, we expected a positive effect of our modernisation variables on economic growth, but our regression results showed that both variables have, on average, a negative impact. On second thoughts, however, this is not a surprising result. All standard literature on catch-up finds a negative relation between relative incomes (with respect to the world frontier) and growth rates. Our results would suggest the same. That is, as countries achieve their structural modernisation, their rates of economic growth decrease. In terms of our theoretical model this indicates that the negative channels dominate over the positive ones. The general decrease in growth rates associated with the smaller advantages of backwardness would more than compensate for the positive impact of catch up on non-price competitiveness of exports. In a similar vein, some factors associated with the expansion of the modern sector (such as the higher inflation pressures that erode price competitiveness and the lesser opportunities for productivity gains through labour reallocation) would have a negative impact on the growth rate that could outweigh the positive impact of this expansion on domestic knowledge creation due to the induced-innovation channel.

The models tested in this chapter also point to some important factors that counterbalance these negative effects and - in some cases- result in net positive effect of structural modernisation on aggregate growth. First and foremost, the specific composition of the modern sector seems to be of fundamental importance in this regard. Our results suggest that an expansion of the modern sector driven by manufacturing can actually lead to higher -instead of lower- growth rates. The opposite seems to be true for the other two sectors we have distinguished within the modern sector: the share of non-manufacturing industry and modern market services showed a negative correlation with economic growth in our sample of countries. This would raise some doubts about the general validity of the recent literature that emphasizes the role of modern services as major engines of economic growth. According to our findings, an expansion of services that is not matched with a similar or greater expansion in manufacturing would result in a slower pace of growth.

This special role of manufacturing in driving economic growth has been extensively documented in the literature and, as we have detailed in CHAPTER 2, several arguments have been put forward to explain it. One argument that has been further explored in this chapter is the one related with the trade channels. According to this argument, manufacturing would play a special role in driving export surpluses, thus alleviating the balance of payment restriction and fostering economic growth. The results of the second part of this chapter confirm this line of reasoning. Our growth 
regressions demonstrate that the share of exports in GDP is one of the most important determinants of economic growth. However, not all exports yield the same results in this regard. It emerges that the share of exported manufacturing value added is the single most important determinant. In the evaluation of what particular specialisation pattern within manufacturing would be the best in terms of growth, our results show mixed evidence. On one hand, high and medium-high tech sectors do not seem to play a significant role in the sample of countries analysed. The sectors with the lower levels of technological intensity, instead, have the largest impact. This might be reflecting an important entry road taken by many of the most successful economies during the period under analysis. As has been well documented all Asian Tigers started their catch-up process by exporting low tech products and have only upgraded to more sophisticated goods once they have already achieved the take-off. But the role of technology groups deserves further research, based on more sophisticated classifications.

Our results regarding the groups of industries according to their estimated level of income elasticity are more in line with our theoretical expectations. While exports belonging to the sectors defined as having high and medium income elasticities of demand showed a positive and significant correlation with growth, the group characterized by low income elasticity of demand was negative and nonsignificant.

It follows that the specific composition of the basket of exports also plays an important role in counterbalancing the forces that lead to lower growth rates as countries achieve their structural modernisation and come closer to the global frontier. Moreover, our results have shown that, in some export groups, the final outcome heavily hinges upon the degree of catch up of the domestic manufacturing sector. The closer to the frontier, the more sophisticated goods it produces and the higher their impact on aggregate growth.

The results obtained in this chapter can also shed new light on the reasons why some countries end up caught in development traps, especially at middle income ranges. On the light of our results, one possible explanation for this outcome would be related to the particular composition of the modern sector and the particular composition of the trade structures in these economies. Countries with a large share of manufacturing in their modern sector or a large share of manufacturing value added in their exports structures would tend to have-ceteris paribus- higher growth rates and thus achieve faster the transition from low to middle and then high incomes. In contrast, countries in which the modern sector is dominated by non-manufacturing sectors or the export structure is heavily oriented towards agricultural products would tend to be more penalized in their growth potential as they achieve their structural modernisation, and thus more likely to end up caught at middle income ranges. In the light of the above, phenomena of premature de- 
industrialization or primarisation of the export structure would be at the core of the disappointing performance shown by the countries that have been previously identified as being in some sort of development trap. The larger Latin American economies and South Africa would be typical examples in this regard.

An important limitation of this chapter is that the sectoral disaggregation used remains quite aggregate. This has been specially the case when we characterized the composition of the modern sector. Distinguishing between manufacturing, nonmanufacturing industry and modern services is only a first step in such characterization, and needs to be explored further. In order to overcome this limitation, the next chapter undertakes an in-depth examination of the sectoral composition of the modern sector and the main patterns of structural change observed within it, in a restricted number of advanced and developing countries for which more disaggregated data is available. 


\section{CHAP'TER 6.}

Sectoral Heterogeneities and Structural Change in the Modern Sector 


\subsection{Introduction}

In the previous chapters we have analysed two fundamental transformations that take place in the process of economic development, namely, the shift of labour to the modern part of the economy (structural change) and the upgrading of the level of technological sophistication in the modern part of the economy (technological catching up). So far, we have examined the modern sector either as a single entity (CHAPTER 4) or distinguishing only broad aggregates within it (CHAPTER 5). Hence, we have not yet fully acknowledged the sectoral heterogeneities that are also present within this aggregate. In this chapter we leave this strong assumption aside and we concentrate on the process of structural transformation that actually takes place within the modern sector. That is, we open the "black box" of the modern market activities (MMA) aggregate.

As we will see, the MMA is also composed by a set of very heterogeneous activities, ranging from low productive and labour intensive textile activities to hightech and capital intensive producers of electronic and optical equipment. The productivity level and technology involved in such a heterogeneous set of activities varies dramatically, making of particular interest the analysis of the specific pattern of sectoral specialization followed by each country. The process of upgrading within the MMA towards activities that at the same time are closer to the technological frontier and present larger opportunities for productivity gains and technological innovation thus constitutes a key element for successful development.

This chapter therefore aims at exploring the process of structural transformation within the MMA aggregate. This requires a far more detailed level of aggregation in the dataset. Data availability will thus restrict the analysis undertaken here to a shorter period of time and a significantly smaller sample of countries. This chapter focuses on a sample of 30 countries for the period 1970-2009. For these countries we have been able to disaggregate the modern sector into 19 broad industries and construct internationally comparable figures for employment, value added and labour productivity.

By examining this more disaggregated dataset, we aim at identifying stylized patterns of structural change within the modern part of the economy that can shed new light on the general trends observed so far. In particular, we will study two related phenomena that lie at the core of the catch-up potential of the modern sector: the reallocation of labour between activities and the specific characteristics of those activities in terms of their distance to the world frontier and their prospects for productivity gains and innovative performance.

With this aim, we propose an analytical strategy based on three consecutive steps. In the first step, we examine the sectoral distribution of labour within the MMA aggregate in different countries of our sample, and identify stylized patterns 
by observing the main changes that take place between different points in time. This characterization complements the analysis of the structural trajectories undertaken in CHAPTER 4 by integrating the specific sector structure that drives those trajectories into the analysis. In the second step we propose a new decomposition technique that provides more grounded evidence about the intuitive patterns found in the graphical examination of the distributions. This technique expands the traditional shift-and-share methodology to the context of technological catch-up. Finally, in the last step, we study the contribution of different sectors to changes in the aggregate technological gap of the modern sector in more detail. This is done examining formal measures on how widespread or concentrated the process of catch up in the various cases studied has been.

Taken together, these three steps of research provide an interesting picture of some stylized patterns of catch-up that can be observed in a cross-country comparison over the last four decades. Moreover, the broad characterization derived from these empirical exercises provides further evidence on the contrasting structural paths followed by successful and unsuccessful economies, thus contributing to our understanding of the forces that drive success in economic development.

The chapter is structured as follows. In Section 6.2 we discuss the data that will be used throughout this chapter and the methodological procedures followed to construct the dataset. Next, in Section 6.3 we examine the country distributions of labour in terms of sectoral distance to the technological frontier and derive some stylized patterns of structural change within the MMA aggregate. This rather intuitive way of characterizing the structural trajectories of different countries sets the stage for the more formal approach implemented in the next two sections. In Section 6.4 we propose a modified version of the traditional shift-and-share technique to assess the relative importance of different components in driving the process of technological catch up. Then, in Section 6.5 we complement this decomposition with an analysis of the specific sectors that have driven these patterns of catch up and we quantify the degree of concentration shown across the different cases under consideration. Finally, Section 6.6 details the main conclusions that can be derived from the analysis.

\subsection{Data}

The analysis of this chapter hinges heavily on the level of disaggregation that is possible to achieve in the data used. Therefore, important efforts have been devoted to open up the MMA aggregate as much as possible in a subset of the countries analysed so far. In this section we detail the specific variables that will be analysed throughout the chapter, the sectoral disaggregation used and the set of countries for which the information is available at this level of disaggregation. 


\subsubsection{Variables}

The main focus of our analysis is on the two variables that compose our index of structural modernisation, but now defined from a sectoral perspective. These variables are the sectoral labour productivity relative to the sectoral productivity at the frontier $\left(\rho_{j}\right)$ and the sectoral share of workers on total labour force $\left(\lambda_{j}\right)$. Formally,

$$
\begin{array}{ll}
\rho_{j}^{i}=\frac{P_{j}^{i}}{P_{j}^{f}} & i=1,2, \ldots, 30 ; j=1,2, \ldots, 19, \mathrm{M} \\
\lambda_{j}^{i}=\frac{N_{j}^{i}}{L^{i}} & i=1,2, \ldots, 30 ; j=1,2, \ldots, 19, \mathrm{M}
\end{array}
$$

where, $P$ stands for labour productivity, $N$ for number of workers, $L$ for the total labour force, the superscript $i$ represents the country ( $f$ being the frontier) and the subscript $j$ the sector ( $M$ being the aggregate of Modern Market Activities).

As explained before, the relative labour productivity is taken as a proxy for the technological gap of a country. The change over time of this variable will therefore be taken as indicative of whether a country is catching up or falling behind. The share in total labour force, in turn, provides indication on the relative size of a sector (or an aggregate in the case of the MMA).

It is important to note that a country can be catching up in some sectors while lagging behind in others, and the final outcome in terms of the MMA aggregate will depend on the relative importance of each group of sectors (in terms of labour employed) and their productivity differentials at the world frontier (or the leading economy). An important lesson from this chapter, as we will see immediately, is that the sectoral specialization pattern plays a very important role in defining the final outcome in terms of the distance to the world leader. A country might have most sectors of the MMA aggregate working with state of art technologies $\left(\rho_{j}\right.$ close to 1$)$ but if it is specialized in activities that show low productivity levels at the frontier, then the gap at the aggregate level of MMA will be still very large.

\subsubsection{Sectors}

Ideally, we would like to perform our analysis at the highest possible disaggregation of activities, probably at three or four-digit level of the industrial classification. This, however, is not possible when the goal is to compare long-term series in a wide array of countries with different levels of development (and thus, statistical capabilities). In such a context, the highest disaggregation that can be typically achieved does not go beyond the nine divisions of the International Standard Industrial Classification (ISIC), revision 2. This is the disaggregation used to define the MMA aggregate in CHAPTER 4. In a restricted number of countries, however, we have been able to expand this division further and disaggregate the manufacturing sector 
into 14 industrial branches, thus getting a disaggregation of 33 sectors, 19 of which are included in the MMA. The analysis of this chapter will concentrate on these 19 sectors. The following table details them and provides the short name that we are going to use throughout the chapter:

Table 6.1. Sectoral disaggregation within Modern Market Activities

\begin{tabular}{clcl}
\hline No. & Full Name & ISIC Codes & Short Name \\
\hline 1 & Mining and Quarrying & $C$ & Mining \\
2 & Food, Beverages and Tobacco & $15 t 16$ & Food \\
3 & Textiles and Textile Products & $17 t 18$ & Textile \\
4 & Leather, Leather and Footwear & 19 & Leather \\
5 & Wood and Products of Wood and Cork & 20 & Wood \\
6 & Pulp, Paper, Paper, Printing and Publishing & $21+22$ & Paper \\
7 & Coke, Refined Petroleum and Nuclear Fuel & 23 & Petroleum \\
8 & Chemicals and Chemical Products & 24 & Chemicals \\
9 & Rubber and Plastics & 25 & Plastics \\
10 & Other Non-Metallic Mineral & 26 & Non-metallic \\
11 & Basic Metals and Fabricated Metal & $27+28$ & Metal \\
12 & Machinery, Nec & 29 & Machinery \\
13 & Electrical and Optical Equipment & $30 t 33$ & Electric Eq. \\
14 & Transport Equipment & $34 t 35$ & Transp. Eq. \\
15 & Manufacturing, Nec; Recycling & $36 t 37$ & Other man. \\
16 & Electricity, Gas and Water Supply & E & Utilities \\
17 & Construction & F & Construction \\
18 & Transport, Storage and Communications & I & Transp. \& Com. \\
19 & Financing, Insurance and Business Services & CtF, JtK-70 & MMA \\
\hline & Modern Market Activities & & Financ \&uss. \\
\hline
\end{tabular}

As we can see, our analysis will focus on five non-manufacturing sectors (Mining, Utilities, Construction, Transport \& Communication and Finances \& Business) and fourteen manufacturing branches.

The specific sources used to construct the variables detailed before at this disaggregation level for the period 1970 to 2009 are detailed in APPENDIX E.

\subsubsection{Countries}

The sample of countries used in this chapter covers a total of 30 economies, nine of which have been identified in CHAPTER 4 as being middle-income economies by 2014. The remaining 21 economies can be further divided into 9 economies that have "recently" graduated into the high-income category 132 and 11 economies that

132 We have included in this group all economies that, according to our series of per capita GNI at 2005 ppp dollars, have turned into the high income category during the last three decades (that is, after 1974). 
have been categorized as high-income economies for a longer span of time ${ }^{133}$. The following table details the countries included in our sample categorising them into these three broad groups:

Table 6.2. Sub-sample of countries analysed in this chapter

\begin{tabular}{lll}
\hline $\begin{array}{l}\text { Mature High-Income } \\
\text { Economies (12) }\end{array}$ & $\begin{array}{l}\text { Newly High } \\
\text { Income Economies (9) }\end{array}$ & Emerging Economies (9) \\
\hline Australia & Chile & Argentina \\
Austria & Finland & Brazil \\
Belgium & Greece & China \\
Canada & Hungary & India \\
Denmark & Ireland & Indonesia \\
France & Japan & Mexico \\
Germany & Korea & Russia \\
Italy & Portugal & South Africa \\
Netherlands & Spain & Turkey \\
Sweden & & \\
United Kingdom & & \\
United States & & \\
\hline
\end{tabular}

In order to have a broad idea about the relative performance of these economies during the last decades, it is interesting to recall their position in Table 4.2 and Table 4.3 of CHAPTER 4. With the only exception of the US, all mature high-income economies had upgraded their income status by at least one category between 1950 and 2014, in most cases moving from the upper-middle income category to the high-income one. Three countries, however, started from a lower income level, and upgraded two income categories during the period: Austria, France and Italy. Within the newly high-income economies we find one country that has managed to climb three income categories during that period (Korea, which moved from the low to the high income category between 1950 and 2014), seven countries that have climbed two categories (Chile, Greece, Hungary, Ireland, Japan, Portugal and Spain, which moved from the lower-middle to the high income category) and one country that have improved only one category (Finland, that moved from the upper middle to the high income category). Finally, in the group of emerging economies we find economies with quite contrasting performances. While China, India, Indonesia and Turkey have all been identified as successful economies that managed to improve

133 That is, economies that have turned into high incomes before 1974. 
their income category between 1950 and 2014 and show no signals of being stuck in their current category, Argentina, Brazil, Mexico, Russia and South Africa have been all classified as being trapped at upper-middle income levels. The latter economies will therefore be given special attention throughout this chapter, and their structural trajectories will be compared with those of the most successful economies from the remaining country groups, in order to identify specific patterns that might contribute in the explanation of their disappointing long-run performance.

\subsection{Structural Characterization}

Our starting point to study the process of structural change within the MMA aggregate consists in characterizing the distribution of sectors within this aggregate in terms of their technological gap with the world frontier. In this section we detail the procedure followed to build and analyse these distributions and we examine the distributional changes in a selected number of countries during the period under consideration.

\subsubsection{Approach}

The focus of this section is placed on the distribution of workers in terms of the technological gap of the sector they belong. In essence, this analysis complements the one undertaken at the end of CHAPTER 4 with an important remark: by looking at this distribution we can now derive a more accurate diagnosis of the structural characteristics of the modern sector.

When we look inside the modern aggregate at a particular point of time we will presumably find a wide array of cases, ranging from sectors that are very close (or at) the technological frontier to sectors that are far away from it. At the risk of some oversimplification we may identify certain stylized patterns of sectoral distribution according to the country's levels of economic development. To begin, we may distinguish between two extreme cases: a poor-developing economy and a rich-advanced one. In the advanced economy we would expect a large modern sector (in terms of its total share in labour force) in which most activities are using state-of-art technology. Therefore, the sectoral distribution should tend to cluster close to the technological frontier. In a developing economy, on the other hand, we would expect a small modern sector in which the vast majority of activities are working with outdated technologies. Thus the sectoral distribution should be concentrated far from the technological frontier. Figure 6.1 illustrates these contrasting features by plotting the stylized distribution for each case ${ }^{134}$.

\footnotetext{
134 Since we will empirically approximate the distance to the technological frontier with measures of relative labour productivity with respect to the world frontier (e.g., sectors with low relative produc-
} 
Figure 6.1. Distribution of labour by sectoral technological gaps.
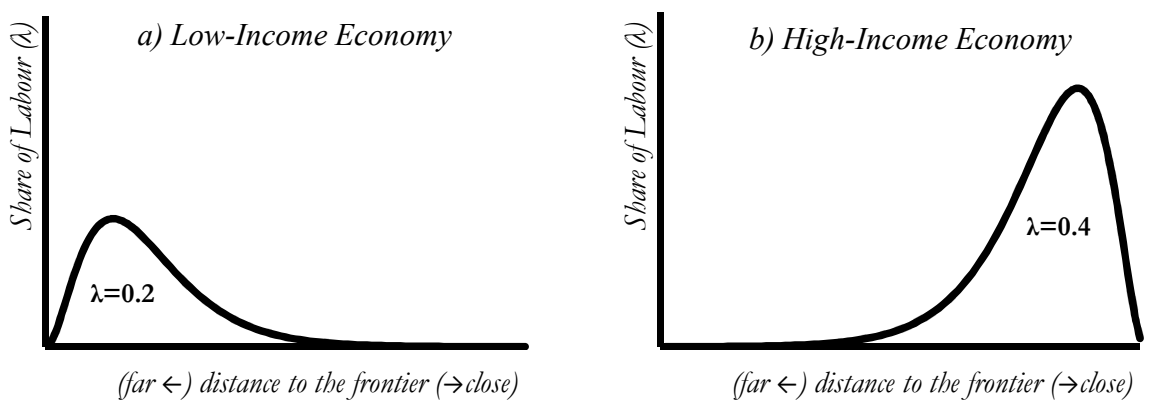

In the figures, all sectors that compose the MMA aggregate are ordered according to their distance to the technological frontier, and then the distribution, in turn, is built in terms of each sector's share in the total labour force. The area below the distribution, therefore, equals the share of MMA in labour force $(\lambda)^{135}$. Hence, by looking at these distributions we can also get a general impression of the relative size of the modern sector.

Following the findings of CHAPTER 4, we have simulated the low-income economy as having a modern sector that employs only $20 \%$ of the labour force (this was the case, for example, for Bangladesh or Kenya in 2007). Moreover, the sectors that compose this aggregate are all clustered at the left-hand side of the graph, illustrating the fact that most of them are very far from the technological frontier. In clear contrast, the figure for the high-income economy has a modern sector that doubles the size of the low-income counterpart (employing $40 \%$ of the labour force, as it was the case, for example, of Australia or Germany in 2007) and clearly clustered at the right hand side of the horizontal axis, indicating that most sectors are very close or at the technological frontier. Note that the area below the first figure is clearly smaller (more specifically, half) than the area below the second figure.

The picture of the developing economy presented in this figure, however, is a quite extreme example of this kind of economies. It will only represent economies at the very first stages of development. As we have stressed in CHAPTER 2, the

tivity will be assumed to have larger gaps than sectors with high relative productivity), the theoretical distributions presented in this section are plotted against an "inverse" measure of distance to the frontier. Thus, the closer a sector is to the origin, the farther away it is from the frontier. This facilitates the interpretation of our empirical results on the light of our theoretical approach

135 Recall that, by definition, $\lambda$ equals the sum of the sectoral $\lambda_{j}$. 
literature points out that many developing economies have, at least, a small fraction of their sectors using technologies that are relative close to the frontier. Then, we would expect to find a small number of sectors in the right hand side of the distribution as well. In Figure 6.2 we take this fact into consideration and we present the stylized picture for a middle-income developing economy.

Figure 6.2. Distribution labour by sectoral technological gaps.

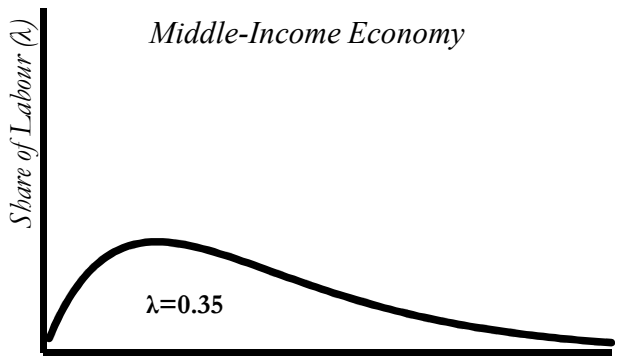

$($ far $\leftarrow)$ distance to the frontier $(\rightarrow$ close $)$

As we can see, in our representation of the middle-income economy the size of the modern sector is quite similar to that of the high-income economy (in the figure, the share of MMA is $35 \%$ of total labour force, only 5 percentage points lower than the corresponding figure for the high-income economy). The main difference is that most sectors are still clustered closer to the origin. In such a case, the economy would have a modern sector that is big enough but very far (on average) from the technological frontier. Another interesting characteristic of Figure 6.2 is that the degree of dispersion in the distribution is now much larger. As compared to both stylized distributions of Figure 6.1 this distribution shows a clearly higher deviation in the intersectoral distance to the frontier. In other words, while in Figure 6.1 both distributions are rather homogeneous (most of the sectors are concentrated close to the mean) in Figure 6.2 we can find all type of cases, ranging from sectors with very large technological gaps to sectors with very small gaps.

The stylized pictures presented so far demonstrate that studying this sort of distributions in a particular point of time may give very interesting insights into the main structural characteristics of an economy. It allows us to define the degree of sectoral heterogeneity in terms of the degree of dispersion and it also provides some intuitions about the relative magnitude of the modern part of the economy (as represented by the total area of the figures). The evolution in time of these distributions deserves similar or even greater attention since it gives insights into the development path followed by an economy. 
Once more, at the risk of some oversimplification, we may identify certain stylized trajectories that these distributions show over time. Here, in particular, we concentrate on four possibilities ${ }^{136}$ : a) Generalized Catching-Up; b) Secular Stagnation; c) Falling-Behind; and d) Partial Catching-Up with Structural Polarization.

136 These trajectories only represent a subset of all the possible trajectories that can be considered. Since our focus will be placed on the economies detailed in Table 6.2, we decided to use as starting point the figure of a middle-income economy (unfortunately we have no data for the poorest countries). A whole trajectory, however, would start from the figure of a low-income economy and would evolve towards any of the four outcomes depicted in Figure 6.3. 
Figure 6.3. Stylized trajectories in the distribution of labour by sectoral technological gaps

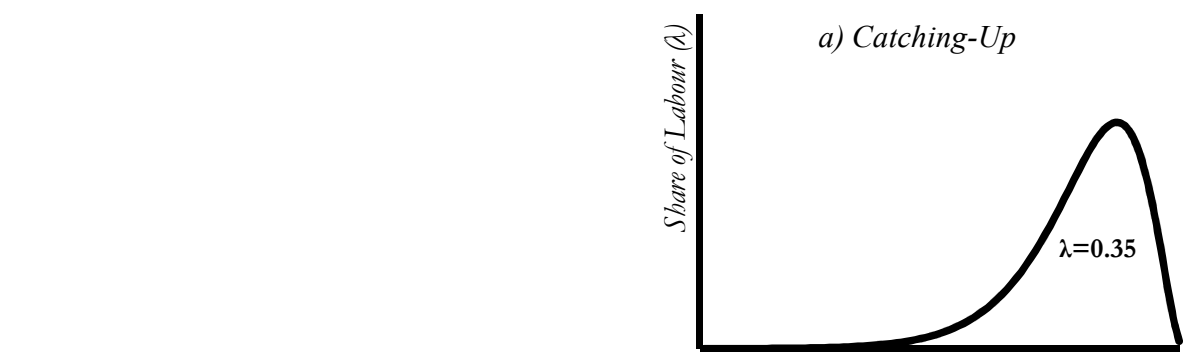

$((f a r \leftarrow)$ distance to the frontier $(\rightarrow$ close $)$

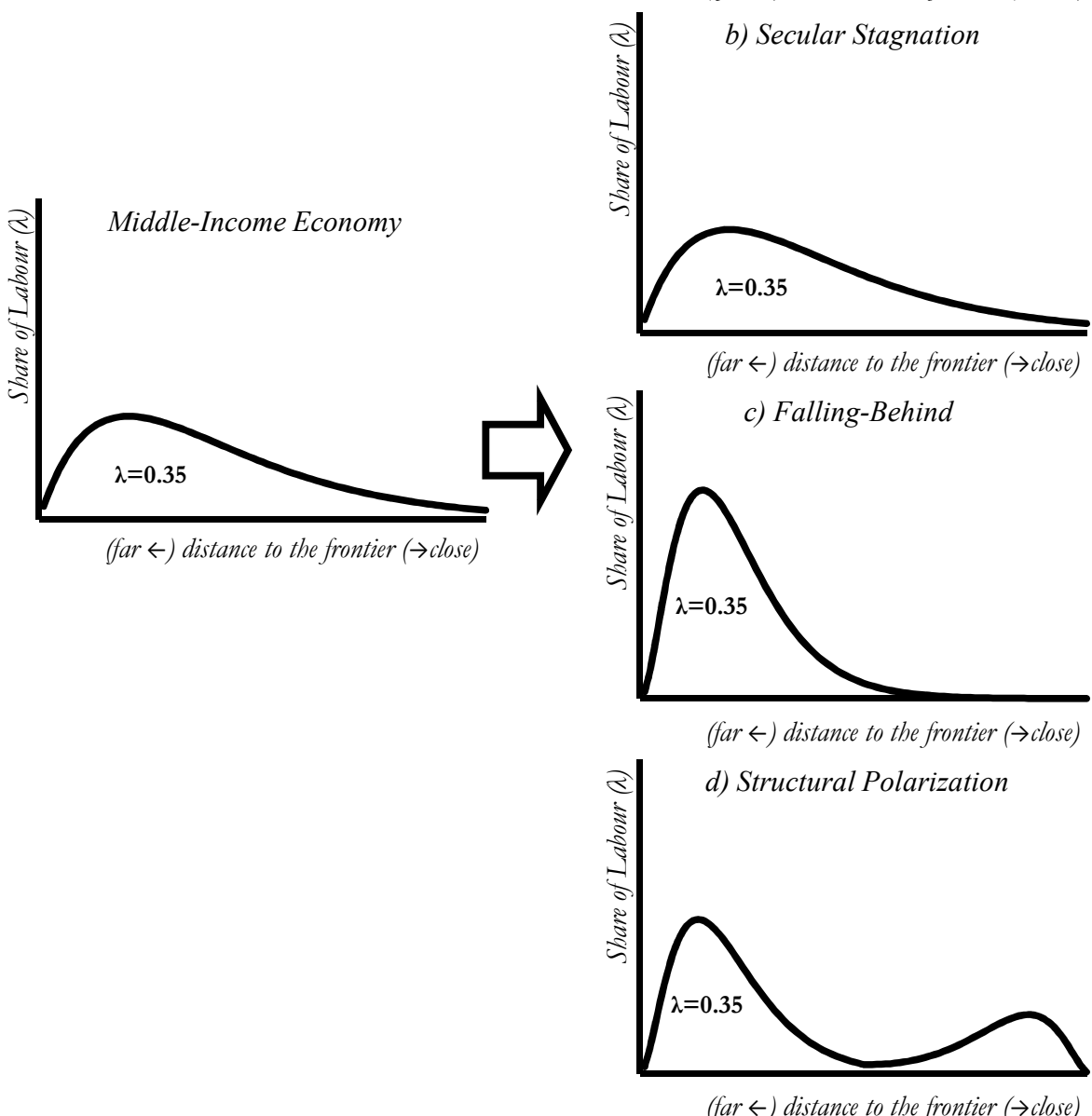

$($ far $\leftarrow$ ) distance to the frontier $(\rightarrow$ close)

Figure 6.3 illustrates each of these trajectories for a country that at the initial point of time (left panel) is characterized as a middle-income developing economy. The 
figures in the right panel would represent the sectoral distribution of this economy at a later point of time (for example, after two or three decades). In all cases it is assumed that the size of the modern sector remains unchanged and the focus is placed on the shifts that take place in the distribution of technology gaps. In the first case, the economy manages to catch up successfully with the world frontier, implying that most sectors narrow the technological gap. In graphical terms, this is reflected by a shift of the whole distribution towards the right hand side. In the second case, all sectors keep the same distance to the world frontier and the distribution remains unchanged between the two moments of time. In the third case, instead, most sectors of the MMA fail to catch up and face an increasing technological gap. This is reflected as a generalized shift of the distribution towards the left hand side of the horizontal axis. Finally, the four case represents an intermediate situation in which only a fraction of the modern sector manages to narrow the technological gap while the rest remains at the same position or lags further behind. Graphically, this implies a bipolarization of the distribution, where a small number of sectors moves rightward while the rest remains at the same place or shift even further to the left. This last case is the most interesting one in terms of our analysis since it has not been given sufficient attention and seems to be typical of countries trapped at middle-income ranges.

\subsubsection{Building the frontier}

The implementation of the proposed approach requires a precise definition of the technological frontier. In the theoretical figures presented above, the productivity of each sector is compared with that of the technological frontier in that sector after which they are ordered according to their distance to that frontier. In our previous analysis, which examined only the aggregate of MMA, the world frontier was defined as the country with the highest productivity level for this aggregate. At the sectoral level, however, the world leader does not always need to be the same country. When we look at particular sectors different countries might be leading the technology race. Leading in the "best" sectors (those with the highest level of productivity or with the most dynamic growth), however, would provide a special bonus and thus increase the chances of being the leader at the aggregate MMA level. This is in fact what our data shows: the world leader is not leading in every single sector. Instead, it shows the world's highest productivity level only in a few sectors but it is close to the technological frontier in almost all the remaining ones. At the same time, its distribution of workers is highly skewed towards the best sectors (i.e., those with the highest productivity level at the frontier). As we will see in more detail in Sections 6.4 and 6.5 it is precisely this interaction between catch-up at the sectoral level and sectoral specialization what drives the aggregate trend of the technological gap. In other words, it is not fruitful to catch up in globally stagnant sectors. 
To further illustrate this point, the following set of figures presents the leading countries of every sector during the period under analysis. In all cases, the estimates have been made as 5-year averages around the indicated year.

Figure 6.4. Productivity at the frontier (millions of 2005 international dollars). By sector, 1970-2009 (5yr averages)
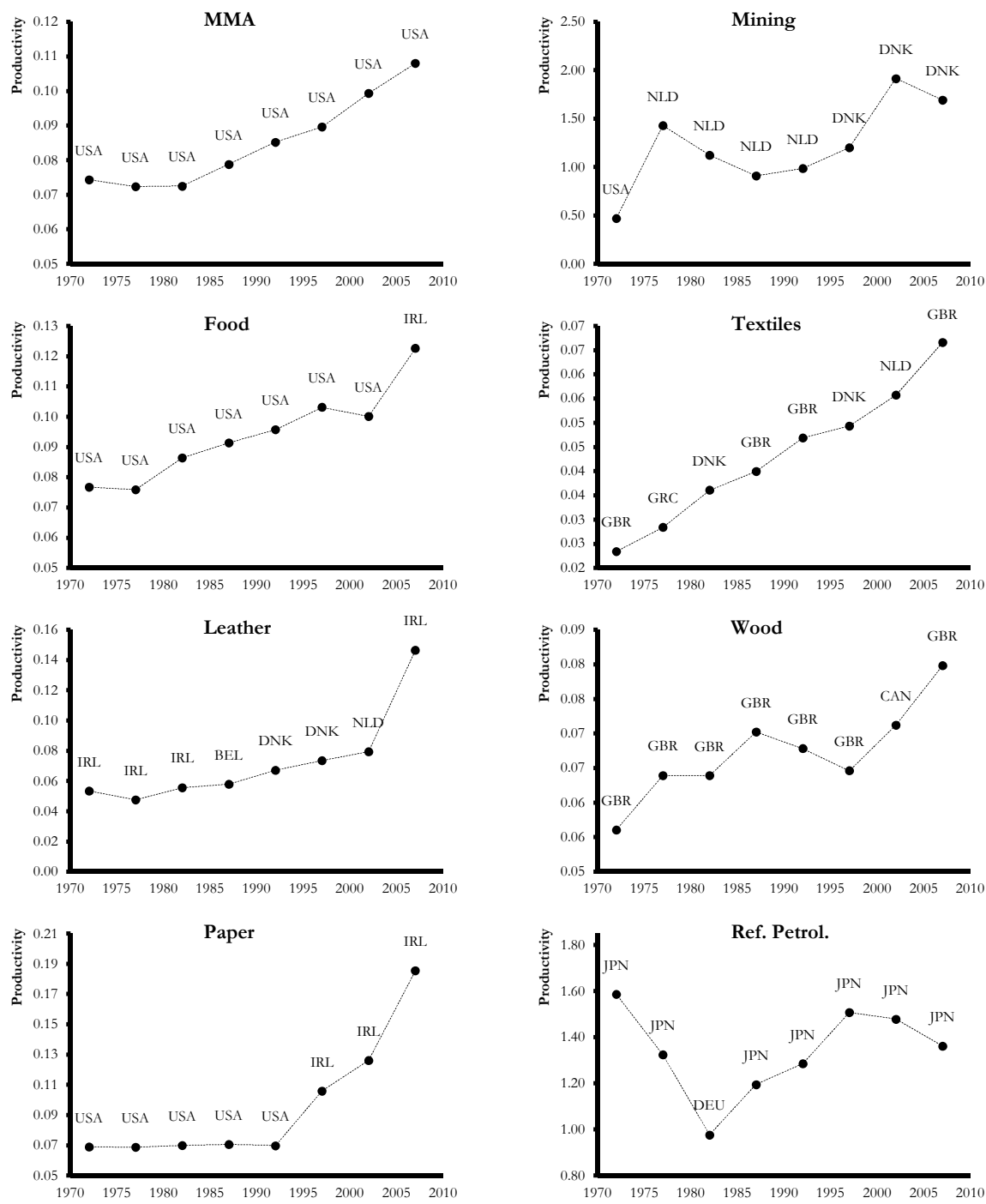
Figure 6.4. Productivity at the frontier (millions of 2005 international dollars). By sector, 1970-2009 (5yr averages) (Cont.)
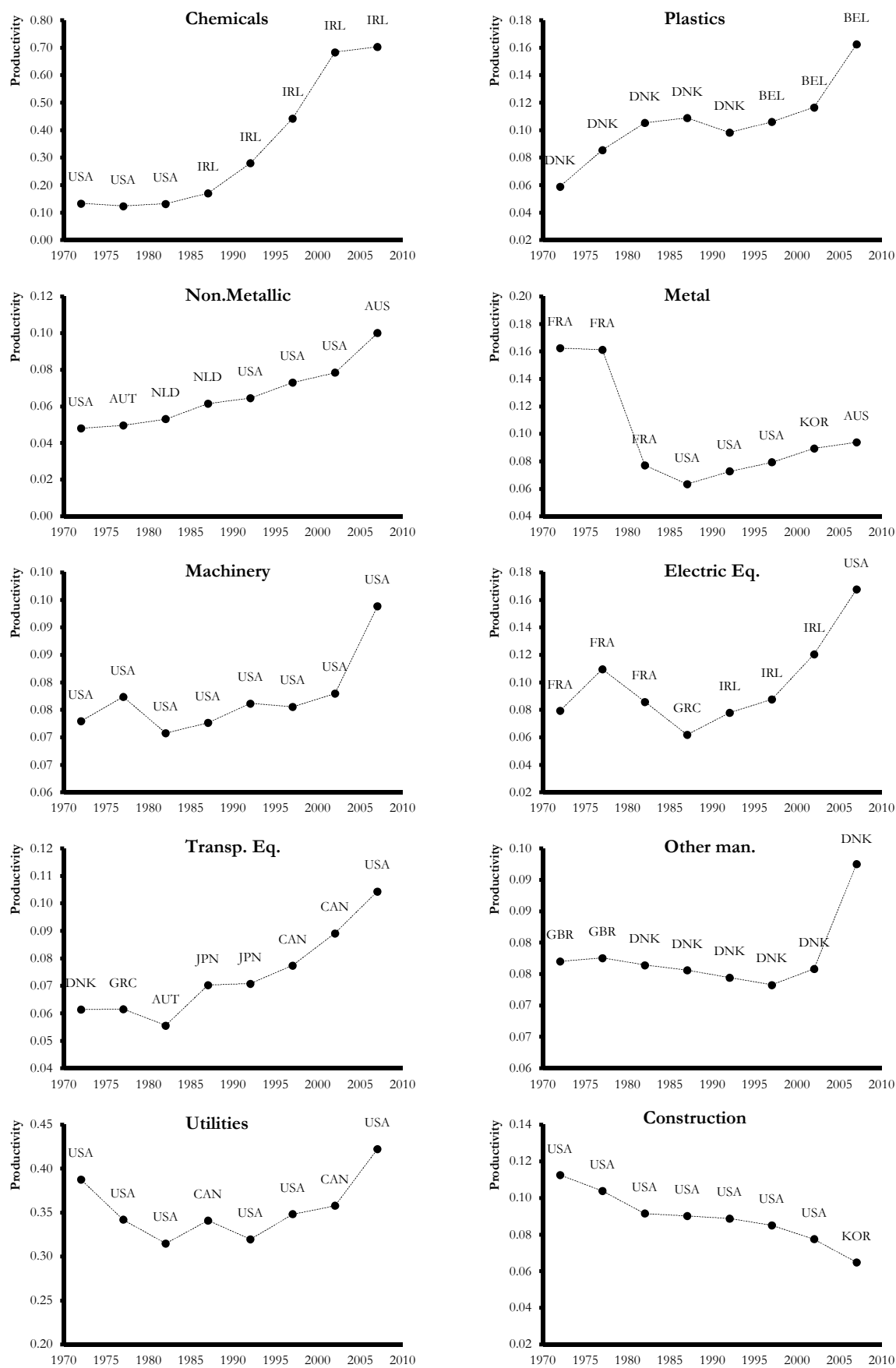
Figure 6.4. Productivity at the frontier (millions of 2005 international dollars). By sector, 1970-2009 (5yr averages) (Cont.)
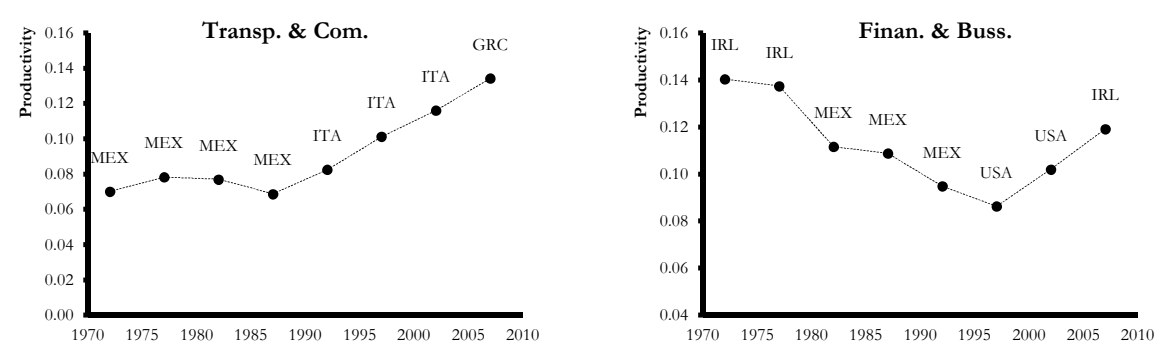

Note: All figures are expressed in constant PPP dollars of 2005 calculated using sector-specific convertors. See CHAPTER 4, Section 4.2.1 for a detailed explanation on the procedures used for the estimations.

As we can see, sectoral leadership in almost all sectors during this period has been contested by only seven countries: Denmark, France, Ireland, Japan, Netherlands, United Kingdom and United States. The latter country has been the undisputed leader at the aggregate level of MMA (as we have already seen in CHAPTER 4) but has not been able to achieve or maintain the leadership in all activities of the modern sector. While at the beginning of the 1970s, the USA was the leader in eight of the 19 sectors, by the end of the 2000s it had only maintained its leadership in four sectors: Machinery, Electric and Optical Equipment, Transport Equipment and Public Utilities. In four other sectors, it has been overtaken by other economies such as Australia (Non-Metallic industries), Ireland (Food, Paper and Chemicals) and Korea (Construction). Other sectors have typically been led by other countries, such as Textiles and Wood (United Kingdom), Refined Petroleum (Japan) and Other Manufacturing (Denmark). The leadership of the remaining sectors has been changing between three or more leaders throughout the period.

An important lesson from this analysis is that the leadership at the world frontier has been changing quite regularly within sectors, while at the aggregate level the world leader has remained the same, namely the USA. This is partially explained by the fact that not all sectors deliver the same result in terms of aggregate productivity and remaining the leader in MMA also implies a certain specialization towards sectors with the better prospects in terms of productivity gains and technological upgrading. This is a point that we will discuss further at the end of this section.

\subsubsection{Sectoral heterogeneities}

Once the frontier has been clearly defined for each sector that is part of the MMA aggregate, it is possible to analyse inter-sectoral differences in terms of the technological gaps faced by the sectors of each country. This relates very closely to a 
growing strand of literature that has been studying, from an empirical perspective, the inter-sectoral differences in terms of labour productivity.

As we have seen in CHAPTER 2, Section 2.5, a large body of literature has emphasized the importance of heterogeneities that arise across sectors in terms of their productivity level and growth potential, a fact that is at the very core of the structural change bonus argument.

An important question that has been left neglected in all these studies is whether this type of heterogeneity is also found when looking at the technological capabilities of different sectors. That is, when looking at the sectoral productivities relative to the world frontier.

The dataset constructed for this chapter provides interesting insights in this regard. In line with the findings of the literature that has focused on the productivity differentials across sectors, our data shows that developing countries tend to present a much larger degree of heterogeneity than the advanced ones in terms of their sectoral technological gaps. This would indicate that in these countries sectors working close to the frontier coexist with sectors that are extremely far from it. The following table, inspired by the corresponding table of McMillan and Rodrik (2011) for labour productivity, presents the evidence in this regard for the last year for which we have data (2007) ${ }^{137}$. The table details, for every country of our sample, the relative productivity of the MMA aggregate $\left(\rho_{M}\right)$, the average coefficient of variation of the relative productivities of the sectors that compose this aggregate, the sectors that show the highest and lowest relative productivity in that particular country and the yearly growth rate of $\rho_{M}$ between 1972 and 2007.

\footnotetext{
${ }^{137}$ In all cases the variables have been calculated as 5-year averages around the indicated year (in this case, 2007) in order to avoid potential problems with outliers. Therefore, the table actually refers to the period 2005-2009.
} 
Table 6.3. Relative labour productivity (world frontier $=100$ ) in $M M A$ and sectoral dispersion, by country. 5-year averages around 2007.

\begin{tabular}{|c|c|c|c|c|c|c|c|c|}
\hline \multirow{2}{*}{$\begin{array}{l}\text { Country } \\
\text { and Group }\end{array}$} & \multirow[t]{2}{*}{ Code } & \multirow{2}{*}{$\rho_{M}$} & \multirow{2}{*}{$\begin{array}{c}\text { Coef. of } \\
\text { variation } \\
\text { of } \rho_{j}\end{array}$} & \multicolumn{2}{|c|}{$\begin{array}{l}\text { Sector with } \\
\text { highest } \rho_{j}\end{array}$} & \multicolumn{2}{|c|}{$\begin{array}{c}\text { Sector with } \\
\text { lowest } \rho_{j} \\
\end{array}$} & \multirow{2}{*}{$\begin{array}{c}\text { Yearly } \\
\text { growth } \\
\text { rate of } \rho_{M} \\
(1972-2007)\end{array}$} \\
\hline & & & & Sector & $\rho_{\max }$ & Sector & $\rho_{\min }$ & \\
\hline \multicolumn{2}{|c|}{$\begin{array}{l}\text { Mature High- } \\
\text { Income Economies }\end{array}$} & $69 \%$ & 0.42 & & & & & $1.1 \%$ \\
\hline Australia & $A U S$ & $70 \%$ & 0.49 & Non-metallic & $100 \%$ & Ref. Petrol. & $8.4 \%$ & $0.9 \%$ \\
\hline Austria & $A U T$ & $69 \%$ & 0.40 & Construction & $90 \%$ & Mining & $5.6 \%$ & $1.4 \%$ \\
\hline Belgium & $B E L$ & $77 \%$ & 0.43 & Plastics & $100 \%$ & Mining & $6.9 \%$ & $1.7 \%$ \\
\hline Canada & $C A N$ & $77 \%$ & 0.44 & Wood & $93 \%$ & Ref. Petrol. & $7.8 \%$ & $0.7 \%$ \\
\hline Denmark & $D N K$ & $65 \%$ & 0.43 & Mining & $100 \%$ & Ref. Petrol. & $7.3 \%$ & $0.6 \%$ \\
\hline France & FRA & $67 \%$ & 0.44 & Construction & $86 \%$ & Mining & $2.8 \%$ & $-0.1 \%$ \\
\hline Germany & $D E U$ & $61 \%$ & 0.45 & Textile & $74 \%$ & Mining & $1.8 \%$ & $0.5 \%$ \\
\hline Italy & ITA & $58 \%$ & 0.50 & Transp.eCom. & $93 \%$ & Mining & $3.9 \%$ & $0.4 \%$ \\
\hline Netherlands & $N L D$ & $70 \%$ & 0.30 & Textile & $94 \%$ & Ref. Petrol. & $37.0 \%$ & $0.7 \%$ \\
\hline Sweden & SWE & $72 \%$ & 0.37 & Wood & $83 \%$ & Mining & $5.2 \%$ & $1.6 \%$ \\
\hline U. Kingdom & GBR & $68 \%$ & 0.45 & Textile & $100 \%$ & Ref. Petrol. & $2.5 \%$ & $1.8 \%$ \\
\hline United States & USA & - & 0.37 & Macbinery & $100 \%$ & Mining & $17.5 \%$ & $0.0 \%$ \\
\hline \multicolumn{2}{|c|}{$\begin{array}{l}\text { Newly High-Income } \\
\text { Economies }\end{array}$} & $56 \%$ & 0.55 & & & & & $1.4 \%$ \\
\hline Chile & CHL & $36 \%$ & 0.51 & Construction & $47 \%$ & Chemic. & $7.9 \%$ & $0.7 \%$ \\
\hline Finland & $F I N$ & $68 \%$ & 0.46 & Electric Eq. & $97 \%$ & Mining & $3.2 \%$ & $1.6 \%$ \\
\hline Greece & $G R C$ & $58 \%$ & 0.68 & Transp. ¿ Com. & $100 \%$ & Mining & $2.7 \%$ & $0.6 \%$ \\
\hline Hungary $^{(a)}$ & HUN & $31 \%$ & 0.62 & Financ \&Buss. & $45 \%$ & Mining & $0.7 \%$ & $0.2 \%$ \\
\hline Ireland & $I R L$ & $97 \%$ & 0.46 & Chemic. & $100 \%$ & Ref. Petrol. & $1.4 \%$ & $2.0 \%$ \\
\hline Japan & $J P N$ & $58 \%$ & 0.55 & Ref. Petrol. & $100 \%$ & Mining & $3.5 \%$ & $0.9 \%$ \\
\hline Korea & KOR & $60 \%$ & 0.63 & Construction & $100 \%$ & Mining & $3.6 \%$ & $3.9 \%$ \\
\hline Portugal & PRT & $38 \%$ & 0.53 & Transp. ECom. & $57 \%$ & Mining & $1.1 \%$ & $1.3 \%$ \\
\hline Spain & ESP & $55 \%$ & 0.47 & Construction & $81 \%$ & Mining & $2.0 \%$ & $0.6 \%$ \\
\hline \multicolumn{2}{|c|}{$\begin{array}{l}\text { Emerging Econo- } \\
\text { mies }\end{array}$} & $25 \%$ & 0.76 & & & & & $1.4 \%$ \\
\hline Argentina & $A R G$ & $27 \%$ & 0.66 & Metal & $48 \%$ & Electric Eq. & $4.9 \%$ & $0.0 \%$ \\
\hline Brazil & $B R A$ & $16 \%$ & 0.57 & Construction & $25 \%$ & Ref. Petrol. & $2.7 \%$ & $-0.6 \%$ \\
\hline China ${ }^{(b)}$ & $\mathrm{CHN}$ & $18 \%$ & 0.96 & Financ \&Buss. & $54 \%$ & Mining & $1.3 \%$ & $7.2 \%$ \\
\hline India & $I N D$ & $10 \%$ & 0.80 & Financ \&Buss. & $26 \%$ & Mining & $0.5 \%$ & $2.1 \%$ \\
\hline Indonesia(b) & $I D N$ & $14 \%$ & 0.83 & Financ \&̋uss. & $31 \%$ & Plastics & $2.5 \%$ & $-0.2 \%$ \\
\hline Mexico & MEX & $35 \%$ & 0.74 & Transp. ECom. & $60 \%$ & Ref. Petrol. & $2.9 \%$ & $-1.0 \%$ \\
\hline Russia(c) & RUS & $27 \%$ & 0.76 & Metal & $40 \%$ & Leather & $2.8 \%$ & $2.2 \%$ \\
\hline South Africa & $Z A F$ & $29 \%$ & 0.65 & Financ $\nLeftarrow B u s s$. & $44 \%$ & Mining & $2.0 \%$ & $-0.2 \%$ \\
\hline Turkey (c) & TUR & $45 \%$ & 0.83 & Financ \&Buss. & $91 \%$ & Mining & $1.8 \%$ & $3.0 \%$ \\
\hline
\end{tabular}

Notes: (a) Yearly growth rate refers to period 1992-2007; (b) Yearly growth rate refers to period 1987-2007; (c) Yearly growth rate refers to period 1997-2007.

Many interesting insights can be derived from Table 6.3. First and foremost, we can see that our proxy of the relative technological level in the aggregate of modern 
activities $\left(\rho_{M}\right)$ is highly correlated with the income groups into which the countries of our sample have been divided. As expected, the group of mature high-income economies shows the highest average relative technology level at about $70 \%$ of the USA level. The cross-country differences within this group are quite small, ranging from a lower bound of 58\% (Italy) to an upper bound of 77\% (Canada). In the case of the newly high-income economies, the group average is quite a bit lower $(56 \%)$ but also with much more variation within the group, ranging from 31\% (Hungary) to $97 \%$ (Ireland). The last group has an average relative productivity of only $25 \%$ and the differences between countries are also pronounced. In this case, the lowest level is found in India which shows a relative productivity of only $10 \%$, while the country with the highest relative productivity (Turkey) reaches the $45 \%$ of USA productivity in MMA. Still we should keep in mind that these figures correspond to a portion of the economy (the modern part) and therefore are far from being indicative of what is happening at the national level. As we have seen in CHAPTER 4 , this set of activities typically account for a very small portion of the labour force in developing countries.

Secondly, it is interesting to see that the degree of dispersion in relative levels of sectoral technology (as represented by the coefficient of variation of the distribution) tends to increase as we move from the first to the last group. Once more, this can be taken as indication of the fact that the degree of sectoral heterogeneity (now defined in terms of the technological capabilities) is much higher in developing economies than in advanced economies. In fact, a strong negative correlation can be found between the level of $\rho_{M}$ and the coefficient of variation of its sectoral distribution, as the following figure clearly illustrates: 
Figure 6.5. Relationship between sectoral heterogeneity and technological catching up. 30 countries, 5-year average around 20007

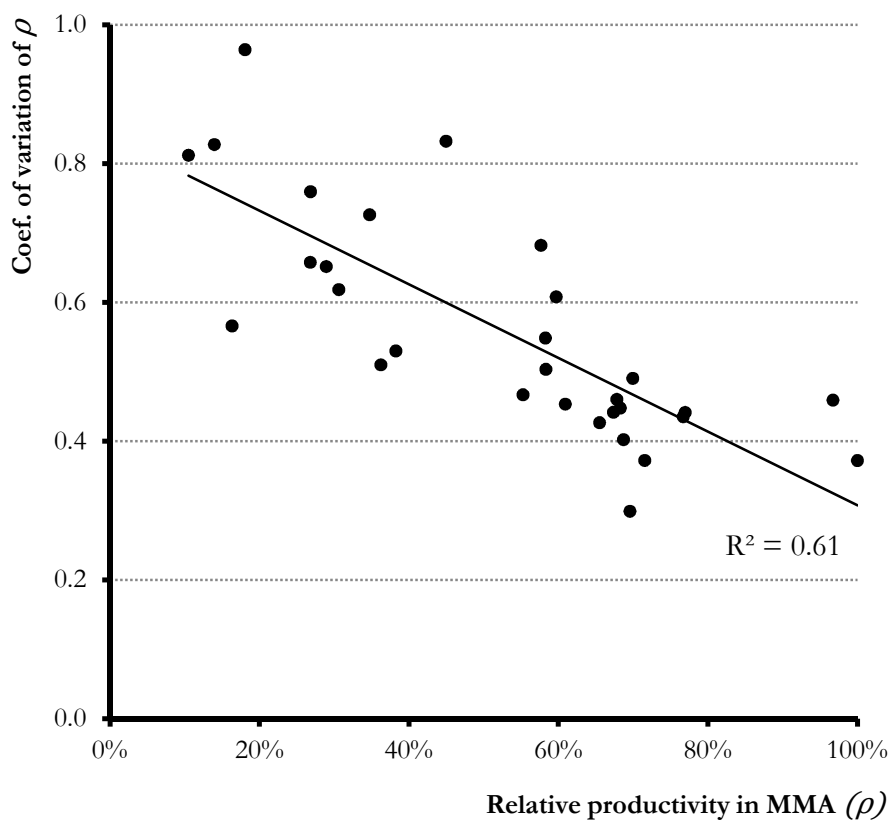

This strong correlation can also be observed when comparing the sectoral distributions of the two extreme cases of our sample: India and the US. Following the approach indicated at the beginning of this section, the following figure presents the corresponding distributions in each of these countries around the year 2007138 .

\footnotetext{
138 All distributions presented in this chapter have been calculated for the corresponding variables using 5-year averages around the indicated year. The histograms of the figures have been calculated using a bin width of 0.5 (that is, ranges of 5 percentage points of relative labour productivity with respect to the world frontier). Over each figure a smoothed distribution has been calculated using the kdensity command of Stata 13. In computing this command we have used a Gaussian kernel density function with a bandwidth of 0.5 .
} 
Figure 6.6. Distribution of labour by sectoral relative productivity.

India and the United States, 5-year averages around 2007
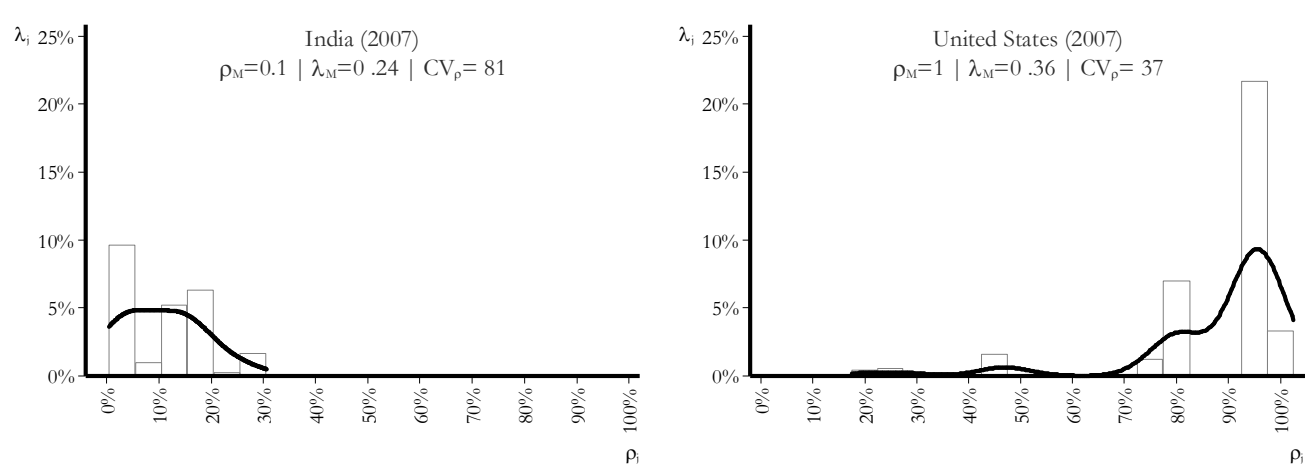

As we can see in the first panel of the figure, the sectoral distribution of India is quite in line with our expectations for a lower-middle income economy. Not only is the size of the modern sector quite modest (employing less than a quarter of the labour force as indicated by the value of $\lambda_{M}$ equal to $24 \%$ ), but its sectoral distribution is also heavily skewed towards the lower ranges of relative productivity, with only a few cases achieving a relative productivity above $25 \%$ of the world frontier. In clear contrast, USA modern sector employs almost $40 \%$ of the labour force and its workers are mostly located at very high ranges of relative productivity, with a clear peak in the distribution at a level of relative productivity of about $95 \%$ of the world frontier. Comparing the levels of dispersion in each country we can notice that the coefficient of variation of the modern sector in India is more than twice as high as that of the US. As stated above, the sectoral heterogeneity across sectors in terms of the distance to the technological frontier seems to diminish as countries develops.

This characterization for the most recent years provides interesting insights about the salient structural features that distinguish developing and advanced economies. As we have seen, not only does the relative productivity of modern activities tend to increase as economies get richer, but also the dispersion in the distance to the frontier at the sectoral level tends to diminish.

\subsubsection{Structural trajectories}

We turn now to the study of the movements in time of the sectoral distributions in a subsample of countries that we will use to illustrate the stylized patterns derived in the theoretical section. In line with CHAPTER 4, we focus on the analysis of two broad sets of countries: successful catching up economies and economies caught in a development trap. In each set we include four economies. In the first set we in- 
clude the two best performers of each high income group of Table 6.2. These are the countries that have improved the most their structural modernization index between the endpoints of the period: Belgium and Sweden (in the group of mature economies) and Ireland and Korea (in the group of newly high-income economies). The second set includes four economies caught in the upper middle-income trap: Argentina, Brazil, Mexico and South Africa. These are the trapped countries for which we have information covering the whole period.

The points of time of the analysis have been chosen in order to cover the end points of the period and an intermediate observation. The intermediate observation, in turn, has been set in the early 1980s in order to capture two growth regimes with very different characteristics for the four upper-middle-income economies. Thus, we study three points of times: 1972, 1982 and 2007. As explained before, in all cases our figures have been constructed using 5-year averages around the indicated year to minimize potential biases arising from outlier behaviour in specific years.

We start by looking at the trajectories followed by the successful economies. The following figure presents the corresponding distributions for Belgium and Sweden: 
Figure 6.7. Distribution of labour by sectoral relative productivity in successful mature high-income economies. 5-year averages around 1972, 1982 and 2007.
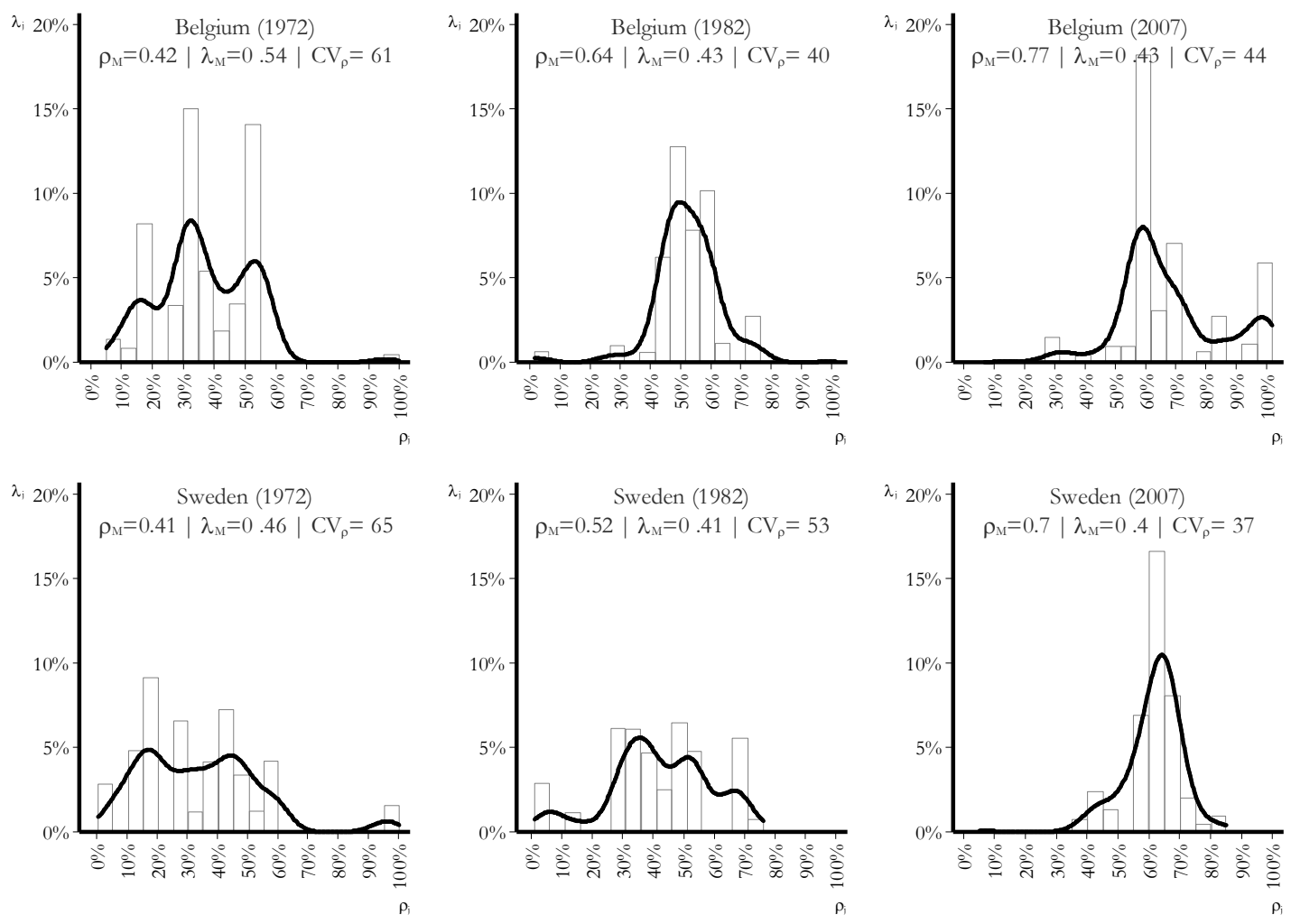

In both countries we can see a clear shift of the distribution to the right hand side of the horizontal axis, in line with the rapid catching up rate achieved at the aggregate level of $\mathrm{MMA}^{139}$. More interestingly, we also find a sharp reduction in the coefficient of variation of the sectoral gaps. This coefficient drops from 60 to 43 in Belgium and from 64 to 37 in Sweden. Looking at the shape of the distribution we can see that in both economies the sectors tended to cluster together around a relative productivity level of $60 \%$, although in Belgium it is possible to perceive a smaller peak also at the frontier. Another common characteristic of both economies is the reduction in the size of the modern sector, especially between the first and second year. This is particularly marked in Belgium, where the share of labour employed in the modern sector falls from 54 to $43 \%$ in only one decade.

\footnotetext{
139 As detailed in Table 6.3 the yearly growth rates of relative productivity in MMA have been 1.7\% for Belgium and $1.6 \%$ for Sweden, both rates substantially above the group average of $1.1 \%$.
} 
Despite the reduction of the modern sector both economies can be taken as clear examples of a generalized catching up trajectory, in which most activities reduce their technological gap and end up clustering together in the right corner of the graph. The trajectory described thus matches very well with panel $a$ of Figure 6.3. The important achievements of these economies during the period are also visible when looking at the evolution of the modernisation index, as defined in CHAPTER 4. Between 1972 and 2007 the index increased from 0.23 to 0.33 in Belgium and from 0.19 to 0.28 in Sweden. The reduction of the gap thus more than compensated the contraction in the size of the modern sector.

The cases of Ireland and Korea also seem to fall in the category of generalized catching-up. The following figure presents the corresponding distributions:

Figure 6.8. Distribution of labour by sectoral relative productivity in successful newly bigh-income economies. 5-year averages around 1972, 1982 and 2007.
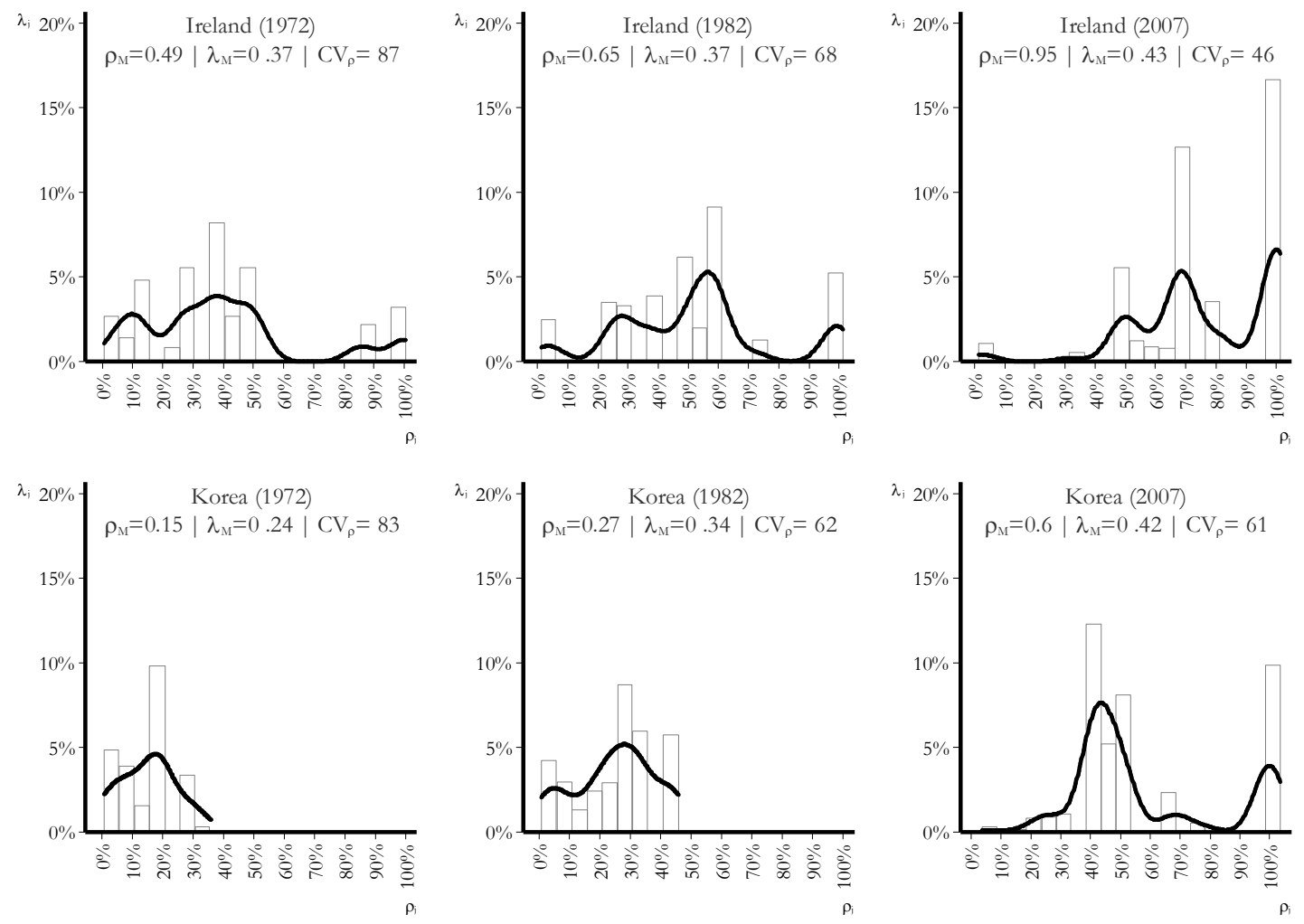

Once more, we notice that the distribution of labour according to the distance to the world frontier gradually shifts towards the right hand side of the horizontal axis 
while the degree of dispersion of the distribution falls steadily. The shift to the right is not surprising considering that these economies show two of the fastest rates of catch-up of our sample of 30 countries $^{140}$. What is more interesting is the fact that they managed to do so while expanding quite noticeably the size of their modern sector. The share of MMA in total labour force in Ireland increased from 37\% in the early 1970 s to $43 \%$ by 2007 . Still more impressive, the share in Korea jumped from 24 to $42 \%$ in only three decades. In 1972 the figure of Korea still very much resembled the pattern characterizing low or lower-middle-income economies. In fact, it was almost identical to the distribution of India in 2007. By 1982, this distribution had already shown significant changes and a clear shift towards upper ranges of relative productivity. Also interestingly, the coefficient of variation had dropped significantly, from an extremely high level of 85 to 64. In the following 25 years, this shift has continued at a very rapid pace and by the end of the period the sectoral distribution of labour is much closer to that of an advanced economy. The coefficient of variation, however, remains still quite high and the shape of the distribution shows a strange peak at the right most corner. This peak, however, is only explained by the dynamics of one sector (Construction) that has experienced an astonishing catch-up during the period. Given the importance of this sector in terms of labour absorption (by 2007 it employed almost $20 \%$ of all worker in the modern sector) it is not surprising that such a peak emerges. If this sector would be excluded from the analysis, the coefficient of variation would fall and the trajectory depicted by the corresponding set of figures would also resemble very much the one previously defined as generalized catching up.

Once more, these successful trajectories are also noticeable when looking at the evolution of the modernisation index. Both economies showed a remarkable increase between 1972 and 2007. In the case of Korea, the index jumped from 0.03 to 0.25 while in Ireland it rose from 0.18 to 0.41 .

We turn now to analyse the structural trajectories of our set of countries trapped at middle-income levels (see Figure 6.9).

140 The yearly growth rates are $2 \%$ and $3.9 \%$ respectively. See Table 6.3 for the details. 
Figure 6.9. Distribution of labour by sectoral relative productivity in countries trapped at middle incomes. 5-year averages around 1972, 1982 and 2007.
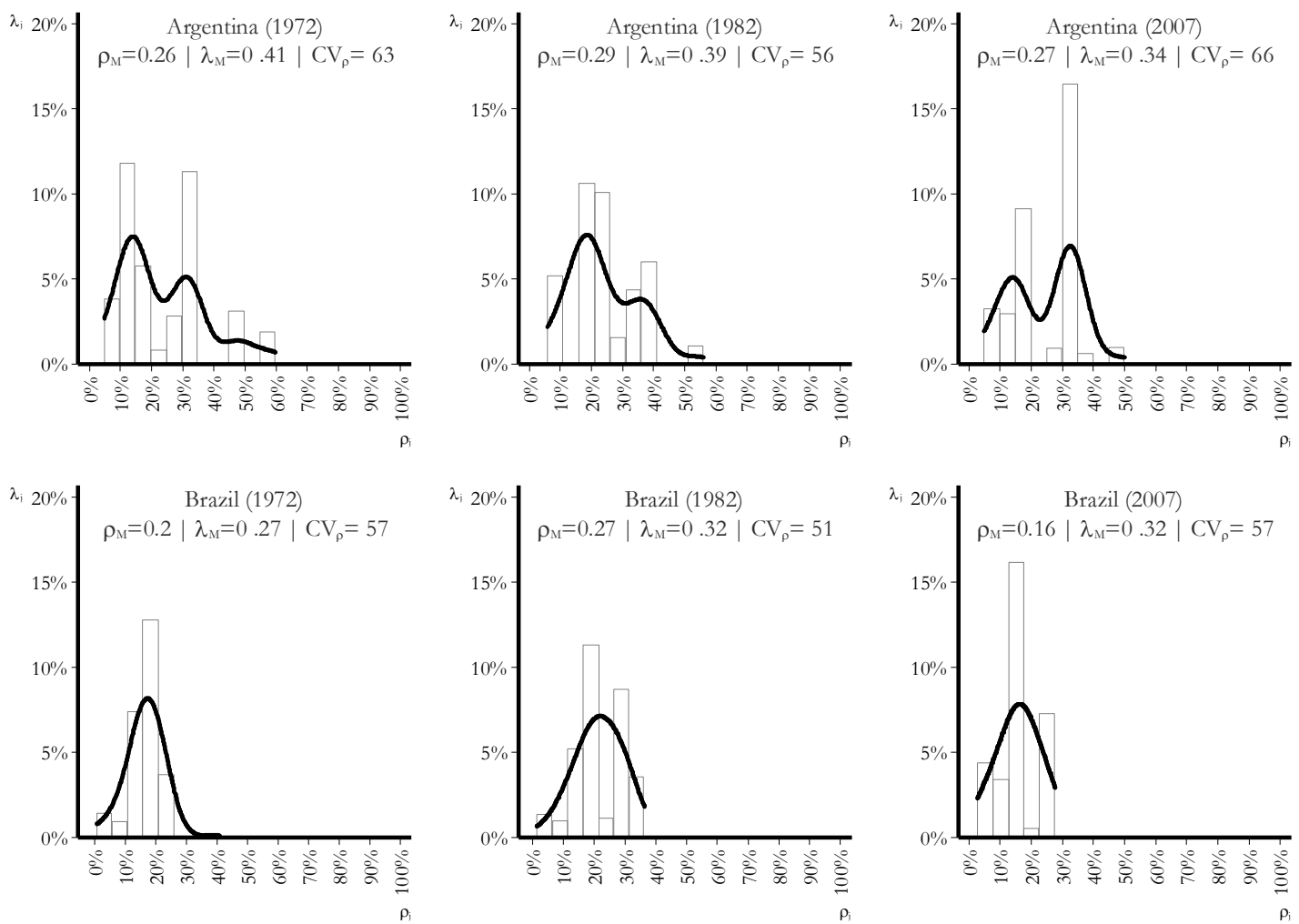
Figure 6.9. Distribution of labour by sectoral relative productivity in countries trapped at middle incomes. 5-year averages around 1972, 1982 and 2007. (Cont.)
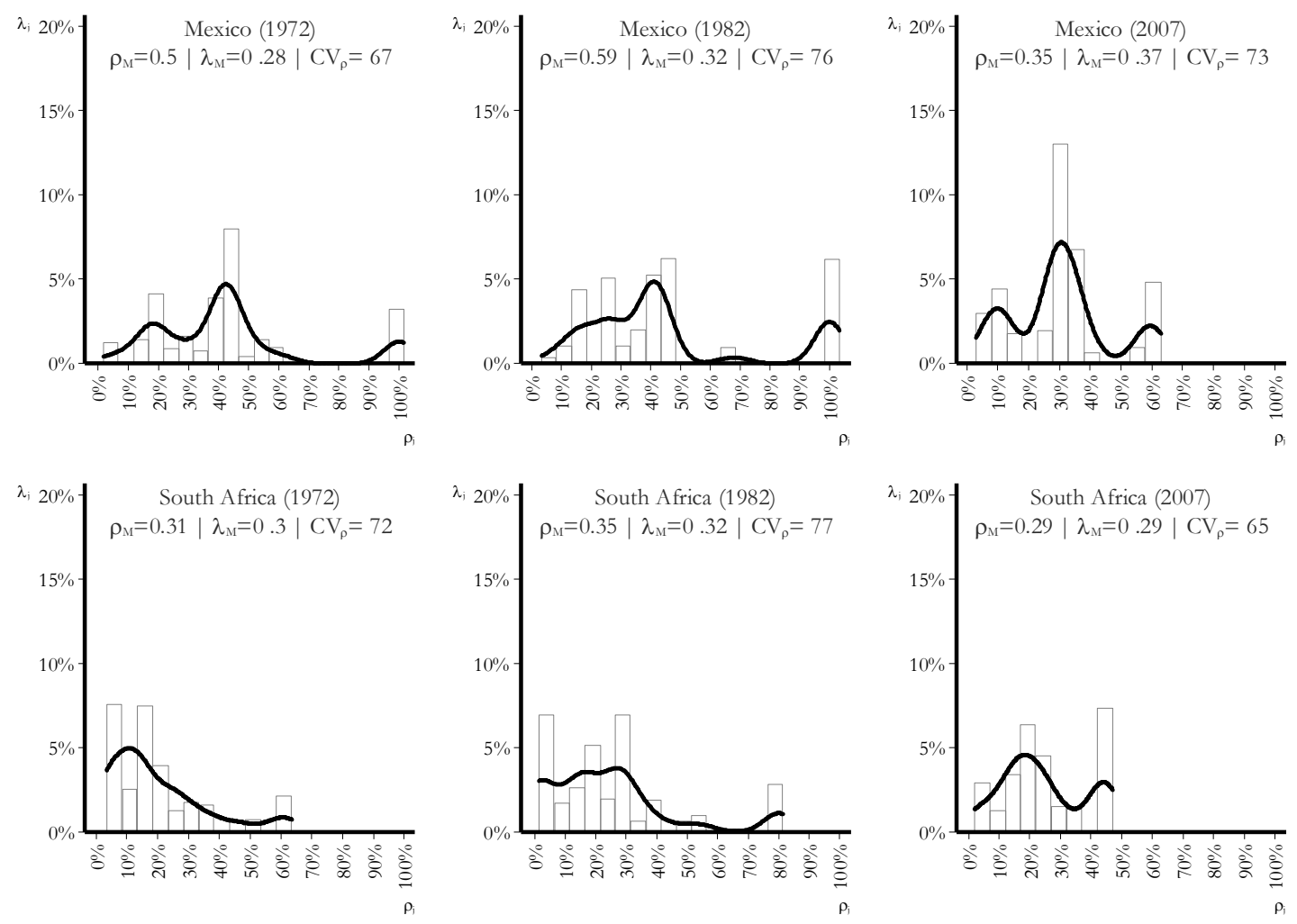

In clear contrast with the previous cases, the set of countries trapped at middle income levels do not show a generalized rightward movement in their distributions. On the contrary, the pattern shown by these economies is typically that of partial catching up with structural polarization, as represented in panel $d$ of Figure 6.3. Looking at the end points of the period we can notice that in three of the four cases these distributions tend towards a bi-polar shape. This is especially clear in the cases of Argentina and South Africa. At the beginning of the 1970s both economies showed a distribution that corresponded quite accurately with our stylized picture for a middle income economy, with a clear peak at very low ranges of relative productivity and a very long tail. In the following 35 years, an important fraction of workers remained in sectors with a very large technology gap while other workers managed to move towards sectors with middle-range technology gaps. By 2007 one can identify two clear peaks in both countries, indicating that only a small fraction of the modern sector has managed to reduce the technological gap. However, even 
this small fraction of catching-up sectors remain quite far from the frontier, at best reaching half of the leader's productivity level. Another important remark regarding these two economies is that the process of polarization has taken place in a context of a shrinking modern sector. The share of labour in MMA dropped from 41 to $34 \%$ in Argentina and from 30 to $29 \%$ in South Africa. Thus the index of modernisation actually showed a negative trend ${ }^{141}$.

The case of Mexico presents an even deeper polarization. The coefficient of variation of this economy was lower than that of South Africa and similar to that of Argentina at the beginning of the 1970s, but it skyrocketed in the following decades and ended up being the highest of the subsample. By the end of the period the distribution of the Mexican modern sector showed three clear peaks: one at extremely low levels of relative productivity (about 10\% of the frontier), one at quite high levels $(60 \%$, similar to Sweden) and an intermediate one in between. In this case, however, the polarization of the distribution has taken place in a context of a rapidly expanding modern sector, with a labour share that climbed from 28 to $37 \%$ of total labour force. The net effect according to the modernisation index was still negative, falling slightly from 0.14 to 0.13 between 1972 and 2007 .

The trends observed in these three economies provide an important lesson. Even though these economies show increase (or stagnation) in their aggregate technological gap it would not be entirely correct to characterize them as falling behind economies. The concept of partial catching up with structural polarization seems much more accurate for this type of trajectory.

The case of Brazil, instead, corresponds more with the stylized trajectory previously defined as falling behind. In this case, the distribution seems to move slightly to the left but the coefficient of variation remains exactly the same between the beginning and the end points of the period. Within this period, however, there are two very different trends. Between 1972 and 1982 we can see a pattern of generalized catching up. The whole distribution moves to the right, though not very dramatically. Moreover, the share of labour in the modern sector increases quite substantially from 28 to $32 \%$ in only one decade. In the subsequent period, however, the whole distribution moves in the opposite direction, more than counterbalancing the gains of the first decade. These opposite trends are also reflected in the evolution of the modernisation index. While in the first period the Brazilian economy achieved a quite remarkable increase of this index, almost duplicating its level (from 0.05 in 1972 to 0.09 in 1982), in the second period, the index dropped and ended up at the same level of 1972.

\footnotetext{
${ }^{141}$ In Argentina the drop was more pronounced, from 0.11 in 1972 to 0.09 in 2007. In South Africa it decreased slightly, from 0.09 to 0.08 .
} 
The examination of the distribution of labour according to the sectoral distance to the frontier provides very interesting insights in certain salient feature of the catch-up process, especially when we compare the experience of successful and unsuccessful economies. In short, the evidence presented in this section suggest that a major difference between this two sets of countries lies in the diffusion of technological upgrading from one sector to another. While successful economies have managed to diminish their degree of structural polarization in a process that has evenly affected to the majority of the labour force involved in the modern part of the economy, countries trapped at middle income ranges have been unable to engage their whole labour force in this process. As a result, their distributions by the end of the period looked much more dispersed and polarized. An important challenge for these economies is to achieve a more balanced and diffused process of technological learning in order to reduce the distance to the world frontier for an increasing share of the labour force that is already in the modern part of the economy.

Though very informative about the general characteristics of the modern sector, these distributions tell us little about the particular specialization pattern of a country. As it was already emphasized, the specific set of sectors in which an economy bases the largest share of its production has a clear impact on the aggregate level of the technological gap. To account for this fact, we close this section by providing some discussion of this issue that will be later addressed more formally in the next sections.

\subsubsection{Specialization patterns}

Looking only at the sectoral gaps gives us no indication of the relative importance of each sector in terms of technological level and productivity gains. To put it simply, an economy might have all its labour force employed in a sector that is using the state-of-art technology and therefore has a sectoral gap equal to zero. But, if this sector has a very low level of technological sophistication globally (or, more precisely for our empirical analysis, a low productivity level in absolute terms), then the economy under consideration will probably lie still far from the world productivity leader. In other words, the particular set of sectors in which an economy (or the MMA aggregate) has specialized matters a lot. Specializing in sectors with higher global productivity (either static or dynamic) will give a country a bonus and will thus contribute to a reduction of its aggregate productivity gap.

To illustrate this feature, the following figure presents the distribution of workers in MMA activities according to the relative productivity level of each sector at the technological frontier for three countries at different stages of development: United States, Brazil and India. 
Figure 6.10. Distribution of labour by sectoral relative productivity at the frontier. Brazil, India and the United States, 5-year averages around 2007.

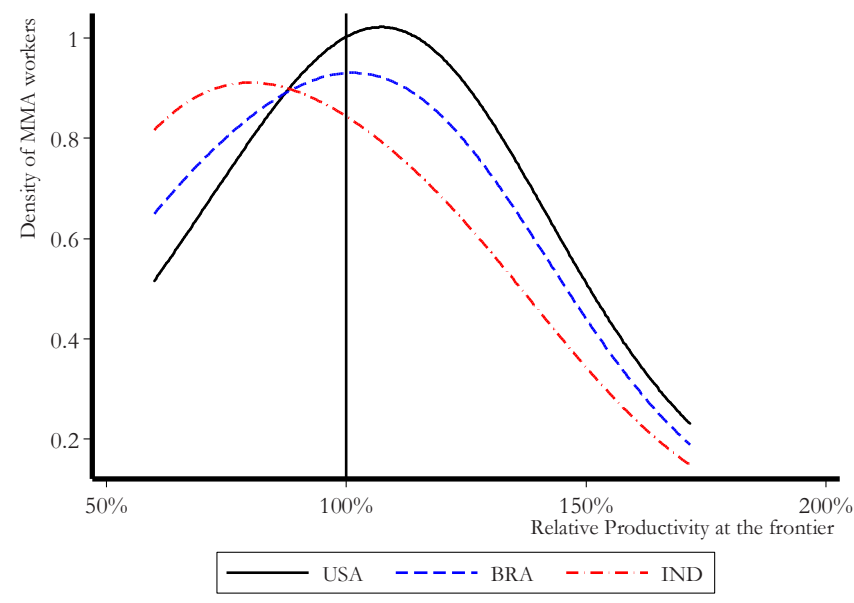

Note: Own elaboration using kdensity command in Stata 13, with a Gaussian Kernel function and a bandwidth of 0.3

In Figure 6.10 the horizontal axis now shows the relative productivity of each sector with respect to the average productivity of MMA at the frontier, assuming that the technological gap is zero. That is, it orders sectors according to the following indicator:

$$
R P_{j}^{f}=\frac{P_{j}^{f}}{P_{M}^{f}} \quad j=1,2, \ldots, 19
$$

where, $P_{j}^{f}$ stands for the productivity of sector $j$ at the frontier, and $P_{M}^{f}$ refers to the productivity of the MMA aggregate at the frontier.

Hence, it gives an indication on the productivity potential of each sector when using state of art technologies. A vertical line at the value of $100 \%$ has also been included in the figure to distinguish sectors with higher (potential) productivity than average. Specializing in sectors that are at the right of this vertical line would provide a "specialization bonus" to the country. Theoretically, if all sectors of a country have the same distance to the world frontier for each sector, then the further to the right the economy is, the higher its aggregate productivity in MMA will be.

By looking at the distribution of labour once the sectors have been ordered in this way, we can derive interesting insights regarding the specialization pattern of different countries. In particular, from this figure we can already see that the USA is the world leader not only because most of its sector are close to the technological frontier (as shown in Figure 6.6), but also because it is specialized in good sectors. As 
we can see most of its distribution is concentrated at the right of the vertical line indicating that the majority of USA workers in the modern sector are employed in sectors with above-average productivity at the frontier.

The opposite holds for India. We have already seen that most sectors are clustered far from the technological frontier (with relative productivities that range between 5 and 25\%). On top of this, the average productivity of Indian modern sector is further penalized by the fact that the country is mainly specialized in sectors that have below average productivity at the frontier. These are the sectors with the lowest potential for productivity gains.

Brazil, instead, takes an intermediate position. As in the case of India, we have seen in Figure 6.9 that most sectors are very far from their technological frontiers. Many of these sectors, however, are good sectors, in the sense that they show relatively high levels of productivity at the frontier. Reducing the gap in these sectors is therefore more challenging but at the same time provides an extra bonus in aggregate terms. As a result, the aggregate technological gap in the modern sector of Brazil is smaller than that of India.

From the previous discussion it should become clear that catch-up is not only a process that take place at the sectoral level, but it also entails a transformation in the productive structures, even within the modern sector. Moving towards sectors with higher potential for productivity gains is at the core of this process. In terms of Figure 6.10, this would again involve a movement of the whole distribution towards the right hand side of the horizontal axis ${ }^{142}$.

The following figure illustrates this point for the case of Korea between 1972 and 2007:

142 Note that as result of technological change, the specific sectors with higher potential for productivity gains might also change over time. This is a point that we will develop further in the next section. 
Figure 6.11. Distribution of labour by sectoral relative productivity at the frontier in 2007. Korea, 5-year averages around 1972, 1982 and 2007
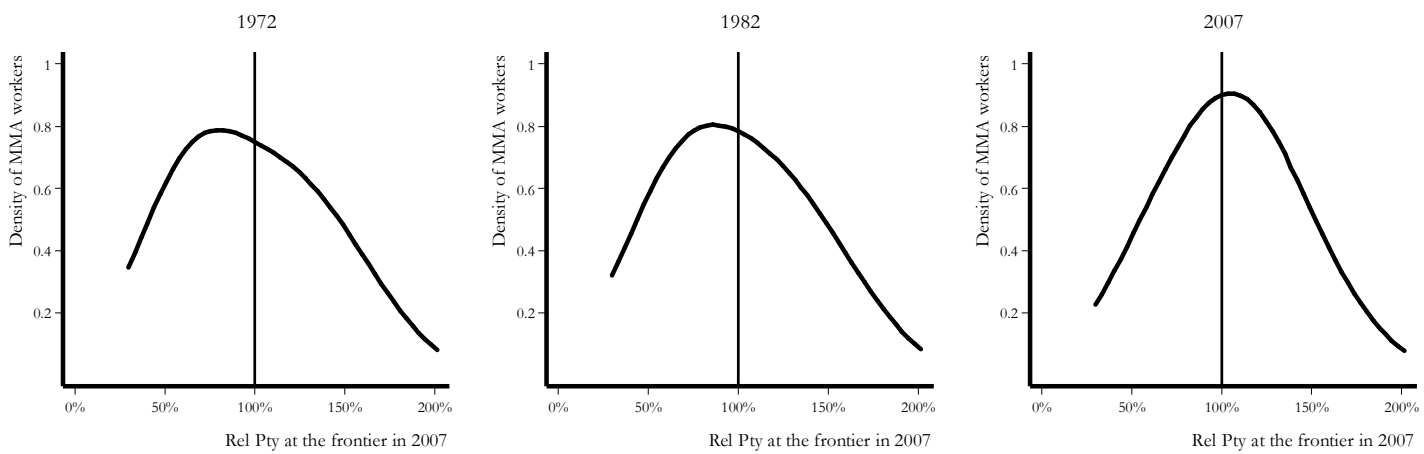

Note: Own elaboration using kdensity command in Stata 13, with a Gaussian Kernel function and a bandwidth of 0.3

As we can see, once the sectors are ordered by the level of relative productivity at the frontier in the final year (in this case, 2007), an interesting picture emerge of the changes that takes place in the specialization pattern of an economy. In the particular case of Figure 6.11 we can see how labour in the modern sector of Korea has gradually shifted towards sectors with better prospects of productivity gains at the world frontier.

Successful catch-up, therefore, is fuelled by a simultaneous process of catch-up at sectoral level (as we have seen, for example, in Figure 6.7 and Figure 6.8 for the cases of Belgium, Ireland, Korea and Sweden) and upgrading towards sectors with higher potential for productivity gains (as we have seen in the last picture for Korea).

In what follows, an attempt is made to capture both elements in a single framework oriented to quantify the relative importance of each of them in the process of catch-up.

\subsection{Patterns of Structural Change}

This section provides a systematic empirical elaboration of the stylized facts derived from the examination of the sectoral distributions in the previous section. Specifically, we propose a modified version of the traditional shift-and-share technique oriented at measuring the relative contribution of structural change and sectoral catch-up to the changes of the technological gap in MMA aggregate.

As stated in CHAPTER 2, Section 2.5, the shift-and-share technique has been extensively used to analyse the process of economic development from a structural change perspective. This technique provides a simple and rather intuitive way to disentangle the relative contributions of the changes that take place within and be- 
tween the entities that compose an aggregate. It has been typically used to analyse the relative contribution of sectoral productivity gains and labour reallocation in the aggregate productivity growth of an economy.

The approach proposed here goes beyond the usual analysis of productivity gains within sectors and investigates the sectoral contributions to aggregate technological catch-up. That is, our focus is on the technological gap instead of on labour productivity. By doing so, it provides important insights on the relative forces driving the process of catch-up. An interesting contribution in this line can be found in Timmer (2000). In his analysis of structural change in Asian NICs manufacturing industries, the author proposes a modified version of the shift-and-share method to account for differences in productivity gaps. The basic idea is to test whether in developing countries (in this case, Asian NICs) factor inputs are mainly concentrated in branches with relatively low levels of labour productivity whereas in advanced countries (in this case, the US) labour is concentrated more in capital intensive industries with higher labour productivity levels. In order to do so, the author takes an interspatial (instead of intertemporal) perspective and decomposes the difference in labour productivity levels in manufacturing into differences due to intrabranch productivity differentials and differences in the structure of employment. His main conclusion is that, in the case of the Asian NICs between 1963 and 1993 differences in the structure of manufacturing sector with respect to the US did little to explain gaps in labour productivity. As we will see immediately, the approach proposed in this thesis extends the aforementioned method by accounting, in a more explicit fashion, for the productivity differentials at the frontier and the impact of initial specialization patterns in the final outcome.

In the literature this issue has also been approached by means of the so called data envelopment analysis (DEA) technique. Originally developed to estimate production frontiers in firm-level analysis, this technique has also been extensively used to analyse productivity growth at the country level, distinguishing changes in efficiency and changes in technology as major drivers of productivity gains (Färe et al., 1994; Kumar and Russell, 2002; Los and Timmer, 2005). The first component is typically associated with catching-up (moving closer to the frontier, at a given input mix) while the second component is typically associated with innovation (shifts of the frontier, also at a given input mix). According to this approach, a third source of productivity gains is related to changes in the input mix of a country, from old to new technologies, in a process of technological upgrading. Los and Timmer (2005), for example, estimate the relative contribution of these three components (that they call assimilation, localized innovation and creating potential) to productivity growth in a sample of 53 countries over the period 1965-1990. Their focus is at the aggregate level, and the technologies are defined according to the labour productivity and the average capital-labour ratio of each economy. They find evidence of catching up 
through assimilation, but they remark that the process seems to be slow and very heterogeneous across countries.

The approach here proposed has a similar goal but differs in the tools and data used. We also aim at studying the relative importance of three components, namely, distance to the frontier, movements at the frontiers and technological upgrading. Our approach, however, is disaggregated in nature and looks exclusively at one factor (labour). Moreover, the focus is on catching up rather than on productivity growth.

\subsubsection{Approach}

Our departure point is the equation describing our proxy for the technological gap in the modern sector for a given point of time. That is:

$$
\rho_{M, t}=\frac{P_{M, t}^{i}}{P_{M, t}^{u}}
$$

Equation (6.4) is the equivalent of Equation (6.1), but for the aggregate of MMA. As before, $P$ stands for labour productivity, the superscript represents the country and the subscript describes the sector and time considered. The superscript of the denominator, however, now reads $u$ instead of $f$. This has been done on purpose to draw attention to the fact that we are now comparing with the leading economy (the US) instead of with specific sectoral frontiers. Since now we want to decompose the variation of this particular variable, all comparisons should be made with the same country (the leader). This point will be addressed in further detail below.

The productivity in the modern sector $\left(P_{M, t}^{i}\right)$ is, by definition, equivalent to the average value of the sectoral productivities that compose this aggregate, weighted by their labour shares $\left(s_{j, t}^{i}\right)$. That is:

$$
P_{M, t}^{i}=\frac{Y_{M, t}^{i}}{N_{M, t}^{i}}=\frac{\sum_{j} Y_{j, t}^{i}}{N_{M, t}^{i}}=\sum_{j} \frac{Y_{j, t}^{i}}{N_{j, t}^{i}} \frac{N_{j, t}^{i}}{N_{M, t}^{i}}=\sum_{j} P_{j, t}^{i} s_{j, t}^{i}
$$

where $Y$ stands for Value Added and $s_{j}$ represents the share of sector $j$ in the total labour force employed by the MMA aggregate.

Now, entering equation (6.5) in equation (6.4) yields:

$$
\rho_{M, t}=\frac{\sum_{j} P_{j, t}^{i} s_{j, t}^{i}}{P_{M, t}^{u}}=\sum_{j} \frac{P_{j, t}^{i}}{P_{j, t}^{u}} \frac{P_{j, t}^{u}}{P_{M, t}^{u}} s_{j, t}^{i}=\sum_{j} \rho_{j, t}^{i} r_{j, t}^{u} s_{j, t}^{i}
$$

That is, the relative productivity in MMA can be defined as the sectoral sum of a multiplication across three components: the sectoral productivity relative to the leader $\left(\rho_{j, t}^{i}\right)$, the relative sectoral productivity in the leading country $\left(r_{j, t}^{u}\right)$ and the sectoral labour share in total MMA employment $\left(s_{j, t}^{i}\right)$. The term $r_{j, t}^{u}$ deserves further 
explanation. It provides indication on how productive is the sector under consideration in the leading economy when compared to the MMA average (also, of the leading economy). Hence, it could be taken as a proxy of the level of technological sophistication of that particular sector. If $r_{j, t}^{u}$ is larger than the unity, then that sector would have higher than average potential for productivity gains. Reducing the technological gap in sectors with large $r_{j, t}^{u}$ will provide higher benefits in terms of the aggregate productivity gap. The final outcome, however, will depend on the relative size of the sector. If the sector employs too few workers, then the effect will still be marginal. But if it is a sector that absorbs a large portion of the modern sector employment, then the effect will be much larger.

To analyse the changes in time of the technological gap we simply take differences in equation (6.6):

$$
\Delta \rho_{M}=\sum_{j} \rho_{j, \mathrm{~T}}^{i} r_{j, \mathrm{~T}}^{u} S_{j, \mathrm{~T}}^{i}-\sum_{j} \rho_{j, 0}^{i} r_{j, 0}^{u} s_{j, 0}^{i}
$$

Where 0 and $T$ are two points in time.

After some manipulation, equation (6.7) becomes ${ }^{143}$ :

$$
\Delta \rho_{M}=\underbrace{\sum_{j} s_{j, 0}^{i} r_{j, \mathrm{~T}}^{u} \Delta \rho_{j}^{i}}_{\begin{array}{c}
\text { within sector } \\
\text { catch up }
\end{array}}+\underbrace{\sum_{\begin{array}{c}
\text { static } \\
\text { structural change }
\end{array}}^{\sum_{j}^{u} r_{j, \mathrm{~T}}^{u} \Delta \rho_{j}^{i} \Delta s_{j}^{i}}}_{\begin{array}{c}
\text { structural change } \\
\sum_{j} \rho_{j, 0}^{i} r_{j, \mathrm{~T}}^{u} \Delta s_{j}^{i}
\end{array}}+\underbrace{\sum_{j} \rho_{j, 0}^{i} s_{j, 0}^{i} \Delta r_{j}^{u}}_{\begin{array}{c}
\text { synamic } \\
\text { specialization }
\end{array}}
$$

In line with traditional shift-and-share approaches, we have decomposed the changes in the technological gap in various components. The first component (within sector catch up) summarizes the contribution of the reduction of the gaps at the sectoral level. The next two components summarize the effects of labour reallocation. Shifts of labour towards sectors with smaller (larger) gap will tend to reduce (increase) the aggregate gap, as captured by the static structural change component. By the same token, shifts of labour towards sectors that have narrowed (increased) the gap during the period will tend to reduce (increase) the aggregate gap, as captured by the dynamic structural change component. The last component (initial specialization), in turn, captures the effect of the sectoral structure at the initial moment, given the changes that have taken place in the leading economy. Being specialized in sectors that have been very dynamic in the leading economy will provide -ceteris paribus- an extra bonus with regard to the reduction of the aggregate gap. This, of course, will only be true if those sectors manage to keep at least the same distance to the leader that they had at the beginning of the period, for which reason the component is weighted by the initial sectoral gap $\left(\rho_{j, 0}^{i}\right)$. If the

${ }^{143}$ See APPENDIX D for the formal demonstration of this result. 
sectoral gap has been increasing, the positive effect of initial specialization will be offset by the first component. It is also important to note that the other components are all weighted by the relative sectoral productivity of the leader in the final year $\left(r_{j, T}^{u}\right)$. Therefore, the structural change components will also capture changes in the quality of a country's sectors. Movements of labour to sectors that have low relative productivity in the leading economy will be penalized while movement of labour to sectors that have high relative productivity in the leading economy will provide an extra bonus in their contribution to the reduction of the aggregate technological gap ${ }^{144}$.

The proposed decomposition is thus able to capture the various elements that we have previously identified as major drivers of technological catch-up from a structural change perspective. It should be noted, however, that shift-and-share type decompositions hinge upon several assumptions, and if they are not met, it might lead to an underestimation of the real contribution of the structural change components (Timmer and Szirmai, 2000). Three issues are particular relevant for our analysis: i) the assumption that marginal productivity equals average productivity; ii) the incidence of spillovers; and iii) the casual links between growth of output and productivity.

In the procedure described above, we assumed that all workers within one particular sector have the same productivity. Therefore, the average productivity of a sector does not change when workers migrate from one sector to another. But, if a sector is shedding surplus labour (as it might typically be the case in agriculture or informal activities), then average productivity will rise because the unproductive workers are leaving the sector. In such a case, part of the within productivity effect should be in fact imputed to the structural change component, since productivity is rising due to the shift of labour to another sector. In the particular case that we are analysing, however, it seems safe to assume that the incidence of surplus labour is not very important since we are looking exclusively at the aggregate of modern market activities. The other two issues, instead, might be more problematic. On the one hand, rent or technological spillovers might introduce a causal link between the increase of labour share in one sector and productivity gains in other sectors. If

\footnotetext{
144 The proposed decomposition could be further extended to avoid weighting these components by the $r_{j}^{u}$ of year $T$. In such a case, three extra components would be added to account for the changes in the relative productivity at the frontier and the corresponding interactions with the changes in the other two components. In APPENDIX D we provide the details of such decomposition. Here we prefer to use the simplified version that has only four components. This particular variant of the decomposition has also the advantage of being the one that provides the closest connection with the graphical approach implemented in the first part of the chapter. Recall that in the figures of Section 6.3.5 we weighted the sectoral distributions of each country by the relative productivity at the frontier in the last year of the analysis (that is, 2007).
} 
structural change involves a shift towards sectors with strong spillovers, then the shift-and-share technique will underestimate the impact of structural change. On the other hand, in the presence of Kaldor-Verdorn-type increasing returns, part of the within effect in an expanding sector could also be regarded as steaming from the structural change component since it is the reallocation of labour to that particular sector what explains the increasing productivity. Unfortunately none of these two elements (spillovers and increasing returns) can be easily factored into the analysis. Hence, we should keep in mind that our results regarding the impact of structural change on aggregate catch up might be underestimated due to these limitations.

We turn now to analyse the main results obtained when applying this technique to our data.

\subsubsection{Sectoral dynamics in the leading economy}

Before presenting the results of the decomposition it is important to examine in some detail the sectoral dynamics in the economy that we are using as benchmark for comparison. That is, the leading economy in terms of aggregate MMA productivity, which for all periods of our sample is the USA (see first panel of Figure 6.4). In particular, it is interesting to know the relative position of each sector at the end of the period under analysis and their productivity growth rate. The following table summarizes this information for the years 1972 and 2007: 
Table 6.4. Sectoral productivity in the world leader (United States). Absolute and relative levels. 5-year averages around 1972 and 2007.

\begin{tabular}{|c|c|c|c|c|c|c|c|c|c|}
\hline \multirow[b]{2}{*}{ No. } & \multirow[b]{2}{*}{ Sector } & \multicolumn{3}{|c|}{1972} & \multicolumn{3}{|c|}{2007} & \multicolumn{2}{|c|}{ Variation } \\
\hline & & $\begin{array}{c}2005 \text { US } \\
\text { dollars } \\
\text { (thousands) }\end{array}$ & $\begin{array}{l}\text { Relative } \\
\text { Level }^{*}\end{array}$ & Rank & $\begin{array}{c}2005 \text { US } \\
\text { dollars } \\
\text { (thousands) }\end{array}$ & $\begin{array}{l}\text { Relative } \\
\text { Level* }^{*}\end{array}$ & Rank & $\begin{array}{c}\text { Yearly } \\
\text { Growth } \\
\text { Rate }\end{array}$ & Rank. \\
\hline 1 & Mining & 470.3 & $633 \%$ & 1 & 296.8 & $275 \%$ & 3 & $-1.3 \%$ & 18 \\
\hline 2 & Food & 76.7 & $103 \%$ & 6 & 98.9 & $92 \%$ & 9 & $0.7 \%$ & 14 \\
\hline 3 & Textile & 9.8 & $13 \%$ & 18 & 54.6 & $51 \%$ & 18 & $5.0 \%$ & 4 \\
\hline 4 & Leather & 7.7 & $10 \%$ & 19 & 43.2 & $40 \%$ & 19 & $5.0 \%$ & 3 \\
\hline 5 & Wood & 41.2 & $55 \%$ & 14 & 59.9 & $55 \%$ & 17 & $1.1 \%$ & 11 \\
\hline 6 & Paper & 69.0 & $93 \%$ & 9 & 86.3 & $80 \%$ & 11 & $0.6 \%$ & 16 \\
\hline 7 & Petroleum & 125.5 & $169 \%$ & 4 & 770.8 & $713 \%$ & 1 & $5.3 \%$ & 2 \\
\hline 8 & Chemicals & 133.5 & $179 \%$ & 3 & 190.3 & $176 \%$ & 4 & $1.0 \%$ & 12 \\
\hline 9 & Plastics & 45.6 & $61 \%$ & 13 & 77.1 & $71 \%$ & 12 & $1.5 \%$ & 8 \\
\hline 10 & Non-metallic & 48.1 & $65 \%$ & 12 & 74.6 & $69 \%$ & 14 & $1.3 \%$ & 10 \\
\hline 11 & Metal & 56.2 & $76 \%$ & 11 & 75.5 & $70 \%$ & 13 & $0.8 \%$ & 13 \\
\hline 12 & Machinery & 73.0 & $98 \%$ & 7 & 93.9 & $87 \%$ & 10 & $0.7 \%$ & 15 \\
\hline 13 & Electric Eq. & 17.8 & $24 \%$ & 17 & 167.7 & $155 \%$ & 5 & $6.6 \%$ & 1 \\
\hline 14 & Transp. Eq. & 57.9 & $78 \%$ & 10 & 104.4 & $97 \%$ & 8 & $1.7 \%$ & 7 \\
\hline 15 & Other man. & 20.2 & $27 \%$ & 16 & 70.9 & $66 \%$ & 15 & $3.7 \%$ & 5 \\
\hline 16 & Utilities & 387.7 & $521 \%$ & 2 & 422.2 & $391 \%$ & 2 & $0.2 \%$ & 17 \\
\hline 17 & Construction & 112.5 & $151 \%$ & 5 & 62.9 & $58 \%$ & 16 & $-1.6 \%$ & 19 \\
\hline 18 & Transp.\&Com. & 40.6 & $55 \%$ & 15 & 108.6 & $101 \%$ & 7 & $2.9 \%$ & 6 \\
\hline 19 & Financ ¿Buss. & 70.5 & $95 \%$ & 8 & 112.6 & $104 \%$ & 6 & $1.3 \%$ & 9 \\
\hline & $M M A$ & 74.4 & $100 \%$ & & 108.1 & $100 \%$ & & $1.1 \%$ & \\
\hline
\end{tabular}

Note: The relative productivity is defined as the ratio between the sectoral productivity and the weighted average of the MMA aggregate.

A first feature that stands out in Table 6.4 is the stability across time in the ranking of sectors according to their relative productivity. Comparing the rankings of 1972 and 2007 we see that most sectors have stayed at a very similar position, climbing (or dropping) at most three positions between the two years. There are only three exceptions to this pattern: Construction dropped dramatically from the fifth to the sixteenth position, while Transport and Telecommunications and Electrical Equipment climbed eight and 11 rank positions respectively. In both years, the top four sectors in terms of productivity level are the same: Refined Petroleum, Public Utilities, Mining and Chemicals. The least productive are also the same: Textiles, Leather, Wood and Other Manufacturing. These results are not surprising and they correspond very closely to the capital intensity of each sector. The most productive are, at the same time, the most capital intensive while the less productive are, at the same time, the most labour intensive. Perhaps less intuitive is the rank of sectors according to the productivity gains between the beginning and the end of the period. Looking at the last column of the table we can see that the most dynamic sectors in the leading 
economy have been, in many cases, the least productive ones. Textiles, Leather and Other Manufacturing (previously invoked due to their low relative productivity) rank among the top five performers in terms of their yearly productivity growth rate. Public Utilities and Mining, on the other hand, rank among the five worst performers in terms of productivity gains in the leading economy. As expected, Electric Equipment is the sector with the highest dynamism in terms of productivity gains during the period. In line with this, three other sectors that deserve special attention are Transport Equipment, Transport and Communications and Financial and Business Services. These sectors combine both high productivity levels in the last year together with relatively high productivity growth rates during the period. Therefore, an initial specialization pattern oriented towards these sectors will tend to give an extra bonus in terms of the catch-up potential of a country.

\subsubsection{Decomposition results}

We turn now to present the results of our decomposition. As in Section 6.3, we split the period of analysis in two sub-periods: 1972-1982 and 1982-2007. We have also split our sample of countries in three groups: mature high-income economies, newly high-income economies and emerging economies. Special attention will be given to the cases of success and failure already discussed in the previous sections.

The following table presents the results for the first period. 
Table 6.5. Decomposition results. First period (1972-1982).

Percentage points of the aggregate growth rate in $M M A$ relative productivity

\begin{tabular}{|c|c|c|c|c|c|c|c|}
\hline \multirow{3}{*}{$\begin{array}{l}\text { Country and } \\
\text { Groups }\end{array}$} & \multirow{3}{*}{ Code } & \multirow{3}{*}{$\begin{array}{c}\text { Annual } \\
\text { Catch Up } \\
\text { Rate }\end{array}$} & \multicolumn{5}{|c|}{ Contribution to Catch Up Rate (in percentage points) } \\
\hline & & & \multirow{2}{*}{$\begin{array}{c}\text { Within } \\
\text { Sector } \\
\text { Catch Up }\end{array}$} & \multirow{2}{*}{$\begin{array}{c}\text { Initial } \\
\text { Specializa- } \\
\text { tion }\end{array}$} & \multicolumn{3}{|c|}{ Structural change } \\
\hline & & & & & Total & Static & Dynamic \\
\hline \multicolumn{2}{|c|}{$\begin{array}{l}\text { Mature High-Income } \\
\text { Economies }\end{array}$} & $2.4 \%$ & 1.55 & 0.53 & 0.35 & 0.54 & -0.20 \\
\hline Australia & AUS & $2.6 \%$ & 1.91 & 0.17 & 0.54 & 0.70 & -0.16 \\
\hline Austria & $A U T$ & $2.6 \%$ & 1.61 & 0.85 & 0.12 & 0.33 & -0.21 \\
\hline Belgium & $B E L$ & $4.2 \%$ & 2.62 & 0.96 & 0.58 & 0.59 & -0.01 \\
\hline Canada & $C A N$ & $2.4 \%$ & 2.35 & -0.52 & 0.54 & 0.46 & 0.08 \\
\hline Denmark & DNK & $2.0 \%$ & 1.10 & 0.99 & -0.06 & 0.24 & -0.29 \\
\hline France & FRA & $0.2 \%$ & -1.20 & 0.90 & 0.54 & 0.55 & -0.01 \\
\hline Germany & $D E U$ & $2.3 \%$ & 1.88 & 0.08 & 0.31 & 0.40 & -0.08 \\
\hline Italy & ITA & $2.5 \%$ & 1.24 & 0.72 & 0.50 & 1.04 & -0.55 \\
\hline Netherlands & NLD & $3.6 \%$ & 3.30 & 0.43 & -0.15 & 0.24 & -0.40 \\
\hline Sweden & SWE & $2.5 \%$ & 0.84 & 0.83 & 0.82 & 1.12 & -0.30 \\
\hline U. Kingdom & $G B R$ & $1.9 \%$ & 1.45 & 0.43 & 0.07 & 0.30 & -0.24 \\
\hline \multicolumn{2}{|c|}{$\begin{array}{l}\text { Newly High-Income } \\
\text { Economies }\end{array}$} & $2.7 \%$ & 1.83 & 0.49 & 0.35 & 0.50 & -0.16 \\
\hline Chile & CHL & $2.4 \%$ & 1.34 & 0.25 & 0.81 & 0.71 & 0.10 \\
\hline Finland & FIN & $2.5 \%$ & 1.97 & 0.52 & 0.04 & 0.25 & -0.20 \\
\hline Greece & $G R C$ & $1.0 \%$ & 0.31 & 0.60 & 0.07 & 0.06 & 0.00 \\
\hline Hungary & HUN & - & - & - & - & - & - \\
\hline Ireland & IRL & $2.9 \%$ & 0.86 & 0.96 & 1.09 & 1.82 & -0.73 \\
\hline Japan & $J P N$ & $1.8 \%$ & 1.78 & -0.09 & 0.12 & 0.28 & -0.16 \\
\hline Korea & KOR & $5.8 \%$ & 4.91 & 0.58 & 0.27 & 0.30 & -0.03 \\
\hline Portugal & PRT & $2.0 \%$ & 1.36 & 0.72 & -0.04 & -0.01 & -0.03 \\
\hline Spain & ESP & $2.9 \%$ & 2.07 & 0.38 & 0.42 & 0.61 & -0.20 \\
\hline \multicolumn{2}{|c|}{ Emerging Economies } & $1.7 \%$ & 0.92 & 0.45 & 0.37 & 0.45 & -0.08 \\
\hline Argentina & $A R G$ & $1.0 \%$ & -0.07 & 0.79 & 0.25 & 0.23 & 0.02 \\
\hline Braqil & $B R A$ & $3.0 \%$ & 1.77 & 0.82 & 0.42 & 0.38 & 0.04 \\
\hline China & $\mathrm{CHN}$ & - & - & - & - & - & - \\
\hline India & $I N D$ & - & - & - & - & - & - \\
\hline Indonesia & $I D N$ & - & - & - & - & - & - \\
\hline Mexico & MEX & $1.7 \%$ & 0.82 & 0.63 & 0.24 & 0.54 & -0.30 \\
\hline Russia & RUS & - & - & - & - & - & - \\
\hline South Africa & $\mathrm{ZAF}$ & $1.3 \%$ & 1.16 & -0.45 & 0.59 & 0.65 & -0.06 \\
\hline Turkey & TUR & - & - & - & - & - & - \\
\hline
\end{tabular}

Note: The values are expressed in percentage points of the aggregate growth rate in MMA relative productivity. Hence, the sum by rows gives the yearly average presented in the third column of the table. This average, in turn, is calculated as the compound rate of growth of relative labour productivity in MMA between endpoints of the period. 
The period covered in the table could be regarded as a period of widespread convergence among the countries considered here ${ }^{145}$. All countries in our sample have managed to reduce (to different degrees) their technological gap with the world leader. As expected, the best performer is Korea with yearly rate of relative productivity growth of $6 \%$. With more modest rates, Belgium, Netherlands and Brazil also stand out within our sample.

In terms of the decomposition, the within component is by far the most important. This is in line with the results obtained by most studies using this technique, according to which the within effect tends to dominate over the between effect (see CHAPTER 2, Section 2.5). Nevertheless, the remaining components also show some interesting patterns that are worth studying. In line with our expectations, the initial specialization component tends to be quite high in mature high-income economies such as Belgium, Denmark and France. In fact, the negative sign of the sectoral catch-up in the latter country could be partly explained by this fact. Since it was highly specialized in those sectors where the USA has shown the most rapid productivity gains, it has been unable to keep the same distance with the world leader. Other countries with similar trends have been Argentina, Brazil and Ireland. But while in the first one the sectoral catch-up has also contributed negatively, in the other two economies it has been positive, showing that these economies have been able to tap into the technological wave of improvements steaming from the leading economy. Last but not least, the structural change component though being the smallest one (in average) in every country group, it contributed positively across all emerging and newly high-income countries, demonstrating the important role of labour reallocation in the process of development. Among them, Chile, Ireland and South Africa stand out as the economies with the highest contribution from structural change. Looking at the last two columns of the table we can also find interesting counterbalancing forces between the static and dynamic reallocation components. While the static component contributes positively in all cases, the dynamic one is always negative or very close to zero.

Summing up, Table 6.5 provides a general picture about the main patterns of catching up during the 1970s. Throughout this decade almost all countries of our sample have managed to reduce their technological distance with the world leader, mainly by reducing their gaps at the sectoral level. Some countries (especially in Europe but also in Latin America) seem to have benefitted from the fact that they showed an initial specialization in those sectors where the leader has been moving

\footnotetext{
145 It is important to emphasize that this table refers to the catch-up in the modern sector. Similar calculations for the total economy would deliver the same trends but with much more modest rates of catch-up. This is especially the case for the mature high-income economies. If we would consider the total economy (including modern and non-modern activities) the average rate of catch up will still be positive, but closer to $1 \%$.
} 
the frontier most rapidly and, at the same time, enough domestic capabilities to absorb these technological improvements. The reallocation of labour between sectors has also contributed positively to the catch-up of most countries but to very different degrees.

We turn now to analyse the results of the decomposition for the second period (see Table 6.6). In clear contrast with the previous period, the changes in the technological gap of MMA between 1982 and 2007 are far from homogeneous across countries. In this case one third of our sample has lagged behind while the remaining two thirds managed to narrow the gap with the US.

The contrast stands out quite clearly when looking at the emerging economies. While China, India, Turkey and Russia showed very rapid catch-up with the world leader, Brazil, Mexico, South Africa -and to a lesser extent- Argentina and Indonesia lagged further behind and witnessed an ever increasing technological gap. The main component behind this contrasting pattern is, once more, the within component. In the cases of Argentina, Mexico and South Africa the positive effect of the initial specialization also stands out, though it is always outweighed by the rapid increase of the technological gaps at the sectoral level. This would indicate that a major constraint for these countries lies in the fact that they have been unable to follow the rapid rate of technological change of the leading economy in those sectors in which they are specialized. Such a pattern would be expected for the advanced mature economies (and it is in fact observed in the richest European economies, such as Belgium, Germany, Italy and The Netherlands). In a way, these upper-middle-income economies are suffering problems that are more likely to arise in the advanced economies, in a clear indication of the type of trap in which they are caught. Interestingly, in the emerging economies that have actually managed to reduce their gap the initial specialization component is negligible.

Another interesting insight that can be derived from Table 6.6 relates to the counterbalancing forces of the static and dynamic structural change components. While in the mature high-income economies the static component tends to be negative and the dynamic positive, in the newly high-income economies and the emerging economies the opposite seems to be true. In these economies the static component tends to be positive while the dynamic component is negative. The only exceptions are Japan and India. This would indicate that in the developing world, labour tended to be absorbed by sectors that had already achieved an above average level of catch-up at the beginning of the period, but that were unable to maintain that distance with the leading economy. In the economies that were already high income at the beginning of the period, instead, labour tended to be absorbed by those sectors that managed to reduce their gap starting from a lagged situation. 
Table 6.6. Decomposition results. Second period (1982-2007)

Percentage points of the aggregate growth rate in $M M A$ relative productivity

\begin{tabular}{|c|c|c|c|c|c|c|c|}
\hline \multirow{3}{*}{$\begin{array}{l}\text { Country and } \\
\text { Groups }\end{array}$} & \multirow{3}{*}{ Code } & \multirow{3}{*}{$\begin{array}{l}\text { Annual } \\
\text { Catch Up } \\
\text { Rate }\end{array}$} & \multicolumn{5}{|c|}{ Contribution to Catch Up Rate (in percentage points) } \\
\hline & & & \multirow{2}{*}{$\begin{array}{c}\text { Within } \\
\text { Sector } \\
\text { Catch Up }\end{array}$} & \multirow{2}{*}{$\begin{array}{c}\text { Initial } \\
\text { Specializa- } \\
\text { tion }\end{array}$} & \multicolumn{3}{|c|}{ Structural change } \\
\hline & & & & & Total & Static & Dynamic \\
\hline \multicolumn{2}{|c|}{$\begin{array}{l}\text { Mature High-Income } \\
\text { Economies }\end{array}$} & $0.3 \%$ & -0.63 & 1.10 & -0.14 & -0.27 & 0.13 \\
\hline Australia & AUS & $0.2 \%$ & 0.14 & 0.18 & -0.13 & 0.02 & -0.15 \\
\hline Austria & $A U T$ & $0.9 \%$ & 0.36 & 0.58 & -0.02 & -0.07 & 0.06 \\
\hline Belgium & $B E L$ & $0.7 \%$ & -0.98 & 1.92 & -0.21 & -0.58 & 0.37 \\
\hline Canada & $C A N$ & $0.0 \%$ & -0.20 & 0.26 & -0.04 & -0.10 & 0.06 \\
\hline Denmark & $D N K$ & $0.0 \%$ & -0.35 & 0.51 & -0.13 & -0.37 & 0.24 \\
\hline France & FRA & $-0.2 \%$ & -1.03 & 0.73 & 0.08 & 0.19 & -0.11 \\
\hline Germany & $D E U$ & $-0.2 \%$ & -4.58 & 4.30 & 0.05 & -2.41 & 2.47 \\
\hline Italy & $I T A$ & $-0.4 \%$ & -1.62 & 1.21 & 0.01 & 0.44 & -0.43 \\
\hline Netherlands & $N L D$ & $-0.4 \%$ & -1.82 & 1.94 & -0.49 & -0.69 & 0.20 \\
\hline Sweden & SWE & $1.3 \%$ & 1.30 & 0.05 & -0.06 & 0.64 & -0.70 \\
\hline U. Kingdom & GBR & $1.7 \%$ & 1.89 & 0.46 & -0.64 & -0.04 & -0.60 \\
\hline \multicolumn{2}{|c|}{$\begin{array}{l}\text { Newly High-Income } \\
\text { Economies }\end{array}$} & $0.9 \%$ & 0.42 & 0.44 & 0.05 & 0.30 & -0.25 \\
\hline Chile & CHL & $0.1 \%$ & -0.04 & 0.64 & -0.51 & -0.15 & -0.36 \\
\hline Finland & FIN & $1.3 \%$ & 1.21 & 0.05 & 0.03 & 0.17 & -0.14 \\
\hline Greece & $G R C$ & $0.5 \%$ & 0.42 & 0.47 & -0.39 & 0.49 & -0.88 \\
\hline Hungary(a) $^{(a)}$ & HUN & $0.2 \%$ & -0.60 & 0.23 & 0.60 & 1.40 & -0.80 \\
\hline Ireland & $I R L$ & $1.6 \%$ & 1.48 & 0.29 & -0.18 & 0.65 & -0.82 \\
\hline Japan & $J P N$ & $0.6 \%$ & -0.51 & 1.05 & 0.05 & -0.62 & 0.66 \\
\hline Korea & KOR & $3.2 \%$ & 2.67 & 0.14 & 0.39 & 0.44 & -0.05 \\
\hline Portugal & PRT & $1.1 \%$ & 0.69 & 0.04 & 0.34 & 0.59 & -0.25 \\
\hline Spain & ESP & $-0.4 \%$ & -1.53 & 1.07 & 0.10 & -0.29 & 0.38 \\
\hline \multicolumn{2}{|c|}{ Emerging Economies } & $1.0 \%$ & 0.66 & 0.26 & 0.09 & 0.68 & -0.58 \\
\hline Argentina & $A R G$ & $-0.3 \%$ & -1.38 & 0.96 & 0.10 & 0.60 & -0.49 \\
\hline Brazil & $B R A$ & $-2.0 \%$ & -2.17 & 0.22 & -0.05 & 0.43 & -0.48 \\
\hline China $^{(b)}$ & $C H N$ & $7.2 \%$ & 7.33 & 0.01 & -0.14 & 0.15 & -0.28 \\
\hline India & $I N D$ & $2.1 \%$ & 1.24 & 0.10 & 0.76 & 0.41 & 0.35 \\
\hline Indonesia $^{(b)}$ & $I D N$ & $-0.2 \%$ & 0.53 & -0.39 & -0.30 & 1.54 & -1.85 \\
\hline Mexico & MEX & $-2.1 \%$ & -2.67 & 0.81 & -0.26 & 0.43 & -0.69 \\
\hline Russia(c) & RUS & $2.2 \%$ & 2.36 & -0.52 & 0.35 & 0.38 & -0.03 \\
\hline South Africa & $Z A F$ & $-0.8 \%$ & -2.06 & 0.99 & 0.32 & 1.88 & -1.56 \\
\hline Turkey ${ }^{(c)}$ & TUR & $3.0 \%$ & 2.74 & 0.20 & 0.04 & 0.26 & -0.22 \\
\hline
\end{tabular}

Note: (a) Period refers to the years 1992-2007; (b) Period refers to the years 1987-2007; (c) Period refers to the years 1997-2007.

The results obtained in our decomposition analysis provide interesting insights on the main trends driving the process of structural change and catch-up within the modern sector of the economy. According to our data, there are interesting con- 
trasts not only between advanced and developing economies but also between countries within the latter category.

\subsection{Sectoral Contributions}

The last step in characterizing the catch-up process within the MMA consists in analysing in further detail the particular sectoral composition that drove this process. The main goal of this analysis is to explore whether technological catch-up is concentrated within a particular subset of industries or is widespread, affecting the whole productive structure. This analysis follows an approach proposed in Harberger (1998) that has been used to analyse the general patterns of structural change in Asian manufacturing (Timmer and Szirmai (2000) and, more recently, to analyse the impact of ICT technologies on aggregate productivity growth (Inklaar and Timmer, 2007; van Ark and Smits, 2005). The main idea behind this approach is to look at the distribution of industry contributions to aggregate productivity growth and distinguish different patterns according to how dispersed or concentrated is this distribution. As indicated in CHAPTER 2, Section 2.5, Harberger distinguishes two main patterns: a mushroom pattern (in which only a few industries account for most of the aggregate productivity growth) and a yeast pattern (in which industries contribute more equally to productivity growth).

In order to quantify the contribution of different sectors to the aggregate dynamics of catch-up in the MMA, however, we first need to adjust our decomposition formula to capture more precisely the relative importance of each sector. In doing so, we follow the approach put forth by van Ark and Timmer (2003) and subsequently used in many contributions such as Wang and Szirmai (2008), de Vries et al. (2013) and Timmer et al. (2014).

In Section 6.5.1 we present the corresponding adjustment of the decomposition equations for the context that we are analysing. In Section 6.5.2 we show the main results obtained.

\subsubsection{Approach}

Following van Ark and Timmer (2003) it is important to impute the structural change component to the sectors that have actually increased their share of employment. In the standard procedure, this effect is allocated rather mechanically without considering its cause. This might lead to negative sectoral contributions that are difficult to interpret. Moreover, all sectors with expanding shares would have positive structural change effects even if they have lower productivity (or wider technological gaps, in the present analysis) than the shrinking sectors.

To solve this sort of inconsistencies, the authors propose to impute all the structural change effects only to the sectors that have actually expanded their labour 
shares during the period, making a distinction between expanding sectors that had higher productivity than the shrinking sectors on average (which will result in a positive structural change effect) and expanding sectors that had productivity levels below the average levels of the shrinking sectors (which will result in a negative structural change effect).

In order to make a similar adjustment in our context, we first need to determine the average levels of $\rho$ and $r$ in the sectors that have lost labour shares during the period of analysis. That is,

$$
\begin{gathered}
\tilde{\rho}_{0}^{i}=\sum_{h} \frac{\left(s_{h, \mathrm{~T}}^{i}-s_{h, 0}^{i}\right)}{\left(s_{H, \mathrm{~T}}^{i}-s_{H, 0}^{i}\right)} \rho_{h, 0}^{i} \quad ; \quad \forall h: s_{h, \mathrm{~T}}^{i}<s_{h, 0}^{i} \\
\tilde{\rho}_{\mathrm{T}}^{i}=\sum_{h} \frac{\left(s_{h, \mathrm{~T}}^{i}-s_{h, 0}^{i}\right)}{\left(s_{H, \mathrm{~T}}^{i}-s_{H, 0}^{i}\right)} \rho_{h, \mathrm{~T}}^{i} \quad ; \quad \forall h: s_{h, \mathrm{~T}}^{i}<s_{h, 0}^{i} \\
\tilde{r}_{\mathrm{T}}^{u}=\sum_{h} \frac{\left(s_{h, \mathrm{~T}}^{i}-s_{h, 0}^{i}\right)}{\left(s_{H, \mathrm{~T}}^{i}-s_{H, 0}^{i}\right)} r_{h, \mathrm{~T}}^{u} \quad ; \quad \forall h: s_{h, \mathrm{~T}}^{i}<s_{h, 0}^{i}
\end{gathered}
$$

where, the subscript $b$ identifies the shrinking sectors (i.e., sectors that have lost labour share during the period), $H$ stands for the set of all shrinking sectors and a wave over a variables indicates the average of that variable across all shrinking sectors in the corresponding period. These values are calculated as weighted averages using as weights the contribution of each sector to the total decline in the labour share of the shrinking sectors between 0 and $T$.

Using equations (6.9) to (6.11) we can now modify our decomposition formula to get more accurate results concerning the sectoral contributions to aggregate catch-up ${ }^{146}$ :

\footnotetext{
146 The original formulation of van Ark and Timmer (2003) uses averages between years to make the decomposition invariant to a particular base. This, however, would eliminate the dynamic components. Since we want to keep these components our adjustment is closer to the one proposed in de Vries et al. (2013) that extends the modification to adjust the dynamic structural change as well.
} 


$$
\begin{gathered}
\Delta \rho_{M}=\underbrace{\sum_{j}^{J} s_{j, 0}^{i} r_{j, \mathrm{~T}}^{u} \Delta \rho_{j}^{i}}_{\begin{array}{c}
\text { within sector } \\
\text { catch up }
\end{array}}+\underbrace{\sum_{k}^{K}\left(\rho_{k, 0}^{i} r_{k, \mathrm{~T}}^{u}-\tilde{\rho}_{0}^{i} \tilde{r}_{\mathrm{T}}^{u}\right) \Delta s_{k}^{i}}_{\begin{array}{c}
\text { static } \\
\text { structural change }
\end{array}}+\underbrace{\sum_{k}^{K}\left(r_{k, \mathrm{~T}}^{u} \Delta \rho_{k}^{i}-\tilde{r}_{\mathrm{T}}^{u} \Delta \tilde{\rho}\right) \Delta s_{k}^{i}}_{\begin{array}{c}
\text { dynamic } \\
\text { structural change }
\end{array}} \\
+\underbrace{\sum_{j}^{J} \rho_{j, 0}^{i} s_{j, 0}^{i} \Delta r_{j}^{u}}_{\begin{array}{c}
\text { initial } \\
\text { specialization }
\end{array}}
\end{gathered}
$$

where $J$ stands for the whole set of sectors and $K$ represents the set of expanding sectors (i.e., sectors in which $s_{k, \mathrm{~T}}^{i}>s_{k, 0}^{i}$ ).

As we can see, in this new formulation the structural change effect is only imputed to the set $K$ of expanding sectors. If the sector absorbing labour has a smaller technological gap than the average of shrinking sectors (all weighted by the relative sectoral productivity at the leading economy in the last period) the static effect will be positive. Otherwise, it will be negative. By the same token, if the speed of catchup of a certain expanding sector (weighted by its relative sectoral productivity at the leading economy in the last period) is more rapid than the average rate of catch-up in the shrinking sectors, then it will have a positive dynamic structural change effect. The contrary will be true if the expanding sector is catching up at a lower rate.

Equation (6.12) will be used to calculate the contribution of each sector to the aggregate catch-up in MMA. Once these contributions are calculated, the next step of the analysis consists in studying how concentrated or dispersed the catching up process has been. As we have already mentioned, this will be done following the approach put forth by Harberger (1998). That is, we look at Lorenz-type diagrams in which the cumulative contribution of all sectors included in MMA to the catchup of this aggregate is depicted against the cumulative labour share of these sectors in the MMA aggregate. In these figures, the cumulative share is compared with a hypothetical distribution in which all sectors contribute in the same amount than their share in MMA labour force (the so called "perfect equality" line). The difference between the two provides interesting insights in the degree of concentration of the catching up process in each economy.

It is important to notice that in these diagrams (unlike traditional Lorenz curves) the cumulative distribution is ordered starting from the sectors that show disproportionally large contributions (as compared to their shares in labour force) to the sectors that show very small or even negative contributions. Hence, the curvature of the diagram is decreasing instead of increasing. In our case, we sort the sectors in decreasing order according to the following indicator: 


$$
\theta=\frac{c_{j}^{i}}{s_{j, 0}^{i}}
$$

where, $c_{j}^{i}$ stands for the contribution of sector $j$ to the aggregate catch-up of country $i$ between years 0 and $T$.

When studying these diagrams we will look specifically at three summary statistics that illustrate their salient features in a concise way ${ }^{147}$ : a) the aggregate rate of catch-up; b) the cumulative employment share of sectors with positive rates of catch-up ${ }^{148}$; and c) the curvature of the diagram, measured as the area between the line of "perfect equality" (the diagonal line) and the observed Harberger curve, divided by the total area of the diagram.

The last measure is the most important for our purposes and hereafter will be denoted with the Greek capital letter $\Pi$. The larger this relative area, the more concentrated the catching up process is. If all sectors reduce their gap at the same rate, then $\Pi$ will be zero. If only one (small) sector explains the whole reduction of the gap, then the area $\Pi$ will be close to one.

Figure 6.12 illustrates these features. It provides the Harberger diagram for a hypothetical economy that has shown a quite concentrated pattern of sectoral catch-up. Only half of the workers in the modern sector belong to industries that have actually reduced their technological gap (all industries up to the maximum of the Harberger curve). The remaining share of labour force belongs to industries in which the gap has increased and thus their contribution has been negative (partially offsetting the positive contribution of the catching-up sectors). As a result, the area between the Harberger curve and the perfect equality line (shaded area in the figure) is quite large, indicating an important degree of concentration and a pattern closer to the mushroom growth.

\footnotetext{
147 These summary statistics are equivalent to the ones used in Inklaar and Timmer (2007) to analyze the patterns of industry-level productivity growth in USA and Europe.

148 In Inklaar and Timmer (2007) this is taken as an indicator of the pervasiveness of growth.
} 
Figure 6.12. Harberger diagram

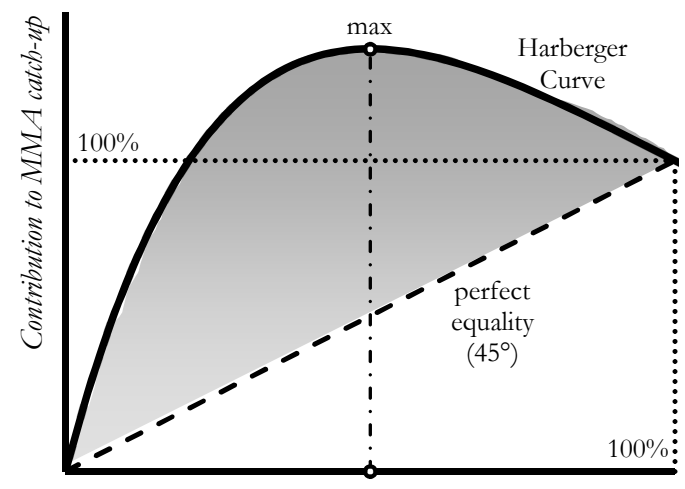

Share of $M M A$ employment in $t=0$

\subsubsection{Yeast versus mushrooms}

In Table 6.7 we present the results of the Harberger diagrams for every country of our sample in the two periods previously analysed.

The table confirms some of the salient features that have already been described in the previous sections of this chapter. It shows that in the best performers the process of catch-up tended to be evenly distributed across the whole range of sectors that belong to MMA (i.e., presented a yeast pattern from the Harberger perspective). This can be observed in both periods under consideration. In the first period the best performers (in terms of catch up) among the non mature economies were, in decreasing order, Korea, Brazil, Ireland, Spain and Finland. In the five economies we can see that the relative area $\Pi$ indicating the level of concentration in the catch-up process was quite small, ranging from 0.27 to 0.33 . In clear contrast, most of the remaining newly high-income and emerging economies with available data for the first period (Argentina, Chile, Greece, Mexico and South Africa) present values of $\Pi$ much larger, that range between 0.44 and 0.66 , reflecting a pattern closer to mushroom pattern of growth in Harberger's analogy. Moreover, the catchup process has not been as pervasive as in the case of the best performers: at least one quarter of the workers employed in the modern sector has been excluded from this process, while in the five countries previously identified as best performers this process included at least $90 \%$ of MMA workers. 
Table 6.7. Decomposition results: concentration degree of the catching up process. 1972-1982 and 1982-2007

\begin{tabular}{|c|c|c|c|c|c|c|c|}
\hline \multirow[b]{2}{*}{$\begin{array}{l}\text { Country } \\
\text { and Groups }\end{array}$} & \multirow[b]{2}{*}{ Code } & \multicolumn{3}{|c|}{ 1972-1982 } & \multicolumn{3}{|c|}{ 1982-2007 } \\
\hline & & $\begin{array}{l}\text { Annual } \\
\text { Rate of } \\
\text { Catch-Up }\end{array}$ & $\begin{array}{c}\text { Relative Area } \\
\text { (П) }\end{array}$ & $\begin{array}{l}\text { Labour } \\
\text { Share of } \\
\text { catching-up } \\
\text { sectors }\end{array}$ & $\begin{array}{c}\text { Annual } \\
\text { Rate of } \\
\text { Catch- } \\
U p\end{array}$ & $\begin{array}{c}\text { Relative Area } \\
\text { (П) }\end{array}$ & $\begin{array}{l}\text { Labour } \\
\text { Share of } \\
\text { catching-up } \\
\text { sectors }\end{array}$ \\
\hline \multicolumn{2}{|c|}{$\begin{array}{l}\text { Mature High- } \\
\text { Income Economies }\end{array}$} & $2.4 \%$ & 0.37 & $93.2 \%$ & $0.3 \%$ & 0.74 & $57.1 \%$ \\
\hline Australia & AUS & $2.6 \%$ & 0.23 & $99.8 \%$ & $0.2 \%$ & 0.83 & $56.2 \%$ \\
\hline Austria & $A U T$ & $2.6 \%$ & 0.22 & $100.0 \%$ & $0.9 \%$ & 0.45 & $61.8 \%$ \\
\hline Belgium & $B E L$ & $4.2 \%$ & 0.28 & $97.9 \%$ & $0.7 \%$ & 0.59 & $80.1 \%$ \\
\hline Canada & $C A N$ & $2.4 \%$ & 0.29 & $97.3 \%$ & $0.0 \%$ & 0.96 & $54.0 \%$ \\
\hline Denmark & $D N K$ & $2.0 \%$ & 0.39 & $70.1 \%$ & $0.0 \%$ & 0.98 & $27.4 \%$ \\
\hline France & $F R A$ & $0.2 \%$ & 0.90 & $91.4 \%$ & $-0.2 \%$ & 0.86 & $45.2 \%$ \\
\hline Germany & $D E U$ & $2.3 \%$ & 0.32 & $97.4 \%$ & $-0.2 \%$ & 0.86 & $54.7 \%$ \\
\hline Italy & $I T A$ & $2.5 \%$ & 0.27 & $88.7 \%$ & $-0.4 \%$ & 0.74 & $56.2 \%$ \\
\hline Netherlands & $N L D$ & $3.6 \%$ & 0.39 & $100.0 \%$ & $-0.4 \%$ & 0.81 & $52.7 \%$ \\
\hline Sweden & SWE & $2.5 \%$ & 0.29 & $96.8 \%$ & $1.3 \%$ & 0.51 & $71.4 \%$ \\
\hline U. Kingdom & GBR & $1.9 \%$ & 0.44 & $86.2 \%$ & $1.7 \%$ & 0.52 & $68.0 \%$ \\
\hline \multicolumn{2}{|c|}{$\begin{array}{l}\text { Newly High-Income } \\
\text { Economies }\end{array}$} & $2.7 \%$ & 0.39 & $87.2 \%$ & $0.9 \%$ & 0.67 & $56.6 \%$ \\
\hline Chile & CHL & $2.4 \%$ & 0.44 & $65.9 \%$ & $0.1 \%$ & 0.95 & $37.4 \%$ \\
\hline Finland & $F I N$ & $2.5 \%$ & 0.27 & $96.0 \%$ & $1.3 \%$ & 0.56 & $71.4 \%$ \\
\hline Greece & GRC & $1.0 \%$ & 0.66 & $74.7 \%$ & $0.5 \%$ & 0.83 & $38.7 \%$ \\
\hline Hungary $^{(a)}$ & HUN & & & & $0.2 \%$ & 0.91 & $56.7 \%$ \\
\hline Ireland & IRL & $2.9 \%$ & 0.28 & $96.3 \%$ & $1.6 \%$ & 0.62 & $66.7 \%$ \\
\hline Japan & $J P N$ & $1.8 \%$ & 0.48 & $81.3 \%$ & $0.6 \%$ & 0.69 & $50.6 \%$ \\
\hline Korea & KOR & $5.8 \%$ & 0.33 & $91.1 \%$ & $3.2 \%$ & 0.30 & $100.0 \%$ \\
\hline Portugal & PRT & $2.0 \%$ & 0.35 & $92.6 \%$ & $1.1 \%$ & 0.52 & $67.5 \%$ \\
\hline Spain & ESP & $2.9 \%$ & 0.28 & $99.7 \%$ & $-0.4 \%$ & 0.63 & $20.8 \%$ \\
\hline \multicolumn{2}{|c|}{$\begin{array}{l}\text { Emerging Econo- } \\
\text { mies }\end{array}$} & $1.7 \%$ & 0.50 & $79.4 \%$ & $1.0 \%$ & 0.50 & $53.7 \%$ \\
\hline Argentina & $A R G$ & $1.0 \%$ & 0.59 & $74.3 \%$ & $-0.3 \%$ & 0.72 & $27.5 \%$ \\
\hline Brazil & $B R A$ & $3.0 \%$ & 0.33 & $95.3 \%$ & $-2.0 \%$ & 0.35 & $5.9 \%$ \\
\hline China ${ }^{(b)}$ & $C H N$ & & & & $7.2 \%$ & 0.31 & $96.9 \%$ \\
\hline India & $I N D$ & & & & $2.1 \%$ & 0.44 & $91.5 \%$ \\
\hline Indonesia ${ }^{(b)}$ & $I D N$ & & & & $-0.2 \%$ & 0.95 & $30.0 \%$ \\
\hline Mexico & MEX & $1.7 \%$ & 0.55 & $72.1 \%$ & $-2.1 \%$ & 0.37 & $13.4 \%$ \\
\hline Russia(c) & RUS & & & & $2.2 \%$ & 0.41 & $85.7 \%$ \\
\hline South Africa & $Z A F$ & $1.3 \%$ & 0.52 & $75.8 \%$ & $-0.8 \%$ & 0.60 & $41.0 \%$ \\
\hline Turkeyy(c) & TUR & & & & $3.0 \%$ & 0.40 & $91.1 \%$ \\
\hline
\end{tabular}

Notes: (a) Second period refers to the years 1992-2007; (b) Second period refers to the years 1987-2007;

(c) Second period refers to the years 1997-2007.

Similar patterns can be observed in the second period. In these years, the best performers are China and Korea, and in both cases the values of $\Pi$ have been quite 
small while the process has affected to more than $95 \%$ of the workers. India, Turkey and Russia also show a very rapid rate of catch-up (though slower than Korea and China). In these economies, however, the process has been more concentrated as indicated by relative areas larger than 0.4 . Other economies with modest reductions of the gap such as Chile and Greece simultaneously show the largest levels of concentration in this process, with values of $\Pi$ of 0.95 and 0.83 respectively.

Another interesting feature that comes out from this analysis is that the countries that have lagged behind at the aggregate level also tend to show very concentrated distributions. This suggests that their falling behind is due to weak productivity performance of a few sectors. This seems to be the case in Argentina, Indonesia, South Africa and Spain, where the aggregate gap increases and, at the same time, the relative areas are very large. Moreover, in all cases there is a non-negligible share of workers in the modern part of the economy that actually belongs to sectors that have reduced their technological gap. This finding is in line with the previous characterization in some of these countries as having followed a structural trajectory of partial catching-up with structural polarization. Brazil is a special case. It also presents an extremely negative catch-up rate but with a low level of concentration (a relative area of 0.35) and a negligible share of labour in catching up sectors (only $6 \%$ ). This would reinforce our characterization of this economy as suffering a process of generalized falling behind during the last three decades.

A last point to take into consideration when analysing these trends is the changing size of the modern sector. This has been already pointed out when analysing the productivity distribution of selected countries in the first section of this chapter, and deserves further attention here. As we have seen in CHAPTER 4 it is precisely the interaction between the size of the modern sector and its catch-up potential what defines our index of structural modernisation. Therefore, to finalize our characterization we specify the changes that took place in the share of this aggregate in total labour force during the periods studied, along with the changes in the average relative productivity and the corresponding results in terms of the structural modernisation index (see Table 6.8). 
Table 6.8. Annual growth rates of the structural modernisation index $(\Omega)$, the relative productivity of $M M A\left(\varrho_{M}\right)$ and the share of $M M A$ workers in total labour force $\left(\lambda_{M}\right)$ by country and sub-period (in percentages)

\begin{tabular}{|c|c|c|c|c|c|c|c|}
\hline \multirow{2}{*}{$\begin{array}{l}\text { Country } \\
\text { and Groups }\end{array}$} & \multirow{2}{*}{ Code } & \multicolumn{3}{|c|}{ First Period (1972-1982) } & \multicolumn{3}{|c|}{ Second Period (1982-2007) } \\
\hline & & $\Omega$ & $\varrho \mathrm{M}$ & $\lambda_{M}$ & $\Omega$ & $\varrho \mathrm{M}$ & $\lambda_{\mathrm{M}}$ \\
\hline \multicolumn{2}{|c|}{$\begin{array}{l}\text { Mature High- } \\
\text { Income Economies }\end{array}$} & 1.0 & 2.4 & -1.4 & 0.2 & 0.3 & -0.2 \\
\hline Australia & AUS & 0.9 & 2.6 & -1.6 & 0.0 & 0.2 & -0.2 \\
\hline Austria & $A U T$ & 2.3 & 2.6 & -0.3 & 0.6 & 0.9 & -0.3 \\
\hline Belgium & $B E L$ & 1.8 & 4.2 & -2.2 & 0.7 & 0.7 & 0.0 \\
\hline Canada & $C A N$ & 1.1 & 2.4 & -1.2 & 0.0 & 0.02 & -0.02 \\
\hline Denmark & $D N K$ & -0.1 & 2.0 & -2.1 & 0.2 & 0.0 & 0.2 \\
\hline France & FRA & -0.8 & 0.2 & -1.0 & -0.6 & -0.2 & -0.4 \\
\hline Germany & $D E U$ & 1.0 & 2.3 & -1.2 & -0.9 & -0.2 & -0.7 \\
\hline Italy & ITA & 2.2 & 2.5 & -0.2 & -0.3 & -0.4 & 0.1 \\
\hline Netherlands & $N L D$ & 1.4 & 3.6 & -2.1 & -0.1 & -0.4 & 0.3 \\
\hline Sweden & SWE & 1.2 & 2.5 & -1.2 & 1.2 & 1.3 & -0.1 \\
\hline U. Kingdom & GBR & 0.1 & 1.9 & -1.8 & 1.1 & 1.7 & -0.6 \\
\hline \multicolumn{2}{|c|}{$\begin{array}{l}\text { Newly High-Income } \\
\text { Economies }\end{array}$} & 2.6 & 2.7 & -0.1 & 1.2 & 0.9 & 0.3 \\
\hline Chile & $\mathrm{CHL}$ & -0.2 & 2.4 & -2.6 & 1.1 & 0.1 & 1.0 \\
\hline Finland & FIN & 2.3 & 2.5 & -0.2 & 1.1 & 1.3 & -0.2 \\
\hline Greece & GRC & 1.3 & 1.0 & 0.4 & 0.0 & 0.5 & -0.5 \\
\hline Hungary $^{(a)}$ & HUN & & & & 1.5 & 0.2 & 0.8 \\
\hline Ireland & $I R L$ & 2.9 & 2.9 & 0.0 & 2.2 & 1.6 & 0.6 \\
\hline Japan & $J P N$ & 1.7 & 1.8 & -0.1 & 0.3 & 0.6 & -0.3 \\
\hline Korea & KOR & 9.7 & 5.8 & 3.8 & 4.0 & 3.2 & 0.8 \\
\hline Portugal & PRT & 1.7 & 2.0 & -0.3 & 0.9 & 1.1 & -0.2 \\
\hline Spain & ESP & 1.1 & 2.9 & -1.7 & -0.2 & -0.4 & 0.2 \\
\hline \multicolumn{2}{|c|}{$\begin{array}{l}\text { Emerging Econo- } \\
\text { mies }\end{array}$} & 2.7 & 1.7 & 0.9 & 1.6 & 1.0 & 0.6 \\
\hline Argentina & $A R G$ & 0.4 & 1.0 & -0.6 & -0.8 & -0.3 & -0.5 \\
\hline Brazil & $B R A$ & 5.0 & 3.0 & 2.0 & -2.1 & -2.0 & -0.1 \\
\hline China $^{(b)}$ & $C H N$ & & & & 8.0 & 7.2 & 0.8 \\
\hline India & $I N D$ & & & & 3.7 & 2.1 & 1.6 \\
\hline Indonesia $^{(b)}$ & $I D N$ & & & & 2.0 & -0.2 & 2.2 \\
\hline Mexico & MEX & 3.2 & 1.7 & 1.5 & -1.6 & -2.1 & 0.5 \\
\hline Russia(c) & RUS & & & & 2.4 & 2.2 & 0.2 \\
\hline South Africa & $Z A F$ & 2.2 & 1.3 & 0.8 & -1.2 & -0.8 & -0.5 \\
\hline Turkeyy(c) & TUR & & & & 3.9 & 3.0 & 0.9 \\
\hline
\end{tabular}

Notes: (a) Second period refers to the years 1992-2007; (b) Second period refers to the years 19872007; (c) Second period refers to the years 1997-2007.

As the table indicates, the size of the modern sector has shrunken in several countries, in both periods. This is quite pronounced, but also expected, in some highincome mature economies (take the examples of Belgium, France, Germany and 
the United Kingdom). In these economies, raising incomes and age has probably led to a shift in domestic demand towards personal services, health and education which might, at least in part, explain this trend. We can also observe important declines in some economies from the other categories. In fact, many of the newly high-income economies have also shown a decreasing size of the modern sector, especially during the first period. However, in most cases, this negative trend was more than compensated by a significant reduction of the technological gap, resulting in a positive variation of the modernisation index. In clear contrast, the negative growth in the labour absorption of the modern sector in Argentina, Brazil and South Africa during the second period took place in a context of increasing technological gap and resulted in a sharp decline of the structural modernisation index.

The examination of Table 6.7 and Table 6.8 also suggest a negative correlation between the degree of concentration in the catch-up process (as captured by the relative area $\Pi$ ) and the performance of the structural modernisation index. The economies that present the higher growth rates for this index in the first period (Finland, Ireland, Korea and Brazil) are, at the same time, the economies that showed the smallest relative areas. The same seems to be true in the second period: Korea, China, India, Russia and Turkey were the economies that achieved the fastest increases in the structural modernisation index. All of them presented, during that period, relative areas much smaller than the sample average.

The evidence presented in these tables thus suggests that successful structural modernisation is more likely associated with a yeast pattern of catching-up, in which most industries that compose the modern sector play an active role in the process. When the catch-up process is concentrated in few industries, instead, the capacity of the modern sector to absorb an increasing share of labour force seems to be limited and the resulting outcome in terms of the structural modernisation index tends to be disappointing. This finding is in line with the theoretical foundation of the thesis and reinforces the idea that a major obstacle to escape from the middle-income trap lies in the specialization in a small number of activities with low spillovers potential to the rest of the economy.

\subsection{Final Remarks}

In this chapter we have opened the black box of the modern market activities aggregate and have provided a detailed investigation of the patterns of structural change that take place within this aggregate. The main focus of the chapter has been placed on analyzing how the composition and sectoral shifts within this group of sectors impact on the aggregate level of relative productivity and the catch up dynamics of the modern sector across time. 
This has been done on the basis of three complementary steps, namely: i) the examination of the sectoral distribution of employment according to the distance to the technological frontier; ii) the decomposition of catch up into various components related to within and between sector dynamics; and iii) the analysis of how concentrated or dispersed the process has been.

The results of these complementary steps provide interesting insights into the general pattern of structural transformation in the set of economies examined. In particular, the empirical evidence presented in this chapter suggests that there are at least three stylized patterns with contrasting characteristics.

The first one, represented by the most successful economies of our sample (such as Ireland, Korea and Sweden) could be regarded as a pattern of structural transformation with generalized catch up. In such a case, the modern sector of the economy manages to expand and, at the same time, reduces its technological gap with the world frontier. This process is widespread, evenly affecting most of the sectors included in the MMA. The whole sectoral distribution tends to shift towards ranges of lower gaps (the right side of our figures -technological upgrading) and at the same time the sectoral heterogeneity (in terms of technological gaps) tends to diminish. The process is not concentrated in a few activities, but tends to be pervasive, across all sectors. Structural change tends to play quite an important role, though catch-up within sectors typically dominates over any other component.

In clear contrast, some countries show a pattern that can be regarded as generalized falling behind (this seems to be the case, for example, in Brazil after 1980). In such a case, the whole distribution of sectors tends to move to the left as technological gaps increase. This results from a quite uniform process that seems to affect all sectors evenly. That is, the technological gap increases across all sectors and there are none (or very few) industries counterbalancing this trend.

Between these two extreme cases, our findings suggest an intermediate pattern that we have labelled partial catch up with structural polarization Argentina, Mexico and South Africa seem to have followed this pattern. In this case, the sectoral distribution does not show a clear shift. Instead, it becomes more dispersed with some clear twin peaks emerging. Some sectors lag further behind while others manage to reduce the technological gap. The coefficient of variation tends to increase and the process of catch up tends to be concentrated in a few sectors. The final outcome (either an increase or a reduction in the aggregate gap) tends to obscure this heterogeneous behaviour.

The last pattern seems to be particularly relevant to characterize economies that have been caught in a middle-income trap. As we have stressed in the previous chapters, failure to achieve a proper structural modernisation might lead to low or middle-income traps. In the light of the findings of this chapter we can conclude 
that an important obstacle to achieve such transformation relies on the specific set of sectors that compose and drive the modern sector. If only a few dynamic sectors achieve catch up while the others lag further behind, then the prospects of achieving these transformations are quite limited.

In such a case, the particular set of activities that dominates the modern sector is not able to pull the rest of the economy into a process of generalized catch up. The corollary of this result is that if a country is specialized in sectors with little scope for technological diffusion to the rest of the economy (or more specifically, of the modern sector), then a trajectory of partial catch up and polarization will emerge naturally. Specific interventions are thus needed, either to foster the spillovers that might arise from the dominating sectors or to diversify the economy towards sectors with higher potential to pull the rest of the economy in a process of generalized catch up.

Hence, an interesting extension for the analysis undertaken in this chapter would be the examination of the technological diffusion potential of different sectors. This is an area that has been addressed by a flourishing empirical literature on $\mathrm{R} \& \mathrm{D}$ and inter-sectoral technology spillovers. This literature typically combines patent data and input-output relationships to build technology-flow matrices and examine the potential of different sectors to diffuse technological innovations and capabilities (Hauknes and Knell, 2009; Hwang and Lee, 2014; Los and Verspagen, 2004; Verspagen and Loo, 1999). The recent release of large datasets with internationally comparable input-output tables for many advanced and developing countries (such as the WIOD) might significantly contribute in this line. In fact, with the only exception of Argentina and Chile, all countries examined in this section are included in that database. This is an issue that we aim at exploring in future research.

Another interesting line of research in which this analysis could be extended is the examination of the heterogeneities that arise within particular sectors. A long strand of literature has pointed out the widespread, profound and persistent heterogeneity across firms that is also present within broad sectors, in terms of size, performance and technological capabilities (Dosi et al., 2010). The structural characterization of the catch-up process proposed in this chapter would greatly benefit from some insights into the micro dynamics that drove the results at the aggregate level, at least in some of the countries here studied. Such an extension would enable us to explore, for example, the type of phenomenon that Dosi et al. (2012) has recently label as neo-dualism. That is, “...the steady co-existence of a group of dynamic firms with a generally bigger ensemble of much less technologically progressive firms which nonetheless survive quite comfortably, possibly exploiting local market niches" (op. cit., p. 1062). Some interesting steps in this direction for the case of Brazil can be found in Catela et al. (2012). 



\section{CHAPTER 7. \\ Conclusions}




\subsection{Research Findings}

The main goal of this thesis was to investigate economic development as a process of structural transformation. In particular, the thesis postulated that there are two key transformations that need to be achieved in order to catch up with the advanced world: on one hand, the absorption of an increasing share of the labour force in the modern part of the economy (structural change); on the other hand, the technological upgrading of these modern sectors (technological catch up). Failure to achieve either of these transformations will eventually lead to low- or middleincome traps, in which only a fraction of the society can reap the benefits of the international flows of technological knowledge.

This general hypothesis has been grounded in a series of theoretical contributions that, from different perspectives, have acknowledged the fundamental role of structural change and technological catch up in the process of economic development. The first part of the thesis has been devoted to building a formal mathematical model of catch up that, combining these theoretical perspectives, was able to deliver interesting insights on different structural trajectories that an economy may follow in its path towards development. The model showed that in an economy characterized by: a) a dual economic structure; b) a large technological gap in the modern sector; and c) a binding restriction on external accounts, the steady state growth rate will depend on the dynamic interaction of the share of labour force in the modern sector and the relative stock of technological knowledge in that sector. Moreover, the model demonstrates that multiple equilibria can be obtained depending on the initial conditions of these variables and the underlying parameters. These equilibrium points, in turn, can be associated with low- and middle-income traps that need to be avoided in order to achieve successful catch up with the advanced countries.

The theoretical findings of the model were confirmed and its implications explored further in the empirical part of the thesis. In particular, a new index of structural modernisation was proposed to account for the salient features stressed by the model. The index acknowledges the fundamental role played by structural change and technological upgrading in the process of economic development. The examination of this index across a large dataset of countries, confirmed that countries caught in development traps are, at the same time, countries that have been unable to achieve the proper level of modernisation. That is, countries that have either failed to expand their modern sector and absorb productively their labour force, or have failed to tap into international flows of technological knowledge and reduce their gap with the world frontier.

This index has proved to be extremely useful not only to make comparisons between countries but also to examine the structural trajectories followed by specific 
economies over time. The most successful economies have clearly managed to pass through various regions of the structural modernisation landscape without getting trapped anywhere in between. The less successful economies, instead, have been trapped at specific regions of the landscape, without being able to move forward towards the upper-right regions. In terms of our theoretical model, these economies seem to be caught in the basin of attraction of the bad equilibria.

The intuitive insights provided by these trajectories have been further supported by an econometric exercise in which the process of structural modernisation has been integrated in the general framework of growth regressions. This exercise has revealed interesting patterns that help us understand why some countries are caught in development traps. On one hand, the results of our regressions indicate that the sectoral composition of the modern sector significantly matters for the final outcome in terms of economic growth. According to these findings, having a vibrant and dynamic manufacturing sector would counterbalance the tendency of growth rates to slow down as countries achieve higher levels of structural modernisation. Moreover, the positive effects of other variables included in growth regressions seem to be mediated by the relative size of manufacturing within the modern part of the economy. Our results suggest that the positive effects typically found for education and openness in driving economic growth are stimulated by a larger manufacturing sector and hampered by a smaller one.

On the other hand, the key role of exports -important in the balance of payments constrained model- has also been highlighted by our regression results. Thus the level of exports is another factor that counterbalances the tendency for growth rates to decline as countries achieve higher levels of modernisation. Higher exports would tend to alleviate the balance-of-payments restriction and, at the same time, stimulate technological learning and capacity building stemming from the exposure to foreign markets. However, not all exports seem to deliver the same growth benefits. According to our results, it is the export of manufacturing value added that contributes most to economic growth. In examining what specific kinds of manufacturing exports would yield the better growth results, our findings were not conclusive. While exports belonging to sectors typically classified as high or mediumhigh technology intensive showed no significant relation with growth, medium-low and low technology intensive sectors were found to have highly significant and positive effects. This result might reflect the fact that the most successful economies of our sample have grounded their initial take off precisely in the export of these low- or middle-low-technology intensive sectors. When looking at different export groups classified according to their average income elasticity in world markets, instead, the results were in line with our theoretical expectations: the groups of high and medium income elasticity showed positive and highly significant impacts on growth, while the low elasticity group presented a negative, though not statisti- 
cally significant, coefficient. Another interesting finding obtained in this part of the analysis is that in many manufacturing export groups (classified either by technology intensity or average income elasticity) the impact on growth heavily depends on the degree of catch-up of the domestic manufacturing sector. One possible interpretation of this outcome is that what really matters for growth is the level of technological sophistication of the exported good, an insight that was also contained in our theoretical model.

Being aware of the important heterogeneities that characterise the modern sector in developing countries, the final part of the thesis has been devoted to explore in further detail the sectoral composition of the modern sector and its evolution over time. An important finding was that the technological upgrading of the modern sector also depends on the structural transformations that take place within this aggregate. As CHAPTER 6 shows, shifts of economic activity towards sectors with higher levels of productivity and higher technological potential have been a key element in the catching up dynamics of successful economies. In contrast, the patterns of catch up in those countries caught in the middle-income trap (especially in Latin America) have been concentrated in a few industries and tended towards a polarize structure where the differences between sectors have increased over the last forty years. These results suggest that an important challenge ahead for these economies is how to achieve a broad diffusion of technological learning across a larger number of sectors, even within the modern part of the economy.

\subsection{Policy Implications}

A number of policy implications emerge from the main findings of this thesis.

First and foremost, our findings acknowledge that structural change should be given a prime importance in policy goals. If the market forces lead the economy towards a negative specialization, then public intervention is needed. But not all policy intervention will help. As shown in the theoretical model proposed in the thesis, this intervention should combine supply and demand elements in an effective and pragmatic way, establishing goals in the medium and long term. Increasing the levels of education and capability of the population will certainly help in absorbing knowledge from abroad and reducing technological gaps. However, if these skills are not matched with the necessary stimulus for demand, then increasing number of skilled workers will populate the traditional sector or end up unemployed, without contributing to the aggregate development of the economy. Therefore, these horizontal policies aimed at building domestic capacity and infrastructure should go hand to hand with industrial and technological policies aimed at upgrading and diversifying the productive structure. The ultimate goal of these policies should be the expansion of the modern sector and the reduction of its technological gap. 
By the same token, a policy aimed at opening the economy indiscriminately in a short period of time will hardly foster long-term economic growth, unless the domestic producers are able to cope with international competition and enter in foreign markets. Stimulating manufacturing exports with higher value added has been shown to be a major channel to spur economic growth. Both the theoretical and empirical results of this thesis suggest that efforts to move towards goods with higher income elasticity of demand in international markets will greatly increase the effectiveness of such a policy.

Another important policy implication of our analysis has to do with the diffusion of productivity gains across the productive structure. Successful countries managed to improve their levels of productivity and reduce their technological gaps with the frontier in a sustained and extended way, involving the vast majority of industries that compose the modern sector in this process. The less successful ones, instead, have shown islands of convergence in a sea of divergence. Therefore, policies aimed at opening up these circuits of restricted convergence would be another key for the successful transformation of these economies. Strengthening the linkages between booming domestic industries and the rest of the economy would be one important step in this direction. When these industries have limited scope to strengthen such linkages and spillovers, however, direct interventions might be required to diversify the economy towards sectors that have higher potential to diffuse technological learning across the whole productive structure.

\subsection{Limitations and Further Research}

The research undertaken in this thesis opens several avenues for future research.

At the theoretical level, the proposed model can be extended in several directions, in order to overcome some of the main limitations that have already been highlighted.

Though extremely useful in terms of simplicity and traceability, the linear setting used in the model imposes some strong assumptions that cannot always be observed in the real world. In particular, it implies that the channels through which certain variables affect economic growth, impact exactly in the same way regardless of the level of development obtained. The inclusion of non-linearities in some of the building functional relations could easily mitigate this limitation. One step in this direction would be the introduction of a non-linear specification for the international spillovers, as in Verspagen (1991). Such a setting would be more in line with the original ideas of the catching-up theorists and would allow for a more accurate exploration of the role of absorptive capacities and technological congruence at different stages of development. In a similar vein, introducing a retardation 
mechanism in the Kaldor-Verdoorn coefficient, as in Rada (2007), would yield a more realistic pattern in the growth rate of output as countries become richer.

Similar considerations might be raised for the dual character of the model. By considering only two sectors, the derivation and solution of its main dynamic relationships has been easily manageable and traceable. However, such a setting disregards the important heterogeneities that can also be observed within the modern part of the economy, as demonstrated in CHAPTER 6. Integrating these heterogeneities into the model would significantly improve its explanatory power. This could be done introducing a multi-sectoral structure within the modern sector. One way to do this would be to model the modern sector as producing a continuum of goods with different technological characteristics, as in Cimoli and Porcile (2013). Alternatively, the modern sector could be modelled using a dynamic Input-Output framework, in line, for example, with Los and Verspagen (2006).

At the empirical level, an important issue left unexplored in this thesis relates to the underlying determinants of structural modernisation. The literature reviewed and our theoretical model already identified several potential determinants that could be examined in empirical research. These candidates can be grouped in two broad categories. On one hand, there is a series of factors affecting the technological capabilities of the countries -and thus, the supply side of the economy- such as the domestic efforts in $\mathrm{R} \& \mathrm{D}$, the national capabilities to absorb foreign technologies and the scope for imitation and diffusion of technology. On the other hand, there are several factors affecting the demand faced by the domestic economy, such as the terms of trade in international transactions, the income-elasticity of exports and the macroeconomic environment. The specific effect of these and other factors can be tested using econometric techniques over the large panel dataset that has been constructed for this thesis. In future research we intend to explore this avenue.

A second direction in which the empirical analysis of this thesis could be extended deals with the reasons why some countries show a pattern of partial catch up with structural polarisation. As detailed before, one possible explanation has to do with the heterogeneous potential of different sectors to diffuse technological learning and pull the economy into a process of generalized catch up. An empirical exploration on the sectoral linkages and technological spillovers across sectors in the sample of countries analysed in CHAPTER 6 would provide interesting insights in this line. This is another avenue that we aim to investigate in future research.

This short summary of the main findings and possible extensions indicates that the thesis provides an interesting ground for the theoretical and empirical analysis of economic development as a process of structural transformation. We hope that it can also serve as a guideline for potential lines of future research. 


\section{REFERENCES}

Abramovitz, M. (1986). Catching up, forging ahead, and falling behind. Journal of Economic history, 46(2), 385-406.

Acevedo, A., Mold, A., and Perez, E. (2009). The sectoral drivers of economic growth: A long-term view of Latin American economic performance. Cuadernos Económicos de ICE, 78, 1-26.

Alesina, A., Spolaore, E., and Wacziarg, R. (2005). Trade, Growth and the Size of Countries. In P. Aghion \& S. Durlauf (Eds.), Handbook of economic growth, Volume $1 B$ (Vol. 1, pp. 1499-1542). NorthHolland.

Amable, B. (1993). Catch-up and convergence: a model of cumulative growth. International Review of Applied Economics, 7(1), 1-25.

Anderson, E. (2007). Identifying chronically deprived countries: results from cluster analysis. CRPC Working Paper, 70 (January).

Andreoni, A., and Lopez Gomez, C. (2012). Can we live on services? Exploring manufacturingservices interfaces and their implications for industrial policy design. DRUID Academy Conference 2012.

Atesoglu, H. (1993). Manufacturing and economic growth in the United States. Applied Economics, 25, 67-69.

Azariadis, C., and Stachurski, J. (2005). Poverty traps. In P. Aghion \& S. Durlauf (Eds.), Handbook of economic growth. Volume 2 (pp. 295-384). Elsevier.

Bahmani, M., Harvey, H., and Hegerty, S. W. (2013). Empirical tests of the Marshall-Lerner condition: a literature review. Journal of Economic Studies, 40(3), 411-443.

Bairam, E. (1991). Economic growth and Kaldor's law: the case of Turkey, 1925-78. Applied Economics, 23, 1277-1280.

Ball, L., Roux, N., and Hofstetter, M. (2012). Unemployment in Latin America and the Caribbean. Open Economies Review, 24(3), 397-424.

Baltagi, B. H., Bresson, G., and Pirotte, A. (2003). Fixed effects, random effects or Hausman-Taylor?: A pretest estimator. Economics letters, 79, 361-369.

Barro, R. J. (1991). Economic growth in a cross section of countries. The Quarterly Journal of Economics, 106(2), 407-443.

Barro, R. J., and Lee, J. W. (2013). A new data set of educational attainment in the world, 1950-2010. Journal of Development Economics, 104, 184-198.

Barro, R. J., and Sala-i-Martin, X. (1991). Convergence across states and regions. Brookings Papers on Economic Activity, 1, 107-182.

Barro, R. J., and Sala-i-Martin, X. (1995). Economic Growth. New York: McGraw-Hill.

Baumol, W. (1986). Productivity growth, convergence, and welfare: what the long-run data show. The American Economic Review, 76(5), 1072-1085.

BCC. (2011). Cuentas Nacionales de Chile. 2003-2010. Santiago: Banco Central de Chile.

BCC. (2012). Indicadores económicos y sociales regionales de Chile, 1980-2010. Santiago: Banco Central de Chile.

Bell, T. (1984). Unemployment in South Africa. Institute for Social \& Economic Research, University of Durban-Westville, Occasional Paper Series, 10.

Bernard, A., and Durlauf, S. (1995). Convergence in international output. Journal of applied econometrics, 10(2), 97-108.

Bernat, A. J. (1996). Does manufacturing matter? A spatial econometric view of Kaldor's laws. Journal of Regional Science, 36(3), 463-477. 
Blecker, R. A. (2013). Long-run growth in open economies: export-led cumulative causation or a balance-of-payments constraint? In G. Harcourt \& P. Kriesler (Eds.), Handbook of Post-Keynesian Economics, Volume 1 Theory and Origins. Oxford: Oxford University Press.

Bloom, D., Canning, D., and Sevilla, J. (2003). Geography and poverty traps. Journal of Economic Growth, 8(4), 355-378.

Boeke, J. H. (1930). Dualistische Economie. Leiden: Reprinted in J.H.Boeke, Indonesian Economics: The Concept of Dualism in Theory and Practice, Den Haag, van Hoeve, 1961.

Bolt, J., and van Zanden, J. L. (2013). The First Update of the Maddison Project; Re-Estimating Growth Before 1820. Maddison Project Working Paper, 4(January).

Bosworth, B., and Triplett, J. (2007). The early 21st century US productivity expansion is still in services. International Productivity Monitor, 14(Spring), 3-19.

Botta, A. (2009). A structuralist North-South model on structural change, economic growth and catching-up. Structural Change and Economic Dynamics, 20(1), 61-73.

Boyer, R. (1988). Formalizing growth regimes. In G. Dosi, C. Freeman, R. Nelson, G. Silverberg, \& L. Soete (Eds.), Technical change and economic theory (pp. 609-631). London and New York: Pinter Publisher.

Carmignani, F., and Mandeville, T. (2010). Never been industrialized: a tale of African structural change. MRG University of Queensland discussion paper series, 37.

Cashin, P. (1995). Economic Growth and Convergence Across the Seven Colonies of Australasia: 1861-1991. Economic Record, 71, 132-144.

Cashin, P., and Sahay, R. (1996). Regional economic growth and convergence in India. Finance and Development, 33(March), 49-52.

Castaldi, C. (2009). The relative weight of manufacturing and services in Europe: An innovation perspective. Technological Forecasting and Social Change, 76(6), 709-722.

Castellacci, F. (2002). Technology Gap and Cumulative Growth: Models and outcomes. International Review of Applied Economics, 16(3), 333-346.

Castellacci, F. (2007). Evolutionary and New Growth Theories. Are They Converging? Journal of Economic Surveys, 21(3), 585-627.

Castellacci, F. (2008). Technological paradigms, regimes and trajectories: Manufacturing and service industries in a new taxonomy of sectoral patterns of innovation. Research Policy, 37(6-7), 978-994.

Catela, E. Y., Cimoli, M., and Porcile, G. (2012). Productivity and structural heterogeneity in the Brazilian manufacturing sector: trends and determinants. LEM Working Paper Series, 2012/20(November).

Chakravarty, S., and Mitra, A. (2009). Is industry still the engine of growth? An econometric study of the organized sector employment in India. Journal of Policy Modeling, 31(1), 22-35.

Chenery, H. B., Robinson, S., and Syrquin, M. (1986). Industrialization and Growth: A Comparative Study. New York: Oxford University Press.

Chenery, H. B., and Taylor, L. (1968). Development Patterns: Among Countries and Over Time. The Review of Economics and Statistics, 50(4), 391-416.

Cimoli, M. (2005). Structural heterogeneity, technological asymmetries and growth in Latin America. MPRA Paper. Santiago: ECLAC / IDB.

Cimoli, M., and Dosi, G. (1995). Technological paradigms, patterns of learning and development: an introductory roadmap. Journal of Evolutionary Economics, (5), 243-268.

Cimoli, M., Dosi, G., and Stiglitz, J. (2009). Industrial Policy and Development. The Political Economy of Capabilities Accumulation. New York: Oxford University Press.

Cimoli, M., and Porcile, G. (2010). Specialization, Wage Bargaining and Technology in a Multigoods Growth Model. Metroeconomica, 61(1), 219-238. 
Cimoli, M., and Porcile, G. (2013). Technology, structural change and BOP-constrained growth: a structuralist toolbox. Cambridge Journal of Economics, 37(5), 1-23.

Cimoli, M., Porcile, G., and Rovira, S. (2010). Structural change and the BOP-constraint: why did Latin America fail to converge? Cambridge Journal of Economics, 34(2), 389-411.

Cimoli, M., Primi, A., and Pugno, M. (2005). An enclave-led model of growth: the structural problem of informality persistence in Latin America. GRADE Discussion Paper, 4, 1-33.

Cleveland, W. S. (1979). Robust Locally and Smoothing Weighted Regression Scatterplots. Journal of the American Statistical Association, 74(368), 829-836.

Cohen, D., and Soto, M. (2007). Growth and human capital: good data, good results. Journal of Economic Growth, 12(1), 51-76.

Cohen, and Levinthal, D. A. (1990). Absorptive capacity: a new perspective on learning and innovation. Administrative science quarterly, 35(1), 128-152.

Cornwall, J. (1976). Diffusion, convergence and Kaldor's laws. The Economic Journal, 86(342), 307-314.

Cornwall, J. (1977). Modern Capitalism: Its Growth and Transformation. Martin Roberston, London.

Cornwall, J., and Cornwall, W. (1994). Growth theory and economic structure. Economica, 1992, 237 251.

Cripps, T. F., and Tarling, R. J. (1973). Growth in Advanced Capitalist Economies, 1950-1970. Cambridge Occasional Paper, 40.

Criscuolo, P., and Narula, R. (2008). A novel approach to national technological accumulation and absorptive capacity: aggregating Cohen and Levinthal. The European Journal of Development Research, 20(1), 56-73.

Dahlman, C., and Nelson, R. R. (1995). Social absorption capability, national innovation systeems and economic development. In D. H. Perkins \& B. H. Koo (Eds.), Social capability and long-term growth. Basingstoke: Macmillan.

Dasgupta, S., and Singh, A. (2005). Will services be the new engine of Indian economic growth? Development and Change, 36(6), 1035-1057.

Dasgupta, S., and Singh, A. (2006). Manufacturing, services and premature de-industrialization in developing countries. CBR Working Papers, 327, 1-29.

De Benedictis, L. (1998). Cumulative Causation, Harrod's Trade Multiplier and Kaldor's Paradox: the Foundations of Post Keynesian Theory of Growth Differentials. In Economic Dynamics, Trade and Growth: Essays on Harrodian Themes (pp. 253-280). Macmillan.

De Vries, G. (2010). Productivity, Firm Heterogeneity, and Policy Reforms in Latin America. PhD Thesis. Groningen: Groningen University.

De Vries, G., Erumban, A., Timmer, M., Voskoboynikov, I., and Wu, H. (2012). Deconstructing the BRICs: Structural transformation and aggregate productivity growth. Journal of Comparative Economics, 40(2), 211-227.

De Vries, G., Timmer, M., and de Vries, K. (2013). Structural transformation in Africa: Static gains, dynamic losses. GGDC Research Memorandum, 136.

Desdoigts, A. (1999). Patterns of economic development and the formation of clubs. Journal of economic growth, 330(September), 305-330.

Díaz-Bautista, A. (2003). Mexico's Industrial Engine of Growth: Cointegration and Causality. Revista Momento Economico, 126(march), 34-41.

DNCN. (2006). Generación del Ingreso e Insumo de Mano de Obra. Buenos Aires: Direción Nacoinal de Cuenta Nacionales. Ministerio de Economía de la República Argentina.

Domar, E. (1946). Capital expansion, rate of growth, and employment. Econometrica, Journal of the Econometric Society, 14(2), 137-147.

Dosi, G., Freeman, C., Nelson, R. R., Silverberg, G., and Soete, L. (1988). Technical Change and Economic Theory (p. 646). London: Pinter Publisher. 
Dosi, G., Grazzi, M., Tomasi, C., and Zeli, A. (2012). Turbulence underneath the big calm? The micro-evidence behind Italian productivity dynamics. Small Business Economics, 39(4), 1043-1067.

Dosi, G., Lechevalier, S., and Secchi, A. (2010). Introduction: Interfirm heterogeneity--nature, sources and consequences for industrial dynamics. Industrial and Corporate Change, 19(6), 1867-1890.

Dosi, G., Pavitt, K., and Soete, L. (1990). The economics of technical change and international trade. LEM Book Series. New York: New York University Press.

Dowrick, S., and DeLong, J. (2003). Globalization and convergence. In M. D. Bordo, A. M. Taylor, \& J. G. Williamson (Eds.), Globalization in historical perspective. Chicago and London: University of Chicago Press.

Dowrick, S., and Nguyen, D. (1989). OECD comparative economic growth 1950-85: catch-up and convergence. The American Economic Review, 79(5), 1010-1030.

Drakopoulos, S., and Theodossiou, I. (1991). Kaldorian approach to Greek economic growth. Applied Economics, 23, 1683-1689.

Durlauf, S., and Johnson, P. a. (1995). Multiple regimes and cross $\square$ country growth behaviour. Journal of Applied Econometrics, 10(4), 365-384.

Durlauf, S., Johnson, P. A., and Temple, J. (2005). Growth econometrics. In P. Aghion \& S. Durlauf (Eds.), Handbook of economic growth (pp. 555-677). North-Holland.

ECLAC. (1986). Statistical Yearbook for Latin America and the Caribbean.

ECLAC. (2010). Time for Equality. Closing Gaps, Opening Trails. Santiago: ECLAC.

ECLAC. (2012). Structural change for equality. An integrated approach to development. Santiago: United Nations.

Eeckhout, J., and Jovanovic, B. (2012). Occupational choice and development. Journal of Economic Theory, 147(2), 657-683.

Eichengreen, B., and Gupta, P. (2011). The two waves of service-sector growth. Oxford Economic Papers, 65(1), 96-123.

Fagerberg, J. (1988a). International competitiveness. The Economic Journal, 98(391), 355-374.

Fagerberg, J. (1988b). Why Growth Rates Differ. In G. Dosi, C. Freeman, R. Nelson, G. Silverberg, \& L. Soete (Eds.), Technical change and economic theory (pp. 432-457). London and New York: Pinter Publisher.

Fagerberg, J. (1994). Technology and international differences in growth rates. Journal of Economic Literature, 32(3), 1147-1175.

Fagerberg, J. (2000). Technological progress, structural change and productivity growth: a comparative study. Structural Change and Economic Dynamics, 11(4), 393-411.

Fagerberg, J. (2007). The dynamics of technology, growth and trade: A Schumpeterian perspective. In H. Hanusch \& A. Pika (Eds.), Elgar Companion to Neo-Schumpeterian Economics (Vol. 25, pp. 705-718).

Fagerberg, J., and Godinho, M. (2005). Innovation and catching-up. In J. Fagerberg, D. Mowery, \& R. Nelson (Eds.), The Oxford Handbook of Innovation. Oxford: Oxford University Press.

Fagerberg, J., Srholec, M., and Verspagen, B. (2010). Innovation and economic development. In B. H. Hall \& N. Rosenberg (Eds.), Handbook of the Economics of Innovation (1st ed., Vol. 2, pp. 833-872). Elsevier B.V.

Fagerberg, J., and Verspagen, B. (1999). "Modern Capitalism" in the 1970s and 1980s. Working Papers Archives, 1999002.

Fagerberg, J., and Verspagen, B. (2002). Technology-gaps, innovation-diffusion and transformation: an evolutionary interpretation. Research Policy, 31(8-9), 1291-1304.

Färe, R., Grosskopf, S., Norris, M., and Zhang, Z. (1994). Productivity growth, technical progress, and efficiency change in industrialized countries. The American economic review, 84(1), 66-83.

Feenstra, R. (1996). US imports, 1972-1994: Data and concordances. NBER Working Paper Series, 5515. 
Feenstra, R., Inklaar, R., and Timmer, M. (2013). The Next Generation of the Penn World Table. NBER Working Paper Series, 19255.

Fei, J. C. H., and Ranis, G. (1997). Growth and Development from an Evolutionary Perspective. Oxford: Blackwell Publisher.

Felipe, J. (1998). The role of the manufacturing sector in Southeast Asian development: a test of Kaldor's first law. Journal of Post Keynesian Economics, 20(3), 463-485.

Felipe, J. (2012). Tracking the Middle-Income Trap: What is it, Who is in it, and Why? (Part 1). ADBI Working Papers, 306(March).

Felipe, J., Leon-Ledesma, M., Lanzafame, M., and Estrada, G. (2009). Sectoral engines of growth in developing Asia: stylized facts and implications. Malaysian Journal of Economic Studies, 46(2), 107-133.

Frankel, J. (2012). The natural resource curse: a survey of diagnoses and some prescriptions. CID Working Paper, 233.

Gallup, J. L., Sachs, J. D., and Mellinger, a. D. (1999). Geography and Economic Development. International Regional Science Review, 22(2), 179-232.

Garrett, G. (2004). Globalization's missing middle. Foreign Affairs, 83(6), 84-96.

Gerschenkron, A. (1962). Economic backwardness in historical perspective. Economic backwardness in historical perspective. Cambridge: The Belknap Press.

Gill, I., and Kharas, H. (2007). An East Asian Renaissance. Ideas for Economic Growth. World Bank, Washington, DC (p. 382). Washington DC: The World Bank.

Goode, R. (1959). Adding to the Stock of Physical and Human Capital. The American Economic Review, 49(2), 147-155.

Gouvea, R. R., and Lima, G. T. (2010). Structural change, balance-of-payments constraint, and economic growth: evidence from the multisectoral Thirlwall's law. Journal of Post Keynesian Economics, 33(1), 169-204.

Gouvêa, R. R., and Lima, G. T. (2013). Balance-of-payments-constrained growth in a multisectoral framework: A panel data investigation. Journal of Economic Studies, 40(2), 240-254.

Guillaumont, P. (2009). Caught in a trap. Identifying the least developed countries. Paris: Economica.

Hansen, J., and Zhang, J. (1996). A Kaldorian approach to regional economic growth in China. Applied Economics, 28, 679-685.

Harberger, A. (1998). A vision of the growht process.

Harrod, R. (1939). An essay in dynamic theory. The Economic Journal, 49(193), 14-33.

Hatzichronoglou, T. (1997). Revision of the high-technology sector and product classification. OECD Science, Technology and Industry Working Papers, 1997/02.

Hauknes, J., and Knell, M. (2009). Embodied knowledge and sectoral linkages: An input-output approach to the interaction of high- and low-tech industries. Research Policy, 38(3), 459-469.

Hausman, J. (1978). Specification tests in econometrics. Econometrica: Journal of the Econometric Society, 46(6), 1251-1271.

Hausman, J., and Taylor, W. (1981). Panel data and unobservable individual effects. Econometrica: Journal of the Econometric Society, 49(6), 1377-1398.

Hausmann, R., Hwang, J., and Rodrik, D. (2007). What you export matters. Journal of Economic Growth, 12(1), 1-25.

Hidalgo, C., and Hausmann, R. (2008). A network view of economic development. Developing alternatives, 5-10.

Hidalgo, C., Klinger, B., Barabási, A.-L., and Hausmann, R. (2007). The product space conditions the development of nations. Science (New York, N.Y.), 317(5837), 482-7.

Hill, H. (1986). LDC manufactured exports: Do definitions matter? Some examples from ASEAN. ASEAN Economic Bulletin. 
Hobday, M. (1995). Innovation in East Asia: The Challenge to Japan. Aldershot, Hants, England: E. Elgar.

Hobijn, B., and Franses, P. (2000). Asymptotically perfect and relative convergence of productivity. Journal of Applied Econometrics, 15(1), 59-81.

Hofman, A., Mas, M., Aravena, C., and Fernández, J. (2014). Structural change in four Latin American countries: An international perspective. Paper presented at the third World KLEMS Conference Tokyo, Japan, May 19-20, 2014.

Hwang, W.-S., and Lee, J.-D. (2014). Interindustry Knowledge Transfer and Absorption via Two Channels: The Case of Korea. Global Economic Review, 43(2), 131-152.

Infante, R., and Sunkel, O. (2009). Chile: towards inclusive development. Cepal Review, 97(April), 133152.

Inklaar, R., O’Mahony, M., and Timmer, M. (2005). ICT and Europe's productivity performance: industry-level growth account comparisons with the United States. Review of Income and Wealth, 51(4), $505-536$.

Inklaar, R., and Timmer, M. (2007). Of Yeast and Mushrooms: Patterns of Industry-Level Productivity Growth. German Economic Review, 8(2), 174-187.

Inklaar, R., and Timmer, M. (2012). The Relative Price of Services. Review of Income and Wealth, 1-16.

Jacob, J., and Osang, T. (2007). Institutions, Geography and Trade $\square$ : A Panel Data Study 1. Association Meetings, (214).

Jankowska, A., Nagengast, A., and Perea, J. R. (2012). The product space and the middle-income trap: Comparing Asian and Latin American experiences. OECD Development Centre Working Paper, 311(April).

Jorgenson, D. W., Ho, M. S., and Samuels, J. D. (2012). A Prototype Industry-Level Production Account for the United States, 1947-2010. Second World KLEMS Conference, Harvard University, August 9, 2012.

Joshi, S. (2011). Can IT and ITES be an engine of growth for India: An empirical analysis. World Journal of Science, Technology and Sustainable Development, 8(1), 25-39.

Kaldor, N. (1966). Causes of the Slow Rate of Economic Growth of the United Kingdom: An Inaugural Lecture. Cambridge University Press.

Kaldor, N. (1967). Strategic Factors in Economic Development. Ithaca: Cornell University Press.

Kathuria, V., and Raj, R. (2009). Is Manufacturing an Engine of Growth in India? Analyis in the Post Nineties. Paper for the UNU-WIDER/UNU-MERIT/UNIDO Workshop, Pathways to Industrialisation in the 21st Century. New Challenges and Emerging Paradigms, Maastricht 22-23 October.

Khan, K., and Siddiqi, W. (2011). Impact of Manufacturing Industry on Economic Growth in Case of Pakistan: A Kaldorian Approach. Contemporary Research in Business, 3(1), 1021-1037.

Kim, L., and Nelson, R. R. (2000). Technology, Learning, and Innovation. Experiences of Newly Industrializing Economies. New York: Cambridge University Press.

Krueger, A. O. (1983). Employment and Labor Markets in Less Developed Countries. In Trade and Employment in Developing Countries (Vol. I, pp. 10-29). Chicago: University of Chicago Press.

Kucera, D., and Roncolato, L. (2012). Structure matters: sectoral drivers of growth and the labour productivity-employment relationship. ILO Working Papers, 471734.

Kumar, S., and Russell, R. (2002). Technological change, technological catch-up, and capital deepening: relative contributions to growth and convergence. American Economic Review, 92(3), 527 548.

Kuznets, S. (1966). Modern Economic Growth. New Haven: Yale University Press.

Kuznets, S. (1971). Economic Growth of Nations: Total Output and Production Structure. Cambridge Massachusetts: The Belknap Press of Harvard University Press.

Lavopa, A., and Szirmai, A. (2012a). Industrialization, employment and poverty. UNU-MERIT Working Paper Series, 081. 
Lavopa, A., and Szirmai, A. (2012b). Manufacturing growth, manufacturing exports and economic development, 1960-2010. Paper presented at the 14th ISS Conference, Brisbane, Australia.

Lee, K. (2013). Schumpeterian Analysis of Economic Catch-up: Knowledge, Path-creation, and the Middle-income Trap. Cambridge: Cambridge University Press.

León-Ledesma, M. A. (2002). Accumulation, innovation and catching-up: an extended cumulative growth model. Cambridge Journal of Economics, 26, 201-216.

Lewis, W. (1954). Economic development with unlimited supplies of labour. The manchester school.

Lin, J. Y. (2011). New Structural Economics: A Framework for Rethinking Development. The World Bank Research Observer, 26(2), 193-221.

Los, B., and Timmer, M. (2005). The "appropriate technology" explanation of productivity growth differentials: An empirical approach. Journal of Development Economics, 77(2), 517-531.

Los, B., and Verspagen, B. (2004). Technology spillovers and their impact on productivity. In Elgar Companion to Neo-Scbumpeterian Economics (pp. 574-593). Cheltenham: Edward Elgar.

Los, B., and Verspagen, B. (2006). The evolution of productivity gaps and specialization patterns. Metroeconomica, 4, 464-493.

Lucas, R. (1988). On the Mechanisms of Economic Development. Journal of Monetary Economics, 22(1), $3-42$.

Lutz, W. (2007). Reconstruction of populations by age, sex and level of educational attainment for 120 countries for 1970-2000. Vienna Yearbook of Population Research, 2007, 193-235.

Mamgain, V. (1999). Are the Kaldor-Verdoorn Laws Applicable in the Newly Industrializing Countries? Review of Development Economics, 3(3), 295-309.

Mankiw, N. G., Romer, D., and Weil, D. N. (1992). A contribution to the empirics of economic growth. Quarterly Journal of Economics, 107(2), 407-437.

Maroto, A., and Rubalcaba, L. (2008). Services productivity revisited. The Service Industries Journal, 28(3), $337-353$

Maroto-Sánchez, A., and Cuadrado-Roura, J. R. (2009). Is growth of services an obstacle to productivity growth? A comparative analysis. Structural Change and Economic Dynamics, 20(4), 254-265.

Mattoo, A. (2009). Is Service Sector a Source of Growth? In E. Ghani \& S. Ahmed (Eds.), Accelerating growth and job creation in South Asia (pp. 175-203). New Delhi: Oxford University Press.

McCombie, J. S. L. (1983). Kaldor's laws in retrospect. Journal of Post Keynesian Economics, 5(3), 414-429.

McCombie, J. S. L., and Thirlwall, A. P. (1997). Economic growth and the balance of payments constraint revisited. In P. Arestis, G. Palma, \& M. Sawyer (Eds.), Markets, Unemployment and Economic Policy: Essays in Honour of Geoffrey Harcourt (pp. 498-511). London: Routledge.

McMillan, M., and Rodrik, D. (2011). Globalization, structural change and productivity growth. In M. Bacchetta \& M. Jansen (Eds.), Making Globalization Socially Sustainable (pp. 49-85). Genève: ILOWTO.

McMillan, M., Rodrik, D., and Verduzco-Gallo, Í. (2014). Globalization, Structural Change, and Productivity Growth, with an Update on Africa. World Development, 63, 11-32.

Metcalfe, J. (2001). Institutions and progress. Industrial and corporate change, 10(3), 561-586.

Millin, M., and Nichola, T. (2005). Explaining economic growth in South Africa: a Kaldorian approach. International Journal of Technology Management and Sustainable Development, 4(1), 47-62.

Morawetz, D. (1977). Twenty-five Years of Economic Development. 1950 to 1975 (p. 144). Washington DC: The World Bank.

Moreno-Brid, J. (1998). On capital flows and the balance-of-payments-constrained growth model. Journal of Post Keynesian Economics, 21(2), 283-298.

Mowery, D. C., and Nelson, R. (1999). The Sources of Industrial Leadership: Studies of Seven Industries. Cambridge: Cambridge University Press. 
Myint, H. (1980). The Economics Of Developing Countries (5th ed.). London: Hutchinson University Library.

Naastepad, C. (2005). Technology, demand and distribution: a cumulative growth model with an application to the Dutch productivity growth slowdown. Cambridge Journal of Economics, 30(3), 403434.

Nanayakkara, A. (2004). Employment and Unemployment in Sri Lanka: Trends, Issues, and Options. Department of Census and Statistics Sri Lanka.

Naudé, W., Szirmai, A., and Lavopa, A. (2013). Industrialization Lessons from BRICS: A Comparative Analysis. IZA Discussion Paper Series, 7543 (August).

Necmi, S. (1999). Kaldor's growth analysis revisited. Applied Economics, 31(5), 653-660.

Nehru, V., Swanson, E., and Dubey, A. (1995). A new database on human capital stock in developing and industrial countries: Sources, methodology, and results. Journal of development Economics, 46, 379401.

Nelson, R. R. (1956). A Theory of the Low-Level Equilibrium Trap in Underdeveloped Economies. The American Economic Review, 46(5), 894-908.

Nelson, R. R. (1996). The Sources of Economic Growth. London: Harvard University Press.

Nelson, R. R., and Winter, S. G. (1982). An evolutionary theory of economic change. Cambridge: Belknap Press/Harvard University Press.

O'Mahony, M., and van Ark, B. (2003). EU productivity and competitiveness: an industry perspective: can Europe resume the catching-up process?.

Ocampo, J. A., Rada, C., and Taylor, L. (2009a). Growth and Sectoral Policy. In Growth and Policy in Developing Countries: A Structuralist Approach (pp. 121-141). New York: Columbia University Press.

Ocampo, J. A., Rada, C., and Taylor, L. (2009b). Growth Rates, Economic Structures, and Energy Use. In Growth and Policy in Developing Countries. A Structuralist Approach (pp. 37-57). New York: Columbia University Press.

OECD. (2003). Science, Technology and Industry Scoreboard 2003. Paris: OECD Publishing.

Ohkawa, K., and Rosovsky, H. (1973). Japanese Economic Growth: Trend Acceleration in the Twentieth Century (p. 327). Stanford: Stanford University Press.

Ohno, K. (2009). Avoiding the Middle-Income Trap: Renovating Industrial Policy Formulation in Vietnam. Asean Economic Bulletin, 26(1), 25-43.

Paap, R., Franses, P. H., and van Dijk, D. (2005). Does Africa grow slower than Asia, Latin America and the Middle East? Evidence from a new data-based classification method. Journal of Development Economics, 77(2), 553-570.

Palley, T. I. (2012). Growth, Unemployment and Endogenous Technical Progress: a Hicksian Resolution of Harrod'S Knife-Edge. Metroeconomica, 63(3), 512-541.

Palley, T. I. (2013). A Kaldor-Hicks-Goodwin-Tobin-Kalecki model of growth and distribution. Metroeconomica, 64(2), 319-345.

Palma, G. (2005). Four sources of de-industrialisation and a new concept of the Dutch Disease. In J. A. Ocampo (Ed.), Beyond Reforms: structural dynamics and macroeconomic vulnerability. Stanford University Press and World Bank.

Park, J. (2004). International and Intersectoral R\&D Spillovers in the OECD and East Asian Economies. Economic Inquiry, 42(4), 739-757.

Pavitt, K. (1984). Sectoral patterns of technical change: towards a taxonomy and a theory. Research policy, 13(1984), 343-373.

Peneder, M. (2003). Industrial structure and aggregate growth. Structural Change and Economic Dynamics, 14(4), 427-448.

Pérez, C. (2010). Technological dynamism and social inclusion in Latin America: a resource-based production development strategy. Cepal Review, 100, 121-141. 
Persson, J. (1997). Convergence across the Swedish counties, 1911-1993. European Economic Review, 41, 1835-1852.

Pieper, U. (2000). Deindustrialisation and the social and economic sustainability nexus in developing countries: Cross- country evidence on productivity and employment. The Journal of Development Studies, (August 2012), 66-99.

Pieper, U. (2002). Patterns of inter-sectoral diffusion of technological growth: income, concentration, and public capital stocks. MERIT-Infonomics Research Memorandum series, 2002-010.

Pieper, U. (2003). Sectoral regularities of productivity growth in developing countries--a Kaldorian interpretation. Cambridge Journal of Economics, 27(6), 831-850.

Pilat, D. (2001). Innovation and Productivity in Services: State of the Art. In Innovation and Productivity in Services (pp. 17-58). Paris: OECD.

Pinto, A. (1971). El Modelo de Desarrollo Reciente de la America Latina. El trimestre economico, 38(150), 477-498.

Pinto, A. (1976). Naturaleza e Implicaciones de la Heterogeneidad Estructural de America Latina. El trimestre economico, 37(145), 83-100.

PREALC. (1982). Mercado de Trabajo en Cifras, 1950-1980. ILO. Programa Regional de Empleo para América Latina y el Caribe.

Prebisch, R. (1950). The economic development of Latin America and its principal problems. New York: United Nations. Dept. of Economic Affairs.

Pritchett, L. (1997). Divergence, big time. The Journal of Economic Perspectives, 11(3), 3-17.

Quah, D. T. (1996). Twin Peaks: Growth and Convergence in Models of Distribution Dynamics. The Economic Journal, 106(437), 1045-1055.

Rada, C. (2007). Stagnation or transformation of a dual economy through endogenous productivity growth. Cambridge Journal of Economics, 31(5), 711-740.

Ramani, S., and Szirmai, A. (2014). Innovation in India: The Challange of Combining Economic Growth with Inclusive Development. In Innovation in India: Combining Economic Growth with Inclusive Development. Delhi: Cambridge University Press.

Ramsey, F. (1928). A mathematical theory of saving. The economic journal, 38(152), 543-559.

Ranis, G. (2012). Labor Surplus Revisited. Yale University Economic Growth Center Discussion Paper Series, 1016(September).

Ranis, G., and Fei, J. C. H. (1961). A theory of economic development. The American Economic Review, 51(4), 533-565.

Robertson, P., and Ye, L. (2013). On the Existence of a Middle Income Trap. University of Western Australia Economics Discussion Paper, 12.

Robson, M., Townsend, J., and Pavitt, K. (1988). Sectoral patterns of production and use of innovations in the UK: 1945-1983. Research Policy, 17, 1-14.

Rodrik, D. (2008). The real exchange rate and economic growth. Brookings Papers on Economic Activity, Fall, 365-412.

Rodrik, D. (2009). Growth after the Crisis. CEPR Discussion Paper, 7480, 1-46.

Romer, P. M. (1986). Increasing returns and long-run growth. The journal of political economy, 5(October), 1002-1037.

Sachs, J. D. (2005). The End of Poverty: Economic Possibilities for Our Time. New York: The Penguin Press.

Sala-i-Martin, X. (1996). Regional cohesion: evidence and theories of regional growth and convergence. European Economic Review, 40, 1325-1352.

Salter, W. E. G. (1960). Productivity and Technical Change. Cambridge: Cambridge University Press.

Scherer, F. (1982). Inter-industry technology flows in the United States. Research policy, 11, 227-245.

Scott, M. (1989). A New View of Economic Growth. Oxford: Clarendon Press. 
Sen, A. (1966). Peasants and Dualism with or without Surplus Labor. The Journal of Political Economy, 74(5), 425-450.

Sheehan, P. (2008). Beyond industrialization: new approaches to development strategy based on the service sector. UNU-WIDER Working Paper, 2008/ 60.

Shioji, E. (2001). Composition Effect of Migration and Regional Growth in Japan. Journal of the Japanese and International Economies, 15(1), 29-49.

Singer, H. (1950). The distribution of gains between investing and borrowing countries. The American Economic Review, 40(2), 473-485.

Singh, A. (1977). UK industry and the world economy: a case of de-industrialisation. Cambridge Journal of Economics, 1(2), 113-36.

Solow, R. (1956). A contribution to the theory of economic growth. The quarterly journal of economics, 70(1), 65-94.

Spithoven, A. (2000). An explanation for the rising share of services in employment. International Journal of Social Economics, 27(12), 1205-1230.

Stehrer, R. (2012). Trade in Value Added and the Value Added in Trade. WIOD Working Paper Series, 8.

Stiroh, K. (2001). Information technology and the US productivity revival: what do the industry data say? American Economic Review, 92(5), 1559-1575.

Stubbs, R. (1999). War and Economic Development in East and Southeast Asia Industrialization Export-Oriented. Comparative Politics, 31(3), 337-355.

Stubbs, R. (2005). Retbinking Asia's economic miracle: the political economy of war, prosperity, and crisis. New York: Macmillan.

Sunkel, O. (1978). La Dependencia y la Heterogeneidad Estructural. El trimestre economico, 45(1), 3-20.

Swan, T. (1956). Economic Growth and Capital Accumulation. Economic Record, 32, 334-361.

Szirmai, A. (2011). Industrialisation as an engine of growth in developing countries, 1950-2005. Structural Change and Economic Dynamics.

Szirmai, A. (2013). Explaining Success and Failure in Economic Development. In B. van Ark \& P. Rao (Eds.), World Economic Performance: Past, Present and Future (pp. 227-267). Cheltenham, UK: Edward Elgar.

Szirmai, A. (2015). Economic Development, Structural Change and Industrialisation. In The Dynamics of Socio-Economic Development: An Introduction (forthcoming). Cambridge University Press.

Szirmai, A., and Verspagen, B. (2011). Manufacturing and Economic Growth in Developing Countries, 1950-2005. UNU-MERIT Working Paper Series, 2011-069.

Targetti, F., and Foti, A. (1997). Growth and productivity: a model of cumulative growth and catching up. Cambridge Journal of Economics, 21(1), 27-43.

Temple, J. (2005). Dual economy models: a primer for growth economists. The Manchester School, 73(4), 435-479.

Ten Raa, T., and Wolff, E. N. (2000). Engines of growth in the US economy. Structural Change and Economic Dynamics, 11(4), 473-489.

Terrell, K., and Svejnar, J. (1990). How industry-labor relations and government policies affect Senegal's economic performance. World Bank Working Papers, 271.

Thirlwall, A. P. (1983). A plain man's guide to Kaldor's growth laws. Journal of Post Keynesian Economics, 5(3), 345-358.

Thirlwall, A. P. (2011). Balance of payments constrained growth models: history and overview. PSL Quarterly Review, (May).

Thirlwall, A. P., and Dixon, R. J. (1979). A model of export-led growth with a balance of payments constraint. In J. K. Bowers (Ed.), Inflation, development and integration : essays in bonour of A. J. Brown (pp. 173-192). Leeds: Leeds University Press. 
Thirlwall, A. P., and Hussain, N. (1982). The balance of payments constraint, capital flows and growth rate differences between developing countries. Oxford Economic Papers, 34(3), 498-510.

Timmer (ed), M. (2012). The World Input-Output Database (WIOD): Contents, Sources and Methods. WIOD Working Paper Series, 10.

Timmer, M. (2000). The Dynamics of Asian Manufacturing. A Comparative Perspective in the Late Twentieth Century. Cheltenham, UK: Edward Elgar.

Timmer, M., and de Vries, G. (2009). Structural change and growth accelerations in Asia and Latin America: a new sectoral data set. Cliometrica, 3(2), 165-190.

Timmer, M., de Vries, G., and de Vries, K. (2014). Patterns of Structural Change in Developing Countries. GGDC Research Memorandum, 149(July).

Timmer, M., and Szirmai, A. (2000). Productivity growth in Asian manufacturing: the structural bonus hypothesis examined. Structural Change and Economic Dynamics, 11(4), 371-392.

Tregenna, F. (2007). Which Sectors Can be Engines of Growth and Employment in South Africa?: An Analysis of Manufacturing and Services. Paper presented at HSRC EGDI Roundtable "The Changing Character of Industrial Development: What Implications for Growth, Employment and Income Distribution?," May.

Tregenna, F. (2008). Characterising deindustrialisation: An analysis of changes in manufacturing employment and output internationally. Cambridge Journal of Economics, 33(3), 433-466.

Triplett, J., and Bosworth, B. (2003). Productivity measurement issues in services industries: Baumol's disease has been cured. FRBNY Economic Policy Review, (September), 23-33.

Turnham, D. (1971). The employment problem in less developed countries. OECD DCS Employment Series, 1, 151.

Turnham, D., and Eröcal, D. (1990). Unemployment in developing countries: new light on an old problem. OECD Development Centre Working Paper, 22.

UN. (1971). Classification of commoditites by industrial origin (No. 43) (Vol. 2).

UNDESA. (2008). Handbook on the Least Developed Country Category: Inclusion, Graduation, and Special Support Measures. New York: United Nations, Department of Economic and Social Affairs.

UNECA. (2005). African Socio-Economic Indicators 2005. Addis Ababa: United Nations Economic Commission for Africa (UNECA).

Van Ark, B., and Piatkowski, M. (2004). Productivity, innovation and ICT in Old and New Europe. International Economics and Economic Policy, 1(2-3), 215-246.

Van Ark, B., and Smits, J. P. (2005). Technology Regimes and Productivity Growth in Europe and the United States: A Comparative and Historical Perspective. Institute of European Studies UC Berkeley Working Paper, AY0510-01.

Van Ark, B., and Timmer, M. (2003). Asia's productivity performance and potential: The contribution of sectors and structural change. Groningen: University of Groningen and Conference Board.

Vandemoortele, J. (1991). Employment Issues in Sub-Saharan Africa. AERC Special Papers Series, 14.

Veblen, T. (1915). Imperial Germany and the industrial revolution. New York: Macmillan.

Verspagen, B. (1991). A new empirical approach to catching up or falling behind. Structural Change and Economic Dynamics, 2(2), 359-380.

Verspagen, B. (1993). Uneven growth between interdependent economies: an evolutionary view on technology gaps, trade and growth. Avebury: Ashgate Publisher.

Verspagen, B., and Loo, I. De. (1999). Technology spillovers between sectors. Technological Forecasting and Social Change, 235, 215-235.

Wang, L., and Szirmai, A. (2008). Productivity growth and structural change in Chinese manufacturing, 1980-2002. Industrial and Corporate Change, 17(4), 841-874.

Wells, H., and Thirlwall, A. P. (2003). Testing Kaldor's growth laws across the countries of Africa. African Development Review, 15(2-3), 1-17. 
Wolff, E. N. (2011). Spillovers, linkages, and productivity growth in the US economy, 1958 to 2007. NBER Working Paper Series, 16864.

Wölfl, A. (2003). Productivity Growth in Services Industries: An Assessment of Recent Patterns and the Role of Measurement. OECD Science, Technology and Industry Working Papers, 2003/07.

Woo, W. T. (2012). China meets the middle-income trap: the large potholes in the road to catchingup. Journal of Chinese Economic and Business Studies, 10(4), 313-336.

World Bank. (2010). The Changing Wealth of Nations. Measuring Sustainable Development in the New Millennium. Washington DC: The World Bank.

World Bank. (2014). How we classify countries. A Short History. Retrieved from http://data.worldbank.org/about/country-classifications/a-short-history

Wu, Y. (2008). Growth, Expansion of Markets, and Income Elasticities in World Trade. Review of International Economics, 16(4), 654-671.

Yeats, A. (1991). How conflicting definitions of "manufactures" distort output and trade statistics. World Bank. Working Papers, 760.

Yeats, A. (1992). Can a Manufactured Good Cease to be a Manufactured Good Merely by Crossing a National Frontier? Bulletin of Economic Research, 44(3), 199-219.

Young, A. (1996). Measuring R\&D in the Services. OECD Science, Technology and Industry Working Papers, 07. 
APPENDIX A.

Appendix to Chapter 3 
This appendix presents some mathematical technicalities that for space reasons could not be included in CHAPTER 3. In particular, Section A.1 details the steps followed to determine the viability conditions for Equilibrium 4, Section A.2 demonstrates the stability properties of each equilibrium point under these sets of conditions and Section A.3 provides the formal demonstrations for the signs of the partial derivatives presented in Table 3.6.

\section{A.1. Viability Conditions}

In this section we derive the particular restrictions that need to be imposed to the parameters of the model in order to get a viable equilibrium with non-zero values for the state variables. That is, an equilibrium in which the four viability conditions defined in Section 3.3.1 are simultaneously satisfied.

As we have previously stated, VC1 and VC2 will be satisfied if and only if the numerator and denominator of $\rho_{4}^{*}$ and $\lambda_{4}^{*}$ are simultaneously positive or negative. That is:

Table A. 1. Cases in which VC1 and VC2 are satisfied

\begin{tabular}{ccc}
\hline Condition & CASE 1 & CASE 2 \\
\hline VC 1: $\rho_{4}^{*}>0$ & $(B F-C E)>0 \wedge(C D-A F)>0$ & $(B F-C E)<0 \wedge(C D-A F)<0$ \\
VC 2: $\lambda_{4}^{*}>0$ & $(B F-C E)>0 \wedge(A E-B D)>0$ & $(B F-C E)<0 \wedge(A E-B D)<0$ \\
\hline
\end{tabular}

Regardless of the signs, VC3 and VC4 will be satisfied if and only if the absolute value of the denominator is larger or equal than the absolute value of the numerator. That is:

Table A. 2. Cases in which VC3 and VC4 are satisfied

\begin{tabular}{cc}
\hline Condition & CASE 1 and 2 \\
\hline$V C$ 3: $\rho_{4}^{*} \leq 1$ & $|B F-C E| \geq|C D-A F|$ \\
$V C$ $4: \lambda_{4}^{*} \leq 1$ & $|B F-C E| \geq|A E-B D|$ \\
\hline
\end{tabular}

Given that $V C 1$ and $V C 2$ can be satisfied under two sets of different conditions, we need to analyze each of them separately. 


\section{A.1.1. Case 1: positive denominator in Equilibrium 4}

To satisfy $V C 1$ and $V C 2$ we need that $(C D-A F)$ and $(A E-B D)$ are simultaneously positive.

Bearing in mind that $B<0, C>0, E>0$ and $F<0$, this will never happen if $A<0$ and $D<0$. By the same token, both conditions will always hold if $A>0$ and $D>0$. If only one of this terms is negative (either $A$ or $D$ ) then we need to explicitly specify the conditions stated before.

The following table summarizes the conditions needed in each sub-case:

Table A. 3. VC1 and VC2 in Case 1

\begin{tabular}{ccc}
\hline Sub-Cases & VC 1 & VC 2 \\
\hline Case 1.1: $(B F-C E)>0 \wedge A>0 \wedge D>0$ & n.a. & n.a. \\
Case 1.2: $(B F-C E)>0 \wedge A>0 \wedge D<0$ & $(C D-A F)>0$ & $(A E-B D)>0$ \\
Case 1.3: $(B F-C E)>0 \wedge A<0 \wedge D>0$ & $(C D-A F)>0$ & $(A E-B D)>0$ \\
\hline
\end{tabular}

To grasp the intuition behind these conditions, it is interesting to re-express them in terms of the slopes and intercepts of the system form by the equilibrium curves, and represented in Figure 3.1. That is:

Table A. 4. VC 1 and VC 2 in Case 1 (in terms of slopes and intercepts)

\begin{tabular}{|c|c|c|c|c|c|c|c|c|c|c|c|}
\hline \multicolumn{6}{|c|}{ Sub-Cases } & \multicolumn{3}{|c|}{ VC 1} & \multicolumn{3}{|c|}{ VC 2} \\
\hline & \multirow{2}{*}{$A$} & \multirow{2}{*}{$D$} & \multicolumn{3}{|c|}{ (slopes) } & \multicolumn{3}{|c|}{$(y$-intercept $)$} & \multicolumn{3}{|c|}{$(x$-intercept $)$} \\
\hline & & & $\dot{\rho}=0$ & & $\dot{\lambda}=0$ & $\dot{\rho}=0$ & & $\dot{\lambda}=0$ & $\dot{\rho}=0$ & & $\dot{\lambda}=0$ \\
\hline Case 1.1: & + & + & $-\frac{B}{C}$ & $>$ & $-\frac{E}{F}$ & \multicolumn{3}{|c|}{ n.a. } & \multicolumn{3}{|c|}{ n.a. } \\
\hline Case 1.2: & + & - & $-\frac{B}{C}$ & $>$ & $-\frac{E}{F}$ & $-\frac{A}{C}$ & $<$ & $-\frac{D}{F}$ & $-\frac{A}{B}$ & $>$ & $-\frac{D}{E}$ \\
\hline Case 1.3: & - & + & $-\frac{B}{C}$ & $>$ & $-\frac{E}{F}$ & $-\frac{A}{C}$ & $<$ & $-\frac{D}{F}$ & $-\frac{A}{B}$ & $>$ & $-\frac{D}{E}$ \\
\hline
\end{tabular}

If the slope of the $\rho$-insocline is larger than the slope of the $\lambda$-insocline, and $A$ and $D$ are both positive (Case 1.1) then conditions $V C 1$ and $V C 2$ will always hold. If, on the other hand, either $A$ (Case 1.2) or $D$ (Case 1.3) are negative, then we need to impose two additional conditions: that the y-intercept of the $\rho$-insocline is smaller 
than the $\mathrm{y}$-intercept of the $\lambda$-insocline and that the $\mathrm{x}$-intercept of the $\rho$-insocline is larger than the $\mathrm{x}$-intercept of the $\lambda$-insocline.

In each case, the conditions detailed will ensure that the equilibrium values for the non-zero steady state are positive. To ensure that they are also less or equal than one, we need to impose in addition VC3 and VC4. In terms of the slopes and intercepts of the system these conditions become:

Table A. 5. VC 3 and VC 4 in Case 1, in terms of slopes and intercepts

\begin{tabular}{|c|c|c|c|c|c|c|c|c|c|c|c|}
\hline \multicolumn{6}{|c|}{ Sub-Cases } & \multicolumn{3}{|c|}{ VC 3} & \multicolumn{3}{|c|}{ VC 4} \\
\hline & \multirow{2}{*}{$A$} & \multirow{2}{*}{$D$} & \multicolumn{3}{|c|}{ (slopes) } & \multirow[b]{2}{*}{$(y$-int. diff. $)$} & \multirow{2}{*}{\multicolumn{2}{|c|}{ (slope diff.) }} & \multirow[b]{2}{*}{$(x$-int. diff. $)$} & \multirow{2}{*}{\multicolumn{2}{|c|}{ (slope diff.) }} \\
\hline & & & $\dot{\rho}=0$ & & $\dot{\lambda}=0$ & & & & & & \\
\hline $\begin{array}{c}\text { Case } \\
1.1\end{array}$ & + & + & $-\frac{B}{C}$ & $>$ & $-\frac{E}{F}$ & $\left(-\frac{D}{F}\right)-\left(-\frac{A}{C}\right)$ & $\leq$ & $\left(-\frac{B}{C}\right)-\left(-\frac{E}{F}\right)$ & $\left(-\frac{A}{B}\right)-\left(-\frac{D}{E}\right)$ & $\leq$ & $\left.-\frac{F}{E}\right)-\left(-\frac{C}{B}\right)$ \\
\hline $\begin{array}{c}\text { Case } \\
1.2\end{array}$ & + & - & $-\frac{B}{C}$ & $>$ & $-\frac{E}{F}$ & $\left(-\frac{D}{F}\right)-\left(-\frac{A}{C}\right)$ & $\leq$ & $\left(-\frac{B}{C}\right)-\left(-\frac{E}{F}\right)$ & $\left(-\frac{A}{B}\right)-\left(-\frac{D}{E}\right)$ & $\leq$ & $\left.\frac{F}{E}\right)-\left(-\frac{C}{B}\right)$ \\
\hline $\begin{array}{c}\text { Case } \\
1.3\end{array}$ & - & + & $-\frac{B}{C}$ & $>$ & $-\frac{E}{F}$ & $\left(-\frac{D}{F}\right)-\left(-\frac{A}{C}\right)$ & $\leq$ & $\left(-\frac{B}{C}\right)-\left(-\frac{E}{F}\right)$ & $\left(-\frac{A}{B}\right)-\left(-\frac{D}{E}\right)$ & $\leq$ & $\left.-\frac{F}{E}\right)-\left(-\frac{C}{B}\right)$ \\
\hline
\end{tabular}

These conditions basically state that the slope differential should be greater than the intercept differentials. Regardless of the sub-case, if the slope differential is sufficiently large then $\rho_{4}^{*}$ and $\lambda_{4}^{*}$ will always be less than one.

We already know all the conditions needed to get a viable equilibrium under different assumptions on $A$ and $D$ for the case in which the slope of the $\rho$-insocline is larger than the slope of the $\lambda$-insocline. We turn now to analyze the second case.

\section{A.1.2. Case 2: negative denominator in Equilibrium 4}

Following the same procedure than in the previous case, we arrive to these viability conditions: 
Table A. 6. VC 1 and VC 2 in Case 2, in terms of slopes and intercepts

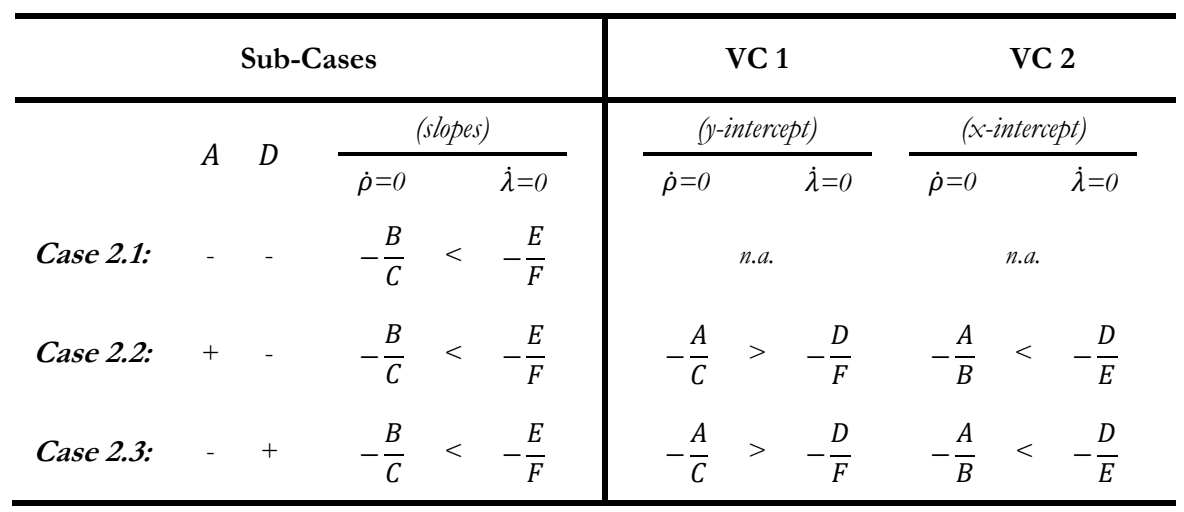

Note that once the sign of the slope differential is changed, the signs of the remaining conditions change as well. In addition, it is interesting to mention that, in this case, if the terms $A$ and $D$ are simultaneously negative the equilibrium will always deliver positive values for $\rho_{4}^{*}$ and $\lambda_{4}^{*}$, no matter the magnitude of $A$ and $D$.

Turning now to analyse VC3 and VC4, we find the same pattern. Now that the sign of the slope condition has change, the signs of the remaining conditions change as well:

Table A. 7. VC 3 and VC 4 in Case 2, in terms of slopes and intercepts

\begin{tabular}{|c|c|c|c|c|c|c|c|c|c|c|c|}
\hline \multicolumn{6}{|c|}{ Sub-Cases } & \multicolumn{3}{|c|}{ VC 3} & \multicolumn{3}{|c|}{ VC 4} \\
\hline & \multirow{2}{*}{$A$} & \multirow{2}{*}{$D$} & \multicolumn{3}{|c|}{ (slopes) } & \multirow[b]{2}{*}{$(y$-int. diff. $)$} & & \multirow[b]{2}{*}{ (slope diff.) } & \multirow[b]{2}{*}{$(x$-int. diff. $)$} & & \multirow[b]{2}{*}{ (slope diff.) } \\
\hline & & & $\dot{\rho}=0$ & 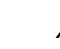 & $\dot{\lambda}=0$ & & & & & & \\
\hline $\begin{array}{c}\text { Case } \\
2.1\end{array}$ & - & - & $-\frac{B}{C}$ & & $-\frac{E}{F}$ & $\left(-\frac{D}{F}\right)-\left(-\frac{A}{C}\right)$ & $\geq$ & $\left(-\frac{B}{C}\right)-\left(-\frac{E}{F}\right)$ & $\left(-\frac{A}{B}\right)-\left(-\frac{D}{E}\right)$ & $\geq$ & $\left(-\frac{F}{E}\right)-\left(-\frac{C}{B}\right)$ \\
\hline $\begin{array}{c}\text { Case } \\
2.2\end{array}$ & + & 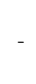 & $-\frac{B}{C}$ & $<$ & $-\frac{E}{F}$ & $\left(-\frac{D}{F}\right)-\left(-\frac{A}{C}\right)$ & $\geq$ & $\left(-\frac{B}{C}\right)-\left(-\frac{E}{F}\right)$ & $\left(-\frac{A}{B}\right)-\left(-\frac{D}{E}\right)$ & $\geq$ & $\left(-\frac{F}{E}\right)-\left(-\frac{C}{B}\right)$ \\
\hline $\begin{array}{c}\text { Case } \\
2.3\end{array}$ & & + & $-\frac{B}{C}$ & $<$ & $-\frac{E}{F}$ & $\left(-\frac{D}{F}\right)-\left(-\frac{A}{C}\right)$ & $\geq$ & $\left(-\frac{B}{C}\right)-\left(-\frac{E}{F}\right)$ & $\left(-\frac{A}{B}\right)-\left(-\frac{D}{E}\right)$ & $\geq$ & $\left(-\frac{F}{E}\right)-\left(-\frac{C}{B}\right)$ \\
\hline
\end{tabular}




\section{A.2. Stability Properties}

In this section we show that under Case 1 Equilibrium 4 will always be stable and that the first, second and third equilibrium will be stable in Case 2.1, 2.2 and 2.3 respectively.

Before analysing each steady state it is important to recall that in a linear system of two dimensions, according to the Routh-Hurwitz criterion, an equilibrium point will be stable if the trace of the corresponding Jacobian matrix evaluated in that point is negative and the determinant is positive. That is, if:

$$
\begin{aligned}
& \operatorname{tr}\left(J a c^{E}\right)<0 \\
& \operatorname{det}\left(J a c^{E}\right)>0
\end{aligned}
$$

If, instead, both determinant and trace are positive then the equilibrium will be unstable. Finally, if the determinant is negative, the equilibrium will be a saddle point regardless of the sign of the trace.

In our case, the Jacobian of the system formed by equations (3.26) and (3.27) is:

$$
J a c=\left[\begin{array}{cc}
A+2 B \rho+C \lambda & C \rho \\
E \lambda & D+E \rho+2 F \lambda
\end{array}\right]
$$

Hence, the trace and determinant are given by the following expressions:

$$
\begin{aligned}
& \operatorname{tr}(J a c)=A+D+2 B \rho+E \rho+C \lambda+2 F \lambda \\
& \operatorname{det}(J a c)=C \lambda(D+2 F \lambda)+A(D+E \rho+2 F \lambda)+2 B \rho(D+E \rho+2 F \lambda)
\end{aligned}
$$

Replacing the equilibrium values in the corresponding expressions of the trace and the determinant of the Jacobian of the system yields the following results: 
Table A. 8. Trace and determinant of the Jacobian for each equilibrium

\begin{tabular}{ccc}
\hline Equilibrium & Trace & Determinant \\
\hline $\boldsymbol{E}_{\mathbf{1}}$ & $A+D$ & $A D$ \\
$\boldsymbol{E}_{\mathbf{2}}$ & $-\frac{(A E-B D)}{B}-A$ & $\frac{(A E-B D)}{B} A$ \\
$\boldsymbol{E}_{\mathbf{3}}$ & $-\frac{(C D-A F)}{F}-D$ & $\frac{(C D-A F)}{F} D$ \\
$\boldsymbol{E}_{\mathbf{4}}$ & $\frac{B(C D-A F)+F(A E-B D)}{(B F-C E)}$ & $\frac{-(A E-B D)(C D-A F)}{-(B F-C E)}$ \\
\hline
\end{tabular}

Now, by looking at the expressions of this table and recalling the conditions that defined each of the six sub-cases detailed in the previous section, it is possible to determine the sign of the trace and determinant and, therefore, the stability properties of each equilibrium in each sub-case. The following table summarizes these results. 


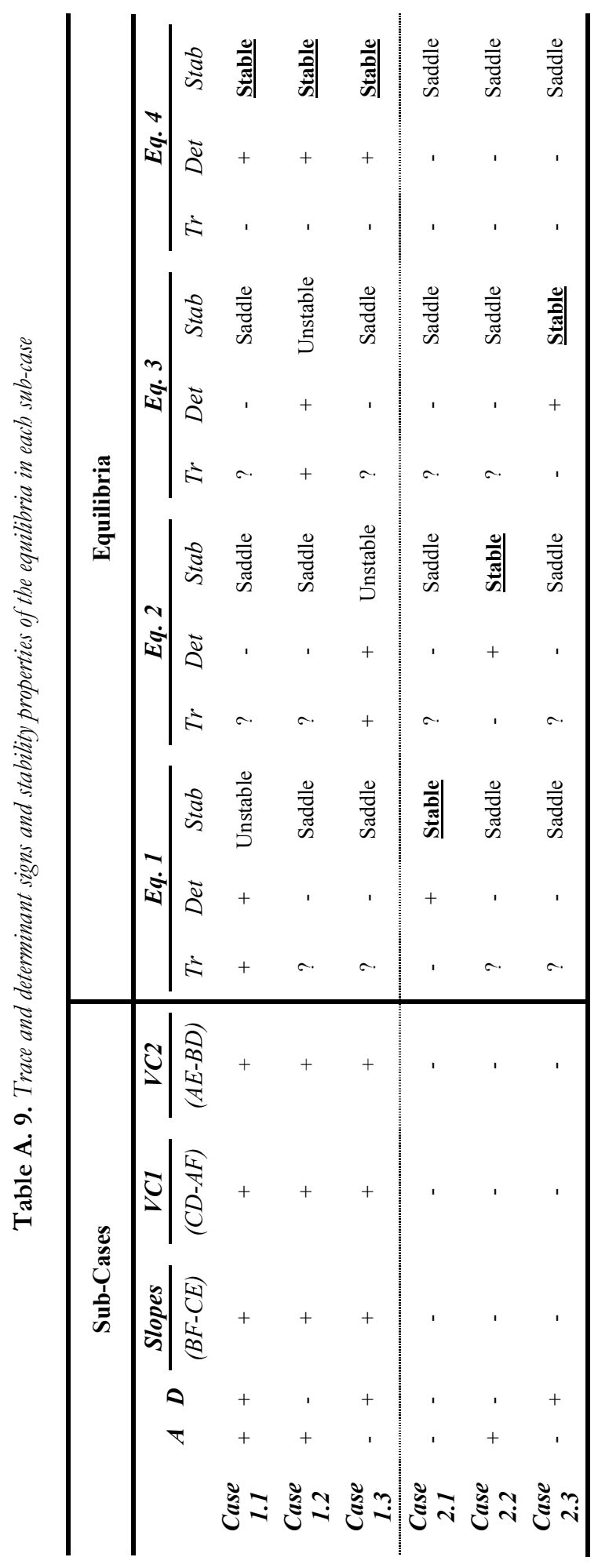




\section{A.3. Comparative statics}

In this section we present the partial derivatives of the equilibrium values of $\rho_{4}^{*}$ and $\lambda_{4}^{*}$ with respect to the deep parameters of the model. In most cases, the sign of these derivatives can be unambiguously determined using the conditions established along CHAPTER 3. For some parameters, however, the direction of the effect will depend on some additional conditions.

In order to simplify the analysis, we express all derivatives in terms of the capital letters $A, B, C, D, E$ and $F$ defined in Section 3.3. This procedure makes much easier the derivation of the corresponding signs. As it is shown in Table A. 10 the signs of the partial derivatives of each of these terms with respect to the deep parameters of the model is almost always unambiguously determined and therefore the analysis is significantly reduced.

Working under the assumption that $\chi>a$ and $\gamma<1$, we already know the signs of four of the six terms $(B<0 ; C>0 ; E>0 ; F<0)$. Moreover, since we are analysing changes in the vicinity of the fourth equilibrium, the slope condition should also hold $(S=a \theta \sigma-z \beta \psi>0)$. Recalling this information and making use of the partial derivatives detailed in Table A. 10 we turn now to analyse the partial effects of changes in each of the deep parameters of the model.

\section{A.3.1. Marshall-Lerner condition $(\boldsymbol{a})$}

$$
\begin{aligned}
& \frac{\partial \rho_{4}^{*}}{\partial a}=\frac{\stackrel{+}{\overbrace{4}^{*}} \overbrace{\left(C \frac{\partial E}{\partial a}-B \frac{\partial F}{\partial a}\right)}^{-\chi \theta a+\gamma(z \beta \psi-\chi \theta \sigma)<0}+\overbrace{\left(C \frac{\partial D}{\partial a}-A \frac{\partial F}{\partial a}\right)}^{?}}{\underset{+}{S}} \gtrless 0 \\
& \frac{\partial \lambda_{4}^{*}}{\partial a}=\frac{\stackrel{+}{\tilde{\lambda}_{4}^{*}} \overbrace{\left(C \frac{\partial E}{\partial a}-B \frac{\partial F}{\partial a}\right)}^{-\chi \theta a+\gamma(z \beta \psi-\chi \theta \sigma)<0}+\overbrace{\left(A \frac{\partial E}{\partial a}-B \frac{\partial D}{\partial a}\right)}^{?}}{\underbrace{S}_{+}} \gtrless 0
\end{aligned}
$$

The first derivative $\left(\partial \rho_{4}^{*} / \partial a\right)$ will be positive if and only if:

$$
\rho_{4}^{*}<-\frac{C(\partial D / \partial a)-A(\partial F / \partial a)}{C(\partial E / \partial a)-B(\partial F / \partial a)}
$$

Otherwise, it will be negative.

The second derivative $\left(\partial \lambda_{4}^{*} / \partial a\right)$ will be positive if and only if:

$$
\lambda_{4}^{*}<-\frac{A(\partial E / \partial a)-B(\partial D / \partial a)}{C(\partial E / \partial a)-B(\partial F / \partial a)}
$$

Otherwise, it will be negative. 


\section{A.3.2. Exogenous rate of currency depreciation $(b)$}

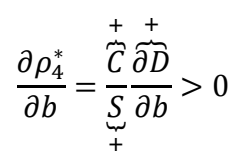

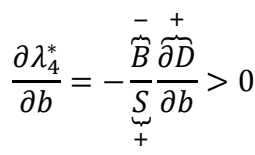

\section{A.3.3. Technological accumulation in the leading economy $\left(\widehat{T}_{M}^{f}\right)$}

$$
\begin{aligned}
& \frac{\partial \rho_{4}^{*}}{\partial \widehat{T}_{M}^{f}}=-\underbrace{\tilde{m}_{+}}_{+} \frac{\overbrace{\partial A}^{-}}{\partial \hat{T}_{M}^{f}}<0 \\
& \frac{\partial \lambda_{4}^{*}}{\partial \widehat{T}_{M}^{f}}=\underbrace{\stackrel{+}{E}}_{+} \underset{\overbrace{+}^{S}}{\frac{-}{\partial A}} \frac{-}{\partial \hat{T}_{M}^{f}}<0
\end{aligned}
$$

\section{A.3.4. Investment-Output ratio $(k)$}

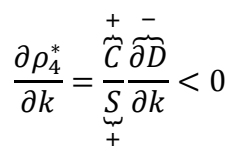

$$
\begin{aligned}
& \frac{\partial \lambda_{4}^{*}}{\partial k}=-\underbrace{\overline{\omega_{m}}}_{+} \frac{\overline{\tilde{m}}}{\partial \bar{D}}<0
\end{aligned}
$$

\section{A.3.5. Population growth $(n)$}

$$
\begin{aligned}
& \frac{\partial \rho_{4}^{*}}{\partial n}=-\frac{\bar{m}}{\underbrace{S}_{+}} \frac{\overline{\tilde{m}}}{\partial \hat{A}}<0 \\
& \frac{\partial \lambda_{4}^{*}}{\partial n}=\underbrace{\stackrel{+}{\tilde{E}_{\omega}} \frac{\overline{\tilde{D}}}{\partial n}}_{+\underset{+}{S}}<0
\end{aligned}
$$

\section{A.3.6. World income $(\widehat{Z})$}

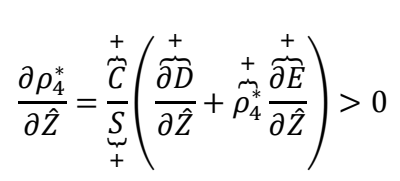

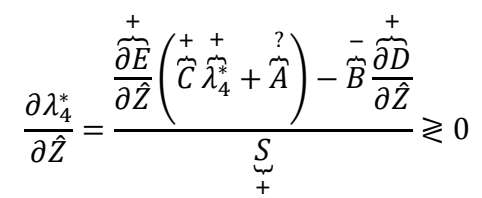

The second derivative $\left(\partial \lambda_{4}^{*} / \partial \hat{Z}\right)$ will be negative if and only if:

$$
\lambda_{4}^{*}<\left(-\frac{A}{C}\right)+\overbrace{\frac{B}{C} \frac{\partial D / \partial \hat{Z}}{\partial E / \partial \hat{Z}}}^{-}
$$

This means that $\lambda_{4}^{*}$ should be smaller than the $y$-intercept of the $\rho$-insocline $\left(-\frac{A}{C}\right)$. However, since both the $\rho$-insocline and the $\lambda$-insocline have positive slope, this can never happen. Therefore, the sign of the derivative will always be positive. 


\section{A.3.7. Sensitivity of productivity growth to knowledge accumulation}

$(\alpha)$

$$
\begin{aligned}
& \frac{\partial \rho_{4}^{*}}{\partial \alpha}=\frac{\rho_{4}^{*}\left(C \frac{\partial E}{\partial \alpha}-B \frac{\partial F}{\partial \alpha}\right)+\left(C \frac{\partial D}{\partial \alpha}-A \frac{\partial F}{\partial \alpha}\right)}{S}=\underbrace{\frac{\stackrel{+}{\tilde{h}_{\beta}}(\overbrace{(a-\chi)}^{-}}{(a \theta \sigma-z \beta \psi)}}_{+}<0 \\
& \frac{\partial \lambda_{4}^{*}}{\partial \alpha}=\frac{\lambda_{4}^{*}\left(C \frac{\partial E}{\partial \alpha}-B \frac{\partial F}{\partial \alpha}\right)+\left(A \frac{\partial E}{\partial \alpha}-D \frac{\partial D}{\partial \alpha}\right)}{S}=\frac{\stackrel{+}{\tilde{h} \sigma(-} \underbrace{-}_{+}}{\underbrace{(a \theta \sigma-z \beta \psi)}_{(a-\chi)}}<0
\end{aligned}
$$

\section{A.3.8. Induced innovation coefficient $(\beta)$}

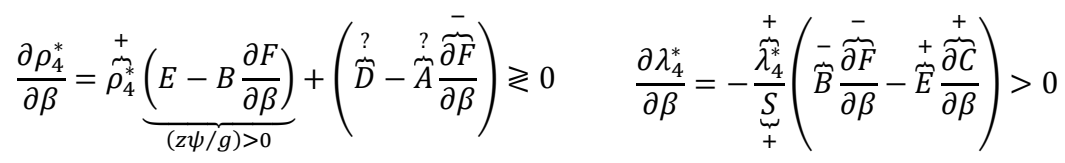

The first derivative $\left(\partial \rho_{4}^{*} / \partial \beta\right)$ will be positive if and only if:

$$
\rho_{4}^{*}>\frac{D-A(\partial F / \partial \beta)}{B(\partial F / \partial \beta)-E}
$$

Otherwise, it will be negative.

\section{A.3.9. Kaldor-Verdoorn coefficient $(\gamma)$}

$$
\begin{aligned}
& \frac{\partial \rho_{4}^{*}}{\partial \gamma}=\frac{\rho_{4}^{*}\left(C \frac{\partial E}{\partial \gamma}-B \frac{\partial F}{\partial \gamma}\right)+\left(C \frac{\partial D}{\partial \gamma}-A \frac{\partial F}{\partial \gamma}\right)}{S}=\underbrace{\frac{\stackrel{+}{n \beta} \overbrace{(a-\chi)}^{-}}{(a \theta \sigma-z \beta \psi)}}_{+}<0 \\
& \frac{\partial \lambda_{4}^{*}}{\partial \gamma}=\frac{\lambda_{4}^{*}\left(C \frac{\partial E}{\partial \gamma}-B \frac{\partial F}{\partial \gamma}\right)+\left(A \frac{\partial E}{\partial \gamma}-D \frac{\partial D}{\partial \gamma}\right)}{S}=\underbrace{\frac{+}{\tilde{n} \sigma} \widetilde{\sigma_{(a-\chi)}^{-}}}_{+}<0
\end{aligned}
$$

\section{A.3.10.Domestic investments in $R \& D(\zeta)$}

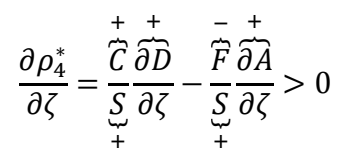

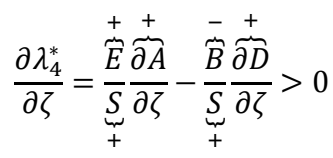




\section{A.3.11. Sensitivity of wage inflation to structural modernization $(\theta)$}

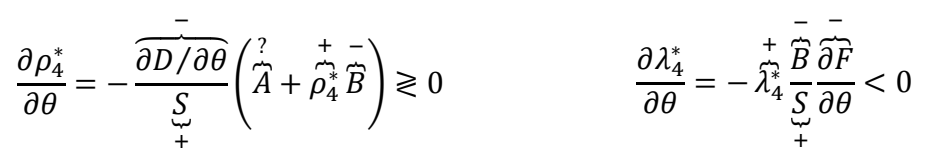

The first derivative $\left(\partial \rho_{4}^{*} / \partial \theta\right)$ will be positive if and only if:

$$
\rho_{4}^{*}<-\frac{A}{B}
$$

That is, if $\rho_{4}^{*}$ is lower than the $\mathrm{x}$-intercept of the $\rho$-insocline. Once more, since both curves have positive slopes, this will never happen. Therefore, the derivative will always be negative.

\section{A.3.12.Sensitivity of productivity growth to capital intensification $(\mu)$}

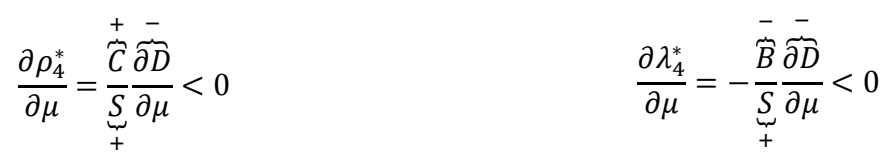

\section{A.3.13.Autonomous income elasticity of exports $(\xi)$}

$$
\begin{gathered}
\frac{\partial \rho_{4}^{*}}{\partial \xi}=\frac{\rho_{4}^{*}\left(C \frac{\partial E}{\partial \xi}-B \frac{\partial F}{\partial \xi}\right)+\left(C \frac{\partial D}{\partial \xi}-A \frac{\partial F}{\partial \xi}\right)}{S}=\frac{\overbrace{\tilde{z}}^{+}}{\underbrace{(a \theta \sigma-z \beta \psi)}_{+}}>0 \\
\frac{\partial \lambda_{4}^{*}}{\partial \xi}=\frac{\lambda_{4}^{*}\left(C \frac{\partial E}{\partial \xi}-B \frac{\partial F}{\partial \xi}\right)+\left(A \frac{\partial E}{\partial \xi}-D \frac{\partial D}{\partial \xi}\right)}{S}=\underbrace{\frac{+}{(a \theta \sigma}}_{+} \underbrace{\tilde{z}^{+}}_{+}>0
\end{gathered}
$$

\section{A.3.14.Absorptive capacity $(\sigma)$}

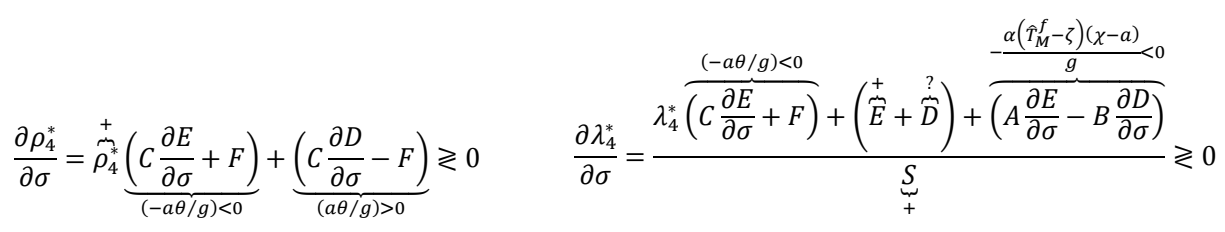

The first derivative $\left(\partial \rho_{4}^{*} / \partial \sigma\right)$ will be positive if and only if:

$$
\rho_{4}^{*}<\overbrace{-\frac{C(\partial D / \partial \sigma)-F}{C(\partial D / \partial \sigma)+F}}^{1}
$$

It follows that the derivative will always be positive unless the domestic economy manages to leap-frog the leading economy $\left(\rho_{4}^{*}>1\right)$. 
The second derivative $\left(\partial \lambda_{4}^{*} / \partial \sigma\right)$ will be positive if and only if:

$$
\lambda_{4}^{*}<-\frac{(E+D) g-\alpha\left(\hat{T}_{M}^{f}-\zeta\right)(\chi-a)}{a \theta}
$$

\section{A.3.15. Income-elasticity of imports $(\chi)$}

$$
\begin{aligned}
& \frac{\partial \rho_{4}^{*}}{\partial \chi}=\frac{\rho_{4}^{*}\left(C \frac{\partial E}{\partial \chi}-B \frac{\partial F}{\partial \chi}\right)+\left(C \frac{\partial D}{\partial \chi}-A \frac{\partial F}{\partial \chi}\right)}{S}=\frac{\stackrel{+}{\tilde{\beta}} \overbrace{\left[n(1+\gamma)+\alpha \hat{T}_{M}^{f}+\mu k\right]}^{+}}{-\underbrace{(a \theta \sigma-z \beta \psi)}_{+}}<0 \\
& \frac{\partial \lambda_{4}^{*}}{\partial \chi}=\frac{\lambda_{4}^{*}\left(C \frac{\partial E}{\partial \chi}-B \frac{\partial F}{\partial \chi}\right)+\left(A \frac{\partial E}{\partial \chi}-D \frac{\partial D}{\partial \chi}\right)}{S}=\frac{\stackrel{+}{\tilde{\sigma}} \overbrace{\left[n(1+\gamma)+\alpha \hat{T}_{M}^{f}+\mu k\right]}^{+}}{-\underbrace{(a \theta \sigma-z \beta \psi)}_{+}}<0
\end{aligned}
$$

\section{A.3.16.Gap punishment on income-elasticity of exports $(\psi)$}

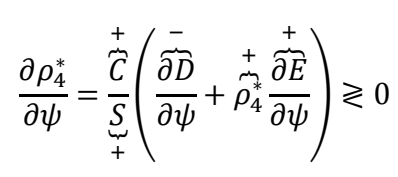

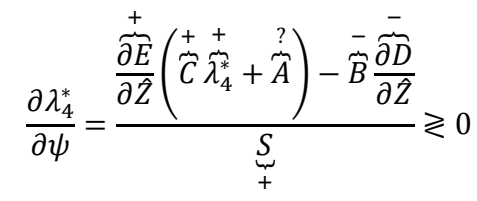

The first derivative $\left(\partial \rho_{4}^{*} / \partial \psi\right)$ will be positive if and only if:

$$
\rho_{4}^{*}>\overbrace{-\frac{\partial D / \partial \psi}{\partial E / \partial \psi}}^{1}
$$

It follows that the derivative will always be negative unless the domestic economy manages to leapfrog the leading economy $\left(\rho_{4}^{*}>1\right)$.

The second derivative $\left(\partial \lambda_{4}^{*} / \partial \psi\right)$ will be positive if and only if:

$$
\lambda_{4}^{*}>\left(-\frac{A}{C}\right)+\frac{B}{C} \frac{\overbrace{\partial D / \partial \hat{Z}}^{-1}}{\partial E / \partial \hat{Z}} \Rightarrow \lambda_{4}^{*}>-\frac{A+B}{C} \Rightarrow \lambda_{4}^{*}>\frac{h-\zeta}{\beta}
$$

This would happen only at very high levels of $\rho_{4}^{*}$ and therefore the sign will most probably be negative. 


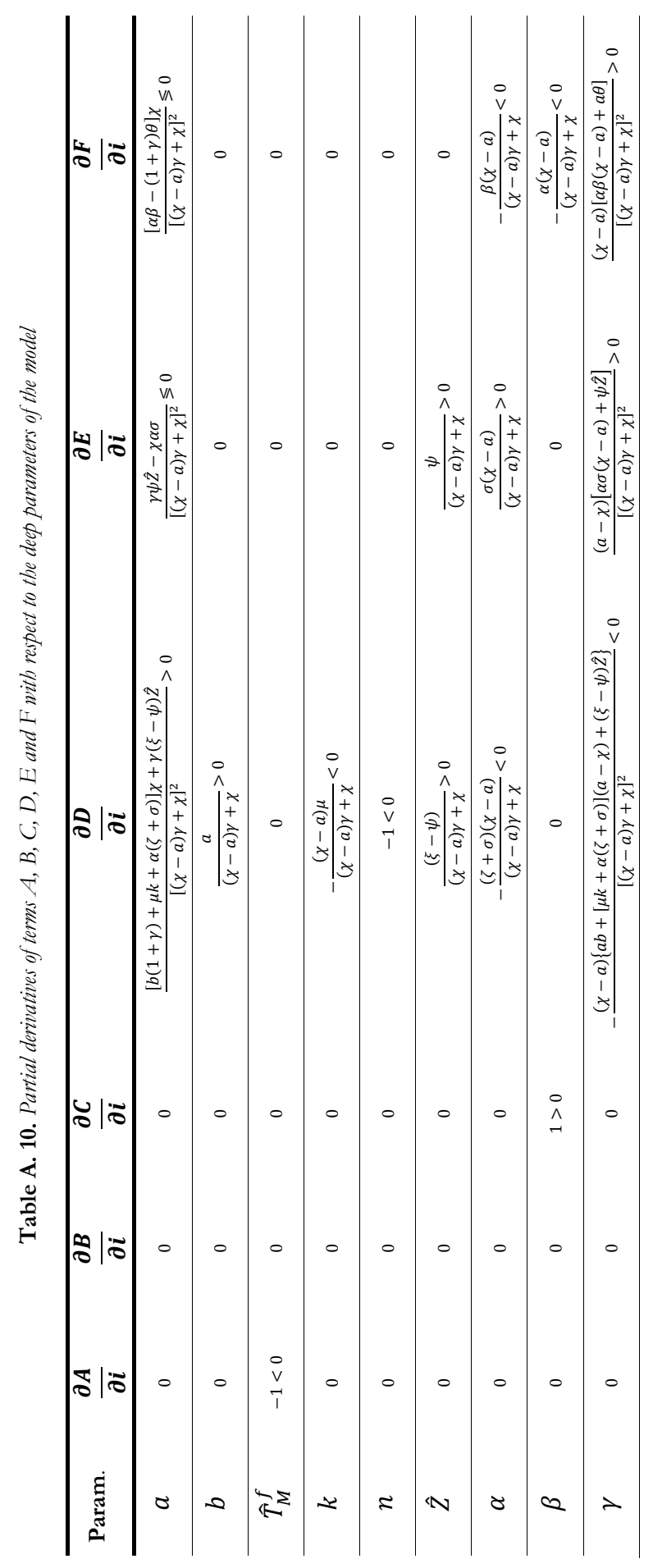




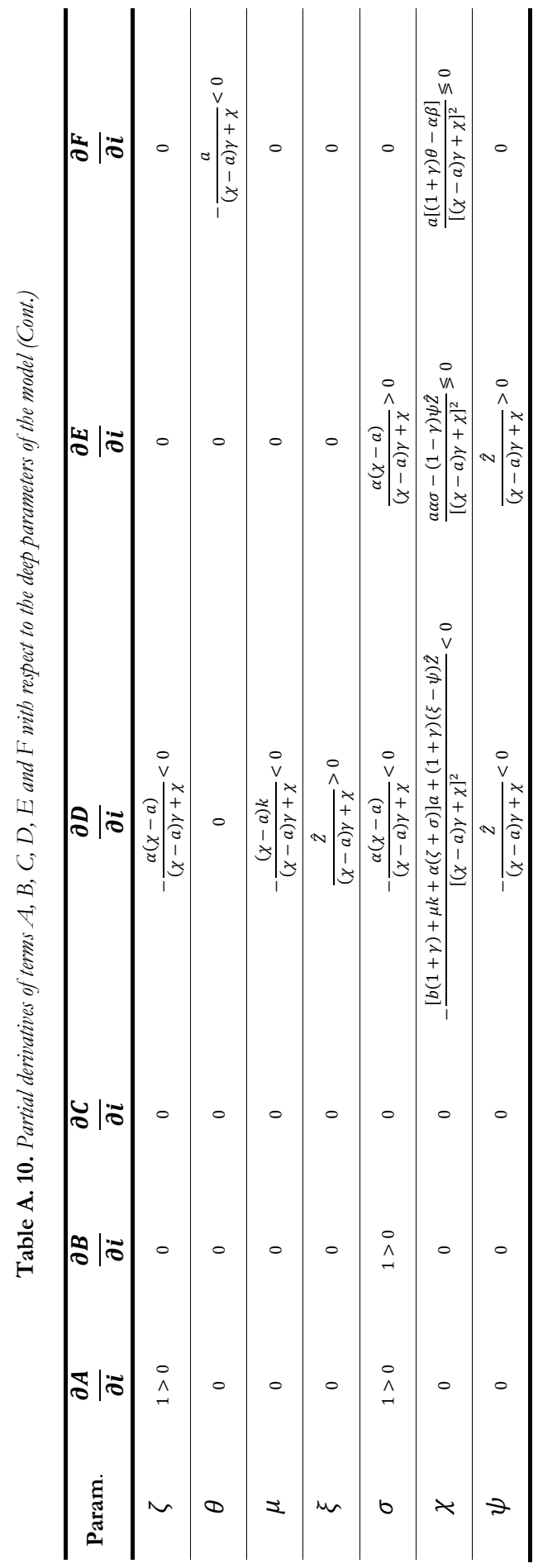



APPENDIX B.

Appendix to Chapter 4 


\section{B.1. Defining the Development Traps}

In this appendix we present the detailed data used to determine the thresholds needed for our operational definition of the development traps.

The first two tables specify the list of countries that have transited from lower middle to upper middle incomes (Table B. 1) and from upper-middle to high incomes (Table B. 2) during the period under analysis. As explained in Section 4.2.2, the average number of years needed to graduate by the upper quartile of these countries has been used to determine which countries are now in the lower-middleincome trap and the upper-middle-income trap. The corresponding results are presented in Table B. 3, which specifies the relevant information for the countries of our sample that in 2013 were classified as middle-income economies. In particular, for each of these countries it provides information on: a) the number of years it has been in its current category since 1950; b) the average annual growth rate of per capita GNI between 1993 and 2013; and c) the projected total number of years it will be in its current category given the growth rate of the last two decades. Our identification of countries that are already in the middle-income trap or are projected to be in the middle-income trap arise from the comparison of a) and c) with the corresponding thresholds, as indicated in the last column of the table.

Next, in Table B. 4 we detail the list of low-income countries in our sample, their average annual growth rate over the period 1993-2013 and the projected number of years they will need to overcome this income category, given that growth rate. As explained before, the distribution obtained is used to determine the countries in the poverty trap.

At the end of this appendix we also present three figures illustrating the distributions of countries used to determine the corresponding thresholds, with the relevant descriptive statistics. 
Table B. 1. Economies that turned to lower-middle incomes (LMI) after 1950 and graduated to uppermiddle incomes (UMI) before 2014. 11 countries.

\begin{tabular}{llccc}
\hline \multirow{2}{*}{ id } & Country & \multicolumn{2}{c}{ Turning year } & Years needed \\
& & became LMI & became UMI & graduate \\
\cline { 3 - 4 } & China & 1998 & 2011 & 13 \\
\hline CHN & 1963 & 1979 & 16 \\
TWN & Taiwan & 1973 & 1990 & 17 \\
BWA & Botswana & 1966 & 1985 & 19 \\
KOR & Korea & 1955 & 1976 & 21 \\
MKD & Macedonia & 1959 & 1981 & 22 \\
SRB & Serbia & 1981 & 2008 & 27 \\
THA & Thailand & 1962 & 1992 & 30 \\
MYS & Malaysia & 1959 & 1995 & 36 \\
\hline MUS & Mauritius & 1958 & 2001 & 43 \\
BGR & Bulgaria & 1951 & 1994 & 43 \\
BRA & Brazil & & & $\mathbf{2 2}$ \\
\hline & Median & & $\mathbf{1 1}$ \\
& Standard Deviation & & $\mathbf{3 3}$ \\
& Upper Quartile & & & $\mathbf{4 1}$ \\
\hline
\end{tabular}


Table B. 2. Economies that turned to upper-middle incomes (UMI) after 1950 and graduated to high incomes (HI) before 2014. 20 countries.

\begin{tabular}{|c|c|c|c|c|}
\hline \multirow{2}{*}{ id } & \multirow{2}{*}{ Country } & \multicolumn{2}{|c|}{ Turning year } & \multirow{2}{*}{$\begin{array}{l}\text { Years needed } \\
\text { to graduate }\end{array}$} \\
\hline & & became UMI & became $\mathrm{HI}$ & \\
\hline GRC & Greece & 1963 & 1973 & 10 \\
\hline JPN & Japan & 1963 & 1973 & 10 \\
\hline KOR & Korea & 1985 & 1995 & 10 \\
\hline HKG & Hong Kong & 1969 & 1980 & 11 \\
\hline SGP & Singapore & 1970 & 1981 & 11 \\
\hline TWN & Taiwan & 1979 & 1991 & 12 \\
\hline SVN & Slovenia & 1962 & 1975 & 13 \\
\hline ESP & Spain & 1962 & 1977 & 15 \\
\hline AUT & Austria & 1955 & 1971 & 16 \\
\hline ITA & Italy & 1957 & 1973 & 16 \\
\hline FIN & Finland & 1957 & 1974 & 17 \\
\hline CYP & Cyprus & 1969 & 1987 & 18 \\
\hline FRA & France & 1952 & 1970 & 18 \\
\hline CHL & Chile & 1992 & 2012 & 20 \\
\hline PRT & Portugal & 1969 & 1989 & 20 \\
\hline IRL & Ireland & 1968 & 1990 & 22 \\
\hline ISR & Israel & 1964 & 1987 & 23 \\
\hline HUN & Hungary & 1971 & 2004 & 33 \\
\hline POL & Poland & 1971 & 2007 & 36 \\
\hline \multirow[t]{5}{*}{$\mathrm{HRV}$} & Croatia & 1966 & 2006 & 40 \\
\hline & Median & & & 17 \\
\hline & \multicolumn{3}{|c|}{ Standard Deviation } & 9 \\
\hline & \multicolumn{3}{|l|}{ Upper Quartile } & 21 \\
\hline & \multicolumn{3}{|c|}{ Average for the Upper Quartile } & 31 \\
\hline
\end{tabular}


Table B. 3. Characterization of middle-income economies (MIEs). 40 countries.

\begin{tabular}{|c|c|c|c|c|c|c|c|c|c|}
\hline ID & Country & $\begin{array}{l}\text { Categ. } \\
\text { in } 2013\end{array}$ & $\begin{array}{l}\text { Year coun- } \\
\text { try turned } \\
\text { to current } \\
\text { category }\end{array}$ & $\begin{array}{l}\text { Years } \\
\text { in that } \\
\text { categ. }\end{array}$ & $\begin{array}{l}\text { Average } \\
\text { annual } \\
\text { growth } \\
\text { rate } \\
(1993-2013)\end{array}$ & $\begin{array}{l}\text { Proj. } \\
\text { years } \\
\text { to turn } \\
\text { categ. }\end{array}$ & $\begin{array}{l}\text { Total pro- } \\
\text { jected } \\
\text { years in } \\
\text { category }\end{array}$ & $\begin{array}{l}\text { Cut- } \\
\text { off }\end{array}$ & Status \\
\hline & & (1) & (2) & (3) & (4) & (5) & $(6)=(3)+(5)$ & (7) & (8) \\
\hline ARG & Argentina & UMI & 1960 & 54 & $1.8 \%$ & 6 & 60 & 31 & UMIT \\
\hline AZE & Azerbaijan & UMI & 2009 & 5 & $5.9 \%$ & 10 & 15 & 31 & NT \\
\hline BGR & Bulgaria & UMI & 2001 & 13 & $3.2 \%$ & 8 & 21 & 31 & NT \\
\hline BOL & Bolivia & LMI & 1950 & 64 & $1.9 \%$ & 27 & 91 & 41 & LMIT \\
\hline BRA & Brazil & UMI & 1994 & 20 & $1.9 \%$ & 21 & 41 & 31 & UMIT* \\
\hline BWA & Botswana & UMI & 1990 & 24 & $2.6 \%$ & 2 & 26 & 31 & NT \\
\hline $\mathrm{CHN}$ & China & UMI & 2011 & 3 & $9.0 \%$ & 7 & 10 & 31 & NT \\
\hline COL & Colombia & UMI & 2006 & 8 & $1.9 \%$ & 28 & 36 & 31 & UMIT* \\
\hline CRI & Costa Rica & UMI & 1998 & 16 & $2.4 \%$ & 14 & 30 & 31 & NT \\
\hline ECU & Ecuador & UMI & 2008 & 6 & $1.7 \%$ & 34 & 40 & 31 & UMIT* \\
\hline EGY & Egypt & LMI & 1982 & 32 & $2.7 \%$ & 10 & 42 & 41 & LMIT* \\
\hline GEO & Georgia & LMI & 1980 & 34 & $5.6 \%$ & 5 & 39 & 41 & NT \\
\hline IDN & Indonesia & LMI & 1993 & 21 & $3.0 \%$ & 18 & 39 & 41 & NT \\
\hline IND & India & LMI & 2006 & 8 & $5.1 \%$ & 16 & 24 & 41 & NT \\
\hline IRN & Iran & UMI & 2000 & 14 & $2.3 \%$ & 17 & 31 & 31 & NT \\
\hline JOR & Jordan & LMI & 1961 & 53 & $2.7 \%$ & 11 & 64 & 41 & LMIT \\
\hline $\mathrm{KAZ}$ & Kazakhst. & UMI & 2004 & 10 & $3.3 \%$ & 12 & 22 & 31 & NT \\
\hline LKA & Sri Lanka & LMI & 1993 & 21 & $4.6 \%$ & 6 & 27 & 41 & NT \\
\hline MAR & Morocco & LMI & 1984 & 30 & $3.2 \%$ & 15 & 45 & 41 & LMIT* \\
\hline MDA & Moldova & LMI & 1980 & 34 & $1.3 \%$ & 59 & 93 & 41 & LMIT* \\
\hline MEX & Mexico & UMI & 1972 & 42 & $1.1 \%$ & 14 & 56 & 31 & UMIT \\
\hline MKD & Macedonia & UMI & 1976 & 38 & $1.8 \%$ & 28 & 66 & 31 & UMIT \\
\hline $\mathrm{MNG}$ & Mongolia & LMI & 2004 & 10 & $7.0 \%$ & 7 & 17 & 41 & NT \\
\hline MUS & Mauritius & UMI & 1995 & 19 & $3.4 \%$ & 4 & 23 & 31 & NT \\
\hline MYS & Malaysia & UMI & 1992 & 22 & $3.1 \%$ & 1 & 23 & 31 & NT \\
\hline NAM & Namibia & LMI & 1959 & 55 & $2.3 \%$ & 5 & 60 & 41 & LMIT \\
\hline PAK & Pakistan & LMI & 2006 & 8 & $2.0 \%$ & 54 & 62 & 41 & LMIT* \\
\hline PER & Peru & UMI & 2008 & 6 & $3.6 \%$ & 16 & 22 & 31 & NT \\
\hline PHL & Philippines & LMI & 1973 & 41 & $2.5 \%$ & 24 & 65 & 41 & LMIT* \\
\hline $\mathrm{ROM}$ & Romania & UMI & 1972 & 42 & $3.0 \%$ & 9 & 51 & 31 & UMIT \\
\hline RUS & Russia & UMI & 1980 & 34 & $2.4 \%$ & 1 & 35 & 31 & UMIT \\
\hline SRB & Serbia & UMI & 1981 & 33 & $5.8 \%$ & 8 & 41 & 31 & UMIT \\
\hline THA & Thailand & UMI & 2008 & 6 & $2.8 \%$ & 22 & 28 & 31 & NT \\
\hline TUR & Turkey & UMI & 1987 & 27 & $2.4 \%$ & 4 & 31 & 31 & NT \\
\hline UKR & Ukraine & LMI & 1980 & 34 & $0.7 \%$ & 21 & 55 & 41 & LMIT* \\
\hline URY & Uruguay & UMI & 1991 & 23 & $2.7 \%$ & 4 & 27 & 31 & NT \\
\hline VEN & Venezuela & UMI & 1950 & 64 & $0.5 \%$ & 64 & 128 & 31 & UMIT \\
\hline VNM & Vietnam & LMI & 2005 & 9 & $5.4 \%$ & 15 & 24 & 41 & NT \\
\hline YEM & Yemen & LMI & 2009 & 5 & $0.5 \%$ & - & - & 41 & LMIT* \\
\hline ZAF & S. Africa & UMI & 1969 & 45 & $1.6 \%$ & 26 & 71 & 31 & UMIT \\
\hline
\end{tabular}

Note: The following abbreviations have been used: LMI = lower-middle income; UMI = upper-middle income; LMIT = lower-middleincome trap; UMIT = upper-middle-income trap; NT = no trapped; LMIT* = projected in the LMIT (i.e., using column 6 instead of 3); UMIT* $^{*}$ projected in the UMIT (i.e., using column 6 instead of 3). 
Table B. 4. Projected number of years needed by the low-income economies (LIEs) of our sample to turn into lower-middle-income economies (LMIE), given the growth rate of the last 20 years. 23 countries.

\begin{tabular}{|c|c|c|c|c|c|}
\hline id & Country & $\begin{array}{l}\text { Average annual } \\
\text { growth rate } \\
(1993-2013)\end{array}$ & Start & $\begin{array}{c}\text { Turning } \\
\text { Year }\end{array}$ & $\begin{array}{c}\text { Years } \\
\text { needed to } \\
\text { graduate }\end{array}$ \\
\hline NGA & Nigeria & $3.8 \%$ & 2013 & 2014 & 1 \\
\hline KHM & Cambodia & $5.3 \%$ & 2013 & 2015 & 2 \\
\hline KGZ & Kyrgyz Rep. & $1.4 \%$ & 2013 & 2016 & 3 \\
\hline BGD & Bangladesh & $4.3 \%$ & 2013 & 2018 & 5 \\
\hline GHA & Ghana & $3.8 \%$ & 2013 & 2019 & 6 \\
\hline LSO & Lesotho & $1.3 \%$ & 2013 & 2022 & 9 \\
\hline CMR & Cameroon & $1.1 \%$ & 2013 & 2023 & 10 \\
\hline $\mathrm{TZA}$ & Tanzania & $3.0 \%$ & 2013 & 2029 & 16 \\
\hline BFA & Burkina Faso & $3.0 \%$ & 2013 & 2031 & 18 \\
\hline MOZ & Mozambique & $4.8 \%$ & 2013 & 2032 & 19 \\
\hline ETH & Ethiopia & $4.0 \%$ & 2013 & 2034 & 21 \\
\hline SLE & Sierra Leone & $2.6 \%$ & 2013 & 2034 & 21 \\
\hline UGA & Uganda & $3.1 \%$ & 2013 & 2037 & 24 \\
\hline SEN & Senegal & $1.2 \%$ & 2013 & 2038 & 25 \\
\hline NPL & Nepal & $1.9 \%$ & 2013 & 2042 & 29 \\
\hline KEN & Kenya & $1.2 \%$ & 2013 & 2043 & 30 \\
\hline RWA & Rwanda & $2.1 \%$ & 2013 & 2045 & 32 \\
\hline MLI & Mali & $1.7 \%$ & 2013 & 2059 & 46 \\
\hline ZMB & Zambia & $0.7 \%$ & 2013 & 2081 & 68 \\
\hline MDG & Madagascar & $-0.2 \%$ & 2013 & - & - \\
\hline MWI & Malawi & $0.6 \%$ & 2013 & - & - \\
\hline NER & Niger & $0.8 \%$ & 2013 & - & - \\
\hline TGO & Togo & $1.0 \%$ & 2013 & - & - \\
\hline & \multicolumn{4}{|c|}{ Average projected years (exc. Madagascar, Malawi, Niger and Togo) } & 19 \\
\hline & \multicolumn{4}{|c|}{ Standard Deviation (exc. Madagascar, Malawi, Niger and Togo) } & 17 \\
\hline & \multicolumn{4}{|c|}{ Upper Quintile (exc. Madagascar, Malawi, Niger and Togo) } & 27 \\
\hline
\end{tabular}

Note: Madagascar, Malawi, Niger and Togo are excluded from the distribution analysis because their projected number of years needed to graduate exceeds a century. Hence, they are directly considered trapped and not included in the comparison. 
Figure B. 1. Distribution of countries according to the number of years they needed to graduate from lowermiddle income (LMI) to upper-middle income (UMI) category.

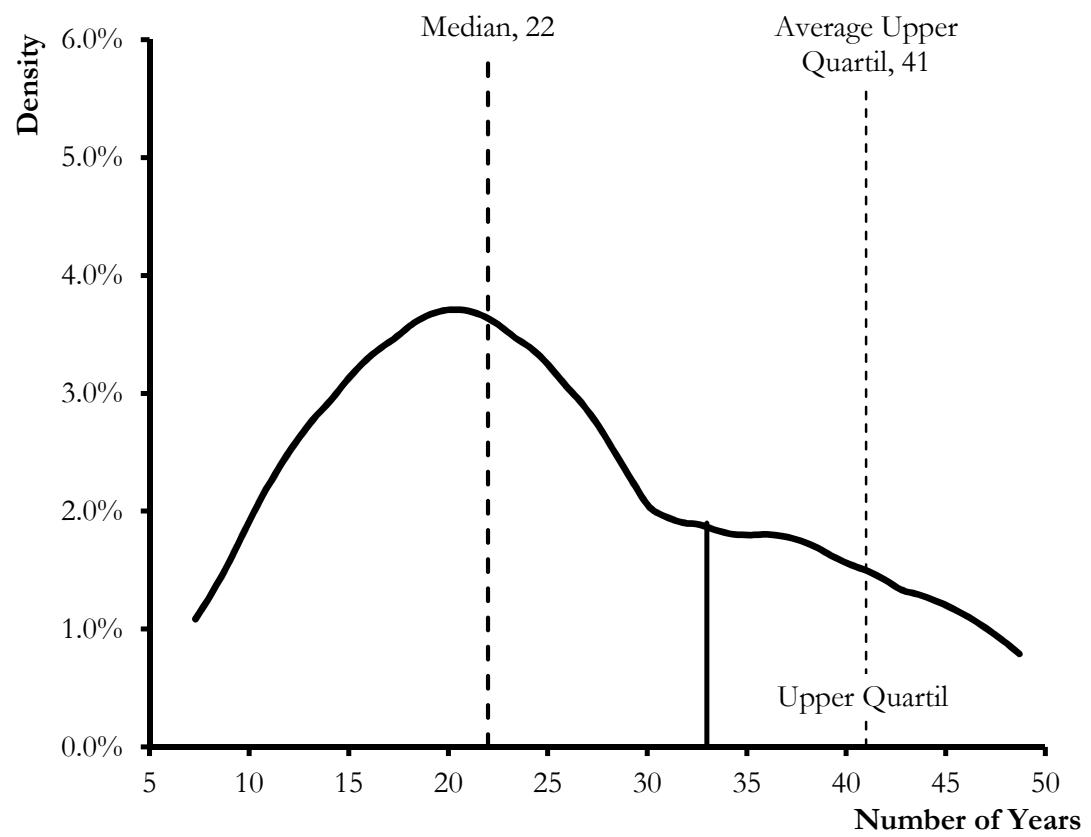

Note: This distribution has been calculated using the kdensity command of Stata 13, over the countries reported in Table B. 1. The kernel used was Epanechnikov with a bandwidth of 3.7024 . 
Figure B. 2. Distribution of countries according to the number of years they needed to graduate from upper-middle income (UMI) to high income (HI) category.

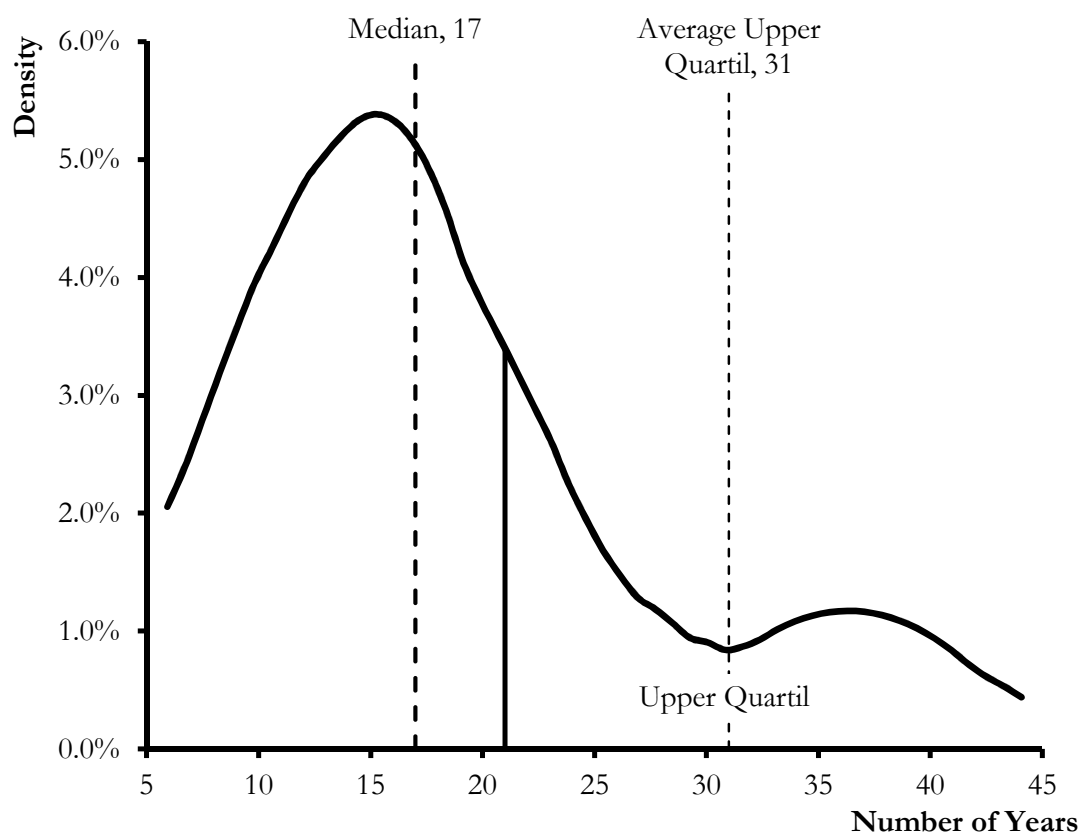

Note: This distribution has been calculated using the kdensity command of Stata 13, over the countries reported in Table B. 2. The kernel used was Epanechnikov with a bandwidth of 6.0254. 
Figure B. 3. Distribution of low income countries (LICs) according to the projected number of years they will need to graduate to the lower-middle income (LMI) category.

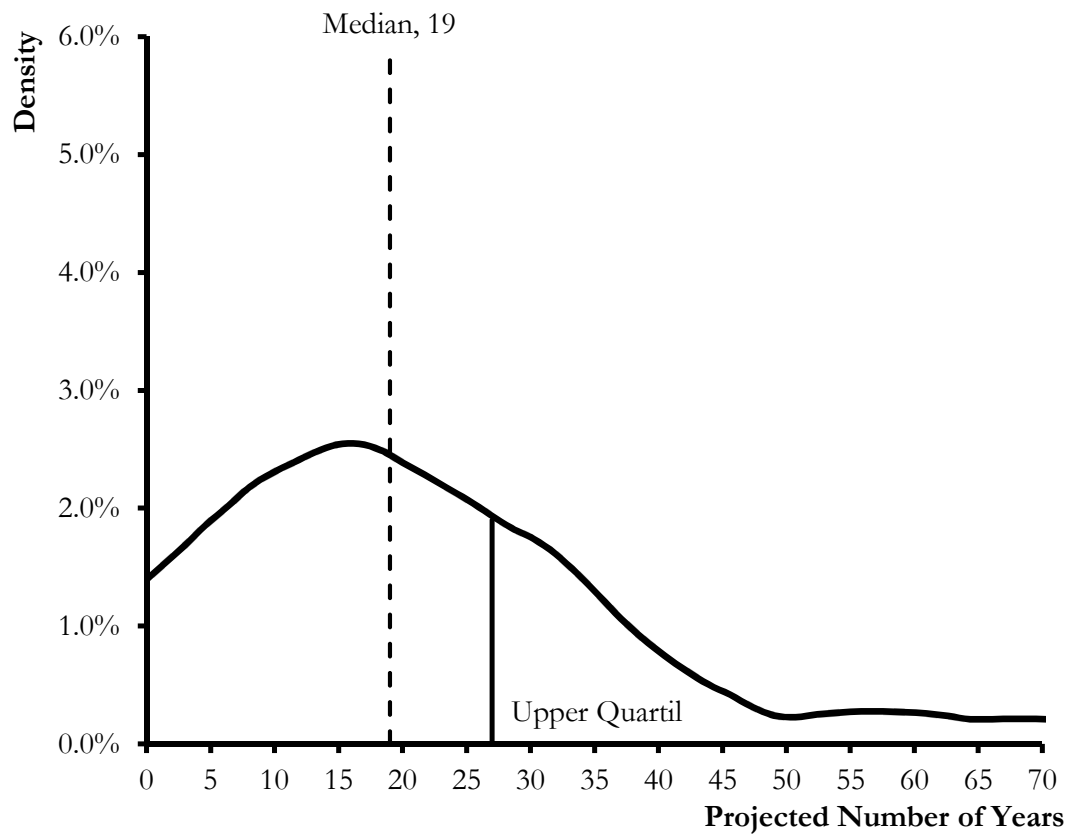

Note: This distribution has been calculated using the kdensity command of Stata 13, over the countries reported in Table B. 4. The kernel used was Epanechnikov with a bandwidth of 4.7422. When constructing the distribution the following countries have not been considered because their projected number of years needed to graduate exceeded a century: Madagascar, Malawi, Niger and Togo. 

APPENDIX C.

Appendix to Chapter 5 
This appendix presents some regression results that for space reasons could not be included in CHAPTER 5. It also details a number of robustness checks that have been performed on the various regressions done in that chapter.

\section{C.1. Regression Results (Figure 5.2 and Figure 5.3)}

Table C. 1. Determinants of growth: manufacturing value added exports by technology intensity groups interacted with relative productivity in manufacturing.

\begin{tabular}{|c|c|c|c|c|}
\hline & Model 10a & Model 10b & Model 10c & Model 10d \\
\hline Constant & $\begin{array}{l}-0.018 \\
(0.017)\end{array}$ & $\begin{array}{l}-0.016 \\
(0.017)\end{array}$ & $\begin{array}{l}-0.026 \\
(0.018)\end{array}$ & $\begin{array}{l}-0.015 \\
(0.016)\end{array}$ \\
\hline CLIMATE & $\begin{array}{l}0.013 \\
(0.013)\end{array}$ & $\begin{array}{l}0.013 \\
(0.012)\end{array}$ & $\begin{array}{l}0.014 \\
(0.014)\end{array}$ & $\begin{array}{l}0.010 \\
(0.012)\end{array}$ \\
\hline RICHNR & $\begin{array}{l}0.005 \\
(0.016)\end{array}$ & $\begin{array}{l}0.005 \\
(0.016)\end{array}$ & $\begin{array}{l}0.005 \\
(0.017)\end{array}$ & $\begin{array}{l}0.004 \\
(0.015)\end{array}$ \\
\hline LNPOP & $\begin{array}{l}0.005 \\
(0.004)\end{array}$ & $\begin{array}{l}0.004 \\
(0.004)\end{array}$ & $\begin{array}{l}0.006 \\
(0.004)\end{array}$ & $\begin{array}{l}0.007^{*} \\
(0.004)\end{array}$ \\
\hline UNDERV & $\begin{array}{l}0.013^{* * *} \\
(0.004)\end{array}$ & $\begin{array}{l}0.013^{* * *} \\
(0.004)\end{array}$ & $\begin{array}{l}0.012^{* * *} \\
(0.004)\end{array}$ & $\begin{array}{l}0.012^{* *} \\
(0.004)\end{array}$ \\
\hline EDU & $\begin{array}{l}0.004^{* *} \\
(0.001)\end{array}$ & $\begin{array}{l}0.004^{* *} \\
(0.001)\end{array}$ & $\begin{array}{l}0.004 * * \\
(0.001)\end{array}$ & $\begin{array}{l}0.003^{*} \\
(0.001)\end{array}$ \\
\hline INV & $\begin{array}{l}-0.038^{* *} \\
(0.014)\end{array}$ & $\begin{array}{l}-0.035^{* *} \\
(0.013)\end{array}$ & $\begin{array}{l}-0.033^{*} \\
(0.013)\end{array}$ & $\begin{array}{l}-0.026 \\
(0.013)\end{array}$ \\
\hline$\rho$ & $\begin{array}{l}0.055^{* *} \\
(0.017)\end{array}$ & $\begin{array}{l}0.055^{* *} \\
(0.017)\end{array}$ & $\begin{array}{l}0.054^{* *} \\
(0.017)\end{array}$ & $\begin{array}{l}0.037^{*} \\
(0.017)\end{array}$ \\
\hline$\lambda$ & $\begin{array}{l}-0.108^{* * *} \\
(0.026)\end{array}$ & $\begin{array}{l}-0.099 * * * \\
(0.027)\end{array}$ & $\begin{array}{l}-0.122 * * * \\
(0.027)\end{array}$ & $\begin{array}{l}-0.103^{* * *} \\
(0.026)\end{array}$ \\
\hline$S_{M A N}$ & $\begin{array}{l}0.067 * * * \\
(0.019)\end{array}$ & $\begin{array}{l}0.063^{* * *} \\
(0.019)\end{array}$ & $\begin{array}{l}0.076^{* * *} \\
(0.018)\end{array}$ & $\begin{array}{l}0.050^{* *} \\
(0.018)\end{array}$ \\
\hline$\rho_{M A N}$ & $\begin{array}{l}0.007 \\
(0.013)\end{array}$ & $\begin{array}{l}-0.008 \\
(0.015)\end{array}$ & $\begin{array}{l}0.007 \\
(0.015)\end{array}$ & $\begin{array}{l}-0.005 \\
(0.015)\end{array}$ \\
\hline$X_{A G R}$ & $\begin{array}{l}0.056 \\
(0.056)\end{array}$ & $\begin{array}{l}0.045 \\
(0.053)\end{array}$ & $\begin{array}{l}0.043 \\
(0.053)\end{array}$ & $\begin{array}{l}0.012 \\
(0.052)\end{array}$ \\
\hline$X_{M I N}$ & $\begin{array}{l}0.053^{*} \\
(0.025)\end{array}$ & $\begin{array}{l}0.050^{*} \\
(0.025)\end{array}$ & $\begin{array}{l}0.058^{*} \\
(0.025)\end{array}$ & $\begin{array}{l}0.051^{*} \\
(0.024)\end{array}$ \\
\hline$X_{V A \mid \text { Htech }}$ & $-0.053(0.099)$ & & & \\
\hline $\begin{array}{l}\rho_{M A N} * X_{V A \mid \text { Htech }} \\
X_{V A \mid \text { MHtech }}\end{array}$ & $0.305(0.232)$ & $-0.239(0.187)$ & & \\
\hline $\begin{array}{l}\rho_{\text {MAN }} * X_{V A \mid M H t e c h} \\
X_{V A \mid M L t e c h}\end{array}$ & & $0.648 *(0.282)$ & $0.142(0.115)$ & \\
\hline $\begin{array}{l}\rho_{\text {MAN }} * X_{V A \mid M L t e c h} \\
X_{V A \mid \text { Ltech }}\end{array}$ & & & $0.139(0.391)$ & $0.306^{* *}(0.116)$ \\
\hline $\begin{array}{l}\rho_{\text {MAN }} * X_{V A \mid \text { Ltech }} \\
\text { p75_90 }\end{array}$ & $\begin{array}{l}-0.011 * * \\
(0.004)\end{array}$ & $\begin{array}{l}-0.011 * * \\
(0.004)\end{array}$ & $\begin{array}{l}-0.012^{* *} \\
(0.004)\end{array}$ & $\begin{array}{l}0.981 *(0.428) \\
-0.014 * * * \\
(0.004)\end{array}$ \\
\hline p90_09 & $\begin{array}{l}-0.001 \\
(0.006)\end{array}$ & $\begin{array}{l}-0.002 \\
(0.006)\end{array}$ & $\begin{array}{l}-0.001 \\
(0.006)\end{array}$ & $\begin{array}{l}-0.007 \\
(0.006) \\
\end{array}$ \\
\hline Rho & 0.884 & 0.884 & 0.902 & 0.876 \\
\hline Countries & 552 & 552 & 552 & 552 \\
\hline Obs & 86 & 86 & 86 & 86 \\
\hline
\end{tabular}


Table C. 2. Determinants of growth: manufacturing value added exports by technology intensity groups interacted with relative productivity in manufacturing.

\begin{tabular}{|c|c|c|c|}
\hline & Model 10e & Model 10f & Model 10g \\
\hline Constant & $\begin{array}{l}-0.021 \\
(0.017)\end{array}$ & $\begin{array}{l}-0.027 \\
(0.018)\end{array}$ & $\begin{array}{l}-0.017 \\
(0.018)\end{array}$ \\
\hline CLIMATE & $\begin{array}{l}0.016 \\
(0.012)\end{array}$ & $\begin{array}{l}0.013 \\
(0.013)\end{array}$ & $\begin{array}{l}0.011 \\
(0.013)\end{array}$ \\
\hline RICHNR & $\begin{array}{l}0.009 \\
(0.015)\end{array}$ & $\begin{array}{l}0.007 \\
(0.017)\end{array}$ & $\begin{array}{l}0.003 \\
(0.017)\end{array}$ \\
\hline LNPOP & $\begin{array}{l}0.005 \\
(0.004)\end{array}$ & $\begin{array}{l}0.006 \\
(0.004)\end{array}$ & $\begin{array}{l}0.006 \\
(0.004)\end{array}$ \\
\hline UNDERV & $\begin{array}{l}0.013^{* * *} \\
(0.004)\end{array}$ & $\begin{array}{l}0.012^{* *} \\
(0.004)\end{array}$ & $\begin{array}{l}0.014^{* * *} \\
(0.004)\end{array}$ \\
\hline EDU & $\begin{array}{l}0.004^{*} \\
(0.001)\end{array}$ & $\begin{array}{l}0.004^{* *} \\
(0.001)\end{array}$ & $\begin{array}{l}0.004^{* *} \\
(0.001)\end{array}$ \\
\hline INV & $\begin{array}{l}-0.040^{* *} \\
(0.013)\end{array}$ & $\begin{array}{c}-0.033^{*} \\
(0.013)\end{array}$ & $\begin{array}{l}-0.033^{*} \\
(0.013)\end{array}$ \\
\hline$\rho$ & $\begin{array}{l}0.049 * * \\
(0.017)\end{array}$ & $\begin{array}{l}0.060^{* * *} \\
(0.017)\end{array}$ & $\begin{array}{l}0.044^{* *} \\
(0.017)\end{array}$ \\
\hline$\lambda$ & $\begin{array}{l}-0.117^{* * *} \\
(0.027)\end{array}$ & $\begin{array}{l}-0.126^{* * *} \\
(0.027)\end{array}$ & $\begin{array}{l}-0.094 * * * \\
(0.026)\end{array}$ \\
\hline$S_{M A N}$ & $\begin{array}{l}0.072^{* * *} \\
(0.018)\end{array}$ & $\begin{array}{l}0.082^{* * *} \\
(0.019)\end{array}$ & $\begin{array}{l}0.062^{* * *} \\
(0.018)\end{array}$ \\
\hline$\rho_{M A N}$ & $\begin{array}{l}0.006 \\
(0.015)\end{array}$ & $\begin{array}{l}-0.006 \\
(0.015)\end{array}$ & $\begin{array}{l}-0.010 \\
(0.013)\end{array}$ \\
\hline$X_{A G R}$ & $\begin{array}{l}0.070 \\
(0.054)\end{array}$ & $\begin{array}{l}0.046 \\
(0.053)\end{array}$ & $\begin{array}{l}0.044 \\
(0.053)\end{array}$ \\
\hline$X_{M I N}$ & $\begin{array}{l}0.065^{* *} \\
(0.025)\end{array}$ & $\begin{array}{l}0.055^{*} \\
(0.024)\end{array}$ & $\begin{array}{l}0.045 \\
(0.024)\end{array}$ \\
\hline$X_{V A \mid \text { Helast }}$ & $\begin{array}{l}0.098 \\
(0.068)\end{array}$ & & \\
\hline$\rho_{M A N} * X_{V A \mid \text { Helast }}$ & $\begin{array}{l}0.165 \\
(0.181)\end{array}$ & & \\
\hline$X_{V A \mid \text { Melast }}$ & & $\begin{array}{l}0.097 \\
(0.088)\end{array}$ & \\
\hline$\rho_{M A N} * X_{V A \mid \text { Melast }}$ & & $\begin{array}{l}0.328 \\
(0.205)\end{array}$ & \\
\hline$X_{V A \mid \text { Lelast }}$ & & & $\begin{array}{l}-0.914^{* *} \\
(0.311)\end{array}$ \\
\hline$\rho_{M A N} * X_{V A \mid \text { Lelast }}$ & & & $\begin{array}{l}4.529 * * * \\
(1.177)\end{array}$ \\
\hline p75_90 & $\begin{array}{l}-0.011^{* *} \\
(0.004)\end{array}$ & $\begin{array}{l}-0.011 * * \\
(0.004)\end{array}$ & $\begin{array}{l}-0.010^{*} \\
(0.004)\end{array}$ \\
\hline p90_09 & $\begin{array}{l}-0.001 \\
(0.006)\end{array}$ & $\begin{array}{l}-0.001 \\
(0.006)\end{array}$ & $\begin{array}{l}-0.002 \\
(0.006)\end{array}$ \\
\hline Rho & 0.872 & 0.895 & 0.903 \\
\hline Obs. & 552 & 552 & 552 \\
\hline Countries & 86 & 86 & 86 \\
\hline
\end{tabular}

\section{C.2. Robustness Checks}


In this section we present some robustness checks on the validity of the estimators and specific variables used throughout CHAPTER 5.

First, we present the results of an exercise aimed at checking whether the HT estimator is indeed preferred to a fixed effects and random effects estimators. Following the approach proposed by Baltagi et al. (2003) we have run individual Hausman specification tests comparing for each model: a) the Fixed effect estimator and the Random effect estimator; and b) the Fixed effect estimator and the HT estimator. If the first test is rejected and the second is not, then the HT estimator would be efficient, consistent and preferred over a Random effect estimator. 
Table C. 3. Hausman's (1978) specification test for the models estimated in the chapter

\begin{tabular}{|c|c|c|c|c|c|c|}
\hline \multirow[b]{2}{*}{ Model } & \multicolumn{3}{|c|}{ Random Effects Estimator } & \multicolumn{3}{|c|}{ Hausman-Taylor Estimator } \\
\hline & $\chi^{2}$-stat & p-value & $\begin{array}{c}\text { Efficient and } \\
\text { consistent }\end{array}$ & $\chi^{2}$-stat & p-value & $\begin{array}{c}\text { Efficient and } \\
\text { consistent }\end{array}$ \\
\hline Model 2 & 26.8 & 0.001 & Rejected & 5.9 & 0.750 & Non Rejected \\
\hline Model 3a & 35.1 & 0.000 & Rejected & 8.6 & 0.568 & Non Rejected \\
\hline Model 3b & 30.3 & 0.001 & Rejected & 6.1 & 0.805 & Non Rejected \\
\hline Model 3c & 39.3 & 0.000 & Rejected & 7.2 & 0.705 & Non Rejected \\
\hline Model 4a & 49.9 & 0.000 & Rejected & 13.6 & 0.253 & Non Rejected \\
\hline Model 4b & 42.8 & 0.000 & Rejected & 8.2 & 0.693 & Non Rejected \\
\hline Model 4c & 53.0 & 0.000 & Rejected & 9.2 & 0.604 & Non Rejected \\
\hline Model 4d & 42.8 & 0.000 & Rejected & 7.8 & 0.728 & Non Rejected \\
\hline Model 4e & 39.1 & 0.000 & Rejected & 7.2 & 0.781 & Non Rejected \\
\hline Model 4f & 43.3 & 0.000 & Rejected & 7.8 & 0.730 & Non Rejected \\
\hline Model 5 & 37.4 & 0.000 & Rejected & 8.1 & 0.616 & Non Rejected \\
\hline Model 6 & 38.1 & 0.000 & Rejected & 8.1 & 0.703 & Non Rejected \\
\hline Model 7 & 40.9 & 0.000 & Rejected & 9.1 & 0.692 & Non Rejected \\
\hline Model 8 & 41.9 & 0.000 & Rejected & 9.2 & 0.683 & Non Rejected \\
\hline Model 9a & 40.4 & 0.000 & Rejected & 9.6 & 0.649 & Non Rejected \\
\hline Model 9b & 38.7 & 0.000 & Rejected & 9.6 & 0.654 & Non Rejected \\
\hline Model 9c & 48.6 & 0.000 & Rejected & 10.5 & 0.570 & Non Rejected \\
\hline Model 9d & 42.8 & 0.000 & Rejected & 10.2 & 0.598 & Non Rejected \\
\hline Model 9e & 37.2 & 0.000 & Rejected & 9.0 & 0.703 & Non Rejected \\
\hline Model 9f & 46.4 & 0.000 & Rejected & 10.2 & 0.602 & Non Rejected \\
\hline Model 9g & 39.8 & 0.000 & Rejected & 9.8 & 0.633 & Non Rejected \\
\hline Model 10a & 40.2 & 0.000 & Rejected & 9.1 & 0.828 & Non Rejected \\
\hline Model 10b & 40.9 & 0.000 & Rejected & 9.2 & 0.819 & Non Rejected \\
\hline Model 10c & 46.9 & 0.000 & Rejected & 10.3 & 0.742 & Non Rejected \\
\hline Model 10d & 38.8 & 0.000 & Rejected & 9.3 & 0.811 & Non Rejected \\
\hline Model 10e & 36.7 & 0.001 & Rejected & 8.4 & 0.866 & Non Rejected \\
\hline Model 10f & 47.8 & 0.000 & Rejected & 10.1 & 0.758 & Non Rejected \\
\hline Model 10g & 41.2 & 0.000 & Rejected & 10.7 & 0.711 & Non Rejected \\
\hline
\end{tabular}

According to the results detailed in Table C. 3, the HT (given the choice done regarding the endogenous and exogenous variables) is the most appropriate estimator to use in all our models. In all cases, the appropriateness of the Random effect model is rejected while the appropriateness of the HT estimator is not rejected. 
The second robustness check that we present in the appendix is oriented to verify if the results of our preferred models in Section 5.2.3 (Models 2 and 3) are driven by the particular set of variables included in the regressions. In particular, we run again the corresponding regressions replacing some of their key variables. First, we explore what happens if we use alternative measures for $\rho$, INV and UNDERV in Model 2. Secondly, we investigate an alternative specification to examine the impact of MMA sectoral composition in Model 3. Instead of including the size of the modern sector (as captured by $\lambda$ ) and the corresponding sectoral share within the modern sector (as capture by the $s_{j}$ ), we directly introduce the share of each sector in total labour force. That is, we introduce the following three variables: $\lambda_{M A N}, \lambda_{N M I}$ and $\lambda_{M M S}$.

The following table presents the results of Model 2 once the variables mentioned above are replaced with alternative measures, in a one by one basis (columns 2 to 4 ) and all together (column 5). In the first alternative model our measure of technological upgrading $(\rho)$ is replaced by the relative per capita income of each country as compared to the US (RELUS). This is the variable used, for example, in Szirmai and Verspagen (2011) to capture the catch-up potential of less advanced nations. Next, in the second alternative specification INV is replaced by the growth rate of physical capital per worker (KPWgr). This variable is calculated from PWT8 and might reflect more accurately the scope for embodied technological change. In the third alternative specification UNDERV is replaced by TTgr, a variable oriented to capture the percentage variation of the terms of trade within the 5-year period considered. Positive values of this variable are expected to have a positive (short-run) impact on growth, similar to the one obtained for the real undervaluation of the currency. This variable is calculated using the corresponding changes in the price level of exports and imports as provided by PWT8 ${ }^{149}$. Finally, the last column of the table presents the results of the model when the three variables are simultaneously replaced.

\footnotetext{
${ }^{149}$ Specifically, and index has been calculated for the evolution of the ratio between price level of exports (pl_x) and the price level of imports (pl_m). TTgr presents the compound growth rate of this index between the first and last year of the corresponding 5-year period. Positive values in this variable reflect an improvement in the terms of trade during the period.
} 
Table C. 4. Robustness check: the effect of alternative measures for the key variables of Model 2.

\begin{tabular}{|c|c|c|c|c|c|}
\hline & $\begin{array}{l}\text { Model } 2 \\
\text { (Orig.) }\end{array}$ & $\begin{array}{l}\text { Model A2 } \\
\text { (RELUS) }\end{array}$ & $\begin{array}{l}\text { Model A2 } \\
\text { (KPW) }\end{array}$ & $\begin{array}{l}\text { Model A2 } \\
\text { (TT) }\end{array}$ & $\begin{array}{l}\text { Model A2 } \\
\text { (Alt. Var.) }\end{array}$ \\
\hline \multirow[t]{2}{*}{ Constant } & 0.008 & 0.004 & 0.010 & $0.031^{* *}$ & $0.026^{* *}$ \\
\hline & $(0.012)$ & $(0.011)$ & $(0.011)$ & $(0.010)$ & $(0.010)$ \\
\hline \multirow[t]{2}{*}{ CLIMATE } & 0.015 & 0.018 & 0.011 & $0.019^{*}$ & $0.020^{*}$ \\
\hline & $(0.010)$ & $(0.010)$ & $(0.009)$ & $(0.010)$ & $(0.009)$ \\
\hline \multirow[t]{2}{*}{ RICHNR } & 0.015 & 0.026 & 0.015 & 0.020 & $0.034^{* *}$ \\
\hline & (0.013) & (0.013) & (0.012) & (0.013) & (0.013) \\
\hline \multirow[t]{2}{*}{ LNPOP } & 0.004 & 0.004 & 0.004 & 0.003 & 0.003 \\
\hline & $(0.003)$ & (0.003) & $(0.003)$ & (0.003) & $(0.003)$ \\
\hline \multirow[t]{2}{*}{ EDU } & 0.002 & 0.002 & $0.004^{* *}$ & 0.000 & 0.002 \\
\hline & (0.001) & $(0.001)$ & $(0.001)$ & $(0.001)$ & (0.001) \\
\hline \multirow[t]{2}{*}{ OPEN } & $0.022^{* * *}$ & $0.024^{* * *}$ & $0.021 * * *$ & $0.019^{* * *}$ & $0.024^{* * *}$ \\
\hline & $(0.006)$ & $(0.006)$ & $(0.006)$ & $(0.006)$ & $(0.006)$ \\
\hline \multirow[t]{2}{*}{$\lambda$} & $-0.097 * * *$ & -0.032 & $-0.105^{* * *}$ & $-0.085^{* * *}$ & -0.024 \\
\hline & $(0.025)$ & $(0.025)$ & $(0.024)$ & $(0.025)$ & $(0.025)$ \\
\hline \multirow[t]{2}{*}{$\rho$} & $-0.043 * * *$ & & $-0.041 * * *$ & $-0.058^{* * *}$ & \\
\hline & $(0.011)$ & & $(0.011)$ & $(0.011)$ & \\
\hline \multirow[t]{2}{*}{ INV } & $0.067 * * *$ & $0.070^{* * *}$ & & $0.068^{* * *}$ & \\
\hline & (0.016) & $(0.016)$ & & (0.017) & \\
\hline \multirow[t]{2}{*}{ UNDERV } & $0.018^{* * *}$ & $0.017 * * *$ & $0.017 * * *$ & & \\
\hline & (0.004) & (0.004) & $(0.004)$ & & \\
\hline \multirow[t]{2}{*}{ RELUS } & & $-0.089 * * *$ & & & $-0.106^{* * *}$ \\
\hline & & $(0.014)$ & & & $(0.015)$ \\
\hline \multirow[t]{2}{*}{ KPWgr } & & & $0.232^{* * *}$ & & $0.239 * * *$ \\
\hline & & & $(0.042)$ & & (0.042) \\
\hline \multirow[t]{2}{*}{ TTgr } & & & & $0.116^{* * *}$ & 0.064 \\
\hline & & & & $(0.035)$ & $(0.034)$ \\
\hline \multirow[t]{2}{*}{ p75_90 } & -0.004 & -0.008 & -0.004 & $-0.015^{* * *}$ & $-0.018^{* * *}$ \\
\hline & (0.004) & (0.004) & $(0.004)$ & $(0.003)$ & $(0.003)$ \\
\hline \multirow[t]{2}{*}{ p90_09 } & 0.003 & -0.002 & 0.001 & $-0.012^{*}$ & $-0.018^{* * *}$ \\
\hline & $(0.006)$ & $(0.006)$ & $(0.006)$ & $(0.005)$ & $(0.005)$ \\
\hline Rho & 0.789 & 0.791 & 0.744 & 0.761 & 0.756 \\
\hline Obs. & 612 & 620 & 602 & 614 & 609 \\
\hline Countries & 92 & 92 & 92 & 93 & 93 \\
\hline
\end{tabular}

We can see that using these alternative measures for our key variables does not bring any significant change in the results obtained in the main text. Perhaps the most important difference is that when RELUS is used instead of $\rho$, the coefficient associated with the share of MMA in total labour becomes not significant. In a way, 
this is an expected result since RELUS would already capture the combined effect of the size and technological gap of the modern sector.

A similar conclusion is obtained when we use the alternative setting to account for the composition of the modern sector (See Table C. 5). Since we still want to control for the size of the modern sector, we enter the three shares at the same time (instead of separately, as it was the case in Models 3a, 3b and 3c, where the size of the modern sector is already accounted by $\lambda$ ). We can see that the only sector that enters with a positive sign is manufacturing. Non-manufacturing industry and modern market services, instead, show a negative and significant coefficient. The significance of the coefficient associated with the manufacturing share, however, now drops and become non-significant. This might be due to a problem of multicollinearity given the fact that the three shares are, by definition, highly correlated.

Table C. 6 presents a last robustness check oriented to analyze if the results of our regressions in Section 5.2 .3 (i.e., the positive effect of manufacturing shares and the negative effect of MMS shares) are driven by the fact that modern services tend to become more important at later stages of development. In particular, we augment Models 3a, 3b and 3c with income-level slope dummies for the corresponding sectoral shares. Interestingly, this last set of regressions also show a quite stable patterns across income levels: the manufacturing share on MMA labour force keeps its positive and significant effect at all income levels, while MMS and NMI keep the negative effect in all income levels, though they are only significant in the case of high-income countries. 
Table C. 5. Robustness check: the effect of an alternative specification for the composition of the modern sector

\begin{tabular}{|c|c|c|c|c|}
\hline & $\begin{array}{l}\text { Model 3a } \\
\text { (orig.) }\end{array}$ & $\begin{array}{l}\text { Model 3b } \\
\text { (orig.) }\end{array}$ & $\begin{array}{l}\text { Model 3c } \\
\text { (orig.) }\end{array}$ & $\begin{array}{l}\text { Model A3 } \\
\left(\lambda_{j}\right)\end{array}$ \\
\hline Constant & $\begin{array}{l}0.026^{*} \\
(0.013)\end{array}$ & $\begin{array}{l}0.016 \\
(0.013)\end{array}$ & $\begin{array}{l}-0.024 \\
(0.015)\end{array}$ & $\begin{array}{l}0.003 \\
(0.011)\end{array}$ \\
\hline CLIMATE & $\begin{array}{l}0.015 \\
(0.010)\end{array}$ & $\begin{array}{l}0.015 \\
(0.011)\end{array}$ & $\begin{array}{l}0.017 \\
(0.011)\end{array}$ & $\begin{array}{l}0.014 \\
(0.010)\end{array}$ \\
\hline RICHNR & $\begin{array}{l}0.016 \\
(0.013)\end{array}$ & $\begin{array}{l}0.015 \\
(0.014)\end{array}$ & $\begin{array}{l}0.020 \\
(0.014)\end{array}$ & $\begin{array}{l}0.016 \\
(0.013)\end{array}$ \\
\hline LNPOP & $\begin{array}{l}0.004 \\
(0.003)\end{array}$ & $\begin{array}{l}0.004 \\
(0.003)\end{array}$ & $\begin{array}{l}0.004 \\
(0.003)\end{array}$ & $\begin{array}{l}0.004 \\
(0.003)\end{array}$ \\
\hline OPEN & $\begin{array}{l}0.024 * * * \\
(0.006)\end{array}$ & $\begin{array}{l}0.022^{* * *} \\
(0.006)\end{array}$ & $\begin{array}{l}0.027 * * * \\
(0.006)\end{array}$ & $\begin{array}{l}0.030 * * * \\
(0.006)\end{array}$ \\
\hline UNDERV & $\begin{array}{l}0.015^{* * *} \\
(0.004)\end{array}$ & $\begin{array}{l}0.019 * * * \\
(0.004)\end{array}$ & $\begin{array}{l}0.016^{* * *} \\
(0.004)\end{array}$ & $\begin{array}{l}0.017 * * * \\
(0.004)\end{array}$ \\
\hline EDU & $\begin{array}{l}0.004^{*} \\
(0.001)\end{array}$ & $\begin{array}{l}0.002 \\
(0.001)\end{array}$ & $\begin{array}{l}0.003 \\
(0.001)\end{array}$ & $\begin{array}{l}0.004^{* *} \\
(0.001)\end{array}$ \\
\hline INV & $\begin{array}{l}0.061 * * * \\
(0.016)\end{array}$ & $\begin{array}{l}0.072^{* * *} \\
(0.017)\end{array}$ & $\begin{array}{l}0.072^{* * *} \\
(0.016)\end{array}$ & $\begin{array}{l}0.067 * * * \\
(0.016)\end{array}$ \\
\hline$\rho$ & $\begin{array}{l}-0.035^{* *} \\
(0.011)\end{array}$ & $\begin{array}{l}-0.044^{* * *} \\
(0.011)\end{array}$ & $\begin{array}{l}-0.039 * * * \\
(0.011)\end{array}$ & $\begin{array}{c}-0.023 * \\
(0.011)\end{array}$ \\
\hline$\lambda$ & $\begin{array}{l}-0.132^{* * *} \\
(0.027)\end{array}$ & $\begin{array}{l}-0.096 * * * \\
(0.024)\end{array}$ & $\begin{array}{l}-0.138^{* * *} \\
(0.027)\end{array}$ & \\
\hline$s_{M M S}$ & $\begin{array}{l}-0.064^{* *} \\
(0.022)\end{array}$ & & & \\
\hline$s_{N M I}$ & & $\begin{array}{l}-0.035 \\
(0.023)\end{array}$ & & \\
\hline$s_{M A N}$ & & & $\begin{array}{l}0.069 * * * \\
(0.019)\end{array}$ & \\
\hline$\lambda_{M M S}$ & & & & $\begin{array}{l}-0.301 * * * \\
(0.066)\end{array}$ \\
\hline$\lambda_{N M I}$ & & & & $\begin{array}{l}-0.399 * * * \\
(0.074)\end{array}$ \\
\hline$\lambda_{M A N}$ & & & & $\begin{array}{l}0.034 \\
(0.031)\end{array}$ \\
\hline p75_90 & $\begin{array}{l}-0.007 \\
(0.004)\end{array}$ & $\begin{array}{l}-0.004 \\
(0.004)\end{array}$ & $\begin{array}{l}-0.005 \\
(0.004)\end{array}$ & $\begin{array}{l}-0.007 \\
(0.004)\end{array}$ \\
\hline p90_09 & $\begin{array}{l}0.001 \\
(0.006)\end{array}$ & $\begin{array}{l}0.004 \\
(0.006)\end{array}$ & $\begin{array}{l}0.005 \\
(0.006)\end{array}$ & $\begin{array}{l}0.002 \\
(0.006)\end{array}$ \\
\hline Rho & 0.784 & 0.809 & 0.820 & 0.792 \\
\hline Obs. & 610 & 610 & 610 & 610 \\
\hline Countries & 91 & 91 & 91 & 91 \\
\hline
\end{tabular}

$* \mathrm{p}<0.05, * * \mathrm{p}<0.01, * * * \mathrm{p}<0.001$ 
Table C. 6. Robustness check: the effect of sectoral composition by income level

\begin{tabular}{|c|c|c|c|}
\hline & Model 3a_Y & Model 3b_Y & Model 3c_Y \\
\hline \multirow[t]{2}{*}{ Constant } & 0.020 & 0.014 & -0.015 \\
\hline & $(0.013)$ & $(0.014)$ & $(0.015)$ \\
\hline \multirow[t]{2}{*}{ CLIMATE } & 0.013 & 0.013 & 0.012 \\
\hline & $(0.008)$ & $(0.010)$ & $(0.010)$ \\
\hline \multirow[t]{2}{*}{ RICHNR } & 0.012 & 0.011 & 0.014 \\
\hline & $(0.011)$ & $(0.013)$ & $(0.013)$ \\
\hline \multirow[t]{2}{*}{ LNPOP } & 0.003 & 0.003 & 0.003 \\
\hline & $(0.002)$ & $(0.003)$ & $(0.003)$ \\
\hline \multirow{2}{*}{ UNDERV } & $0.012 * *$ & $0.017 * * *$ & $0.014 * * *$ \\
\hline & $(0.004)$ & $(0.004)$ & $(0.004)$ \\
\hline \multirow[t]{2}{*}{ EDU } & $0.004^{*}$ & 0.002 & $0.003^{*}$ \\
\hline & $(0.001)$ & $(0.001)$ & $(0.001)$ \\
\hline \multirow[t]{2}{*}{ INV } & $0.054 * *$ & $0.073^{* * *}$ & $0.062^{* * *}$ \\
\hline & $(0.016)$ & $(0.017)$ & $(0.016)$ \\
\hline \multirow[t]{2}{*}{ OPEN } & $0.025^{* * *}$ & $0.021 * * *$ & $0.025^{* * *}$ \\
\hline & $(0.006)$ & $(0.006)$ & $(0.006)$ \\
\hline \multirow[t]{2}{*}{$\rho$} & -0.010 & $-0.031 *$ & $-0.033^{* *}$ \\
\hline & $(0.013)$ & $(0.012)$ & $(0.011)$ \\
\hline \multirow[t]{2}{*}{$\lambda$} & $-0.119 * * *$ & $-0.081 * * *$ & $-0.142^{* * *}$ \\
\hline & $(0.027)$ & $(0.024)$ & $(0.027)$ \\
\hline \multirow[t]{2}{*}{$H I G H * S_{M M S}$} & $-0.089 * * *$ & & \\
\hline & $(0.025)$ & & \\
\hline \multirow[t]{2}{*}{$M I D * s_{M M S}$} & -0.035 & & \\
\hline & $(0.025)$ & & \\
\hline \multirow[t]{2}{*}{$L O W * s_{M M S}$} & -0.048 & & \\
\hline & $(0.028)$ & & \\
\hline \multirow[t]{2}{*}{$H I G H * s_{N M I}$} & & $-0.093^{* *}$ & \\
\hline & & $(0.032)$ & \\
\hline \multirow[t]{2}{*}{$M I D * s_{N M I}$} & & -0.039 & \\
\hline & & $(0.024)$ & \\
\hline \multirow[t]{2}{*}{$L O W * s_{N M I}$} & & -0.034 & \\
\hline & & $(0.027)$ & \\
\hline \multirow[t]{2}{*}{$H I G H * s_{M A N}$} & & & $0.071^{* * *}$ \\
\hline & & & $(0.021)$ \\
\hline \multirow[t]{2}{*}{$M I D * S_{M A N}$} & & & $0.080^{* * *}$ \\
\hline & & & $(0.019)$ \\
\hline \multirow[t]{2}{*}{$L O W * S_{M A N}$} & & & $0.051 * *$ \\
\hline & & & $(0.020)$ \\
\hline p75_90 & $-0.010 *(0.004)$ & $-0.005(0.004)$ & $-0.007(0.004)$ \\
\hline p90_09 & $-0.002(0.006)$ & $0.002(0.006)$ & $0.001(0.006)$ \\
\hline Rho & 0.699 & 0.776 & 0.779 \\
\hline Obs. & 610 & 610 & 610 \\
\hline Countries & 91 & 91 & 91 \\
\hline
\end{tabular}


APPENDIX D.

Appendix to Chapter 6 
In this Appendix we detail the mathematical derivation of the decomposition used in CHAPTER 6 to analyze the patterns of catch-up in the modern sector.

\section{D.1. Catch-up Decomposition}

Our point of departure is the time difference of our index for relative productivity in the modern sector, as described in equation (6.7):

$$
\Delta \rho_{M}=\sum_{j} \rho_{j, \mathrm{~T}}^{i} r_{j, \mathrm{~T}}^{u} s_{j, \mathrm{~T}}^{i}-\sum_{j} \rho_{j, 0}^{i} r_{j, 0}^{u} s_{j, 0}^{i}
$$

We want to rearrange this expression in terms of the changes in its three components. To do so, first we add and subtract the term $\sum_{j} \rho_{j, 0}^{i} r_{j, \mathrm{~T}}^{u} s_{j, 0}^{i}$ and we reorder terms:

$$
\begin{aligned}
\Delta \rho_{M} & =\sum_{j} \rho_{j, \mathrm{~T}}^{i} r_{j, \mathrm{~T}}^{u} s_{j, \mathrm{~T}}^{i}-\sum_{j} \rho_{j, 0}^{i} r_{j, 0}^{u} s_{j, 0}^{i}+\sum_{j} \rho_{j, 0}^{i} r_{j, \mathrm{~T}}^{u} s_{j, 0}^{i}-\sum_{j} \rho_{j, 0}^{i} r_{j, \mathrm{~T}}^{u} s_{j, 0}^{i} \\
& =\sum_{j} \rho_{j, 0}^{i} s_{j, 0}^{i} \Delta r_{j}^{u}+\sum_{j} r_{j, \mathrm{~T}}^{u}\left(\rho_{j, \mathrm{~T}}^{i} s_{j, \mathrm{~T}}^{i}-\rho_{j, 0}^{i} s_{j, 0}^{i}\right)
\end{aligned}
$$

Next, we add and subtract the term $\rho_{j, \mathrm{~T}}^{i} s_{j, 0}^{i}$ in the term within brackets and rearrange to get:

$$
\begin{aligned}
\Delta \rho_{M} & =\sum_{j} \rho_{j, 0}^{i} s_{j, 0}^{i} \Delta r_{j}^{u}+\sum_{j} r_{j, \mathrm{~T}}^{u}\left(\rho_{j, \mathrm{~T}}^{i} s_{j, \mathrm{~T}}^{i}-\rho_{j, 0}^{i} s_{j, 0}^{i}+\rho_{j, \mathrm{~T}}^{i} s_{j, 0}^{i}-\rho_{j, \mathrm{~T}}^{i} s_{j, 0}^{i}\right) \\
& =\sum_{j} \rho_{j, 0}^{i} s_{j, 0}^{i} \Delta r_{j}^{u}+\sum_{j} r_{j, \mathrm{~T}}^{u}\left(\rho_{j, \mathrm{~T}}^{i} \Delta s_{j}^{i}+s_{j, 0}^{i} \Delta \rho_{j}^{i}\right)
\end{aligned}
$$

Finally, we add and subtract the term $\rho_{j, 0}^{i} \Delta s_{j}^{i}$ in the term within brackets and rearrange to get:

$$
\begin{aligned}
\Delta \rho_{M} & =\sum_{j} \rho_{j, 0}^{i} s_{j, 0}^{i} \Delta r_{j}^{u}+\sum_{j} r_{j, \mathrm{~T}}^{u}\left(\rho_{j, \mathrm{~T}}^{i} \Delta s_{j}^{i}+s_{j, 0}^{i} \Delta \rho_{j}^{i}+\rho_{j, 0}^{i} \Delta s_{j}^{i}-\rho_{j, 0}^{i} \Delta s_{j}^{i}\right) \\
& =\sum_{j} \rho_{j, 0}^{i} s_{j, 0}^{i} \Delta r_{j}^{u}+\sum_{j} r_{j, \mathrm{~T}}^{u}\left(\rho_{j, 0}^{i} \Delta s_{j}^{i}+s_{j, 0}^{i} \Delta \rho_{j}^{i}+\rho_{j, \mathrm{~T}}^{i} \Delta s_{j}^{i}-\rho_{j, 0}^{i} \Delta s_{j}^{i}\right) \\
& =\sum_{j} \rho_{j, 0}^{i} s_{j, 0}^{i} \Delta r_{j}^{u}+\sum_{j} r_{j, \mathrm{~T}}^{u}\left(\rho_{j, 0}^{i} \Delta s_{j}^{i}+s_{j, 0}^{i} \Delta \rho_{j}^{i}+\Delta \rho_{j}^{i} \Delta s_{j}^{i}\right) \\
& =\underbrace{\sum_{j} \rho_{j, 0}^{i} s_{j, 0}^{i} \Delta r_{j}^{u}}_{\text {specialization }}+\underbrace{\sum_{j} r_{j, \mathrm{~T}}^{u} \rho_{j, 0}^{i} \Delta s_{j}^{i}}_{\text {structural change }}+\underbrace{\sum_{j} r_{j, \mathrm{~T}}^{u} s_{j, 0}^{i} \Delta \rho_{j}^{i}}_{\text {static }}+\underbrace{\sum_{j} r_{j, \mathrm{~T}}^{u} \Delta \rho_{j}^{i} \Delta s_{j}^{i}}_{\text {catch-up }}
\end{aligned}
$$

That is equivalent to the decomposition used in CHAPTER 6.

It is worth noting that this decomposition could be further extended to avoid weighting the last three components at the $r_{j}^{u}$ level of year T. Using similar logic than in the static and dynamic components of structural change, we could add an 
static and dynamic component for the changes in the sectoral relative productivity at the leading economy in the last three components. Following similar procedures than before, such decomposition would have seven terms as described in the following equation:

$$
\begin{aligned}
& \Delta \rho_{M}==\underbrace{\sum_{j} \rho_{j, 0}^{i} s_{j, 0}^{i} \Delta r_{j}^{u}}_{\begin{array}{c}
\text { initial } \\
\text { specialization }
\end{array}}+\underbrace{\sum_{j} r_{j, 0}^{u} \rho_{j, 0}^{i} \Delta s_{j}^{i}}_{\begin{array}{c}
\text { static } \\
\text { structural change }
\end{array}}+\underbrace{\sum_{j} \rho_{j, 0}^{i} \Delta s_{j}^{i} \Delta r_{j}^{u}}_{\begin{array}{c}
\text { static structural } \\
\text { change with } \\
\text { moving frontier }
\end{array}}+\underbrace{\sum_{j} r_{j, 0}^{u} s_{j, 0}^{i} \Delta \rho_{j}^{i}}_{\begin{array}{c}
\text { within sector } \\
\text { catch-up }
\end{array}} \\
& +\underbrace{\sum_{j} s_{j, 0}^{i} \Delta \rho_{j}^{i} \Delta r_{j}^{u}}_{\begin{array}{c}
\text { within sector } \\
\text { catch-up with } \\
\text { moving frontier }
\end{array}}+\underbrace{\sum_{j} r_{j, \mathrm{~T}}^{u} \Delta \rho_{j}^{i} \Delta s_{j}^{i}}_{\begin{array}{c}
\text { dynamic } \\
\text { structural change }
\end{array}}+\underbrace{\sum_{j} \Delta \rho_{j}^{i} \Delta s_{j}^{i} \Delta r_{j}^{u}}_{\begin{array}{c}
\text { dynamic structural } \\
\text { change with } \\
\text { moving frontier }
\end{array}}
\end{aligned}
$$

Now, all terms are evaluated at the initial year and three more terms are included showing the dynamic effect of changes in the sectoral relative productivity at the leading economy.

Since the formulation with only four terms is easier to interpret and compute we decided to keep this version in the main text of the thesis. In future work we aim at re-evaluating our results in the light of the extended version of the catching-up decomposition. 



\section{APPENDIX E. \\ Constructing the Dataset}


In this Appendix we detail the specific procedures and data sources used for the construction of our dataset. The description is divided by variable. Section E.1 presents the details for the per capita GNI figures, Section E.2 for the sectoral employment and value added figures, Section E.3 for the unemployment rates and Section E.5 for the remaining variables used as regressors in CHAPTER 5. The final section of this appendix presents detailed tables summarizing the specific data sources used (by year) for the construction of these variables in each country of our sample.

\section{E.1. Per capita GNI}

Our figures of per capita GNI by country at 2005 PPP dollars are mainly taken from World Bank's World Development Indicators Database (WDI) ${ }^{150}$. In order to expand the coverage of this variable along time and across countries, four additional sources have been used (in this order, depending on availability):

1) The Conference Board Total Economy Database (TED) ${ }^{151}$

2) Penn World Table 8.0 (PW'T) $)^{152}$

3) Maddison Project Database (MPD) $)^{153}$

4) IMF, World Economic Outlook Database (WEOD) 154

In all cases, the figures of per capita GNI from the WDI have been extrapolated using the growth rates of per capita GDP at constant prices published in the other sources. In Table E. 2 we provide the details of the specific source used by country and years.

\section{E.2. Sectoral Employment and Value Added}

As it was briefly detailed in CHAPTER 4 Section 4.2.3, our figures for sectoral employment and value added have been built using a wide array of sources. These sources have been first ordered according to their data quality, sectoral disaggregation and international comparability, and whenever possible, the best available sources have been given priority in the construction of the individual countries series. In what follows we describe the procedure used in different groups of countries according to the availability of data in the various sources detailed in Section 4.2.3.

For all countries covered by the WIOD ${ }^{155}$ we built benchmark values at 2005 LCU for the year 2005 disaggregated at 35 industries. The figures at 35-industries

\footnotetext{
150 Available at: databank.worldbank.org

${ }^{151}$ Version January 2014. Available at http://www.conference-board.org/data/economydatabase/

152 Available at: www.ggdc.net/pwt. See Feenstra et al. (2013) for the details.

153 Available at: www.ggdc.net/maddison. See Bolt and van Zanden (2013) for the details.

154 Version April 2014. Available at http://www.imf.org/external/data.htm
} 
were then converted into 2005 PPP dollars using the sector-specific convertors published in Inklaar and Timmer (2012) ${ }^{156}$, and extrapolated to the whole period covered by the WIOD (1995-2009).

Wherever data at 35 industries was available for a longer period in the various KLEMS datasets (ASIA-KLEMS, EU-KLEMS or WORLD KLEMS), these estimates have been back cast using these data sources. Following this procedure, we were able to extend the figures of the WIOD disaggregated at 35 industries up to 1970 for 24 countries. For some countries not covered by KLEMS databases we also managed to extend this figures at 35 industries using other sources ${ }^{157}$. In the particular case of the United States, all information for the period 1950-2009 has been extrapolated at 35 industries using the dataset put forth by Jorgenson et al. (2012).

The data for most of these countries have been further extended to the beginning of the 1950s using the GGDC 10-Sector Database. In these cases, the figures were first reordered to match the 10 sectors defined in Table 4.1 and then back cast at this lower disaggregation ${ }^{158}$.

There are two countries for which Inklaar and Timmer (2012) presents sectoral PPPs at 35 industries, even though they are not included in the WIOD: Argentina and Chile. For these countries we built comparable figures on employment and value added at 35 industries using data coming from the National Statistics Institutes (NSI). In the case of Argentina, data of Value Added by sector at 3 digits of the ISIC was provided by the NSI for the period 1993-2007 (both at current and constant prices). This data was reordered to match the 35 industries of the WIOD and converted into 2005 PPP dollars. The numbers for employment at sectoral level (disaggregated at 10 sectors) were also taken from the NSI and also cover the period 1993-2007159. In the case of Chile, data on Value Added at sectoral level was

\footnotetext{
155 This dataset covers 40 countries: the 27 EU countries plus Australia, Canada, Japan, South Korea, Taiwan, the United States and other 7 emerging economies (Brazil, China, India, Indonesia, Mexico, Russia and Turkey). All of them with the only exception of Malta are included in our dataset (Malta is excluded because it had a population of less than a million people in 2010).

156 The authors present two sets of sector-specific PPPs. The first one is disaggregated at 35 industries and covers 42 countries. The second one is disaggregated at 10 sectors but includes a much wider set of countries. In particular, it covers all countries included in the PWT8 (147 countries).

157 These are the cases of Brazil, China and India using the dataset of de Vries et al. (2012).

${ }^{158}$ China and Turkey were extended using two additional sources. In China the APO Database was used to extend the sectoral figures of 1987 (starting year of de Vries et al., 2012) up to 1978. In the case of Turkey the data collected in McMillan and Rodrik (2011) was used to extend the sectoral figures of 1995 up to 1988.

159 Available at www.indec.mecon.ar, theme Cuentas Nacionales: Cuentas Generación del Ingreso e Insumo de Mano de Obra. See DNCN (2006) for the details.
} 
collected from BCC (2011) ${ }^{160}$ which provides information on National Accounts for the period 2003-2010. The level of disaggregation in this dataset, however, did not match the 35-industries of Inklaar and Timmer (2012), and therefore it was further opened using secondary data sources ${ }^{161}$. The figures for employment at 10 sectors for the same period were obtained from BCC $(2012)^{162}$. The estimates of sectoral value added and employment in both countries were then regrouped into 10 sectors and back cast to 1950 using the data set provided in Timmer et al. (2014).

For the abovementioned countries (41 in total) our estimates have been carried out at 35-industries and then converted into 10 industries in order to cover a larger span on time. A subset of these countries has been used for the analysis of CHAPTER 6.

The remaining countries of our sample (59 countries) have been calculated directly at 10 sectors. That means that the benchmark levels for 2005 were calculated for the 10 sectors of Table 4.1 at LCU, then converted into international PPP dollars using the sectoral convertors (at the corresponding disaggregation) and then extrapolated as far as possible using the best available sources. In what follow we detail the sources used for each group of countries (this information is summarized in Table E. 3).

In four countries (Israel, New Zealand, Norway and Switzerland) the data was taken from OECD-STAN Database. This source presents information on employment and value added (at current and constant prices) at a level of disaggregation that can be easily converted into our 10 sectors. The time coverage, however, is not homogeneous and ranges from 40 years in Norway to only eight in Israel.

Two additional sources that provide comparable data at sectoral level have been used extensively: the GGDC 10-Sector Database and the Asian Productivity Organization (APO) Database. Both sources present international comparable data on employment and value added disaggregated, at least, in the 10 broad sectors used here, for a very long span of time (starting on the 1950s, 1960s or 1970s depending

\footnotetext{
160 Available at http://www.bcentral.cl/publicaciones/estadisticas/actividad-economicagasto/aeg01g.htm
}

161 Three sectoral aggregates within manufacturing needed to be opened further: Textiles (ISIC codes 17 to 19), Chemistry (ISIC codes 23 to 25) and Machinery and Metal Products (ISIC codes 28 to 37). For the figures at 2005 prices, sub-sector specific shares were calculated using average values from the national input outputs tables 2003 and 2008 (unfortunately there was not such information for 2005). For the constant figures, instead, the sub-sectoral shares of 2005 were extrapolated using ECLAC-PADI database.

162 Available at http://www.bcentral.cl/publicaciones/estadisticas/informacion-integrada/iei14.htm 
on the country ${ }^{163}$. The series for 30 countries have been constructed using exclusively these three sources (see Table E. 3).

The last 24 countries have been calculated using UNSTATS data for sectoral value added and ILO-KILM8 data for employment complemented with specific data from EUROSTATS and the UN regional economic commissions (ECLAC, ECA and ESCWA). In these cases, however, the time spam covered is significantly reduced due to lack of information, especially on employment by sector before the 1990s. Data for sectoral value added at constant 2005 LCU have been calculated using UNSD, National Accounts Main Aggregates Database. This database provides information on sectoral value added at 2005 LCU for more than 200 countries between 1970 and 2012. The sectoral disaggregation, however, only distinguishes 7 sectors $^{164}$. Thus, these sectoral aggregates have been further opened using sub-sectoral shares at 2005 prices specifically calculated using the data published by UNSD National Accounts Official Country Data (Tables 2.1 and 2.2). Given the shorter coverage (in time and across countries) of the latter, the number of countries and the period for which we could gather the necessary information has been significantly reduced. The main limitation for these countries, however, has been in terms of employment data disaggregated by sector. Our approach here was to use the best available information at major sectors (typically published by regional organization that provides data for international comparisons at sub-regional levels) and open them using the data encompassed in ILO-KILM8 Database. The following table summarizes the main sources used in this regard, the countries included and the sectoral disaggregation:

\footnotetext{
163 The series of sectoral value added of the APO Database have been complemented with information from the United Nation Statistical Division (UNSD) in order to deduct sub-sector 70 (Real Estates) from sector K (Real Estates and Business Services). To do so, the sectoral share of sub-sector 70 in sector $\mathrm{K}$ at constant LCU of 2005 have been calculated using Tables 2.1 and 2.2 of UNSD National Accounts Official Country Data (available at data.un.org).

164 These sectors are: Agriculture, hunting, forestry, fishing (ISIC AtB), Mining, Manufacturing, Utilities (ISIC CtE), Manufacturing (ISIC D), Construction (ISIC F), Wholesale, retail trade, restaurants and hotels (ISIC GtH), Transport, storage and communication (ISIC I) and Other Activities (ISIC $\mathrm{JtP})$.
} 
Table E. 1. Additional sources for sectoral employment

\begin{tabular}{|c|c|c|c|}
\hline Source & Countries & Period & Disaggregation \\
\hline $\mathrm{ADB}(1)$ & $\begin{array}{l}\text { Azerbaijan, Georgia, Ka- } \\
\text { zakhstan, Kyrgyz Republic }\end{array}$ & 2000-2009 & $\begin{array}{l}4 \text { major sectors (Agriculture, Min- } \\
\text { ing, Industry -exc. Mining- and } \\
\text { Services) }\end{array}$ \\
\hline $\begin{array}{l}\text { EUROSTATS: } \\
\text { CPC and ENP (2) }\end{array}$ & $\begin{array}{l}\text { Croatia, Moldova, Mace- } \\
\text { donia, Serbia, Ukraine }\end{array}$ & 2000-2009 & $\begin{array}{l}4 \text { major sectors (Agriculture, In- } \\
\text { dustry -exc. Construction-, Con- } \\
\text { struction and Services) }\end{array}$ \\
\hline UN-ECA (3) & $\begin{array}{l}\text { Burkina Faso, Cameroon, } \\
\text { Lesotho, Madagascar, Mali, } \\
\text { Mozambique, Namibia, } \\
\text { Niger, Rwanda, Sierra } \\
\text { Leone, Togo, Uganda } \\
\end{array}$ & 1990-2004 & $\begin{array}{l}3 \text { major sectors (Agriculture, In- } \\
\text { dustry and Services) }\end{array}$ \\
\hline UN-ECLAC (4) & Ecuador and Uruguay & $1990-2010$ & 9 sectors \\
\hline UN-ESCWA (5) & Jordan and Yemen & $2005-2010$ & $\begin{array}{l}4 \text { major sectors (Agriculture, In- } \\
\text { dustry - exc. Construction-, Con- } \\
\text { struction and Services) }\end{array}$ \\
\hline
\end{tabular}

Notes: 1) ADB, Key Indicators for Asia and the Pacific, various issues; 2) EUROSTAT online, Non-EU Countries, Candidate countries and potential candidates (CPC) and Eastern European Neighbourhood Policy countries (ENP); 3) Refers to UNECA (2005); 4) ECLAC STATS online; 5) ESCWA, Statistical Abstract of the West Africa Region, various issues.

Employment figures by major sectors were then decomposed further using specific employment shares of the constitutive sub-sectors calculated from the ILO-KILM8 Database. In some cases (EUROSTAT for CPC and ENP countries and UN-ECA) the original source did not provide any estimate for the total number of workers and, therefore, total employment was taken from Penn World Tables 8, and then opened by sector using the corresponding shares.

In Table E. 3 we provide the details of the specific source used by country and years to construct our figures of sectoral employment and value added.

\section{E.3. Unemployment}

The figures of unemployment have been estimated separately for three board groups of countries: 1) OECD countries (excluding Chile and Mexico); 2) Latin American countries; and 3) Non-OECD Asian and African countries. 
In the first set of countries (OECD) all data has been collected from OECD.stats, which provides estimates of unemployment rates for all OECD countries starting in the year $1955^{165}$.

For the Latin American countries our main data source has been Ball et al. (2012). These authors provide very long series of (relatively) comparable unemployment rates, covering (depending of the country) the period 1960-2013. In order to expand the time span covered across countries by these series, additional sources have been used. Table E. 4 specifies these sources and the years for which they provide information. Our final figures result from the extrapolation of the unemployment rates estimated in Ball et al. (2012) using these additional sources. In those cases in which there were no data for a linking year between sources, the values of unemployment rates as published in the original sources have been used (unless they were extremely different from the first year with available information in Ball et al., 2012).

In the remaining countries the main data source was ILO KILM8 Dataset. This source provides estimates built by the organization (that are harmonized in order to be internationally comparable) for the period 1991-2010 for all countries in our sample. It also provides information (not harmonized) for a longer period of time, typically starting in the 1980 s, coming from the national statistical offices. On the other hand, ILO LABORSTA Database also contains data coming from national household surveys and population census starting in the early 1960s. Using these sources and a series of historical paper that have specifically dealt with this issue we have calculated growth figures for the unemployment rates and back cast the ILO estimates to cover as many years as possible. In Table E. 5 we specify the sources used in each country and period.

As we have previously mentioned, however, in many of these countries the constructed series of unemployment rates cover a shorter period than our estimates for sectoral employment and value added. In those cases, the unemployed population has been back cast using the growth rates of total employment, under the implicit assumption that the unemployment rates have not changed significantly during these years.

\section{E.4. Other Variables}

In this section we detail the definition and procedures used to calculate the variables that have been used as regressors in the various models estimated in CHAPTER 5.

165 Available at stats.oecd.org, Annual Labour Force Statistics (ALFS). 


\section{E.4.1. Climate zones (CLIMATE)}

This is a dummy variable that takes the value 1 if half or more of the country's area is in temperate zones. It has been calculated using the dataset constructed in Gallup et al. (1999). Temperate zones include temperate deserts, dry temperate areas and wet temperate areas.

\section{E.4.2. Natural resources abundance (RICHNR)}

This is a dummy variable that takes the value 1 if a country is natural resource abundant. It has been calculated using the dataset constructed in World Bank (2010) to measure the wealth of nations. A country is considered natural resource rich if, according to this source, it had an estimated per capita natural capital of at least 7.600 USD in 2005. The cut-off level corresponds to the average value of per capita natural capital across the 152 countries covered by the World Bank's study.

\section{E.4.3. Population (POP)}

The data on population has been taken from World Bank's WDI Database. For the case of Taiwan (country not included in WDI Database) the information was taken from Penn World Tables, version 8.0.

\section{E.4.4. Undervaluation index (UNDERV)}

This index has been calculated following the procedures proposed by Rodrik (2008). In short, this approach has three steps. First, the real exchange rate of each country is calculated as:

$$
\ln R E R_{i, t}=\ln \left(\frac{e_{i, t}}{P P P_{i, t}}\right)
$$

where, $e$ stands for the nominal exchange rate, PPP for the purchasing power parity conversion factor of the GDP, the subscript $i$ indicates the country and $t$ the year.

Next, to account for the Balassa-Samuelson effect, the following regression is run, using fix effects:

$$
\ln R E R_{i, t}=\alpha+\beta y_{i, t}+f_{i}+u_{i, t}
$$

where, $y_{i, t}$ stands for the real GDP per capita of country $i$ in year $t$. The estimated coefficient of $\beta$ provides the appreciation of real exchange rates steaming from the rise of incomes.

Finally, the index of undervaluation is calculated as the difference between the actual real exchange rate and the Balassa-Samuelson adjusted rate:

$$
U N D E R V_{i, t}=\ln R E R_{i, t}-\ln \widehat{R E R}_{i, t}
$$

where $\ln \widehat{R E R}_{i, t}$ is the real exchange rate predicted using equation (E.2). 
To calculate this index, three variables are needed: the nominal exchange rate, the PPP convertor and the real GDP per capita. All variables have been taken from Penn World Tables, version 8.0.

\section{E.4.5. Years of education (EDU)}

This variable refers to the average years of total schooling in the population of fifteen or more years. For most countries, the information has been taken from Barro and Lee (2013). Three additional sources have been used to fill some gaps in Barro and Lee's dataset: Cohen and Soto (2007; Lutz (2007; Nehru et al. (1995)

\section{E.4.6. Investment rate (INV)}

This variable refers to the share of gross capital formation (at current PPP dollars) in total GDP. It has been taken from Penn World Tables, Version 8.0.

\section{E.4.7. Openness (OPEN)}

This variable refers to the degree of openness of the economy and has been calculated as the ratio between total merchandise exports and imports (in current dollars) divided by GDP. For most countries, the data has been taken from UNCTAD online database. This information has been complemented with data from WTO online database to fill some gaps (Indonesia between 1950 and 2002; and Panama between 1950 and 1980). 


\section{E.5. Sources Used and Period Covered}

Table E. 2. Sources used and period covered by country: Per capita GNI

\begin{tabular}{|c|c|c|c|c|c|c|c|c|}
\hline id & Country & Coverage & WDI & \multicolumn{2}{|c|}{ TED } & PWT8 & MPD & WEOD \\
\hline ARG & Argentina & $(1950-2013)$ & $(1960-2006)$ & $(1950-1959)$ & $(2007-2013)$ & & & \\
\hline AUS & Australia & (1950-2013) & $(1960-2012)$ & $(1950-1959)$ & (2013-2013) & & & \\
\hline AUT & Austria & (1950-2013) & (1960-2012) & $(1950-1959)$ & (2013-2013) & & & \\
\hline AZE & Azerbaijan & (1980-2013) & (1994-2012) & (1980-1993) & (2013-2013) & & & \\
\hline BEL & Belgium & $(1950-2013)$ & $(1960-2012)$ & $(1950-1959)$ & (2013-2013) & & & \\
\hline BFA & Burkina Faso & (1950-2013) & (1965-2011) & (1950-1964) & (2012-2013) & & & \\
\hline BGD & Bangladesh & (1950-2013) & $(1973-2012)$ & $(1950-1972)$ & (2013-2013) & & & \\
\hline BGR & Bulgaria & $(1950-2013)$ & $(1980-2012)$ & $(1950-1979)$ & (2013-2013) & & & \\
\hline BOL & Bolivia & $(1950-2013)$ & $(1970-2012)$ & $(1950-1969)$ & (2013-2013) & & & \\
\hline BRA & Brazil & $(1950-2013)$ & $(1960-2012)$ & $(1950-1959)$ & (2013-2013) & & & \\
\hline BWA & Botswana & (1950-2013) & $(1975-2012)$ & & & $(1960-1974)$ & $(1950-1959)$ & (2013-2013) \\
\hline CAN & Canada & (1950-2013) & $(1960-2012)$ & $(1950-1959)$ & (2013-2013) & & & \\
\hline $\mathrm{CHE}$ & Switzerland & $(1950-2013)$ & $(1980-2012)$ & $(1950-1979)$ & (2013-2013) & & & \\
\hline CHL & Chile & (1950-2013) & $(1960-2012)$ & $(1950-1959)$ & (2013-2013) & & & \\
\hline $\mathrm{CHN}$ & China & (1950-2013) & $(1978-2012)$ & $(1950-1977)$ & (2013-2013) & & & \\
\hline CMR & Cameroon & (1950-2013) & $(1967-2012)$ & (1950-1966) & (2013-2013) & & & \\
\hline COL & Colombia & (1950-2013) & $(1960-2012)$ & $(1950-1959)$ & (2013-2013) & & & \\
\hline CRI & Costa Rica & $(1950-2013)$ & $(1960-2012)$ & $(1950-1959)$ & (2013-2013) & & & \\
\hline CYP & Cyprus & (1950-2013) & (1975-2010) & $(1950-1974)$ & (2011-2013) & & & \\
\hline CZE & Czech Republic & (1985-2013) & (1992-2012) & (1985-1991) & (2013-2013) & & & \\
\hline DEU & Germany & $(1950-2013)$ & $(1970-2012)$ & $(1950-1969)$ & (2013-2013) & & & \\
\hline DNK & Denmark & (1950-2013) & $(1970-2012)$ & $(1950-1969)$ & (2013-2013) & & & \\
\hline ECU & Ecuador & (1950-2013) & $(1960-2012)$ & $(1950-1959)$ & (2013-2013) & & & \\
\hline EGY & Egypt & (1950-2013) & $(1965-2012)$ & $(1950-1964)$ & (2013-2013) & & & \\
\hline ESP & Spain & (1950-2013) & $(1960-2012)$ & $(1950-1959)$ & (2013-2013) & & & \\
\hline EST & Estonia & (1980-2013) & (1995-2012) & (1980-1994) & (2013-2013) & & & \\
\hline ETH & Ethiopia & (1950-2013) & $(1981-2012)$ & $(1950-1980)$ & (2013-2013) & & & \\
\hline FIN & Finland & (1950-2013) & $(1960-2012)$ & $(1950-1959)$ & (2013-2013) & & & \\
\hline FRA & France & (1950-2013) & $(1960-2012)$ & $(1950-1959)$ & (2013-2013) & & & \\
\hline GBR & United Kingdom & (1950-2013) & $(1970-2012)$ & $(1950-1969)$ & (2013-2013) & & & \\
\hline GEO & Georgia & (1980-2013) & $(2005-2005)$ & (1980-2004) & (2006-2013) & & & \\
\hline GHA & Ghana & $(1950-2013)$ & (2005-2005) & $(1950-2004)$ & (2006-2013) & & & \\
\hline GRC & Greece & (1950-2013) & $(1960-2012)$ & $(1950-1959)$ & (2013-2013) & & & \\
\hline HKG & Hong Kong & (1950-2013) & (1999-2012) & (1950-1998) & (2013-2013) & & & \\
\hline HRV & Croatia & (1952-2013) & $(1995-2012)$ & (1980-1994) & (2013-2013) & & $(1952-1979)$ & \\
\hline HUN & Hungary & $(1950-2013)$ & $(1960-2010)$ & $(1951-1959)$ & (2011-2013) & & $(1950-1950)$ & \\
\hline IDN & Indonesia & $(1950-2013)$ & $(1960-2012)$ & $(1950-1959)$ & (2013-2013) & & & \\
\hline IND & India & (1950-2013) & $(1960-2012)$ & $(1950-1959)$ & (2013-2013) & & & \\
\hline IRL & Ireland & $(1950-2013)$ & $(2000-2012)$ & $(1950-1999)$ & (2013-2013) & & & \\
\hline IRN & Iran & (1950-2013) & $(1965-2007)$ & $(1950-1964)$ & (2008-2013) & & & \\
\hline ISR & Israel & (1950-2013) & $(1995-2011)$ & (1950-1994) & (2012-2013) & & & \\
\hline ITA & Italy & $(1950-2013)$ & $(1960-2012)$ & $(1950-1959)$ & (2013-2013) & & & \\
\hline JOR & Jordan & (1950-2013) & $(1976-2012)$ & $(1950-1975)$ & (2013-2013) & & & \\
\hline JPN & Japan & (1950-2013) & $(1960-2012)$ & $(1950-1959)$ & (2013-2013) & & & \\
\hline KAZ & Kazakhstan & $(1980-2013)$ & (1993-2012) & $(1980-1992)$ & (2013-2013) & & & \\
\hline KEN & Kenya & (1950-2013) & $(1960-2012)$ & $(1950-1959)$ & (2013-2013) & & & \\
\hline KGZ & Kyrgyz Republic & (1980-2013) & (1992-2012) & (1980-1991) & (2013-2013) & & & \\
\hline KHM & Cambodia & (1950-2013) & (1995-2011) & (1950-1994) & (2012-2013) & & & \\
\hline KOR & Korea & (1950-2013) & $(1960-2012)$ & $(1950-1959)$ & (2013-2013) & & & \\
\hline LKA & Sri Lanka & (1950-2013) & $(1980-2012)$ & $(1950-1979)$ & (2013-2013) & & & \\
\hline
\end{tabular}


Table E. 2. Sources used and period covered by country: Per capita GNI (cont.)

\begin{tabular}{|c|c|c|c|c|c|c|c|c|}
\hline id & Country & Coverage & WDI & \multicolumn{2}{|c|}{ TED } & PWT8 & MPD & WEOD \\
\hline$\overline{\mathrm{LSO}}$ & Lesotho & $(1950-2013)$ & (1966-2012) & & & $(1960-1965)$ & $(1950-1959)$ & (2013-2013) \\
\hline LTU & Lithuania & (1980-2013) & (2005-2005) & (1980-2004) & (2006-2013) & & & \\
\hline LVA & Latvia & (1980-2013) & (1991-2010) & $(1980-1990)$ & (2011-2013) & & & \\
\hline MAR & Morocco & $(1950-2013)$ & $(1965-2012)$ & (1950-1964) & (2013-2013) & & & \\
\hline $\mathrm{MDA}$ & Moldova & $(1980-2013)$ & (1992-2012) & (1980-1991) & (2013-2013) & & & \\
\hline MDG & Madagascar & $(1950-2013)$ & $(1960-2009)$ & $(1950-1959)$ & (2010-2013) & & & \\
\hline MEX & Mexico & (1950-2013) & $(1960-2012)$ & (1950-1959) & (2013-2013) & & & \\
\hline MKD & Macedonia & $(1952-2013)$ & (1990-2012) & (1980-1989) & (2013-2013) & & $(1952-1979)$ & \\
\hline MLI & Mali & $(1950-2013)$ & (1980-2007) & $(1950-1979)$ & (2008-2013) & & & \\
\hline MNG & Mongolia & $(1950-2013)$ & (2005-2012) & & & (1970-2004) & $(1950-1969)$ & (2013-2013) \\
\hline MOZ & Mozambique & $(1950-2013)$ & (1980-2012) & $(1950-1979)$ & (2013-2013) & & & \\
\hline MUS & Mauritius & (1950-2013) & $(1976-2012)$ & & & $(1960-1975)$ & $(1950-1959)$ & (2013-2013) \\
\hline MWI & Malawi & $(1950-2013)$ & $(2003-2011)$ & $(1950-2002)$ & (2012-2013) & & & \\
\hline MYS & Malaysia & $(1950-2013)$ & $(1960-2012)$ & $(1950-1959)$ & (2013-2013) & & & \\
\hline NAM & Namibia & $(1950-2013)$ & (1980-2012) & & & $(1960-1979)$ & $(1950-1959)$ & (2013-2013) \\
\hline NER & Niger & $(1950-2013)$ & (2005-2005) & (1950-2004) & (2006-2013) & & & \\
\hline $\mathrm{NGA}$ & Nigeria & $(1950-2013)$ & (1981-2012) & $(1950-1980)$ & (2013-2013) & & & \\
\hline NLD & Netherlands & (1950-2013) & (1960-2012) & (1950-1959) & (2013-2013) & & & \\
\hline NOR & Norway & $(1950-2013)$ & (1960-2012) & $(1950-1959)$ & (2013-2013) & & & \\
\hline NPL & Nepal & (1950-2013) & (2001-2012) & & & $(1960-2000)$ & $(1950-1959)$ & (2013-2013) \\
\hline NZL & New Zealand & $(1950-2013)$ & $(1977-2011)$ & (1950-1976) & (2012-2013) & & & \\
\hline PAK & Pakistan & $(1950-2013)$ & $(1967-2012)$ & $(1950-1966)$ & (2013-2013) & & & \\
\hline PER & Peru & $(1950-2013)$ & $(1960-2012)$ & $(1950-1959)$ & (2013-2013) & & & \\
\hline PHL & Philippines & $(1950-2013)$ & (1960-2012) & $(1950-1959)$ & (2013-2013) & & & \\
\hline POL & Poland & $(1950-2013)$ & (1991-2012) & $(1950-1990)$ & (2013-2013) & & & \\
\hline PRT & Portugal & $(1950-2013)$ & $(1960-2012)$ & $(1950-1959)$ & (2013-2013) & & & \\
\hline ROM & Romania & $(1950-2013)$ & (1990-2012) & (1950-1989) & (2013-2013) & & & \\
\hline RUS & Russia & $(1980-2013)$ & (1990-2012) & $(1980-1989)$ & (2013-2013) & & & \\
\hline RWA & Rwanda & $(1950-2013)$ & (1970-2012) & & & $(1960-1969)$ & $(1950-1959)$ & (2013-2013) \\
\hline SEN & Senegal & (1950-2013) & $(1968-2012)$ & (1950-1967) & (2013-2013) & & & \\
\hline SGP & Singapore & $(1950-2013)$ & (1975-2012) & $(1950-1974)$ & (2013-2013) & & & \\
\hline SLE & Sierra Leone & $(1950-2013)$ & $(1967-2011)$ & & & (1961-1966) & $(1950-1960)$ & (2012-2013) \\
\hline SRB & Serbia & (1952-2013) & (1999-2011) & & & (1990-1998) & $(1952-1989)$ & (2012-2013) \\
\hline SVK & Slovak Republic & $(1985-2013)$ & $(1992-2010)$ & (1985-1991) & (2011-2013) & & & \\
\hline SVN & Slovenia & $(1952-2013)$ & $(1992-2010)$ & (1980-1991) & (2011-2013) & & $(1952-1979)$ & \\
\hline SWE & Sweden & $(1950-2013)$ & $(1960-2012)$ & $(1950-1959)$ & (2013-2013) & & & \\
\hline TGO & Togo & $(1950-2013)$ & $(1960-2011)$ & & & & $(1950-1959)$ & (2012-2013) \\
\hline THA & Thailand & $(1950-2013)$ & (1965-2012) & (1950-1964) & (2013-2013) & & & \\
\hline TUR & Turkey & $(1950-2013)$ & (1987-2012) & $(1950-1986)$ & (2013-2013) & & & \\
\hline TWN & Taiwan & $(1950-2013)$ & & $(1950-1959)$ & (2012-2013) & $(1960-2011)$ & & \\
\hline TZA & Tanzania & $(1950-2013)$ & (1990-2012) & $(1950-1989)$ & (2013-2013) & & & \\
\hline UGA & Uganda & (1950-2013) & (1982-2011) & (1950-1981) & (2012-2013) & & & \\
\hline UKR & Ukraine & (1980-2013) & (1990-2012) & (1980-1989) & (2013-2013) & & & \\
\hline URY & Uruguay & $(1950-2013)$ & (1960-2012) & $(1950-1959)$ & (2013-2013) & & & \\
\hline USA & United States & (1950-2013) & $(1970-2012)$ & (1950-1969) & (2013-2013) & & & \\
\hline VEN & Venezuela & $(1950-2013)$ & $(1974-2012)$ & (1950-1973) & (2013-2013) & & & \\
\hline VNM & Vietnam & $(1950-2013)$ & (1989-2012) & (1950-1988) & (2013-2013) & & & \\
\hline YEM & Yemen & $(1950-2013)$ & $(1990-2010)$ & (1950-1989) & (2011-2013) & & & \\
\hline $\mathrm{ZAF}$ & South Africa & $(1950-2013)$ & $(1960-2012)$ & $(1950-1959)$ & (2013-2013) & & & \\
\hline $\mathrm{ZMB}$ & Zambia & $(1950-2013)$ & $(1960-2011)$ & $(1950-1959)$ & (2012-2013) & & & \\
\hline
\end{tabular}

Note: Source refers to: WDI $=$ World Development Indicators Database, World Bank; TED = The Conference Board, Total Economy Database; PWT8 = Groningen University, Penn World Tables, version 8.0; MPD = Groningen University, Maddison Project Database; WEOD = International Monetary Fund, World Economic Outlook Database. 
Table E. 3. Sources used and period covered by country: Sectoral Employment and Value Added

\begin{tabular}{|c|c|c|c|c|c|c|c|c|}
\hline id & Country & Coverage & WIOD & KLEMS & GGDC10s & APO & OTHERS & \\
\hline ARG & Argentina & $(1950-2009)$ & & & $(1950-1992)$ & & (1993-2009) & (5) \\
\hline AUS & Australia & $(1970-2009)$ & (1995-2009) & $(1970-1994)$ & & & & \\
\hline AUT & Austria & $(1970-2009)$ & $(1995-2009)$ & (1970-1994) & & & & \\
\hline AZE & Azerbaijan & $(2001-2009)$ & & & & & (2001-2009) & (1) \\
\hline BEL & Belgium & $(1970-2009)$ & (1995-2009) & (1970-1994) & & & & \\
\hline BFA & Burkina Faso & $(2002-2005)$ & & & & & $(2002-2005)$ & (6) \\
\hline BGD & Bangladesh & (1973-2007) & & & & (1973-2007) & & \\
\hline BGR & Bulgaria & $(1995-2009)$ & (1995-2009) & & & & & \\
\hline $\mathrm{BOL}$ & Bolivia & $(1950-2009)$ & & & $(1950-2009)$ & & & \\
\hline BRA & Brazil & $(1950-2009)$ & $(1995-2009)$ & & $(1950-1980)$ & & (1980-1994) & (2) \\
\hline BWA & Botswana & $(1964-2009)$ & & & $(1964-2009)$ & & & \\
\hline CAN & Canada & (1961-2009) & $(1995-2009)$ & & (1961-1994) & & & \\
\hline CHE & Switzerland & (1991-2008) & & & & & (1991-2008) & (9) \\
\hline CHL & Chile & $(1950-2009)$ & & & $(1950-2002)$ & & $(2003-2009)$ & (5) \\
\hline $\mathrm{CHN}$ & China & $(1950-2009)$ & $(1995-2009)$ & & (1950-1986) & & (1987-1994) & (2) \\
\hline CMR & Cameroon & (1996-2005) & & & & & (1996-2005) & (6) \\
\hline $\mathrm{COL}$ & Colombia & $(1950-2009)$ & & & $(1950-2009)$ & & & \\
\hline CRI & Costa Rica & $(1950-2009)$ & & & $(1950-2009)$ & & & \\
\hline CYP & Cyprus & $(1995-2009)$ & (1995-2009) & & & & & \\
\hline CZE & Czech Republic & $(1995-2009)$ & $(1995-2009)$ & & & & & \\
\hline DEU & Germany & $(1970-2009)$ & (1995-2009) & (1970-1994) & & & & \\
\hline DNK & Denmark. & $(1950-2009)$ & (1995-2009) & $(1970-1994)$ & $(1950-1970)$ & & & \\
\hline ECU & Ecuador & $(1990-2009)$ & & & & & $(1990-2009)$ & (7) \\
\hline EGY & Egypt & $(1960-2009)$ & & & $(1960-2009)$ & & & \\
\hline ESP & Spain & $(1950-2009)$ & $(1995-2009)$ & $(1970-1994)$ & $(1950-1970)$ & & & \\
\hline $\mathrm{EST}$ & Estonia & $(1995-2009)$ & $(1995-2009)$ & & & & & \\
\hline ETH & Ethiopia & $(1961-2009)$ & & & $(1961-2009)$ & & & \\
\hline FIN & Finland & $(1970-2009)$ & $(1995-2009)$ & $(1970-1994)$ & & & & \\
\hline FRA & France & $(1950-2009)$ & $(1995-2009)$ & (1970-1994) & $(1950-1970)$ & & & \\
\hline GBR & United Kingdom & $(1950-2009)$ & (1995-2009) & (1970-1994) & $(1950-1970)$ & & & \\
\hline GEO & Georgia & $(1998-2007)$ & & & & & $(1998-2007)$ & (1) \\
\hline GHA & Ghana & $(1960-2009)$ & & & $(1960-2009)$ & & & \\
\hline GRC & Greece & $(1970-2009)$ & $(1995-2009)$ & (1970-1994) & & & & \\
\hline HKG & Hong Kong & (1974-2005) & & & (1974-2005) & & & \\
\hline HRV & Croatia & $(1996-2007)$ & & & & & $(1996-2007)$ & (3) \\
\hline HUN & Hungary & $(1992-2009)$ & $(1995-2009)$ & (1992-1994) & & & & \\
\hline IDN & Indonesia & $(1971-2009)$ & $(1995-2009)$ & & $(1971-1994)$ & & & \\
\hline IND & India & $(1960-2009)$ & $(1995-2009)$ & & $(1960-1980)$ & & (1980-1994) & (2) \\
\hline IRL & Ireland & $(1970-2009)$ & $(1995-2009)$ & (1970-1994) & & & & \\
\hline IRN & Iran & (1973-2007) & & & & (1973-2007) & & \\
\hline ISR & Israel & (2000-2008) & & & & & (2000-2008) & (9) \\
\hline ITA & Italy & (1951-2009) & $(1995-2009)$ & (1970-1994) & $(1951-1970)$ & & & \\
\hline JOR & Jordan & $(2000-2009)$ & & & & & $(2000-2009)$ & (8) \\
\hline JPN & Japan & (1953-2009) & $(1995-2009)$ & (1970-1994) & $(1953-1970)$ & & & \\
\hline KAZ & Kazakbstan & $(1999-2009)$ & & & & & (1999-2009) & (1) \\
\hline KEN & Kenya & (1969-2009) & & & (1969-2009) & & & \\
\hline KGZ & Kyrgyz Republic & (2000-2008) & & & & & (2000-2008) & (1) \\
\hline KHM & Cambodia & (1993-2007) & & & & (1993-2007) & & \\
\hline KOR & Korea & $(1963-2009)$ & $(1995-2009)$ & (1970-1994) & $(1963-1970)$ & & & \\
\hline LKA & Sri Lanka & (1971-2007) & & & & (1971-2007) & & \\
\hline LSO & Lesotho & (1990-2005) & & & & & (1990-2005) & (6) \\
\hline LTU & Lithuania & $(1995-2009)$ & $(1995-2009)$ & & & & & \\
\hline LVA & Latvia & $(1995-2009)$ & $(1995-2009)$ & & & & & \\
\hline MAR & Morocco & $(1960-2009)$ & & & $(1960-2009)$ & & & \\
\hline $\mathrm{MDA}$ & Moldova & (1999-2008) & & & & & (1999-2008) & (3) \\
\hline
\end{tabular}


Table E. 3. Sources used and period covered by country: Sectoral Employment and Value Added (Cont.)

\begin{tabular}{|c|c|c|c|c|c|c|c|c|}
\hline id & Country & Coverage & WIOD & KLEMS & GGDC10s & APO & OTHERS & \\
\hline MDG & Madagascar & $(2005-2005)$ & & & & & $(2005-2005)$ & (6) \\
\hline MEX & Mexico & $(1950-2009)$ & $(1995-2009)$ & & (1950-1994) & & & \\
\hline MKD & Macedonia & $(1997-2009)$ & & & & & $(1997-2009)$ & (3) \\
\hline MLI & Mali & (2005-2005) & & & & & (2005-2005) & (6) \\
\hline MNG & Mongolia & (1970-2007) & & & & $(1970-2007)$ & & \\
\hline $\mathrm{MOZ}$ & Mozambique & (1995-2005) & & & & & (1995-2005) & (6) \\
\hline MUS & Mauritius & $(1970-2009)$ & & & $(1970-2009)$ & & & \\
\hline MWI & Malawi & $(1966-2009)$ & & & $(1966-2009)$ & & & \\
\hline MYS & Malaysia & (1975-2005) & & & $(1975-2005)$ & & & \\
\hline NAM & Namibia & (1993-2005) & & & & & (1993-2005) & (6) \\
\hline NER & Niger & (2005-2005) & & & & & (2005-2005) & (6) \\
\hline NGA & Nigeria & $(1960-2009)$ & & & $(1960-2009)$ & & & \\
\hline NLD & Netherlands & $(1950-2009)$ & $(1995-2009)$ & (1970-1994) & $(1950-1970)$ & & & \\
\hline NOR & Norway & $(1970-2009)$ & & & & & $(1970-2009)$ & (9) \\
\hline NPL & Nepal & (1984-2007) & & & & (1984-2007) & & \\
\hline NZL & New Zealand & (1989-2006) & & & & & (1989-2006) & (9) \\
\hline PAK & Pakistan & (1970-2007) & & & & $(1970-2007)$ & & \\
\hline PER & Peru & $(1960-2009)$ & & & (1960-2009) & & & \\
\hline PHL & Philippines & $(1971-2009)$ & & & $(1971-2009)$ & & & \\
\hline POL & Poland & $(1995-2009)$ & (1995-2009) & & & & & \\
\hline PRT & Portugal & $(1970-2009)$ & (1995-2009) & (1970-1994) & & & & \\
\hline $\mathrm{ROM}$ & Romania & $(1995-2009)$ & $(1995-2009)$ & & & & & \\
\hline RUS & Russia & (1995-2009) & (1995-2009) & & & & & \\
\hline RWA & Rwanda & (1990-2005) & & & & & (1990-2005) & (6) \\
\hline SEN & Senegal & $(1970-2009)$ & & & $(1970-2009)$ & & & \\
\hline SGP & Singapore & $(1970-2009)$ & & & $(1970-2009)$ & & & \\
\hline SLE & Sierra Leone & (2005-2005) & & & & & (2005-2005) & (6) \\
\hline SRB & Serbia & (2004-2009) & & & & & (2004-2009) & (3) \\
\hline SVK & Slovak Republic & $(1995-2009)$ & $(1995-2009)$ & & & & & \\
\hline SVN & Slovenia & $(1995-2009)$ & (1995-2009) & & & & & \\
\hline SWE & Sweden & (1950-2009) & (1995-2009) & (1970-1994) & $(1950-1970)$ & & & \\
\hline TGO & Togo & (2005-2006) & & & & & $(2005-2006)$ & (6) \\
\hline THA & Thailand & $(1960-2009)$ & & & $(1960-2009)$ & & & \\
\hline TUR & Turkey & $(1988-2009)$ & $(1995-2009)$ & & & & (1988-1994) & (4) \\
\hline TWN & Taiwan & $(1963-2009)$ & (1995-2009) & (1970-1994) & $(1963-1970)$ & & & \\
\hline TZA & Tanzania & $(1960-2009)$ & & & $(1960-2009)$ & & & \\
\hline UGA & Uganda & $(2000-2005)$ & & & & & (2000-2005) & (6) \\
\hline UKR & Ukraine & (2001-2009) & & & & & $(2001-2009)$ & (3) \\
\hline URY & Uruguay & $(1990-2009)$ & & & & & (1990-2009) & (7) \\
\hline USA & United States & (1950-2009) & $(1995-2009)$ & (1950-1994) & $(1950-1950)$ & & & \\
\hline VEN & Venezuela & $(1950-2009)$ & & & $(1950-2009)$ & & & \\
\hline VNM & Vietnam & (1990-2007) & & & & (1990-2004) & $(2005-2007)$ & (5) \\
\hline YEM & Yemen & $(1994-2009)$ & & & & & (1994-2009) & (8) \\
\hline $\mathrm{ZAF}$ & South Africa & $(1960-2009)$ & & & $(1960-2009)$ & & & \\
\hline $\mathrm{ZMB}$ & Zambia & $(1965-2009)$ & & & $(1965-2009)$ & & & \\
\hline
\end{tabular}

Note: Source refers to: WIOD = World Input-Output Database; KLEMS = EU, Asia and World KLEMS Databases; GGDC10s = Groningen Growth and Development Centre, 10 Sector Database; APO = Asian Productivity Organization Database; OTHERS = (1) ADB KIAP Database; (2) de Vries et al. (2012); (3) EUROSTAT; (4) McMillan and Rodrik (2011); (5) National Statistics Institute (NIS); (6) UN-ECA; (7) CEPALSTAT; (8) UN-ESCWA; (9) OECD STAN Database. In (1), (3), (6), (7) and (8) these sources have been complemented with data from UNSD and KILM8 Database. 
Table E. 4. Sources used and period covered by country (Latin American countries): Unemployment rate

\begin{tabular}{|c|c|c|c|c|c|c|c|c|}
\hline id & Country & Coverage & $\begin{array}{c}\text { Ball et al. } \\
\text { (2012) }\end{array}$ & $\begin{array}{c}\text { ECLAC } \\
(1986)\end{array}$ & $\begin{array}{c}\text { PREALC } \\
\text { (1982) }\end{array}$ & $\begin{array}{l}\text { CEPAL } \\
\text { STAT }\end{array}$ & Others & \\
\hline ARG & Argentina & $(1963-2013)$ & $(1970-2013)$ & \multirow{4}{*}{$\begin{array}{l}(1978-1980) \\
(1978-1991)\end{array}$} & $(1963-1969)$ & \multirow{3}{*}{ (1981-1988) } & \multirow[b]{2}{*}{ (1972-1975) } & \multirow[b]{2}{*}{ (2) } \\
\hline $\mathrm{BOL}$ & Bolivia & (1976-2011) & (1989-2011) & & (1976-1977) & & & \\
\hline BRA & Brazil & $(1978-2013)$ & (1982-2013) & & & & & \\
\hline CHL & Chile & $(1957-2013)$ & (1957-2013) & & & \multirow{5}{*}{$(1980-1989)$} & & \\
\hline $\mathrm{COL}$ & Colombia & (1963-2013) & $(1975-2013)$ & \multirow[b]{2}{*}{ (1970) } & $(1970-1974)$ & & $(1963-1969)$ & (1) \\
\hline CRI & Costa Rica & (1966-2013) & $(1976-2013)$ & & (1967-1969) & & (1963-1966) & (3) \\
\hline $\mathrm{ECU}$ & Ecuador & (1975-2013) & (1990-2013) & & (1975) & & & \\
\hline MEX & Mexico & (1963-2013) & (1973-2013) & (1970) & & & (1963) & (3) \\
\hline PER & Peru & (1968-2013) & $(1970-2013)$ & & (1969) & & (1968) & (1) \\
\hline URY & Uruguay & $(1967-2013)$ & (1968-2013) & & (1967) & & & \\
\hline VEN & Venezuela & $(1967-2013)$ & (1967-2013) & & & & & \\
\hline
\end{tabular}

Note: The source "Others" refers to: (1) Morawetz (1977); (2) ILO Labour Statistics Yearbook, Various Issues; (3) Turnham (1971). 
Table E. 5. Sources used and period covered by country (non-OECD, Asian and African countries): Unemployment rate

\begin{tabular}{|c|c|c|c|c|c|c|c|c|}
\hline id & Country & Coverage & $\begin{array}{l}\text { KILM8 } \\
\text { (ILO est) }\end{array}$ & $\begin{array}{c}\text { KILM8 } \\
\text { (NAC est) }\end{array}$ & $\begin{array}{c}\text { Morawetz } \\
\text { (1977) }\end{array}$ & $\begin{array}{l}\text { Turnham } \\
\text { and Eröcal } \\
(1990)\end{array}$ & Others & \\
\hline AZE & Azerbaijan & (1991-2012) & (1991-2012) & & & & & \\
\hline BFA & Burkina Faso & (1991-2012) & (1991-2012) & & & & & \\
\hline BGD & Bangladesh & $(1984-2012)$ & $(1991-2012)$ & $(1984-1990)$ & & & & \\
\hline BGR & Bulgaria & (1991-2012) & (1991-2012) & & & & & \\
\hline BWA & Botswana & (1985-2012) & (1991-2012) & $(1985-1990)$ & & & & \\
\hline $\mathrm{CHN}$ & China & (1978-2012) & (1991-2012) & $(1980-1990)$ & & & $(1978-1979)$ & (6) \\
\hline CMR & Cameroon & (1991-2012) & (1991-2012) & & & & & \\
\hline EGY & Egypt & (1991-2012) & (1991-2012) & & & & & \\
\hline ETH & Ethiopia & (1984-2012) & $(1991-2012)$ & (1984-1990) & & & & \\
\hline GEO & Georgia & (1991-2012) & $(1991-2012)$ & & & & & \\
\hline GHA & Ghana & $(1970-2012)$ & $(1991-2012)$ & & $(1970-1970)$ & & $(1987-1987)$ & \\
\hline HUN & Hungary & (1991-2012) & $(1991-2012)$ & & & & & \\
\hline IDN & Indonesia & $(1971-2012)$ & (1991-2012) & & & (1986-1986) & (1971-1971) & (2) \\
\hline IND & India & $(1959-2012)$ & (1991-2012) & & (1971-1971) & & $(1959-1961)$ & (5) \\
\hline IRN & Iran & $(1986-2012)$ & $(1991-2012)$ & $(1986-1990)$ & & & & \\
\hline JOR & Jordan & (1991-2012) & (1991-2012) & & & & & \\
\hline KAZ & Kazakhstan & (1991-2012) & (1991-2012) & & & & & \\
\hline KEN & Kenya & (1978-2012) & (1991-2012) & & & & $(1978-1978)$ & \\
\hline KGZ & Kyrgyz Republic & (1991-2012) & (1991-2012) & & & & & \\
\hline KHM & Cambodia & $(1991-2012)$ & (1991-2012) & & & & & \\
\hline LKA & Sri Lanka & $(1970-2012)$ & (1991-2012) & $(1985-1990)$ & & & $(1970-1981)$ & (3) \\
\hline LSO & Lesotho & (1991-2012) & (1991-2012) & & & & & \\
\hline MAR & Morocco & (1991-2012) & (1991-2012) & & & & & \\
\hline $\mathrm{MDA}$ & Moldova & (1991-2012) & $(1991-2012)$ & & & & & \\
\hline MDG & Madagascar & (1991-2012) & (1991-2012) & & & & & \\
\hline MKD & Macedonia & $(1991-2012)$ & $(1991-2012)$ & & & & & \\
\hline MLI & Mali & (1991-2012) & (1991-2012) & & & & & \\
\hline MNG & Mongolia & (1991-2012) & $(1991-2012)$ & & & & & \\
\hline MOZ & Mozambique & (1991-2012) & (1991-2012) & & & & & \\
\hline MUS & Mauritius & $(1991-2012)$ & $(1991-2012)$ & & & & & \\
\hline MWI & Malawi & $(1983-2012)$ & (1991-2012) & $(1983-1990)$ & & & & \\
\hline MYS & Malaysia & $(1975-2012)$ & (1991-2012) & (1982-1990) & & (1975-1985) & & \\
\hline NAM & Namibia & (1991-2012) & (1991-2012) & & & & & \\
\hline NER & Niger & $(1991-2012)$ & $(1991-2012)$ & & & & & \\
\hline NGA & Nigeria & (1974-2012) & (1991-2012) & & & (1984-1988) & (1974-1983) & \\
\hline NPL & Nepal & $(1991-2012)$ & $(1991-2012)$ & & & & & \\
\hline PAK & Pakistan & $(1970-2012)$ & (1991-2012) & & & $(1970-1986)$ & & \\
\hline PHL & Philippines & $(1970-2012)$ & $(1991-2012)$ & $(1980-1990)$ & & & $(1970-1979)$ & (6) \\
\hline ROM & Romania & (1991-2012) & (1991-2012) & & & & & \\
\hline RWA & Rwanda & $(1991-2012)$ & $(1991-2012)$ & & & & & \\
\hline SEN & Senegal & $(1970-2012)$ & $(1991-2012)$ & & & & $(1970-1980)$ & (4) \\
\hline SLE & Sierra Leone & (1991-2012) & (1991-2012) & & & & & \\
\hline SRB & Serbia & (1991-2012) & $(1991-2012)$ & & & & & \\
\hline TGO & Togo & $(1991-2012)$ & $(1991-2012)$ & & & & & \\
\hline THA & Thailand & $(1969-2012)$ & (1991-2012) & (1980-1990) & $(1969-1969)$ & $(1970-1986)$ & $(1971-1979)$ & (6) \\
\hline TUR & Turkey & (1988-2012) & (1991-2012) & & & & (1988-1990) & (6) \\
\hline TZA & Tanzania & $(1965-2012)$ & (1991-2012) & & (1971-1971) & & (1965-1965) & (5) \\
\hline UGA & Uganda & (1991-2012) & (1991-2012) & & & & & \\
\hline UKR & Ukraine & (1991-2012) & (1991-2012) & & & & & \\
\hline VNM & Vietnam & $(1991-2012)$ & $(1991-2012)$ & & & & & \\
\hline YEM & Yemen & $(1991-2012)$ & (1991-2012) & & & & & \\
\hline $\mathrm{ZAF}$ & South Africa & $(1960-2012)$ & (1991-2012) & & & & $(1960-1982)$ & (1) \\
\hline $\mathrm{ZMB}$ & Zambia & $(1986-2012)$ & $(1991-2012)$ & $(1986-1990)$ & & & & \\
\hline
\end{tabular}

Note: The source "Others" refers to: (1) Bell (1984); (2) Krueger (1983); (3) Nanayakkara (2004); (4) Terrell and Svejnar (1990); (5) Turnham (1971); (6) LABORSTA; (7) Vandemoortele (1991). 
Table E. 6. Manufacturing value added exports. Sources and coverage by country

\begin{tabular}{|c|c|c|c|c|c|c|c|}
\hline \multirow{2}{*}{ id } & \multirow{2}{*}{ Country } & \multirow{2}{*}{$\begin{array}{c}\text { Exports by } \\
\text { sector }^{(1)} \\
\text { (Coverage) }\end{array}$} & \multicolumn{5}{|c|}{ VA-Output Ratios (Sources by period) } \\
\hline & & & UNIDO $^{(2)}$ & $\operatorname{OECD}^{(3)}$ & ECLAC $^{(4)}$ & Back Cast $^{(5)}$ & Extrap. ${ }^{(6)}$ \\
\hline ARG & Argentina & $(1962-2010)$ & $(1982-2004)$ & - & $(1970-2010)$ & $(1962-1969)$ & - \\
\hline AUS & Australia & $(1963-2010)$ & (1963-2008) & - & - & - & $(2008-2010)$ \\
\hline AUT & Austria & $(1963-2010)$ & $(1963-1973)$ & $(1974-2010)$ & - & - & - \\
\hline AZE & Azerbaijan & $(1996-2010)$ & $(1999-2010)$ & - & - & $(1996-1998)$ & - \\
\hline BEL & Belgium & (1962-2010) & (1962-1992) & (1993-2010) & - & - & - \\
\hline $\mathrm{BFA}$ & Burkina Faso & $(1976-2010)$ & $(1962-1985)$ & - & - & - & $(1985-2010)$ \\
\hline BGD & Bangladesh & $(1977-2007)$ & $(1977-2000)$ & - & - & - & $(2000-2007)$ \\
\hline BGR & Bulgaria & (1996-2010) & $(1962-2010)$ & - & - & - & - \\
\hline BOL & Bolivia & (1962-2010) & (1968-2003) & - & - & $(1962-1967)$ & (2003-2010) \\
\hline BRA & Brazil & $(1962-2010)$ & $(1988-2009)$ & - & $(1970-1987)$ & $(1962-1969)$ & (2009-2010) \\
\hline BWA & Botswana & (2000-2010) & (2000-1997) & - & - & - & $(1997-2010)$ \\
\hline CAN & Canada & (1962-2010) & $(1962-2009)$ & (1970-2008) & - & - & (2009-2010) \\
\hline $\mathrm{CHE}$ & Switzerland & $(1962-2010)$ & (1984-1994) & $(1995-2010)$ & - & (1962-1983) & - \\
\hline CHL & Chile & $(1962-2010)$ & (1962-2008) & - & $(2009-2009)$ & - & $(2009-2010)$ \\
\hline $\mathrm{CHN}$ & China & (1985-2010) & $(1985-2009)$ & - & - & - & (2009-2010) \\
\hline CMR & Cameroon & $(1976-2010)$ & (1962-2004) & - & - & - & (2004-2010) \\
\hline COL & Colombia & $(1962-2010)$ & (1962-2007) & - & $(2008-2010)$ & - & - \\
\hline CRI & Costa Rica & (1965-2010) & $(1965-2010)$ & - & - & - & - \\
\hline CYP & Cyprus & $(1970-2010)$ & $(1970-2010)$ & - & - & - & - \\
\hline CZE & Czech Republic & (1993-2010) & $(1993-2009)$ & - & - & - & $(2009-2010)$ \\
\hline DEU & Germany & (1990-2010) & - & $(1990-2010)$ & - & - & - \\
\hline DNK & Denmark & $(1962-2010)$ & $(1962-1969)$ & (1970-2009) & - & - & (2009-2010) \\
\hline $\mathrm{ECU}$ & Ecuador & $(1962-2010)$ & $(1962-2009)$ & - & - & - & $(2009-2010)$ \\
\hline EGY & Egypt & $(1965-2010)$ & (1965-2008) & - & - & - & (2008-2010) \\
\hline ESP & Spain & $(1962-2010)$ & $(1962-1977)$ & $(1978-2009)$ & - & - & (2009-2010) \\
\hline EST & Estonia & (1995-2010) & - & - & - & - & - \\
\hline ETH & Ethiopia & (1993-2010) & $(1993-2010)$ & - & - & - & - \\
\hline FIN & Finland & (1963-2010) & $(1963-1972)$ & $(1973-2010)$ & - & - & - \\
\hline FRA & France & $(1962-2010)$ & $(1962-1975)$ & $(1976-2009)$ & - & - & (2009-2010) \\
\hline GBR & United Kingdom & $(1962-2010)$ & $(1962-1977)$ & $(1978-2009)$ & - & - & (2009-2010) \\
\hline GEO & Georgia & (1996-2010) & - & - & - & - & - \\
\hline GHA & Ghana & $(1962-2010)$ & (1962-2005) & - & - & - & $(2005-2010)$ \\
\hline GRC & Greece & $(1976-2010)$ & $(1962-2009)$ & - & - & - & $(2009-2010)$ \\
\hline HKG & Hong Kong & $(1962-2010)$ & $(1971-2010)$ & - & - & $(1962-1970)$ & - \\
\hline HRV & Croatia & (1992-2010) & (1962-1994) & - & - & - & (1994-2010) \\
\hline HUN & Hungary & $(1976-2010)$ & $(1962-2010)$ & - & - & - & - \\
\hline IDN & Indonesia & $(1962-2010)$ & $(1968-2009)$ & - & - & (1962-1967) & $(2009-2010)$ \\
\hline IND & India & $(1962-2010)$ & $(1962-2009)$ & - & - & - & $(2009-2010)$ \\
\hline IRL & Ireland & $(1963-2010)$ & $(1963-2009)$ & - & - & - & $(2009-2010)$ \\
\hline IRN & Iran & (1963-2010) & $(1963-2007)$ & - & - & - & $(2007-2010)$ \\
\hline ISR & Israel & $(1962-2010)$ & (1962-2008) & - & - & - & $(2008-2010)$ \\
\hline ITA & Italy & $(1962-2010)$ & $(1965-1977)$ & $(1978-2010)$ & - & (1962-1964) & - \\
\hline JOR & Jordan & (1964-2010) & (1964-2010) & - & - & - & - \\
\hline JPN & Japan & $(1962-2010)$ & (1962-1977) & $(1978-2010)$ & - & - & - \\
\hline KAZ & Kazakhstan & (1995-2010) & - & - & - & - & - \\
\hline KEN & Kenya & $(1976-2010)$ & $(1976-2009)$ & - & - & - & $(2009-2010)$ \\
\hline KGZ & Kyrgyz Rep. & $(1995-2010)$ & $(2000-2010)$ & - & - & (1995-1999) & - \\
\hline KHM & Cambodia & $(1962-2010)$ & $(1991-2002)$ & - & - & (1962-1990) & (2002-2010) \\
\hline KOR & Korea & $(1962-2010)$ & $(1962-1977)$ & $(1978-2010)$ & - & - & - \\
\hline LKA & Sri Lanka & $(1962-2010)$ & (1964-2010) & - & - & (1962-1963) & - \\
\hline LSO & Lesotho & $(2000-2009)$ & $(1962-1987)$ & - & - & - & $(1987-2009)$ \\
\hline LTU & Lithuania & $(1992-2010)$ & $(1998-2010)$ & - & - & (1992-1997) & - \\
\hline LVA & Latvia & (1994-2010) & $(1962-2010)$ & - & - & - & - \\
\hline MAR & Morocco & $(1962-2010)$ & $(1965-2010)$ & - & - & (1962-1964) & - \\
\hline $\mathrm{MDA}$ & Moldova & (1994-2010) & $(1999-2010)$ & - & - & (1994-1998) & - \\
\hline
\end{tabular}


Table E. 6. Manufacturing value added exports. Sources and coverage by country (Cont.)

\begin{tabular}{|c|c|c|c|c|c|c|c|}
\hline \multirow{2}{*}{ id } & \multirow{2}{*}{ Country } & \multirow{2}{*}{$\begin{array}{c}\text { Exports by } \\
\text { sector }^{(1)} \\
\text { (Coverage) }\end{array}$} & \multicolumn{5}{|c|}{ VA-Output Ratios (Sources by period) } \\
\hline & & & $\mathrm{UNIDO}^{(2)}$ & $\operatorname{OECD}^{(3)}$ & $\operatorname{ECLAC}^{(4)}$ & Back Cast ${ }^{(5)}$ & Extrap. ${ }^{(6)}$ \\
\hline MDG & Madagascar & $(1976-2010)$ & $(1962-2008)$ & - & - & - & $(2008-2010)$ \\
\hline MEX & Mexico & $(1962-2010)$ & $(1968-1985)$ & $(1986-2010)$ & - & $(1962-1967)$ & - \\
\hline MKD & Macedonia & $(1994-2010)$ & $(1962-2010)$ & - & - & - & - \\
\hline MLI & Mali & $(1977-2010)$ & - & - & - & - & - \\
\hline MNG & Mongolia & $(1996-2007)$ & $(1962-2010)$ & - & - & - & - \\
\hline MOZ & Mozambique & (1994-2010) & (1962-1975) & - & - & - & $(1975-2010)$ \\
\hline MUS & Mauritius & $(1970-2010)$ & $(1970-2009)$ & - & - & - & (2009-2010) \\
\hline MWI & Malawi & (1966-2010) & (1966-2003) & - & - & - & (2003-2010) \\
\hline MYS & Malaysia & (1964-2010) & (1966-2009) & - & - & (1964-1965) & (2009-2010) \\
\hline NAM & Namibia & (2000-2010) & $(1962-1996)$ & - & - & - & (1996-2010) \\
\hline NER & Niger & (1976-2010) & $(1988-2004)$ & - & - & $(1976-1987)$ & (2004-2010) \\
\hline NGA & Nigeria & $(1962-2010)$ & $(1962-1998)$ & - & - & - & (1998-2010) \\
\hline NLD & Netherlands & $(1962-2010)$ & $(1962-1982)$ & $(1983-2010)$ & - & - & - \\
\hline NOR & Norway & $(1962-2010)$ & (1962-2008) & - & - & - & $(2008-2010)$ \\
\hline NPL & Nepal & (1982-2010) & (1984-2010) & - & - & (1982-1983) & - \\
\hline NZL & New Zealand & (1979-2010) & $(1962-2010)$ & - & - & - & - \\
\hline PAK & Pakistan & $(1972-2010)$ & (1972-2008) & - & - & - & $(2008-2010)$ \\
\hline PER & Peru & $(1962-2010)$ & $(1980-2009)$ & - & $(1970-1979)$ & $(1962-1969)$ & (2009-2010) \\
\hline PHL & Philippines & $(1962-2010)$ & (1962-2008) & - & - & - & (2008-2010) \\
\hline POL & Poland & (1980-2010) & $(1980-2010)$ & - & - & - & - \\
\hline PRT & Portugal & $(1962-2010)$ & $(1962-2009)$ & (1978-2008) & - & - & (2009-2010) \\
\hline ROM & Romania & (1989-2010) & $(1962-2010)$ & - & - & - & - \\
\hline RUS & Russia & (1996-2010) & $(1962-2010)$ & - & - & - & - \\
\hline RWA & Rwanda & (1996-2010) & $(1962-2001)$ & - & - & - & (2001-2010) \\
\hline SEN & Senegal & $(1977-2010)$ & $(1962-2010)$ & - & - & - & - \\
\hline SGP & Singapore & (1979-2010) & $(1962-2010)$ & - & - & - & - \\
\hline SLE & Sierra Leone & (1963-2002) & (1979-1995) & - & - & (1963-1978) & $(1995-2002)$ \\
\hline SRB & Serbia & n.a. & - & - & - & - & - \\
\hline SVK & Slovak Rep. & (1994-2010) & $(1962-2010)$ & - & - & - & - \\
\hline SVN & Slovenia & (1992-2010) & $(1962-2010)$ & - & - & - & - \\
\hline SWE & Sweden & $(1962-2010)$ & $(1962-1977)$ & $(1978-2010)$ & - & - & - \\
\hline TGO & Togo & $(1962-2010)$ & $(1975-1986)$ & - & - & $(1962-1974)$ & (1986-2010) \\
\hline THA & Thailand & $(1962-2010)$ & (1965-2008) & - & - & $(1962-1964)$ & (2008-2010) \\
\hline TUR & Turkey & $(1962-2010)$ & (1962-2008) & - & - & - & (2008-2010) \\
\hline TWN & Taiwan & $(1962-2010)$ & $(1974-1998)$ & - & - & $(1962-1973)$ & (1998-2010) \\
\hline TZA & Tanzania & $(1976-2010)$ & $(1976-2009)$ & - & - & - & $(2009-2010)$ \\
\hline UGA & Uganda & $(1976-2010)$ & $(1976-1991)$ & - & - & - & (1991-2010) \\
\hline UKR & Ukraine & (1996-2010) & - & - & - & - & - \\
\hline URY & Uruguay & $(1970-2009)$ & $(1970-2009)$ & - & - & - & - \\
\hline USA & United States & (1962-2010) & $(1962-1977)$ & $(1978-2010)$ & - & - & - \\
\hline VEN & Venezuela & $(1962-2010)$ & $(1962-2000)$ & - & - & - & (2000-2010) \\
\hline VNM & Vietnam & (1997-2009) & - & - & - & - & - \\
\hline YEM & Yemen & $(1976-2010)$ & (1996-2003) & - & - & (1976-1995) & (2003-2010) \\
\hline ZAF & South Africa & (1974-2010) & (1974-2010) & - & - & - & - \\
\hline $\mathrm{ZMB}$ & Zambia & $(1966-2010)$ & $(1966-1996)$ & - & - & - & $(1996-2010)$ \\
\hline
\end{tabular}

(1) United Nations, COMTRADE Database, accessed towards WITS (http://wits.worldbank.org/wits/). Variable: Merchandise exports at 5 and 6 digits levels of SITC (rev. 1 and rev. 2), converted into ISIC rev. 2.

(2) United Nations Industrial Development Organization, INDSTAT Database (CD-ROM, INDSTAT3, 2006; and INDSTAT2, 2011). Variables: manufacturing value added and manufacturing output at current LCU

(3) OECD, Structural Analysis Database (http://www.oecd.org/sti/stan). Variables: manufacturing value added and manufacturing output at current LCU

(4) United Nations Economic Commission for Latin America and the Caribbean, PADI Database (CD-ROM, PADI 2010). Variables: manufacturing value added and manufacturing output at 1985 constant dollars

(5) When none of the three sources had information on Value Added-Output ratios for the year under consideration, the first available ratio was back cast to the rest of the period.

(6) When none of the three sources had information on Value Added-Output ratios for the year under consideration, the last available ratio was extrapolated to the rest of the period. 



\section{VALORISATION}

In accordance to Article 23 of the Regulation governing the attainment for doctoral degree in the Maastricht University, the following section discusses the valorisation opportunities offered by this $\mathrm{PhD}$ thesis. Following the corresponding guidelines, these opportunities are analysed in terms of the social and economic relevance of the thesis, the potential target groups to whom the results can be interesting and the degree of innovativeness of the research methods used.

The main focus of the thesis has been on studying the forces that drive success and failure in economic development. As such, it is a valuable piece for the design of policy strategies both in developing and advanced economies. Hence, the thesis has a social and economic relevance that goes beyond the pure scientific relevance. The main messages of the thesis can result of interest not only to the academic community but also to policy makers and economic development analyst around the world. In particular, it can provide interesting insights to national and international policy makers focusing on innovation policy, technological upgrading and industrial policy.

More specifically, the main findings of the thesis suggest that a well-designed development strategy should try to address the following issues. First and foremost, the productive absorption of labour force. This cannot be achieved if the economy does not have a vibrant and dynamic modern sector. Hence, policies should be aimed at improving the context conditions for the emergence and dynamism of modern, exporting industries. As we have shown, it seems that the manufacturing sector is particularly well suited to achieve such goal. Among other reasons, the scope for exploiting technological innovations and the average income elasticity for manufacturing production tends to be larger than in other sectors.

A second issue relates to the technological upgrading of the economy. The survival through time of the working opportunities generated in the modern part of the economy will heavily depend on the degree of international competitiveness achieved. This competitiveness, in turn, is shaped by the capabilities of the country to enhance innovation and product differentiation. Improving the domestic capabilities to absorb foreign technology and tap into the global flows of knowledge would be a fundamental step in this line.

Last but not least, the equilibrium in the external accounts of the country should always be given special attention when thinking such development strategy. Acknowledging the importance of the external restriction brings again to the centre of attention the capacity of the domestic economy to sell its products in international markets. In the light of our results, this seems to be a pre-condition to achieve success, since it will provide the necessary foreign exchange to import key strategic 
inputs, capital goods and technologies that are not produced domestically. Failure to achieve this goal will doom the long-run sustainability of economic growth process.

In regard to the innovativeness of the research methods proposed, the thesis offers novel and original tools for economic diagnostics. To begin with, the structural modernisation index here proposed can be used to assess the success of different countries (or regions within one country) in achieving the main goals of economic development. In a similar vein, the characterisation of structural trajectories proposed in Chapter 6 can also be used to evaluate the performance of different sectors of the economy and the degree of concentration in technological catching up dynamics. Moreover, the thesis also provides an interesting contribution to the theoretical models that are used to study the dynamics of economic growth. These models, in turn, can be powerful tools to forecast the outcomes of different policies. Finally, the efforts put into the construction of a large dataset with comparable data for 100 countries during the period 1950-2010 can also be used as fertile ground for future research.

In terms of the diffusion of the results of the research, the main outcomes of the thesis have already been published in several working papers from UNUMERIT and some of the chapters are currently being reshaped in order to be submitted to top journals in the field of economic development. Moreover, the results have been presented in several international conferences, workshops and summer schools. These have been fruitful opportunities not only to disseminate the results of this research but also to get important feedbacks and suggestions on how the investigation could be further improved. In particular, the main results of Chapter 3 have been presented at the international conference "Future perspectives on innovation and governance in development", held at Maastricht in November 2014; the main results of Chapter 4 have been presented at 12th Globelics International Conference, "Partnerships for innovation-based development", held at Addis Ababa in October 2014, where it was awarded as one of the best $\mathrm{PhD}$ paper of the conference; a preliminary version of Chapter 5 have been presented at the 14th International Schumpeter Society Conference, "The evolution of economic systems, through innovation, entrepreneurship and competitive processes", held at Brisbane in July 2012; and a preliminary versions of Chapter 6 have been presented at the 7th International PhD School on Innovation and Economic Development, Globelics Academy, held at Tampere in May 2012 and in the 9th Globelics International Conference, "Creativity, Innovation and Economic Development", held at Buenos Aires in November 2011. 


\section{SAMENVA'T'TING}

Het belangrijkste doel van dit proefschrift is het analyseren van economische ontwikkeling als een proces van structurele verandering. Het proefschrift stelt met name dat er twee belangrijke veranderingen gerealiseerd moeten worden om de achterstand met de ontwikkelde wereld weg te werken: ten eerste het opnemen van een steeds groter deel van de beroepsbevolking in het moderne segment van de economie (structurele verandering); ten tweede de technologische opwaardering van deze moderne sectoren (technologische catch $u p$ ). Het mislukken van een van deze veranderingen zal uiteindelijk leiden tot armoede- of middeninkomensval omdat er dan slechts een fractie van de samenleving kan profiteren van de voordelen van de internationale stromen van technologische kennis.

Deze algemene hypothese is gebaseerd op een aantal theoretische bijdragen die -vanuit verschillende invalshoeken- de fundamentele rol van structurele veranderingen en technologische catch $u p$ in het proces van economische ontwikkeling onderkent. Het eerste deel van het proefschrift is gewijd aan de constructie van een formeel wiskundig catch up-model dat door het combineren van deze theoretische perspectieven relevante inzichten kan leveren in de verschillende structurele routes die een economie kan volgen op weg naar ontwikkeling. Een verrassende bijdrage van dit model is dat de volgeconomie wordt afgeschilderd alsof deze een duale structuur heeft en een betalingsbalansbeperking op economische groei, een karakterisering die op een lijn is met de manier waarop dit soort economieën meestal beschreven wordt. Het model is in staat om meerdere evenwichten te genereren op een eenvoudige en gemakkelijk te volgen wijze. De verkregen evenwichten op hun beurt worden geïnterpreteerd als contrasterende resultaten die ook in waarnemingen van historische gebeurtenissen voorkomen. Volgens het model kan een economie, afhankelijk van initiële voorwaarden en onderliggende parameters, een succesvolle inhaalslag met de meest geavanceerde economieën maken door de omvang van de moderne sector te vergroten en de kloof met de technologische koplopers te overbruggen. Maar een economie kan hierin ook falen en op een tussenliggende fase terecht komen, op een laag of een gemiddeld inkomensniveau, in een zogenaamde ontwikkelingsval. Het uiteindelijke resultaat wordt bepaald door de dynamische interactie tussen structurele veranderingen en technologische modernisering in het proces van economische groei.

De meest opvallende uitkomsten van het model worden in het tweede deel van het proefschrift vergeleken met patronen in de empirische data. Hiervoor is een grote dataset op het gebied van werkgelegenheid, toegevoegde waarde en andere variabelen samengesteld en uitgesplitst per sector en eenheden die vergelijkbaar zijn 
op uiteenlopende tijden en plaatsen. Deze variabelen worden gebruikt om een index van structurele modernisering samen te stellen om de economische ontwikkeling te bestuderen. Deze index verbindt de belangrijkste theoretische inzichten van het model met de werkelijke empirische trends. In het kort: de index berekent de productiviteitskloof met de mondiale koplopers in een totaal van activiteiten die worden beschouwd als het moderne deel van de economie. De index beoordeelt deze groep activiteiten ten opzichte van het aandeel van deze activiteiten in de totale beroepsbevolking. Op deze manier combineert het een technologische dimensie (de relatieve productiviteit) en een structurele dimensie (de grootte van de moderne sector) om zo tot een kernachtige maatstaf voor het niveau van moderniteit van een economie te komen. De uitkomsten van deze index worden gebruikt om de relatie tussen structurele modernisering en de eerder genoemde ontwikkelingsval te verkennen. Bij het analyseren van deze relatie wordt het interactieve karakter van de structurele verandering en de technologische catch up benadrukt. Er worden belangrijke inzichten verkregen over de aard van armoede- en middeninkomensval. Het onderzoek van deze index in een uitgebreide dataset van landen bevestigt dat landen die vastzitten in een ontwikkelingsval, dezelfde landen zijn die ook niet in staat zijn om het juiste niveau van modernisering te bereiken. Dat wil zeggen; landen die ofwel hebben gefaald om hun moderne sector uit te breiden en hun arbeidskrachten productief in te zetten, of er niet in zijn geslaagd de internationale technologische kennis in te zetten om de kloof met de mondiale koplopers te verminderen.

Dit onderzoeksgebied wordt verder uitgediept en de belangrijkste variabelen die eerder zijn samengesteld, worden binnen het algemene kader van de groeiregressies geanalyseerd om hun impact op economische groei te bestuderen. Er worden econometrische paneldatatechnieken aangewend om diverse modellen door te rekenen en de rol van deze variabelen in het stimuleren van economische groei te onderzoeken. Naast de theoretische onderbouwing zoals in het eerste deel van het proefschrift wordt beschreven, onderzoekt deze econometrische analyse ook de rol van verschillende sectorale samenstellingen van het moderne deel van de economie in het aansturen van het groeiproces. In het bijzonder wordt er gezocht naar diverse interacties tussen de verklarende variabelen en het aandeel van de drie grote sectoren die tezamen het moderne deel van de economie vormen: industriële, nonindustriële (mijnbouw, nutsbedrijven en bow) en moderne dienstverlening. Daarnaast wordt de rol van de export en bepaalde patronen van handelsspecialisaties hierin geanalyseerd, met speciale aandacht voor de rol van de export van de producerende industrie. Deze analyse onthult interessante patronen die helpen te begrijpen waarom sommige landen vastzitten in een ontwikkelingsval. Aan de ene kant geven de resultaten van de econometrische regressies aan dat de sectorale samenstelling van de moderne sector zeer belangrijk is voor het 
uiteindelijke resultaat van de economische groei. Volgens deze bevindingen zou het hebben van een levendige en dynamische manufacturing sector tegenwicht bieden aan het vertragen van de groeipercentages wanneer landen een hoger niveau van structurele modernisering weten te bereiken. Bovendien lijken de positieve effecten van andere variabelen in de regressies negatief te worden beïnvloed door de relatieve grootte van de productie in het moderne deel van de economie. De positieve effecten die doorgaans te vinden zijn voor onderwijs en openheid in het bevorderen van de economische groei worden gestimuleerd door een grotere productiesector en gehinderd door een kleinere. De regressieresultaten benadrukken ook de belangrijke rol van de export in dit proces, die ook tegenwicht biedt bij de neiging van groeicijfers om te dalen wanneer landen een hoger moderniseringsniveau bereiken. Een hogere export kan leiden tot het matigen van de beperkingen van de betalingsbalans, en tegelijkertijd het technologische leren en capaciteitsopbouw als gevolg van de blootstelling an buitenlandse markten stimuleren. Niet alle export lijkt echter dezelfde groeivoordelen op te leveren. Volgens onze resultaten is de export van de producerende industrie de toegevoegde waarde die het meest bijdraagt aan de economische groei.

Bewust van de belangrijke verscheidenheid die de moderne sector in ontwikkelingslanden karakteriseert, is het laatste deel van het proefschrift gewijd aan een verdere gedetailleerde verkenning van de sectorale samenstelling van de moderne sector en hoe deze verandert in de tijd. Om dit te doen is de analyse gericht op een beperkter aantal landen en een kortere periode waarvoor de vereiste gegevens beschikbaar zijn. De analyse beschouwt 30 landen over de periode 19702010 en identificeert enkele gestileerde patronen van structurele verandering in het moderne aandeel van de economie, en brengt deze in verband met de contrasterende uitkomsten van succesvolle ontwikkeling en middeninkomensval die in de voorgaande hoofdstukken van het proefschrift zijn vermeld. Een belangrijke bevinding is dat de technologische opwaardering van de moderne sector ook afhangt van de structurele veranderingen die plaatsvinden binnen dit geheel. Verschuivingen van economische activiteiten naar sectoren met een hogere productiviteit en een hoger technologisch potentieel hebben een belangrijke rol gespeeld bij de inhaalslag van succesvolle economieën. Daar staat tegenover in landen die vastzitten in een middeninkomensval (vooral in Latijns-Amerika) de patronen van catch up slechts in enkele bedrijfstakken voorkomen en neigen naar een gepolariseerde structuur waar de verschillen tussen de sectoren in de afgelopen veertig jaar zijn toegenomen. Deze resultaten wijzen erop dat het een belangrijke uitdaging voor deze economieën is om een brede verspreiding van technologisch leren over een groter aantal sectoren te bereiken, zelfs binnen het moderne deel van de economie. 



\section{BIOGRAPHY}

Alejandro M. Lavopa was born in San Luis, Argentina in 1981. He obtained his Bachelor's and Master's degree in Economics at the University of Buenos Aires (UBA), Argentina. After graduating he worked as research and teaching assistant at the UBA's Faculty of Economic Sciences. Alejandro joined the UNU-MERIT PhD Programme in Economics and Policy Studies of Technical Change in September 2009. His main research interests include economic development, innovation, structural change and industrial policy. His current research aims at studying the process of technological catch-up as an avenue to escape low- and middle-income traps. His work on these topics resulted in working papers and book chapters and has been presented in several international conferences. Alejandro has also been involved in several projects commissioned by international organizations, such as the United Nations Industrial Development Organization (UNIDO) and World Bank's International Finance Corporation (IFC). 



\section{UNU-MERIT}

2015

\section{Jinjin Zhao}

Urban water management reform: The case of China

\section{4}

\section{Dirk Crass}

The Impact of Brands on Innovation and Firm Performance: Empirical Evidence from Germany

\section{Samyukta Bhupatiraju}

The Geographic Dimensions of Growth and Development

\section{François Lafond}

The evolution of knowledge systems

\section{Annalisa Primi}

Promoting Innovation in Latin America: What Countries Have Learned (and What They Have Not) in Designing and Implementing Innovation and Intellectual Property Policies

\section{Fatoumata Lamarana Diallo}

Evaluation of Meal and Deworming Programs for Primary Schools in Rural Senegal

\section{3}

\section{Anant Kamath}

Information Sharing through Informal Interaction in Low-Tech Clusters

\section{Flavia Pereira de Carvalho}

What we talk about when we talk about Brazilian Mulitantionals: an investigation on Brazilian FDI, economic structure, innovation and the relationship between them

\section{Jun Hou}

Complementarity in Innovation and

Development: A Cross-country Comparison

\section{Rufin Baghana}

Impacts of Government Incentives to R\&D, Innovation and Productivity:

A Microeconometric Analysis of the Québec Case

\section{Lilia I. Stubrin}

High-Tech Activities in Emerging Countries: A Network perspective on the Argentinean biotech activity

\section{2}

\section{Abdul Waheed}

Innovation Determinants

and Innovation as a Determinant:

Evidence from Developing Countries

\section{Bilal Mirza}

Energy Poverty and Rural Energy Markets in Pakistan

\section{Benjamin Engelstätter}

Enterprise Software and Video Games: An Empirical Analysis

\section{Fulvia Farinelli}

Natural Resources, Innovation and Export Growth: The Wine Industry in Chili and Argentina

\section{Rodolfo Lauterbach}

Innovation in Manufacturing: From Product Variety and Labor Productivity Growth to Economic Development in Chile

\section{Kirsten Wiebe}

Quantitative Assessment of Sustainable Development and Growth in Sub-Saharan Africa. 


\section{Julio Miguel Rosa}

Organizational Strategies, Firms' Performance and Spatial Spillovers. The Canadian Case in Research and Development.

\section{Johannes Wilhelmus Marie Boels}

Joseph Schumpeter, honderd jaar economische ontwikkeling. Een historisch-theoretische beschouwing.

\section{1}

\section{Daniel Vertesy}

Interrupted Innovation: Emerging economies in the structure of the global aerospace industry.

\section{Tina Saebi}

Successfully managing alliance portfolios: an alliance capability view.

\section{Nora Engel}

Tuberculosis in India - A case of innovation and control.

\section{Evans Mupela}

Connectivity and growth in Sub-Saharan Africa: The role of communication satellites

\section{Nantawan Kwanjai}

Cross cultural intelligence amid intricate cultural webs: A tale of the UnDutchables in the land of 1002 smiles

\section{Lina Sonne}

Innovation in Finance to Finance Innovation: Supporting pro-poor entrepreneur-based innovation

\section{0}

\section{Fernando Santiago}

Human Resources Management Practices and Learning for Innovation in Developing Countries: Pharmaceutical Firms in Mexico

\section{Zakaria Babutsidze}

Essays on Economies with Heterogenous Interacting Consumers

\section{Bertha Vallejo}

Learning and Innovation Under Changing Market Conditions: The Auto Parts Industry in Mexico

\section{Donatus Ayitey}

Technical Change, Competitiveness and Poverty Reduction: A Study of the Ghanaian Apparel Industry

\section{Sergey Fillipov}

Multinational Subsidiary Evolution: Corporate

Change in New EU Member States

\section{Asel Doranova}

Technology Transfer and Learning under the Kyoto regime; Exploring the Technological Impact of CDM projects in developing countries

\section{9}

\section{Alexis Habiyaremye}

From Primary Commodity Dependence to Diversification and Growth". "Absorptive Capacity and Technological Catch Up in Botswana and Mauritius".

\section{Yoseph Getachew}

The Role of Public Capital in Economic Development

\section{Sandra Leitner}

Embodied Technological Change and Patterns of Investment in Austrian Manufacturing

\section{Semih Akçomak}

The Impact of Social Capital on Economic and Social Outcomes

\section{Abraham Garcia}

The Role of Demand in Technical Change

\section{Saurabh Arora}

Coherence in socio-technical systems: a network perspective on the innovation process

\section{8}

\section{Rutger Daems}

Medicines for the developing world

\section{Johannes Hanel}

Assessing Induced Technology: Sombart's Understanding of Technical Change in the History of Economics 


\section{Rifka Weehuizen}

Mental Capital: the economic significance of mental health

\section{Danielle Cloodt}

The relationship between R\&D partnership formation, social embeddedness and innovative performance

\section{Sabine Fuss}

Sustainable Energy Development under Uncertainty

\section{7}

\section{Tobias Kronenberg}

Reconciling Environmental Conservation with Economic Prosperity: The Feasibility of Double Dividends in the Short and Long Run

\section{Viktoria Kravtsova}

Assessing the Impact of Foreign Direct Investment in Transition Economies

\section{Suhail Sultan}

The Competitive Advantage of Small and Medium Sized Enterprises: The Case of Jordan's Natural Stone Industry

\section{6}

\section{Bulat Sanditov}

Essays on Social Learning and Imitation

\section{Mamata Parhi}

Dynamics of New Technology Diffusion: A Study of the Indian Automotive Industry

\section{Andreas Reinstaller}

Social structures and the innovation process: Their role in the demand of firms and consumers

\section{Rose Kiggundu}

Innovation systems and development: the journey of a Beleaguered Nile Perch Fishery in Uganda

\section{Thomas Pogue}

The Evolution of Research Collaboration in South African Gold Mining: 1886-1933

\section{Geoffrey Gachino}

Foreign Direct Investment, Spillovers and Innovation: The Case of Kenyan Manufacturing Industry

\section{0. Önder Nomaler}

Technological Change, International Trade and Growth: An Evolutionary, Multi-Agents-Based Modeling Approach

\section{5}

\section{Samia Satti Osman Mohamed-Nour} Change and Skill Development in the Arab Gulf Countries

\section{Elad Harison}

Intellectual Property Rights: Economics and Policy Analysis

\section{Daniel Dalohoun}

The relationship between R\&D partnership formation, social embeddedness and innovative performance: a multi-level approach of social embeddedness

\section{Müge Ozman}

Networks, Organizations and Knowledge

\section{Bas Straathof}

Product variety and economic growth: The counteracting effects of scale and idiosyncrasy

\section{Wilfred Schoenmakers}

Knowledge Flows between Multinational Companies: A Patent Data Analysis

\section{Myriam Cloodt}

Mergers and Acquisitions (M\&As) in High-Tech Industries: Measuring the Post-M\&A Innovative Performance of Companies

\section{4}

\section{Paola Criscuolo}

R\&D Internationalisation and Knowledge Transfer. Impact on MNEs and their Home Countries

\section{Maarten Verkerk}

Trust and Power on the Shop Floor 


\section{Gottfried Leibbrandt}

Adoption, harmonization and succession of network technologies across countries

\section{Mark Sanders}

Skill Biased Technical change - Its Origins, the Interaction with the Labour Market and Policy Implications

\section{3}

\section{Nadine Roijakkers}

Inter-firm cooperation in high-tech industries: a study of R\&D partnerships in pharmaceutical biotechnology

\section{Viki Sonntag}

Speed, Scale and Sustainability

\section{Masaru Yarime}

From End-of-Pipe Technology to Clean

Technology

\section{Stéphane Malo}

The combinatorial Chemistry Revolution Sustaining a Superior Performance Position through Technological Learning

\section{2}

\section{Annelies Hogenbirk}

Determinants of Inward Foreign Direct

Investment: the Case of the Netherlands

\section{1}

\section{John Adeoti}

Technology Investment in Pollution Control in Sub-Saharan Africa: The Case of the Nigerian Manufacturing Industry

\section{Edward Huizenga}

Innovation Management: How Frontrunners Stay Ahead. An Empirical Study on Key Success Factors in the ICT sector

\section{0}

\section{Machiel van Dijk}

Technological Change and the Dynamics of Industries. Theoretical Issues and Empirical evidence from Dutch Manufacturing

\section{9}

\section{Jan Cobbenhagen}

Managing Innovation at the Company Level: A Study on Non-Sector-Specific Success Factors

\section{Marjolein Caniëls}

Regional Growth Differentials: The Impact of Locally Bounded Knowledge Spillovers

\section{8}

\section{Aldo Geuna}

Resource allocation and knowledge production: Studies in the economics of university research

\section{6}

\section{Reinoud Joosten}

Dynamics, Equilibria, and Values

\section{Hugo Kruiniger}

Investment, R\&D, and the Financing Decisions of the Firm

\section{5}

\section{Hans van Meij}

Endogenous Technological Change: The Case of Information Technology. Theoretical Considerations and Empirical Results

\section{René Kemp}

Environmental Policy and Technical Change. A Comparison of the Technological Impact of Policy Instruments

\section{Rohini Acharya}

The Impact of New Technologies on Economic Growth and Trade. A Case Study of Biotechnology

\section{Geert Duysters}

The Evolution of Complex Industrial Systems. The Dynamics of Major IT Sectors

\section{Marjan Groen}

Technology, Work and Organisation, A Study of the Nursing Process in Intensive Care Units 
1994

\section{Huub Meijers}

On the Diffusion of Technologies in a Vintage Framework; Theoretical Considerations and Empirical Results

\section{Theon van Dijk}

The Limits of Patent Protection. Essays on the Economics of Intellectual Property Rights

\section{Hans Voordijk}

Naar Integrale Logistiek in Bedrijfsketens, Ontwikkelingen in de Bouw

\section{3}

\section{Paul Diederen}

Technological Progress in Enterprises and Diffusion of Innovations. Theoretical Reflections and Empirical Evidence.

\section{Ben Dankbaar}

Economic Crisis and Institutional Change. The crisis of Fordism from the perspective of the automobile industry

\section{Hanno Roberts}

Accountability and Responsibility: The Influence of Organisation Design on Management Accounting

\section{2}

\section{Bart Verspagen}

Uneven Growth Between Interdependent Economies. An Evolutionary View on Technology Gaps, Trade and Growth

\section{Sjoerd Romme}

A Self-organization Perspective on Strategy Formation

\section{9}

\section{John Spangenberg}

Economies of Scale, and Atmosphere in Research Organisations

\section{8}

\section{John Hagedoorn}

Evolutionary and heterodox innovation analysis: a study of industrial and technological development in process control and information technology 
